\title{
Intermediate Standards for Solar Domestic Hot Water Systems/HUD Initiative
}

Developed for Use in the HUD/States Solar Domestic Hot Water Initiative Program

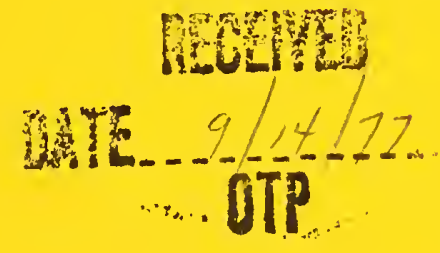

Solar Energy Program

Office of Housing and Building Technology

Center for Building Technology, IAT

National Bureau of Standards

Washington, D. C. 20234

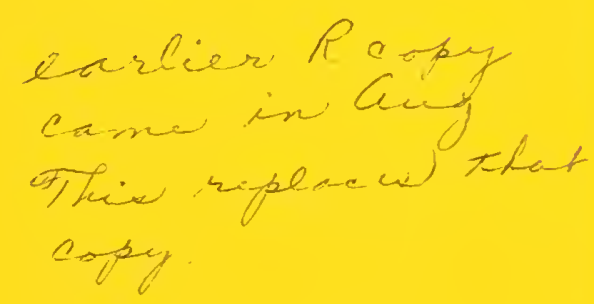

July 1977

\section{Prepared for}

Department of Housing and Urban Development Office of Policy Development and Research

Division of Energy, Building Technology and Standards Washington, D. C. 20410

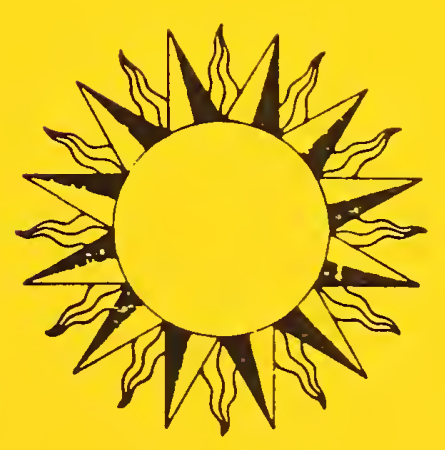





\section{INTERMEDIATE STANDARDS FOR \\ SOLAR DOMESTIC HOT WATER \\ SYSTEMS/HUD INITIATIVE}

Developed for Use in the HUD/States Solar

Domestic Hot Water Initiative Program

Solar Energy Program

Office of Housing and Building Technology

Center for Building Technology, IAT

National Bureau of Standards

Washington, D. C. 20234

July 1977

Prepared for

Department of Housing and Urban Development

Office of Policy Development and Research

Division of Energy, Building Technology and Standards

Washington, D. C. 20410

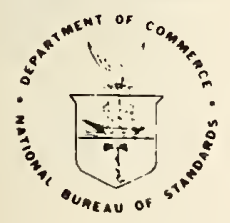

U.S. DEPARTMENT OF COMMERCE, Juanita M. Kreps, Secretary

Dr. Sidney Harman, Under Secretary

Jordan J. Baruch, Assistant Secretary for Science and Technology

NATIONAL BUREAU OF STANDARDS, Ernest Ambler, Acting Director 

The preparation of the original document (HUD/FHA 4930.2) has been a joint effort of members of the Solar Energy Program Team at the National Bureau of Standards, Center for Building Technology. Team members include:

Office of Housing and Building Technology

Robert Dikkers

David Waksman

John Holton

Kenneth DeCorte

William Niessing

Thermal Engineering Section

Elmer Streed

James Hill

John Jenkins

Dennis Jones

Michael McCabe

Mark Hannifan

Materials and Composite Section

Larry Masters

Leopold Skoda

Elizabeth Clark

Paul Brown

Jean-Noel Andre

McClure Godette

Mechanical System Section

James Kao

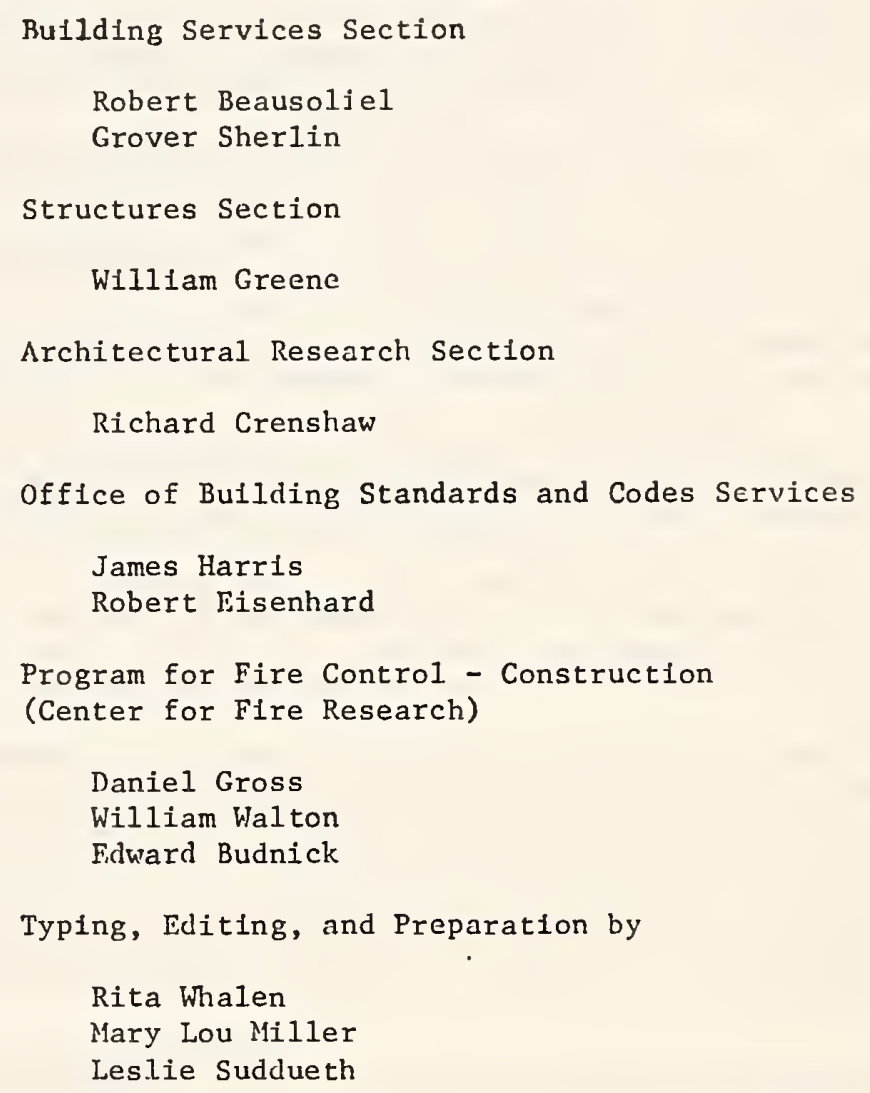

The principal authors of this Solar Domestic Hot Water Standard are:

Michael McCabe

John Holton

Elmer Streed 
The "Intermediate Standards for Solar Domestic Hot Water Systems" are based on the "Intermediate Minimum Property Standards for Solar Heating and Domestic Hot Water Systems" 4930.2 (S/MPS) and are intended for use in the HUD/States Hot Water Initiative Program.

In developing this document, references in the S/MPS to heating and combined heating and hot water applications have been deleted. Some language has been changed and additional commentary added to make this document more useful. All such changes have been identified by a heavy line in the margin.

The HUD/States Hot Water Initiative Program is a program providing financial assistance to homeowners to install solar domestic hot water systems. The program currently is being offered in the states of New Hampshire, Vermont, Massachusetts, Rhode Island, Connecticut, New Jersey, Pennsylvania, Delaware, Maryland, Florida, and 13 counties in New York.

These standards consider only aspects of planning and design that are different from conventional hot water systems by reason of the solar systems under consideration. To the greatest extent possible, they are based on current state-of-the-art practice and on nationally recognized standards including the HUD Minimum Property Standards (MPS) and the HUD "Interim Performance Criteria for Solar Heating and Combined Heating/Cooling Systems and Dwellings." These standards assume a level of building design and construction quality equivalent to local code requirements or the MPS whichever is applicable.

The text makes occasional reference to the MPS which refers to the original underlying HUD standards, the "Minimum Property Standards for One and Two Family Dwellings" 4900.1, the "Minimum Property Standards for Multifamily Housing" 4910.1, and the "Minimum Property Standards for Care Type Housing" 4920.1. The reference is to the same paragraph in all these documents unless otherwise noted. For purposes of the Hot Water Initiative, the references to the "Minimum Property Standards for One and Two Family Dwellings" 4900.1 will be the applicable reference. Reference to MPS 4910.1 and 4920.1 is not essential but has been retained in some instances for fullest explanation of a particular point.

In general, the Chapters and Divisions in this document are organized to parallel the Chapters and Divisions contained in the MPS. Within Divisions, however, these standards do not follow the numbering of the MPS, but rather list the solar topics sequentially. It has been found that this method allows the presentation of these new topics in a manner that is clearly related to the MPS and yet is not made cumbersome. Not all chapters or divisions in the MPS have topics which require coverage for solar energy use; for example, there are no such topics in Chapter 2, Generally Acceptability Criteria, nor in Division 512, Furnishings.

An example will help to illustrate the organization of this document:

Consider hail loads as they relate to solar collectors. Hail loads are not a subject in the MPS, but would be covered in Chapter 6, Division 1, General Structural Requirements if they were. In these standards they are located in Chapter 6, Division 1, Section S-601-7. For comparison, plumbing construction is covered in Chapter 6, Division 15, Section 615-5 of the MPS. In these standards it is a1so located in Chapter 6, Division 15, but in Section S-615-12.

MPS

Hail loads

none

Plumbing

615-5
MPS Solar Supplement

S-601-7

S-615-12

It has frequently bcen found useful to include a commentary on a particular standard, The commentaries are not mandatory, but are intended to give further explanation and guidance to users of the standards on topics which may have special consequences in solar installations. Several appendices are includes which give additional information for assistance in use of the standards. Appendix A presents the calculation procedures to be used to verify the thermal performance of solar domestic hot water systems proposed for the HUD/States Hot Water Initiative Program. Appendix C, "Illustrated Definitions," is presented in the "Intermediate Minimum Property Standards for Solar Heating and Domestic Hot Water Systems" 4930.2, or in the HUD publication, "Solar Hot Water and Your Home" and is not included here. 
The format developed for these standards has been structured to convey information in a number of categories as follows:

S - the prefix used on all sections (for solar) to distinguish them from existing MPS sections

\section{BOLD FACE TYPE - TO PRESENT STANDARDS AND COMMENTARIES APPLICABLE TO MULTIFAMILY HOUSING ONLY}
Conventional type - to present standards applicable to one and two family dwellings, multifamily housing and care type housing

Italics - to present commentaries applicable to one and two fomily dwellings, multifamily housing and care type housing

\section{SI CONVERSION UNITS}

In view of the present accepted practice in this country for building technology, common U.S. units of measurement have been used throughout this document. In recognition of the position of the United States as a signatory to the General Conference of Weights and Measures, which gave official status to the metric SI system of units in 1960, assistance is given to the reader interested in making use of the coherent system of SI units by giving conversion factors applicable to U.S. units used in this document.
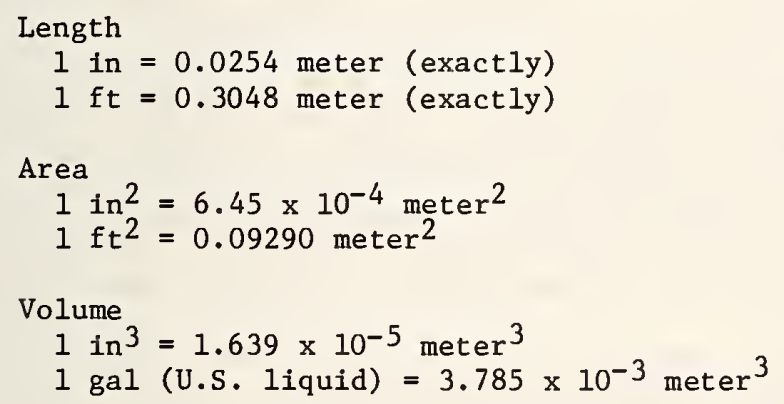

Mass

1 ounce-mass (avoirdupois) $=2.834 \times 10^{-2} \mathrm{kilogram}$

1 pound-mass (avoirdupois) $=0.4536 \mathrm{kilogram}$

Pressure or Stress (Force/Area)

1 inch of mercury $\left(60^{\circ} \mathrm{F}\right)=3.377 \times 10^{3}$ pascal

1 pound-force $/$ inch $^{2}$ (psi) $=6.895 \times 10^{3}$ pascal

Energy

1 foot-pound-force ( $\mathrm{ft} \cdot \mathrm{lbf})=1.356$ joule

$1 \mathrm{Btu}$ (International Table) $=1.055 \times 10^{3}$ joule

1 kilowatt-hour $=3.600 \times 10^{6}$ joule $=3.412 \times 10^{3} \mathrm{Btu}$

Power

1 watt $=1 \times 10^{7} \mathrm{erg} / \mathrm{second}$

$1 \mathrm{Btu} / \mathrm{hr}=0.2929$ watt

Temperature

$$
{ }^{\circ} \mathrm{C}=5 / 9\left(\mathrm{t}^{\circ} \mathrm{F}-32\right)
$$

Heat
$1(B t u \cdot i n) /\left(h \cdot f t^{2} \cdot F\right)=1.442 \times 10^{-1} \mathrm{~W} /(\mathrm{m} \cdot \mathrm{K})($ thermal conductivity)
$1 \mathrm{Btu} / 1 \mathrm{bm} \cdot{ }^{\circ} \mathrm{F}=4.184 \times 10^{3} \mathrm{~J} /(\mathrm{kg} \cdot \mathrm{K})$ (specific heat)
1 langley $=4.184 \times 10^{4} \mathrm{~J} / \mathrm{m}^{2}=1 \mathrm{cal} / \mathrm{cm}^{2}=3.69 \mathrm{Btu} / \mathrm{ft}^{2}$ 
Chapter 1 General Use. ................ . 1-1

Chapter 2 General Acceptab1lity Critexla (Not used) . . . . 2-1

Chapter 3 Site Design. . . . . . . . . . . . 3-1

Chapter 4 Bullding Design. . . . . . . . . . . . 4-1

Chapter 5 Mater1als. .............. 5-1

Chapter 6 Construction .............. 6-1

Appendix A Method for Predicting the Thermal Performance

of Active Solar Domestic Hot Water Heaters. . . . A-1

Append18 B Materlals Tables. . . . . . . . . . . . B-1

Append1x C (Not Used) ............... C-1

Appendix D Definitions . . . . . . . . . . . . D-1

Appendix E Referenced Standards. . . . . . . . . . . E-1

Appendix F Abbreviations .............. . F-1 
General Use

These "Intermediate Standards for Solar Domestic Hot Water Systems/HUD Initiative" shall be used in conjunction with MPS 4900.1, "Minimum Property Standards for One and Two Family Dwellings," MPS 4910.1, "Minimum Property Standards for Multifamily Housing," and MPS 4920.1, "Minimum Property Standards for Care Type Housing." Furthermore, the solar components must provide for the collector of solar energy, conversion of the solar energy to thermal energy, and distribution, storage and control of the thermal energy so obtained. Insofar as applicable, these standards apply to active and passive solar energy systems that utilize building elements, mechanical subsystems or combinations thereof.

Commentary: MPS 4900.1, MPS 4910.1, and 4920.1 are available from HUD offices, and are sold by the Superintendent of Documents, U.S. Government Printing Office, Washington, D.C. 20402.

S-101 VARIATIONS TO STANDARDS

S-101-1 NEW MATERIALS AND TECHNOLOGIES

These standards are intended to encourage the use of new or innovative designs, technologies, methods or materlals in solar applications. These features include designs, methods of construction, systems, subsystems, components, materials and processes which do not comply with the MPS and this document, and whose acceptance cannot be determined by other provisions of these standards. Alternatives, nonconventional or innovative designs, methods, and materials shall demonstrate, however, equivalent quality to these standards in operating effec-tiveness, structural soundness, durability, economy of maintenance or operation, and usability. Varfations shall be made in accordance with Section 101-4 of MPS.

Commentary: One basis for design, fabrication, construction, and acceptance of new and innovative solar systems, subsystems, components, materials, and processes is the "Interim Performance Criteria for Solar Heating and Combined Heating/Cooling Systems and Dwellings," January, 1975, available from GPO, Stock Nromber 0324-01043, price \$1.90.

S-102 PRODUCT AND DESIGN MODIFICATIONS

Variations from approved designs shall be submitted to HUD for review.

Commentary: It is recognized that product or design changes may occur. These changes may affect the performance of the system or its components. 

$\begin{array}{lllllll}\text { C H A P T E R } 2 & 2\end{array}$

GENERAL ACCEPTABILITY CRITERIA

(not used)

2-1 

CHAPTER 3

SITE DESIGN

TABLE OF CONTENTS

Page

S-300 GENERAL . . . . . . . . . . . . . . . . . . . 3-2

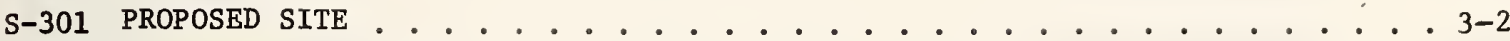

s-301-1 Site Surroundings .................... . 3-2

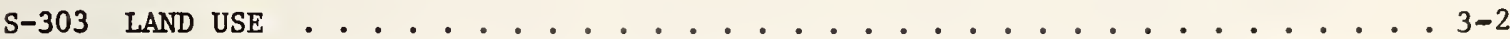

S-303-1 Solar Equipment Location and Arrangement . . . . . . . . . . 3-2

S-303-2 Site Hazards . . . . . . . . . . . . . . . . . 3-3

S-304 LOTS, YARDS AND BUILDING SETBACK DISTANCE . . . . . . . . . . . 3-3

S-304-1 Projection Into Yard Area . . . . . . . . . . . . . . 3-3

S-304-2 Usable Outdoor Area . . . . . . . . . . . . . . . . . 3-3

S-304-3 Snow and Ice .................... . . 3-3

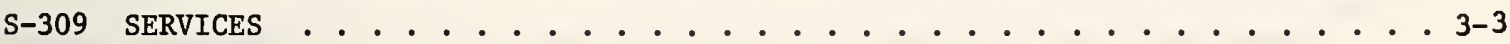

S-309-1 Malntenance ..................... . . 3-3

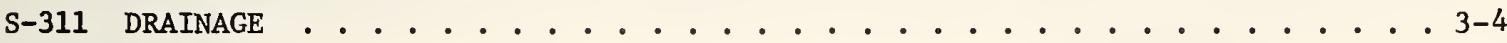

S-311-5 Drainage Swales and Gutters . . . . . . . . . . . . . . 3-4

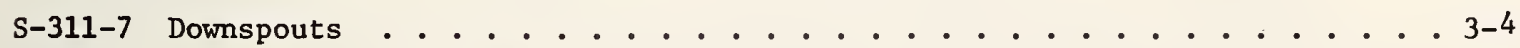

S-312 PLANTING DESIGN . . . . . . . . . . . . . . . . . 3-4

S-312-3 New Plant Material .................. 3-4 
S-300

S-301-1

S-303

S-303-1

GENERAL

The provisions of this chapter are applicable to solar domestic hot water (DHW) systems. This chapter is intended to be used in conjunction with the Minimum Property Standards (MPS) Chapter 3.

PROPOSED SITE

\section{SITE SURROUNDINGS}

Solar bulldings and solar system components shall be located and designed in such a manner as to harmonize with the surrounding community.

Commentary: Solar system components may include elements which are large and visually dominant when viewed from off-site. If not carefully designed and located, such elements can produce a detrimental effect on the overall quality of a residential area.

LAND USE

\section{SOLAR EQUIPMENT LOCATION AND ARRANGEMENT}

Solar buildings and site located solar equipment shall be arranged and located to relate well to:

a. The natural topography.

Commentary: The location of the solar collector should be planned to avoid pockets where frost can collect or unprotected ridges where winds can be more extreme in order to avoid heat losses due to low temperatures and high winds.

b. The climate.

Commentary: The Zocation of the solar collector should be planned to take into account prevailing winds in order to avoid excessive heat losses due to wind and to drifting snow which impair the collection of solar energy. For specific requirements on tilt and orientation see S-615-2.1.2 and C-8, C-9 in Appendix.

c. Attractive on-site and off-site views.

Commentary: Components of the solar system may be Zarge and could block attractive views from the buizding.

d. Existing and proposed site elements such as vegetation, fences, landforms and buildings.

Commentary: Proper relationship of a solar collector to site elements can minimize the shading of the collector and reduce air flow over the collector. Location of the solar building in the northern portion of the site can help to minimize the possibility of shading solar collector surfaces by future off-site development.

e. Existing and proposed pedestrian and vehicular clrculation systems.

Commentary: Proper Zocation of solar equipment in relation to pedestrian circulation may reduce tompering and vandalism. 
f. Existing and proposed surrounding buildings and facilities.

Commentary: The location and orientation of the solar collector should consider physical and chemical air borne waste from nearby facilities such as incinerators and factories which might have an impact on the efficiency of the solar collector. (See S-515-1.5)

\section{SITE HAZARDS}

Special considerations must be given to assure that elements of the solar system do not create unnecessary safety hazards to users.

Commentary: Hazards which require special attention include the reflection of sunlight which creates visual distraction, the projection of sharp edges which influence the movement of people near free-standing collectors, and the proximity of solar components to recognized architectural hazards such as exterior overhangs, stairs, ramps, landings, doors, etc.

S-304

S-304-1

S-304-2

LOTS, YARDS AND BUILDING SETBACK DISTANCE

\section{PROJECTION INTO YARD AREA}

The projection of solar collectors into yards shall conform to those restrictions placed on open balconies, bay windows and uncovered porches in applicable codes and standards.

\section{USABLE OUTDOOR AREA}

Components of the solar system shall not impinge on the requirements for usable outdoor area as specified in applicable codes and standards.

Commentary: Reasonable outdoor open space must be maintained for livability service, emergency access, isolation of fire and protection of adjacent property.

\section{S-304-3 SNOW AND ICE}

In areas which have a snow load of 20 pounds per square foot or greater required by local codes, provisions shall be made over entrances and locations of pedestrian and vehicular ways to restrain or deflect sliding snow and ice masses which may slide off elevated solar system components.

Commentary: Solar system components may often include smooth slippery surfaces located in elevated positions at steep angles. These elements may heat up rapidlu and loosen masses of snow or ice which may slide-off. Means should be provided to prevent a hazard to people or property. Methods such as deflectors, restraints, low friction materials, or design of "safe falz" areas (pedestrian or vehicular ways spaced oway from the building) should be considered.

\section{SERVICES}

\section{MAINTENANCE}

Solar energy components located on the site shall be accessible for cleaning, adjusting, servicing, examination, replacement or repair without trespassing on adjoining property.

Commentary: Components should not be located unnecessarily under buildings or roads or in other places which are difficult to reach. Storage tanks in particular are large and may need periodic replacement or inspection. 
SOLAR COLLECTORS ON ROOFS OVER 3 STORIES MUST HAVE ACCESS PROVIDED FOR CLEANING AND MAINTENANCE,

COMMENTARY: THE USE OF PORTABLE LADDERS IS NOT CONSIDERED TO BE ADEQUATE UNDER THESE CIRCUMSTANCES,

$\mathrm{S}-311$

$S-311-5$

$S-311-7$

$S-311-7.1$

S-312

$S-312-3$

$S-312-3.9$

DRAINAGE

DRAINAGE SWALES AND GUTTERS

Gutters or other means of controlling runoff shall be provided on solar collectors when the soil is of such a nature that excessive erosion or expansion may occur as a result of increased runoff.

DOWNSPOUTS

In addition to method of disposal of 311-7.1 of the MPS, downspouts may be discharged into an acceptable non-potable water storage tank if it is part of the solar system.

Commentary: Current MPS requires that the water from a downspout empty into available storm sewer or on a splash block. When downspouts are used as part of a solar system, it is acceptable for it to empty into a storage tank provided consideration has been given to the quality of the water and its effect on the solar system. (See S-515-2.3)

\section{PLANTING DESIGN}

NEW PLANT MATERIAL

Plant material should be selected and located to prevent the unwanted reduction of thermal output of a solar collector from shading, sap or other by-products of plants. 


\section{CHAPTER 4}

BUILDING DESIGN

TABLE OF CONTENTS

Page

S-400 GENERAL . . . . . . . . . . . . . . . . . . . . . 4-2

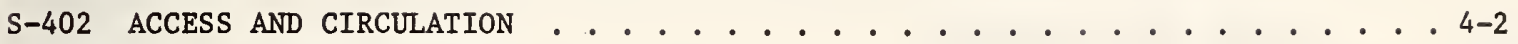

S-402-1 General . . . . . . . . . . . . . . . . . 4-2

S-402-10 Solar Energy Equipment . . . . . . . . . . . . . . . 4-2

S-405 FIRE PROTECTION . . . . . . . . . . . . . . . . . . 4-2

S-405-1 General . . . . . . . . . . . . . . . . . . 4-2

S-405-4 Fire Resistance Requirements ................. . . 4-2

S-405-6 Exits . . . . . . . . . . . . . . . . . . 4-3

S-405-7 Firestopping . . . . . . . . . . . . . . . . . 4-3

S-405-12 Roof Coverings ....................... . . 4-3 
S-400

$S-402$

S-402-1

S-402-1. 1

$S-402-10$

S-405

S-405-1

S-405-1.1

S-405-4

S-405-4.1

$$
S-405-4.2
$$

\section{GENERAL}

The provisions of this chapter are applicable to solar domestic hot water (DHW) systems. This chapter is intended to be used in conjunction with the Minimum Property Standards (MPS) Chapter 4.

\section{ACCESS AND CIRCULATION}

GENERAL

The design and installation of the solar domestic hot water systems shall not impair the normal movement of occupants of the building or emergency personne1.

COMMENTARY: SPECIAL CONSIDERATION SHOULD BE GIVEN TO THE EFFECT OF THE CONFIGURATION OF ROOF-MOUNTED COLLECTORS ON FIRE EXITING, FIRE FIGHTING OR EMERGENCY RESCUE,

\section{SOLAR ENERGY EQUIPMENT}

Solar energy equipment shall be accessible for routine maintenance without disassembling any major structural or mechanical element. Sufficient space or clearance shall be provided based upon solar equipment sizes and potential maintenance equipment sizes to permit examination, replacement, adjusting, servicing and/or maintenance. See Section S-600-5.

Commentary: Accessibility for repair and maintenance should reflect the expected life of the equipment and the frequency of routine maintenance required. An element with a shorter maintenance cycle or life expectancy should be more accessible than one with a long maintenance cycle or life expectancy.

\section{FIRE PROTECTION}

\section{GENERAI}

The incorporation of solar systems into the living unit shall not increase the fire hazard or interfere with the means of safe egress in the event of a fire.

\section{FIRE RESISTANCE REQUIREMENTS}

\section{Integrated Construction}

The incorporation of solar subsystems shall not reduce the fire resistance ratings required by applicable codes and standards.

Commentary: Roof-mounted collectors which are an integral part of the roof constmation shall not reduce the required fire resistance rating of the roof assembly.

\section{Penetrations}

Penetrations through fire-rated assemblies shall not reduce the fire resistance ratings required by applicable codes and standards. 
Components of the solar system shall not be located in such a way as to interfere with the primary or secondary means of occupant egress.

Commentary: The location of solar equipment on a roof shall not reduce the usability of that roof for access or egress. Solar system components located remote from the building but near a means of egress shall not block the means of egress if a fire occurs in the solar system component.

\section{FIRESTOPPING}

Major solar system components that are integral parts of assemblies which normally require firestopping shall be firestopped on all sides. Firestopplng shall be wood blocking of minimum 2 inch nominal thickness or of noncombustible materials providing equivalent protection. Firestopping may be included as an integral part of the component where the component as Installed provides equivalent protection.

Commentary: It is the intent of the section to prevent solar system components from reducing the effectiveness of firestopping. For excrmple, in the case where a solar collector is an integral part of a wood framed wall which would normally be firestopped between studs, firestopping shall be required in the wall above and below the solar collector.

\section{ROOF COVERINGS}

Installation of solar collectors or system components on or as an integral part of the roof shall not reduce the fire retardant characteristics of the roof covering below the level specified by applicable codes and standards. 

CHAPTER 5

MATERIALS

TABLE OF CONTENTS

Page

S-500 GENERAL . . . . . . . . . . . . . . . . . . . 5-2

S-500-1 Applicable Standards . . . . . . . . . . . . . . . 5-2

S-500-2 Exceptions and Re-Statements . . . . . . . . . . . . . 5-2

S-500-3 Suitability of Alternate or Special Materlals . . . . . . . . . 5-2

S-501 GENERAL REQUIREMENTS . . . . . . . . . . . . . . . . . 5-3

S-501-1 General . . . . . . . . . . . . . . . . . . 5-3

S-501-2 Labeling . . . . . . . . . . . . . . . . . . 5-3

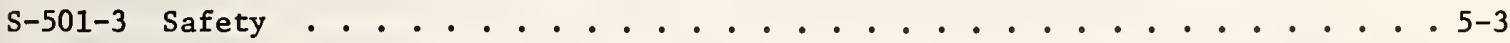

S-501-4 Documentation of Performance . . . . . . . . . . . . . . 5-3

S-515 MECHANICAL - SOLAR POWERED EQUIPMENT . . . . . . . . . . . . . . 5-4

S-515-1 General Provisions ... . . . . . . . . . . . . . 5-4

s-515-2 collectors ..................... . . . 5-5

S-515-3 Energy Transport System . . . . . . . . . . . . . . . . 5-21

S-515-4 Mechanical Supporting Devices . . . . . . . . . . . . . . 5-22

S-515-5 valves ....................... . . 5-23

S-515-6 Pumps and Fans . . . . . . . . . . . . . . . . . 5-23

S-515-7 Thermal Storage Units . . . . . . . . . . . . . . . . 5-24

S-515-8 Heat Transfer Fluids . . . . . . . . . . . . . . . . 5-25

S-515-9 Heat Exchangers . . . . . . . . . . . . . . . . 5-27

S-515-10 Gaskets and Sealants . . . . . . . . . . . . . . . 5-28

S-515-11 Insulation/Thermal and Moisture Protection . . . . . . . . . . 5-29

S-515-12 Catch Basins . . . . . . . . . . . . . . . . . 5-30

S-515-13 Organic Coupling Hoses . . . . . . . . . . . . . . . 5-31 
The provisions in this chapter are applicable to solar domestic hot water (DHW) systems. This chapter is intended to be used in conjunction with the Minimum Property Standards (MPS). Materials provisions (Chapter 5) of the MPS are applicable in addition to the items explicitly discussed in this document.

Commentary: Conditions of potentially deleterious exposure of materials used in solar systems and particularly in solar collectors vary widely with the design and operating characteristics of the system and collectors. The performance of materials in the context of the overall normal and no-flow characteristics of system and collectors should be considered as primary factors in material selection.

Except as modified herein, materials, equipment and installation shall be in accordance with the standards and nationally recognized model codes cited within the body of this document; the current applicable editions and titles of referenced standards and codes are contained in Appendix E. State and local codes which deviate from nationally recognized codes or standards in order to satisfy local conditions may be accepted by HUD if such deviations are identified and substantiated with satisfactory engineering data.

EXCEPTIONS AND RE-STATEMENTS

$S-500-2.1$

Exceptions

Exceptions to the cited standards are included in this document where deemed appropriate by HUD.

$S-500-2.2 \quad$ Re-statements

Certain requirements that are already covered in the referenced standards are re-stated in this document to emphasize the need for implementing these requirements in HUD construction.

Alternate or special materials or products, other than those contained herein may be used when found acceptable by established HUD procedures and Division 513 of MPS and Section S-101 of this document. 
$S-501$

$S-501-1$

S-501-2

S-501-3

$S-501-3.1$

$S-501-4$

\section{GENERAL REQUIREMENTS}

GENERAL

Materials installed shall be of such kind and quality as to assure that the solar energy system will provide a) adequate structural strength, b) adequate resistance to weather, molsture, corrosion and fire, c) acceptable durability and economy of ma1ntenance and market acceptance.

\section{LABELING}

Mendatory labeling requirements, where applicable, are contalned herein for specific materials and products.

Commentary: Installation, operation and maintenconce information requirements are specified in S-600-3.

\section{SAFETY}

Protection of potable water and circulated air

No material, form of construction, fixture, appurtenance or item of equipment shall be employed that will introduce toxic substances, impurities, bacteria or toxic chemicals into potable water and air circulation systems in quantities sufficient to cause disease or harmful physiological effects.

Commentary: This situation is of concem not only as it pertains to ducts, piping, filters and joints but also to storage areas, such as rock beds. In addition, the growth of fungus, mold and mildew is possible when collectors ore applied to a roof surface over the water tight membrone. If the collectors are in contact with the membrane or held cavay from the membrane to allow for drainage, the shaded membrone area can support the growth of mildew and other fungus in some warm, moist climates. Special design considerations should be included to avoid this problem in climates where it can occur.

\section{DOCUMENTATION OF PERFORMANCE}

Documentation of satisfactory long term performance under in-use condition of systems, components, or materials may be used to demonstrate compliance with the standards listed in this chapter. 
MECHANICAL - SOLAR POWERED EQUIPMENT

\section{GENERAL PROVISIONS}

Fire Safety

Assemblies and materials used in the solar systems shall comply with the nationally recognized codes for fire safety under all anticipated operating and no flow conditions.

\section{Effects of External Environment}

The domestic hot water (DHW) system and its various subassemblies shall not be affected by external environmental factors prevalent at the site to an extent that will significantly impair their function during their intended design life.

\section{Temperature and Pressure Resistance}

Components shall be capable of performing their functions for their intended design life when exposed to the maximum and minimum temperatures and pressures that can be developed in the system.

\section{Materials Compatibility}

All materials which are joined directly to or in contact with other materials shall have sufficient chemical compatibility with those materials to prevent deterioration that will significantly impair their function during their intended design life. Provisions shall be made to allow for differences in the expansion and contraction of joined materials due to expected temperature fluctuations.

\section{Airborne Pollutants}

Materials exposed to airborne pollutants while in service, such as ozone, salt spray, sulfur dioxide, oxides of nitrogen and/or hydrogen chloride, shall not be affected by those pollutants to an extent that will significantly impair their function during their intended design life.

\section{Chemical Decomposition Products}

Materials shall not be affected by chemical decomposition products expelled from components under in-use conditions to an extent that will significantly impair their function during their intended design life.

\section{Abrasive Wear}

Exterior materials shall not be affected by abrasive wear caused either by cleaning or by natural factors such as wind blown sand to an extent that will significantly impair their function during their intended design life.

\section{Soil Corrosion}

Materials installed in corrosive soil shall be either of a material unaffected by such soil or shall be isolated from it by a protective coating. The coating and its application shall conform to AWWA C-203. 
Substances that can be leached by moisture from any of the materials within the system which may be exposed to moisture shall not cause corrosive deterioration of any other materials to an extent that will significantly impair their function during their intended design life.

$S-515-1.10$

Leakage

Leakage from assemblies or subassemblies which contain heat transfer fluids shall not significantly impair the function of other components which may come in contact with the leaking heat transfer fluid or create a safety hazard.

S-515-2

$S-515-2.1$

$S-515-2.1 .1$

\section{COLLECTORS}

Genera1

Collectors shall perform their function for their intended design life.

Commentary: In addition to their primary function of collecting solar energy, collector panels can be used as the roofing membrane. They can also be mounted over a roofing membrane or mounted remotely. The primary function of a roofing membrane is to prevent the entrance of water into the structure. When collector panels are designed to fulfill this function, leakage at joints must be considered in the design.

When collectors are mounted over a roofing membrane, consideration should be given to the growth of fungus, mold, and mildew between the roofing membrane and the collector and to potential problems in reroofing under collectors. Also, it is possible, due to extreme temperature differentials, to cause the formation of ice dams which could in turn back water under shingles or other roofing materials, causing rapid deterioration. Consideration should be given to the methods of applying non-integral collectors to roof structures and to the choice of waterproofing membrane.

\section{Labeling and Technical Data Sheets}

Collectors shall be labeled to show the manufacturer's name and address, model number, serial number, and collector weight (dry). Technical data sheets shall also be provided which include collector efficiency as measured according to S-615-2.2, maximum allowable operating and no-flow temperatures and pressures, minimum allowable temperatures, and the types of fluids which can and cannot be used.

Commentary: Other data related to the installation and operating conditions or characteristics is desirable such as the pressure drop across the collector.

\section{S-515-2.1.2 Thermal Stability}

Collectors shall not exhibit a change in the product of $F_{R} \tau \alpha$ (intercept) or $\mathrm{F}_{\mathrm{R}} \mathrm{U}_{\mathrm{L}}$ (slope) that would result in a $10 \%$ or greater decrease in thermal efficiency for the proposed system design operating conditions when evaluated in accordance with the following testing procedure.

\section{Testing Procedure:}

The parameters $F_{R} \tau \alpha$ and $F_{R} U_{L}$ shall be determined in accordance with the test procedure described in ASHRAE Standard 93-77 both before and after exposing the collector panel assembly to the Exposure Test described below. Both the before and after collector thermal performance tests (ASHRAE Standard 93-77) shall be performed utilizing the same test facility under simflar climatic conditions. 
Exposure Test:

A. Test specimen shall consist of a complete air or liquid collector panel assembly.

B. Pre-exposure preparation:

(1) Air collectors shall be sealed and capped with a pressure relief device set to a value within $10 \%$ of the collector manufacturer's maximum recommended operating pressure. The inlet shall be equipped with a means to allow the admission of dry air if internal pressures of less than one (1) atmosphere occur.

(2) Liquid collectors intended for use in all systems (with or without draindown) shall be completely filled with clean tap water, following which the inlet shall be sealed and the outlet provided with a pressure relief valve set to a value of within $10 \%$ of the manufacturer's recommended maximum operating pressure.

(3) Liquid collectors limited to use in systems that draindown when not operating shall be completely filled with clean tap water, following which the water shall be allowed to gravity drain for 15 minutes with the collector mounted at a $45^{\circ}$ tilt angle. The collector inlet shall then be sealed and the outlet provided with a pressure relief valve set to a value of within $10 \%$ of the manufacturer's recommended operating pressure.

\section{Exposure conditions}

Exposure conditions shall consist of 30 days of cumulative exposure to a minimum daily incident solar radiation flux of $1500 \mathrm{Btu} / \mathrm{ft}^{2}$.day as measured in the plane of the collector aperture. The exposure conditions shall include at least one consecutive four-hour period with a minimum flux of $300 \mathrm{Btu} / \mathrm{ft}^{2} \cdot \mathrm{hr}$. In water filled specimens, this must occur after water boilout has occurred. The average ambient temperature shall be $80^{\circ} \mathrm{F}$ or higher during the $300 \mathrm{Btu} / \mathrm{ft}^{2} \cdot \mathrm{hr}$ exposure time. The collector shall be mounted to a rack at a tilt angle such that the incident solar radiation during solar noon is within $\pm 10^{\circ}$ of the normal to the plane of the aperture.

D. Data records

(1) The exposure conditions including insolation, ambient temperature, wind velocity, and precipitation shall be recorded to enable determination of the average daily values. Values shall be recorded every 30 minutes during the $300 \mathrm{Btu} / \mathrm{ft}^{2} \cdot \mathrm{hr}$ exposure.

(2) A regularly scheduled weekly visual inspection shall be made and a record of changes in the physical construction or appearance of the collector kept.

(3) The results of the pre-test and post-test thermal performance shall be plotted on the same graph for comparison purposes.

Commentary: The purpose of the "no-flow" test is to identify, in a short period of time, potential problems with collector materials or construction. The 30 days do not necessarily have to be consecutive but the test should be performed on a continuous basis until the solar radiation levels have been achieved for 30 cumulative days. It is recognized that other heat transfer fluids exist which may be preferred by the manufacturer or designer. If the test is conducted in a manner other than that prescribed, the collector specification shall state the specific conditions used during the test and identify the pertinent limitations regarding collector array installation 
$S-515-2 \cdot 1.3$

\section{S-515-2.1.4 Flashing}

a. Flashing for collector panel supports that penetrate the primary roof membrane shall be designed to prevent the penetration of water or melting snow for the life of the roof system.

b. Flashing systems shall be designed to permit minor repairs without disturbing the roof membrane, collector supports, or collector panels.

c. In general, flashing for roof penetrations shall comply with applicable Sections of 507-5 and 507-8 of the MPS.

Commentary: Suggested practices for flashing used on no-slope or low slope roofs and roof penetrations are provided in the National Roofing Contractors Association's "A Manual of Roofing Practice," 1970.

\section{S-515-2.2 Cover Plates}

\section{S-515-2.2.1 General}

The materials used as glazing for cover plates must meet the following requirements based on materials properties as well as safety considerations. The safety requirements are made with respect to the physical location of the glazing and the exposure risk of persons nearby.

Commentary: Appendix table B-1 lists properties of a number of materials that have been used for cover plates.

S-515-2.2.1.1 Structura1 Requirements

All glazing materials shall be of adequate strength and durability to withstand the loads and forces required by Section S-601 of this document.

\section{S-515-2.2.1.2 Types of Applications}

Applications include windows which act as cover plates for solar collectors, both integral with dwelling construction and freestanding components.

a. Glazing materials other than those specified in b or c below, shall meet the intent of the requirements for glazing in MPS Section 508-8.3.

Commentary: Consumer Product Safety Act, Part 1201, was published in the Federal Register Janumy 6, 2977 and will become effective on July 6, 2977 (except for fire retardant glazing required by ordinance for which the effective date is January 6, 2980). This standard contains mandatory safety standards for architectural glazing materials. 
Film-type glazing materials for the outermost cover plate, if unsupported, may be unacceptable if they can be deflected under load, e.g., a person's hand pushing against the glazing, may present an opportunity for exposure of the film (and the person's hand) to hot surfaces such as the absorber plate. Also, there is a probability of exposure to impact which may result in tearing of the firm.

b. Glazing materials with slopes less than $45^{\circ}$ which extend below $6^{\prime} 0^{\prime \prime}$ (from ground level) shall be safety glazed or otherwise protected against impact of falling bodies.

Commentary: This comonly refers to glazing on which children may climb or against which a passerby may fall.

c. Glazing panels which are an integral part of a roof or rack-mounted system on a roof, not routinely accessible by the occupant, shall meet the requirements of Section S-601.

Commentary: Annealed glass or films may be acceptable.

S-515-2.2.2 Codes and Standards

Materials used as glazing for cover plates shall comply with MPS Section 508, Section S-601 of this document and applicable sections of local building codes and national standards.

S-515-2.2.3 Materials Performance

S-515-2.2.3.1 Thermal Stability

After testing as described in S-515-2.1.2, there shall be no cracking, crazing, warping, sagging, or buckling of the cover plate(s) that will result in premature failure or degradation in collector performance greater than the design limits.

\section{S-515-2.2.3.2 Ultraviolet Stability}

Documentation shall be provided that the cover plate(s) is resistant to degradation by UV radiation that would significantly impair its function during its design life. In lieu of other documentation, the transmittance of the cover plate(s) as measured by ASTM E 424-71 shall not significantly change after exposure using any one of the three aging procedures described below. The computation of solar transmittance based on the spectrophotometric method in E 424 shall be standardized on air mass 2 .

For collectors with multiple covers; the tests below shall be performed with the cover plates in their design configuration.

Commentary: In the absence of other documentation, a change in cover plate transmittance of more than $10 \%$ is considered significant.

\section{Aging Procedure 1}

Expose components or materials to simulated solar radiation (such as xenon arc radiation) for a period of 2000 equivalent sun hours. The exterior surfaces of components which are exposed to rainfall in service shall be subjected to a water spray for a period of 5 minutes during each 60 minutes of the light exposure. For components not exposed to rainfall under normal operating conditions, the water spray shall not be included in the procedure. 


\section{Aging Procedure 2}

Expose components or materials to concentrated natural solar radiation using machines such as those referenced in ANSI 297.1-1975, paragraph 4.3.2 for a perfod of 2000 equivalent sun hours. The exterior surfaces of components which are exposed to rainfall in service shall be subjected to a water spray for a period of 8 minutes during each 60 minutes of sunlight exposure. For components not exposed to ralnfall under normal operating conditions, the water spray shall not be included in the procedure.

\section{Aging Procedure 3}

Expose components and materials to solar radiation outdoors for twelve months. The average dafly flux of the solar radiation, as obtained by averaging the dally fluxes over the twelve month perfod of outdoor exposure, shall be at least $1,500 \mathrm{Btu} / \mathrm{ft}^{2}$.

S-515-2.2.3.3 Glass

Where safety glazing is used, it shall meet the requirements of the MPS, Section 508, as specified in S-515-2.2.1.2 of this document .

S-515-2.2.3.4 Other Materials

Cover plate materials other than glass shall conform to the requirements of MPS, Section 513 and the intent of s-515-2.2.3.3.

Comentary: Appendix Table B-1 lists a number of materials that have been used for cover plates.

S-515-2.3 Absorber Plate

S-515-2.3.1 General

Materials used for absorber plates shall not degrade to an extent that collector performance would be reduced below allowable design limits.

S-515-2.3.2 Materials Performance

S-515-2.3.2.1 Thermal Stability

Any deformation that occurs in the test described in S-515-2.1.2 shall not result in premature failure or degradation in collector performance greater than the design limits.

Commentary: In addition to buckling, sagging, and warping that can be produced in the thermal stability test, consideration should be given to the possibility that repeated boilout cycles can lead to deformation or muture of the absorber plate.

\section{S-515-2.3.2.2 Erosion/Corrosion}

Flow rates shall be maintained below the values listed in Tables S-515-2.3.2 and 2.3.3 to prevent erosive wear. 
Commentary: The variables which have an important impact on the rate of erosion/corrosion are:

1) the quantity and size distribution of solids in suspension

2) the flow rate

3) the pipe diameter

4) the oxygen content of the fluid

5) the angle of the change of flow direction

6) the internal surface condition of the pipe

7) the temperature

8) partial obstmuctions in flow passages which create localized areas of highly turbulent fluid flow

S-515-2.3.2.3 Compatibility with Transfer Medium

a. The absorber plate or flow conduits shall not be pitted, corroded, or otherwise degraded by the heat transfer medium to an extent that will result in failure during its design life. In lieu of other documentation for metals, modifications of tests listed in Table S-515-2.3.1 shall be used to demonstrate compliance with this requirement. For materials other than metals, documentation shall be provided to demonstrate compliance with S-515-1.4 and this requirement.

Commentary: Two types of heat transfer liquid, aqueous and non-aqpresous may be used in the collector system. Generally, corrosion is associated with aqueous transfer media. However, corrosion could also occur in nonaqueous media under one or more of the following conditions:

1) if the liquid is initially agressive to the containment material

2) if liquid decomposition generates corrosive products

3) if water is initially present in the liquid or contaminates the liquid once in use.

b. Metallic absorber plates or flow conduits in direct contact with heat transfer liquids in open systems shall generally be used in accordance with the acceptable conditions listed in Table S-515-2.3.2 where

applicable. Generally unacceptable conditions listed in this table shall be avoided. Documentation shall be provided to demonstrate that materials applications not explicitly covered in Table S-515-2.3.3 meet the intent of $\mathrm{S}-515-1.4$ and $\mathrm{S}-515-2 \cdot 3 \cdot 2 \cdot 3 \mathrm{a}$.

Metallic absorber plates or flow conduits in direct contact with heat transfer liquids in closed systems shall generally be used in accordance with the acceptable conditions listed in Table S-515-2.3.3 where applicable. Generally unacceptable conditions listed in this table shall be avoided. Documentation shall be provided to demonstrate that materials applications not explicitly covered in Table S-515-2.3.3 meet the intent of $\mathrm{S}-515-1.4$ and $\mathrm{S}-515-2 \cdot 3 \cdot 2 \cdot 3 \mathrm{a}$.

Commentary: Tables S-515-2.3.2 and S-515-2.3.3 are intended to provide general guidelines for the selection of metals or alloys for use in solar collectors. Various alloys of the same base metal may be expected to show significant variability in resistance to corrosion. Small concentration changes in a number of chemical species may significantly change the corrosion behavior of a given material at a given temperature. A complete description of this behavior is not possible in this context. Therefore, generally unacceptable use conditions as stated should be avoided unless it has been demonstrated that the metal or alloy performs suitably in the anticipated use condition. Adequate performance is anticipated for normal operation in generally acceptable use conditions.

The stated generally acceptable use conditions are directed toward normal operation. Under the conditions of stagnation, where high temperatures may be encountered, different behavior may occur. It is recommended that specific tests be carried out to ensure adequate materials performance in these conditions. 
SAE Report J447a (1964), Prevention of Corrosion of Metals, provides guidance in preventing corrosion in aqueous media, but its application should be tempered by consideration of the special operating characteristics of solar collectors, e.g., no-flow temperature effects.

Table S-515-2.3.1: Corrosion Test Methods*

Number

Title

Comment

NACE TM-01-71

NACE TM-02-74

NACE TM-02-70

NACE TM-01-69 (1972)

ASTM D1384-70 (1975)

ASTM D2570-73

ASTM D2776-72
Autoclave Corrosion Testing of Metals in High Temperature Water

Dynamic Corrosion Testing of Metals in High Temperature Water

Conducting Controlled Velocity Laboratory Corrosion Tests

Laboratory Corrosion Testing of Metals for the Process Industries

Corrosion Test for Engine Antifreeze in Glassware

Simulated Corrosion Testing of Engine Coolants

Corrosivity of Water in the Absence of Heat Transfer
Modify to reflect conditions present in solar system

Modify to reflect conditions present in solar system

Modify to reflect conditions present in solar system

Describes factors to consider in corrosion testing

Modify to reflect conditions present in solar system

Modify to reflect conditions present in solar system

* Modification of test procedures developed for purposes other than collector material testing shall adequately reflect all expected collector conditions including no-flow conditions.

Commentary: Open and Closed Systems

Open systems are those in which air, in addition to that initially in the transfer liquid, can be absorbed into the liquid by contact with the atmosphere or air entrapped in the system.

Closed systems are those in which the air initially absorbed in the transfer liquid is not replaced to a significant extent. In a closed system, there is no exposure of the liquid to the atmosphere except above the expansion tank (in some cases a nitrogen blanket above the liquid in the expansion tank may be used); there is no entrapped air in the piping or storage systems and the expansion tank is isolated from the flow path between the collector and storage. In addition, liquid leakage requiring frequent make up is avoided. 


\section{Aluminum}

1. When in direct contact with untreated tap water with $\mathrm{pH}<5$ or $>9$.

2. When in direct contact with aqueous liquid containing less electro positive metal ions, such as copper or iron or halide ions.

3. When specific data regarding the behavior of a particular alloy are not available, the velocity of aqueous liquid shall not exceed $4 \mathrm{ft} / \mathrm{sec}$.

4. When in direct contact with a liquid which is in contact with corrosive fluxes.
1. When in direct contact with distilled or deionized water which contains appropriate inhibitors and does not contact copper or iron.

2. When in direct contact with distilled or deionized water which contains appropriate inhibitors and a means of removing heavy metal ions obtained from contact with copper or iron.

3. When in direct contact with stable anhydrous organic liquids.

\section{Copper}

1. When in direct contact with aqueous liquid containing high concentrations of chlorides, sulfates or liquid which contains hydrogen sulfide.

2. When in direct contact with chemicals that can form copper complexes such as ammonium compounds.

3. When in direct contact with an aqueous 1iquid having a velocity greater than $4 \mathrm{ft} / \mathrm{sec} .2 /$

4. When in direct contact with a liquid which is in contact with corrosive fluxes.

5. When in contact with an aqueous 1iquid with a pH lower than 5 .

6. When the copper surface is initially locally covered with a copper oxide film or a carbonasceous film.

7. When operating under conditions conducive to water line corrosion.
1. When in direct contact with distilled, delonfzed or low chloride, low sulfate and low sulfide tap water.

2. When in direct contact with stable anhydrous organic liquids.

Stee1

1. When in direct contact with untreated tap, distilled or deionized water with $\mathrm{pH}<5$ or $>12$.
1. When in direct contact with distilled, deionized or low salt content water which contains appropriate corrosion inhibitors. 
2. When in direct contact with a liquid which is in contact with corrosive fluxes.

3. When in direct contact with an aqueous liquid having a velocity greater than $6 \mathrm{ft} / \mathrm{sec} .2 /$
2. When in direct contact with stable anhydrous organic liquids.

3. When adequate cathodic protection of the steel is used (practical only for storage tanks).

4. When operating under conditions conductve to water line corrosion.

\section{$\underline{\text { Stainless Steel }}$}

1. When the grade of stainless steel selected is not corrosion resistant in the anticipated heat transfer liquid.

2. When in direct contact with a liquid which is in contact with corrosive fluxes.
1. When the grade of stainless steel selected is resistant to pitting, crevice corrosion, intergranular attack and stress corrosion cracking in the anticipated use conditions.

2. When in direct contact with stable anhydrous organic liquids.

\section{Galvanized Stee1}

1. When in direct contact with aqueous liquid containing copper ions.

2. When in direct contact with aqueous liquid with $\mathrm{pH}<7$ or $>12$.

3. When in direct contact with aqueous liquid with a temperature $>55^{\circ} \mathrm{C}$.
1. When adequate cathodic protection of the galvanized parts is used (practical only for storage tanks).

2. When in contact with stable anhydrous organic liquids.

\section{Brass and Other Copper Alloys}

Binary copper-zinc brass alloys (CDA 2XXX series) exhibit generally the same behavior as copper when exposed to the same conditions. However, the brass selected should resist dezincification in the operating conditions anticipated. At zinc contents of $15 \%$ and greater, these alloys become increasingly susceptible to stress corrosion. Selection of brass with a zinc content below $15 \%$ is advised. There are a variety of other copper alloys available, notably copper-nickel alloys, which have been developed to provide improved corrosion performance in aqueous environments.

1/ The use of suitable antifreeze agents and buffers is acceptable provided they do not promote corrosion of the metallic liquid containment system. The use of suitable corrosion inhibitors for specific metals is acceptable provided they do not promote corrosion of other metals present in the system. If thermal or chemical degradation of these compounds occurs, the degradation products shall not promote corrosion.

2)

The flow rates at which erosion/corrosion becomes significant will vary with the conditions of operation. Accordingly, the value listed is approximate. 
TABLE S-515-2.3.3 Generally Acceptable and Unacceptable Use Conditions for Metals

In Direct Contact with Heat Transfer Liquids in Closed Systems

Generally Unacceptable Use Conditions

Generally Acceptable Use Conditions 1/

\section{Aluminum}

1. When in direct contact with untreated tap water with $\mathrm{pH}<5$ or $>9$.

1. When in direct contact with distilled or deionized water which contains appropriate corrosion inhibitors.

2. When in direct contact with liquid containing copper, iron or halide ions.

2. When in direct contact with stable anhydrous organic liquids.

3. When specified data regarding the behavior of a particular alloy are not avallable, the velocity of aqueous liquid shall not exceed $4 \mathrm{ft} / \mathrm{sec}$.

\section{Copper}

1. When in direct contact with an aqueous $11 \mathrm{q}-21$. When in direct contact with untreated uld having a velocity greater than $4 \mathrm{ft} / \mathrm{sec}-$ tap, distilled or deionized water.

2. When in contact with chemicals that can form copper complexes such as

2. When in direct contact with stable ammonium compounds. anhydrous organic liquids.

3. When in direct contact with aqueous liquids which do not form complexes with copper.

\section{Stee1}

1. When in direct contact with liquid having a velocity greater than $6 . \mathrm{ft} / \mathrm{sec} . \underline{2}$

2. When in direct contact with untreated tap, distilled or deionized water with $\mathrm{pH}<5$ or $>12$.
1. When in direct contact with untreated tap, distilled or deionized water with $\mathrm{pH}>5$ or $<12$.

2. When in direct contact with stable anhydrous organic liquids.

3. When in direct contact with aqueous liquids of $\mathrm{pH}>5$ or $<12$.

\section{Stainless Steel}

1. When the grade of stainless steel selected is not corrosion resistant in the ant1cipated heat transfer liquid.

2. When in direct contact with a liquid which is in contact with corrosive fluxes.
1. When the grade of stainless steel selected is resistant to pitting, crevice corrosion, intergranular attack and stress corrosion cracking in the anticipated use conditions.

2. When in direct contact with stable anhydrous organic liquids. 
TABLE S-515-2.3.3 (Contd.)

\section{Galvanized Steel}

1. When in direct contact with water with $\mathrm{pH}<7$ or $>12$.

2. When in direct contact with an aqueous liquid with a temperature $>55^{\circ} \mathrm{C}$.
1. When in contact with water of $\mathrm{pH}>7$ but $<12$.

\section{Brass and Other Copper Alloys}

Binary copper-zinc brass alloys (CDA 2XXX serles) exhibit generally the same behavior as copper when exposed to the same conditions. However, the brass selected shall resist dezincification in the operating conditions anticipated. At zinc contents of $15 \%$ and greater, these alloys become increasingly susceptible to stress corrosion. Selection of brass with a zinc content below $15 \%$ is advised. There are a variety of other copper alloys avallable, notably copper-nickel alloys, which have been developed to provide improved corrosion performance in aqueous environments.

The use of suitable antifreeze agents and buffers is acceptable provided they do not promote corrosion of the metallic liquid containment system. The use of suitable corrosion inhibitors for specific metals is acceptable provided they do not promote corrosion of other metals present in the system. If thermal or chemical degradation of these compounds occurs, the degradation products shall not promote corrosion.

$\underline{2}$

The flow rates at which erosion/corrosion becomes significant will vary with the conditions of operation. Accordingly, the value listed is approximate. 
Corrosion is a very complex phenomenon in which many parameters are of importance. In the case of the corrosion of metals likely to be used in the liquid containment system parameters of importance are:

- the composition of the metals or alloys

- the composition of the water, i.e. the concentrations of salts and dissolved gases and heavy metal ions

- the temperature

- the flow rate and the possibility of erosion-corrosion

- system design factors, particularly the presence of galvanic cells or differential aeration cells

- the presence of additives or their decomposition products

Galvanic cells result from contact between dissimilar metals while differential aeration cells are areas where a metal is in contact with the liquid which has a variable dissolved oxygen content.

\section{Water Composition}

Water composition has an important effect on corrosion. The composition of tap water varies substantially from one geographic area to another. Even within a given area, water composition will vary depending on its source (surface vs. well water) and the time of year. The major variables include: $\mathrm{pH}$, gas content $\left(\mathrm{O}_{2}, \mathrm{CO}_{2}\right)$, chloride content, sulfate content, solids content (organic matter), and conductivity. Because of variation in water, similar variations in the type and severity of corrosion may be expected.

1a. $\mathrm{pH}$

The $p H$ of the transfer liquid will have an important impact on corrosion rates. However, the optimom pH range to achieve minimum corrosion of a given material, will change with temperature [1]. Because varying temperatures occur within a solar heating system and the temperature at a given point wizl change with time, care must be taken to optimize the pH range. It should be noted that the pH of a system immediately after filling is not necessarily the equilibrium $\mathrm{pH}$.

\section{Ib. $\mathrm{O}_{2}$ Content of Aqueous Media}

Generally, corrosion of metals such as $\mathrm{Cu}$ and carbon steel will decrease with a decreasing comount of $\mathrm{O}_{2}$ in aqueous media. In the absence of $\mathrm{O}_{2}$, measurable corrosion of $\mathrm{Cu}$ and steel does not occur. In a closed system, where $\mathrm{O}_{2}$ will be depleted, the corrosion rate will become negligible. Corrosion inhibitors should not be necessary in a completely closed containment system composed of Cu or steel, if the proper $\mathrm{pH}$ is maintained. However, the probability of a closed system remaining closed is uncertain since the eventual intmusion of oxygen cannot be discounted. Therefore, the use of corrosion inhibitors or oxygen scavengers should be considered.

Oxidizing species such as dissolved oxygen act to stabilize the passivity of the protective film on stainless steel. When stainless steel is used in the absence of such species, it may be necesscry to specify a grade which will provide adequate resistance to corrosion attack under these conditions.

11] R. M. Diamant, "The Prevention of Corrosion," Business Books Ltd., London, 1971. 
The corrosion of AI may continue even in the absence of oxygen since an alternative corrosion process can occur. In this process, anodic dissolution of Al is accompanied by the evolution of molecular hydrogen. However, this reaction is expected to be negligible if the pH is maintained between 5 and $?$ in the absence of aggressive ions.

\section{1c. Chlorides}

Chloride concentration should be kept to a minimum since the presence of chlorides in water accelerates corrosion of most metals. Therefore, the metallic collector components selected should be compatible with the chloride level anticipated in the heat transfer liquid. Aside from its initial presence in water, there are several potential sources of chloride in a solar unit:

- Residual chloride from pickling treatment of metallic components. This may also be a source of sulfate; while this is a rather unlikely source of these ions, care should be taken that the components of the system are thoroughly cleaned before assembly.

- Chloride from the decomposition of non-metallic components in the system.

- Chloride from flux used in soldering or brazing components during installation.

\section{Temperature}

The temperature is an important consideration with regard to selection of containment materials. Corrosion in aqueous media generally increases rapidly with temperature until the boiling point is approached. In systems open to the atmosphere, the corrosion rate will tend to decrease due to a sharp decrease in the solubility of oxygen in water at these temperatures. However, in a pressurized system, from which the dissolved oxygen cannot escape, corrosion may continue at an accelerated rate.

\section{Copper in a Recirculating System}

In "once through" systems, copper pipe is usually only connected downstream from iron pipe. Residential plumbing is an example of this. This practice is carried out because small amounts of copper tend to go into solution. When these copper ions contact more active metals such as $\mathrm{Zn}$ or $A Z$, and to a lesser extent, Fe, they are reduced to copper metal which subsequently deposits on the metal surface. When this occurs, a galvanic cell is set up and rapid corrosion initiates. No such effect is anticipated for systems utilizing copper and stainless steel. The presence of a dielectric pipe joint between $\mathrm{Cu}$ and $\mathrm{Al}$ or Fe will not alleviate this problem. Simizar action may be expected if Fe deposits on AZ.

\section{Galvanizing}

Galvanizing has long been used to protect iron or steel from corrosion. Zinc is more active than iron and, when the two are in electrical contact, will corrode preferentially. Thus, the iron is cathodically protected. The rate of corrosion of zinc is generally lower than that of iron. so a relatively thin coating may last for quite a long time. However, there are data indicating that at elevated temperatures approaching $158^{\circ} \mathrm{F}$ $\left(70^{\circ} \mathrm{C}\right)$, this effect is reversed and the iron corrodes rather than the zinc. [2]

[2] G. Butler and H. C. K. Ison, "Corrosion and its Prevention in Waters," Reinhold Publishing, N.Y., 1966. 
In addition, the corrosion rate of zinc itself increases rapidly in the temperature range between 131 and $194^{\circ} \mathrm{F}\left(55\right.$ and $\left.90^{\circ} \mathrm{C}\right)$. Accordingly, the use of galvanized steel above $131^{\circ} \mathrm{F}\left(55^{\circ} \mathrm{C}\right)$ should be considered with care.

\section{Stainless Steel}

While stainless steel is generally regarded as corrosion resistant, it may be susceptible to intergranular attack, pitting, crevice corrosion or stress corrosion cracking. The corrosion resistance of stainless steel varies greatly with the grade used and the thermal treatment. Therefore, the grade of stainless steel selected should be resistant to corrosion when exposed to the anticipated heat transfer liquid.

\section{Galvanic Coupling}

Contact between dissimilar metals in the liquid contairment system should be avoided when aqueous heat transfer media are to be used. However, physical separation of dissimilar metals may not always ensure against galvanic corrosion (see commentary on copper in a recirculation system).

\section{Stress Corrosion}

Collector components may be subject to substantial residual stresses resulting from their fabrication. In addition, thermal cycling during operation may introduce applied stresses. Typical collector designs and operating conditions may be such that it is virtually impossible to avoid residual or applied stresses.

Some metals and alloys are sisceptible to stress corrosion when stressed in the presence of contominants commonly present in water, aqueous fluids, or in the atmosphere. Therefore, the metals used in collectors should be limited to those which are not susceptible to stress corrosion when in contact with the anticipated heat transfer Iiquid.

\section{Expression of the Results of Corrosion Measurements}

Corrosion may be localized in the form of pitting, crevice corrosion, intergranular attack, stress corrosion, or erosion corrosion or it may be uniform. Localized corrosion is generally more destructive since it results in perforation in far shorter periods. Therefore, the type of attack observed should be reported. The measurement technique used in evaluating the severity of attack should also be consistent with the type of attack observed. For example, weight loss measurement would not be completely adequate to assess the degree of domage caused by localized corrosion. Weight loss measurement may be meaningful when the degree of localization of attack is described. However, results should also include pit density, maximom depth of penetration or rate of penetration measurement where appropriate.

ASTM standards $G 1-72, G 16-71$, and $G 46-76$ provide recommended practices relating to corrosion test evaluation.

\section{S-515-2.3.2.4 U1traviolet Stability}

Organic absorber plates shall not degrade to an extent that will significantly impair their function during their design life. when exposed to $\mathrm{UV}$ radiation.

Commentary: Organic absorber plates can crack, embrittle, soften, fade, or undergo other changes that could result in premature failure. 
S-515-2.4

$S-515-2.4 .1$

Genera1

Materials used for absorptive coatings shall not degrade to an extent that collector performance will be reduced below allowable design limits.

Commentary: Appendix Table B-Z lists some charateristics of absorptive coatings currently in use. Absorptive coatings are generally of two types, selective or nonselective. A nonselective coating has an absorptance to emittance ratio near unity whereas in a selective coating, the ratio is higher. A selective coating has a high absorptance (a) over the solar opectrum $(.3$ to $2.0 \mu \mathrm{m})$ with low emittance $(\varepsilon)$ to reduce thermal radiative heat losses.

For coatings applied by an electroplating process, as are many selective coatings, the substrate finish, plating geometry, bath composition, and current density may influence the properties necessary for optimum solar applications.

\section{S-515-2.4.2 Materials Performance}

\section{S-515-2.4.2.1 Thermal Stability}

After testing as described in S-515-2.1.2, there shall be no evidence of checking, cracking, blistering or flaking of the absorptive coating that will significantly impair its function. ASTM methods D660-44 (1970), D661-44 (1975), D714-56 (1974) and D772-47 (1975) shall be used to eva1uate the above properties.

\section{S-515-2.4.2.2 U1traviolet Stability}

Documentation shall be provided that the absorptive coating is not adversely affected by $U V$ radiation to an extent that will significantly impair its function during its intended design life. In lieu of other documentation, the absorptive coating shall not exhibit checking, cracking, blistering, or flaking after testing using any one of the three aging procedures described in $\mathrm{S}-515-2 \cdot 2 \cdot 3 \cdot 2$ in its design configuration.

Commentary: The above tests shall be performed with a cover plate between the absorptive coating and the light source (if so designed) to simulate in-service conditions. The cover plate shall be of the same type and configuration as used in an actual collector.

In the absence of other documentation, a change in absorptive coating a or $\varepsilon$ of $10 \%$ is considered significant.

\section{S-515-2.4.2.3 Moisture Stability}

Documentation shall be provided that the absorptive coating is not adversely affected by moisture with which it comes in contact to an extent that will significantly impair its function during its intended design life. In lieu of other documentation, the absorptive coating shall not exhibit checking, cracking, blistering or flaking after testing for 30 days according to ASTM D 2247-68 (1973).

Commentary: Moisture is not expected to come in contact with absorptive coating in collectors which have a desiccant or in evacuated tube collectors. 
When absorptive coatings are in direct contact with the heat transfer medium documentation shall be provided to show that they are not affected by the medium to an extent that would significantly impair their function during their design lives. In lieu of other documentation, the absorptive coating shall exhibit no checking, cracking, blistering or flaking or signs of erosion after immersion in the fluid transfer medium for 100 hours at the maximum service temperature according to ASTM D1308-57 (1973).

\section{S-515-2.5 Collector Enclosure}

S-515-2.5.1 Genera1

Collector enclosure materials sha1l be in accordance with applicable sections of Division 5 and 6 of the MPS.

Protective coatings, where used, shall be in accordance with Section 509-7 of the MPS.

S-515-2.5.2 Materials Performance

S-515-2.5.2.1 Thermal Stability

After testing as described in S-515-2.1.2, there shall be no cracking or warping of the collector enclosure materials to an extent that would result in premature failure or degradation in collector performance greater than the design limits.

S-515-2.6 Reflective and Antireflective Surfaces

S-515-2.6.1 Genera1

Changes in reflective and antireflective surfaces due to in-use exposure shall not result in a decrease in collector performance below the design limits.

S-515-2.6.2 Materials Performance

S-515-2.6.2.1 Thermal Stability

After testing as in S-515-2.1.2, there shall be no cracking, crazing, delamination or change in reflectance properties of the surfaces to an extent that would result in premature failure or degradation in collector performance greater than the design limits.

\section{S-515-2.6.2.2 U1traviolet Stability}

Documentation shall be provided that the reflectance properties of the surfaces will not be adversely affected by UV radiation to an extent that will significantly impair their function during their design life.

In lieu of other documentation, the reflectance, as measured for air mass 2 by ASTM E 424-71, method A, shall not decrease by more than $10 \%$ after exposure using any one of the three aging procedures described in $5-515-2 \cdot 2 \cdot 3 \cdot 2$. 
This section covers materials used to transport the heat transfer medium to a heat exchanger or storage facility and also those necessary components used to return the heat transfer medium from the heat exchanger or storage facility to the collector subsystem.

S-515-3.1 Applicable Standards for Liquid Systems

5-515-3.1.1 Compliance with MPS

Materials used in the transport system shall be in accordance with Sections 515-3.2, 515-5.1, 515-5.2 and 515-6.4 of the MPS where applicable.

S-515-3.1.2 Other Standards

Materials used for transporting liquids shall be shown to be in compliance with applicable standards.

Commentary: Examples of some standards that may be useful are given in Appendix Table B-4. Most of the standards for piping shown in Appendix Table B-4 are the standards normally considered by the model plumbing codes. Designers may use other ANSI, ASTM, or Federal standards or Specifications that may be more appropriate to their particular design.

S-515-3.2 Materials Performance for Liquid Systems

S-515-3.2.1 Thermal Stability

Components comprising the transport system shall not be damaged by normal thermal expansion and contraction of piping materials under in-use conditions. Proper pipe hangers and supports and fittings shall be used to allow normal movement of piping. See Appendix Table B-4.

S-515-3.2.2 Chemical and Physical Compatibility

a. Materials comprising the transport system shall have sufficient chemical and physical compatibility with organic materials in the system, such as sealants and gaskets, to which they are joined or in contact to prevent significant deterioration.

b. Materials comprising the piping or transport system shall have sufficient chemical and physical compatibility with the heat transfer liquid to prevent significant corrosive wear and deterioration. (For metals, see $S-515-3.2 .5$ )

S-515-3.2.3 Erosion/Corrosion

Materials comprising the transport system shall be in conformance with S-515-2.3.2.2.

S-515-3.2.4 Joints Between Dissimilar Metals

Dissimilar materials joined to form the transport system shall be electrically isolated from each other unless documentation is provided to demonstrate that the joints are sufficiently compatible to prevent corrosive wear and deterioration during their design lives. 
Commentary: Care must be taken to avoid short circuiting of dielectric couplings. For excmple - dielectric couplings used to isolate dissimilar metals which are buried in soil may be ineffective because of contact of the metals with ground water, or dielectric couplings may be short circuited through pipe supports connected to metal structures.

S-515-3.2.5 Metals

Metals used in the transport system which are in direct contact with heat transfer liquids shall be used in accordance with the generally acceptable conditions listed in Tables S-515-2.3.2 or S-515-2.3.3 where applicable. Generally unacceptable conditions listed in these tables shall not be used. Documentation shall be provided to demonstrate that material usages not covered in the tables meet the intent of $\mathrm{s}-515-1.4$ and $\mathrm{s}-515-3.2 .3$.

S-515-4 MECHANICAL SUPPORTING DEVICES

S-515-4.1 General

Mechanical supporting devices including support devices for roof, wall, or remote mounted collectors shall be designed and constructed of materials in accordance with Section 500 of MPS.

S-515-4.3 Pipe and Duct Hangers

Pipe and duct hangers, used to support insulated pipes or ducts, shall be designed to avoid damaging the insulation material.

Commentary: If pipe or duct hangers are installed over the insulation material, metal surface plates should be used to avoid damaging the insulation. 
$S-515-5$

$S-515-5.1$

$S-515-5.2$

S-515-6

S-515-6.1

$S-515-6.2$
VALVES

Applicable Standards

Valves shall be shown to be in compliance with applicable standards. Valves manufactured to other standards not listed but fulfilling the requirements of a particular solar heating system design shall be evaluated in accordance with Sections 513 and 613 procedures and shall be acceptable to the HUD field office.

Commentary: Examples of standards that may be useful are given in Appendix Table B-4. Standards for valves usually present pressure-temperature ratings. Appendix Table B-5 presents these ratings as an example for ball valves, Federal Specification WW-V-35a-2975. National standards do not cover all valves useful to solar heating system design. Valves not covered by standards may be acceptable to HUD if a history of successful usage can be demonstrated by the valve manufacturer or solar heating system designer.

\section{Material Performance}

Valve materials shall be compatible with the heat transfer liquid as required in S-515-1.4 and S-515-3.2.

\section{PUMPS AND FANS}

Applicable Standards

a. Centrifugal, rotary and reclprocating pumps shall be in compliance with the requirements of the Hydraulic Institute [1].

Commentary: A Hydraulic Institute Standard defines the product, material, process or procedure with reference to one or more of the following: nomenclature, composition, construction, dimensions, tolerance, safety, operating characteristics, performance, quality, rating, testing and service for which designed [1].

b. Fans shall comply with the applicable standards of the AMCA or HVI and shall be tested, rated and labeled accordingly.

\section{Material Performance}

Pump materials shall be compatible with the heat transfer liquid as required in S-515-1.4 and S-515-3.2.

[1] Hydraulic Institute, 1230 Keith Bullding, Cleveland, Ohio 44115

HYDRAULIC INSTITUTE STANDARDS FOR CENTRIFUGAL, ROTARY \& RECIPROCATING PUMPS, thirteentb edition, 1975. Library of Congress Card No. A56-4036 
Thermal storage units are defined as any container, space or device which has the capacity to store thermal energy or transfer media (liquid or solid) containing thermal energy for later use.

\section{S-515-7.1 \\ General}

Thermal storage units shall be of sufficiently durable material to fulfill the heating storage requirements of the system for the intended design life of the storage unit.

S-515-7.2 Applicable Standards

Applicable standards for thermal storage materials are presented in Appendix Table B-6. The thermal performance of storage units can be evaluated using ASHRAE Standard 94-77.

\section{S-515-7.3 Labeling}

Pressurized thermal storage containers shall be labeled in accordance with 515-1.2 of the MPS. In addition, labels shall list the maximum operating pressure and temperature and minimum operating temperature.

S-515-7.4 Materials Performance

S-515-7.4.1 Contamination

Thermal storage tank materials, including any interior protective coatings and the heat storage medium used, shall not impart toxicity, undesirable tastes, or odors to either air or water intended for human consumption. For liquid system, the requirements of the U. S. Public Health Service Drinking Water Standards sha11 apply.

\section{S-515-7.4.2 Materials Compatibility}

a. Materials comprising the thermal storage system shall not cause corrosive wear and deterioration which results in premature failure or degradation in storage performance greater than the design limits.

b. Metals used in the thermal storage system which are in direct contact with heat transfer liquid shall be in accordance with the generally acceptable conditions listed in Tables S-515-2.3.2 or S-515-2.3.3, where applicable. Generally unacceptable conditions listed in these tables shall not be used. Documentation shall be provided to demonstrate that material usages not covered in the tables meet the intent of $5-515-1.4$ and $S-515-7.4 .2 a$. 
Genera1

The heat transfer fluid shall be of sufficient stability to perform its intended heat transfer functions for the intended life of the fluid. The heat transfer fluid shall not cause premature fallure or degradation in performance exceeding the design limits as specified in Section S-615-1.1.2, for those parts of the solar energy system with which it comes into contact.

Commentary: Appendix Table B-7 presents a partial listing of properties of several types of heat transfer liquids.

S-515-8.1.1 Labeling

The provisions of the Federal Hazardous Substances Act (1971) shall apply to heat transfer fluids. In addition, heat transfer media classified as combustible shall be labeled as such.

Emergency first aid instructions shall be included on the label of toxic heat transfer fluid containers. A technical data sheet shall be provided with all heat transfer fluids which contains the following information:

Service temperature range

Viscosity over service temperature range

Freezing point

Boiling point

Flash point

Auto ignition temperature

Specific heat over service temperature range

Vapor pressure over service temperature range

Instructions for inspection, treatment and disposal of fluid

Emergency first aid instructions.

For toxic fluids, a list of the chemical components of the fluid shall be available expressed in $\mathrm{mg}$./1iter. This list shall include any substances which comprise more than $0.10 \%$ of the medium.

S-515-8.2 Toxic and Combustible Fluids

S-515-8.2.1 General

Heat transfer fluids which require special handling (e.g., toxic, combustible, corrosive, explosive, etc.) shall not be used unless the systems in which they are used are designed to avoid unnecessary or unreasonable hazards; see Section S-615-10.1.

S-515-8.2.2 Flash point

Temperatures attained by fluids in solar systems under operating and no flow conditions shall not exceed a temperature which is $100^{\circ} \mathrm{F}$ below the flash point of the fluid. In no case shall a liquid with a flash point below $100^{\circ} \mathrm{F}$ or a flammable gas be used. Flash point shall be determined by the methods described in NFPA No. 321, Basic Classification of Flammable and Combustible Liquids. 


\title{
S-515-8.2.3 Atmospheric Concentration of Toxic Materials
}

Commentary: NFPA No. 321 (1973) defines Flammable Liquids as those with flash points below 100\%F and Combustible Liquids as those with flash points at or above $100^{\circ} \mathrm{F}$. This section prohibits the use of flamable liquids (flash point below $100^{\circ} \mathrm{F}$ ) and permits the use of combustible liquids ( flash point at or above $100^{\circ} \mathrm{F}$ ) under prescribed conditions. In common, non-technical usage, the term flamable liquid frequently refers to any liquid with a flash point, including liquids classified as combustible.

\begin{abstract}
The concentration of the vapor of the heat transfer medium in the building's interior atmospheric environment shall not exceed $1 / 10$ th the threshold limft value (TLV) for that particular medium in an 8-hour period.

Commentary: The TLV is primarily concermed with industrial exposures. Because routine household exposure could be for much longer time periods, the 1/10th value of the TLV is recommended. TLV's are under continuous review; a list of currently adopted values is published by the American Conference of Govermment Industrial Hygienists.
\end{abstract}

S-515-8.3 Materials Performance

S-515-8.3.1 Changes in the Heat Transfer Fluid

Except when such changes are allowed by the design of the system, the heat transfer fluid shall not freeze, give rise to excessive precipitation, give rise to sludge, asphaltic or resinous deposits or coatings, otherwise lose its homogeneity, boil, change $\mathrm{pH}$ or undergo changes in viscosity outside the design range when exposed to its intended service temperature and pressure range and other intended operating conditions.

Commentary: Some organic fluids may degrade by oxidation in open systems and thereby be unacceptable for use in such systems while providing satisfactory service in closed systems.

\section{S-515-8.3.2 Chemical Compatibility}

Heat transfer fluids designed to be used in contact with component materials shall not cause deterioration in the component which results in premature failure or degradation in collector performance greater than the design limits. Inhibitors in the concentration used shall be compatible with a11. components in the system with which they come in contact.

Commentary: Guidance is given in Section S-515-2.3.2.2 and S-515-2.3.3.3.

\section{S-515-8.3.3 Thermal Stability}

The heat transfer fluid shall not degrade at temperatures up to the maximum service temperature or cause deterioration of the system components which results in premature failure or degradation in system performance greater than the design limits.specified in Section S-615-1.1.2.

Commentary: This maximum temperature will generally be reached under "no-flow" conditions. Appendix Table B-7 includes data for a number of typical transfer liquids. Some fluids may decompose somewhat at elevated temperatures. For example, ethylene glycol can degrade to form organic acids. Buffers are usually included with such liquids to control the $\mathrm{pH}$. It may be desirable, if fluids decompose with time, to change the fluids periodically. 


\section{HEAT EXCHANGERS}

\section{Genera1}

When nonpotable liquid is used in a solar energy system to transfer heat to domestic (potable) hot water, the design of the heat exchanger shall be such that either a minimum of two walls or interfaces are maintained between the non-potable liquid and the potable water supply or protection is provided in such a manner that equivalent safety is provided.

Commentary: Double wall heat exchanger designs are one way of meeting the intent of this criterion. When double wall heat exchanger designs consisting of two single wall heat exchangers in combination with an intermediary potable heat transfer liquid are used, leakage through one of the walls would result in a single wall configuration. Although this design is considered to meet the intent of this criterion, there are several other designs that avoid this problem.

The use of single wall configurations which solely rely upon potable water pressure to prevent contamination is not considered to be an acceptable solution. Similarly, extra thick single walls are not considered to meet the intent of this criterion.

For approval of other than double wall designs, the procedures described in S-101 ahould be utilized.

Potable water as defined by the Public Health Service Drinking Water Standards is considered suitable for systems with single wall exchangers as long as its quality is maintained to the Public Health Service Drinking Standards.

\section{S-515-9.2 Applicable Standards}

Heat exchangers shall be in compliance with the applicable standards given in S-515-9.2.1 and S-515-9.2.2. Exchangers manufactured to other standards not listed but fulfilling the requirements of a particular solar heating system design may be acceptable.

\section{S-515-9.2.1 Tubular Heat Exchangers}

Tubular heat exchangers shall be in compliance with the appropriate requirements of TEMA.

\section{S-515-9.2.2 Heating Coils}

Forced circulation air-heating coils shall be in compliance with the requirements of ARI Standard 410.

\section{S-515-9.3 Material Performance}

Heat exchanger material shall be compatible with the heat transfer fluid as required in $\mathrm{S}-515-1.4$ and $\mathrm{S}-515-3.2$. 
S-515-10.1 Applicable Standards

laulking and sealants shall be in accordance with 507-6 of the MPS, where applicable. Gaskets which seal pressurized systems shall withstand the maximum service pressure when tested in accordance with ASTM D 1081-60 (1974).

Commentary: Since gaskets and sealants used in solar systems may not be adequately covered by existing specifications, Appendix Table $B-8$ is included to serve as a guide in selecting specific sealing materials.

\section{S-515-10.2 Materials Performance}

S-515-10.2.1 Thermal Stability

Gaskets and sealants included in the test described in S-515-2.1.2 shall not exhibit cracking, loss of elasticity, outgassing, or loss of adheston sufficient to Impair their function at the completion of the test.

Commentary: A potential problem with sealants and gaskets used in collectors is that during no-flow conditions outgassing may occur with the outgassing products being deposited on the interior surface of the cover plate. Such deposits can reduce the transmittance of the cover plate.

S-515-10.2.2 Chemfcal and Physical Compatibility

a. Gaskets and sealants shall be chemically and physically compatible with the substrates to which they are joined.

Commentary: Compatibility of gaskets and sealants with substrates may be evaluated in the process of testing materials for compliance with the Federal Specifications listed in Appendix Table B-8.

b. Documentation shall be provided to show that gaskets and sealants in direct contact with the heat transfer fluld are not degraded by the fluld. In lieu of other documentation, gaskets and sealants which are in direct contact with heat transfer fluld shall not exhibit signIficant expansion, cracking, loss of elasticity or loss of adhesion when immersed for 100 hours in the heat transfer fluid at the maximum service temperature. ASTM D 471-75 or F 146-72 shall be used as a guide in performing these tests.

\section{S-515-10.2.3 U1traviolet Stability}

Gaskets and sealants that are normally exposed to UV radiation in service shall not be adversely affected by such radiation. Documentation shall be provided demonstrating that such materials are capable of withstanding exposure to sunlight for their design lives without functional impairment.

Commentary: Data obtained under ambient environmental exposure conditions will be accepted if data obtained under in service conditions is unavailable.

Gaskets of ethylene propylene diene manomer (EPDM) rubber or silicone mubber are examples of materials that may be appropriate for these applications. 
These requirements apply to both fixed and movable insulation installed in conjunction with or as an integral part of the solar system. Materials used for insulation shall be of sufficient proven effectiveness and durability under the expected operating conditions to assure that required design conditions concerning heat losses, sound control and fire rating are attained. Insulation in contact with the ground shall not be adversely affected by soil, vermin or water. Insulating materials shall be in accordance with 507-3 of the MPS and S-607-3. Insulating materials for air ducts shall be in accordance with S-515-3.1. Materials used for waterproofing shall be in accordance with Section 507-1 of the MPS. Materials used for vapor barrfers shall be in accordance with Section 507-2 of the MPS.

Commentary: When movable insulation is used in passive systems, design considerations should be given to ensure protection of the insulation from structural domage, degradation due to weather or other degrading factors.

\section{S-515-11.1.1 Flame Spread Classification}

The flame spread classification index for all insulation materials shall not exceed the following values:

$\begin{array}{lr}\text { Plastic Foam } & 25 \\ \text { Loose Fill Insulation } & 50 \\ \text { Other Insulation Material } & 150\end{array}$

The ASTM E84 flame spread test method sha11 be the basis for evaluating the surface burning characteristics of the insulation materials. Where fibrous blankets with facings are to be used, the surface burning characteristics of the complete faced insulation blanket shall be measured.

Commentary: No single test is sufficient to provide a full estimate of performance of a product in a fire. Plastic fooms and loose fill insulation are difficult to evaluate in ASTM E-84. The requirement of Flome spread classification of 25 maximum for plastic fooms and 50 for loose fill insulation will provide as much safety assurance as is possible with current test methods. Such a classification shall not be construed as the equivalent of "noncombustible." Many insulation materials, including those consisting of cellulose, plastic foom and fibrous glass (containing organic binder) are combustible materials which will burn and release heat, especially when exposed to continuous large fire sources.

\section{S-515-11.1.2 Flame Resistance Permanency}

Chemical retardant insulations shall retain their flame resistance throughout their service lifetime. The procedures and equipment specified in ASTM C739-73, Section 10.4, "Flame Resistance Permanency" shall be used in judging the effect of aging on the permanence of any flame retardants used during manufacture. 
S-515-11.2.1.1 Thermal Stability

Collector insulation shall not degrade at the maximum service temperature to an extent which results in premature failure or degradation in collector performance greater than the design limits specified in Section S-615-1.1.2.

After testing as described in S-515-2.1.2, there shall be no swelling or other dimensional changes in the collector insulation, outgassing or physical changes resulting in the decrease in thermal performance in excess of that permitted in the test.

Commentary: Organic materials found in insulation have been known to evolve from collector insulation during system operation, leaving a coating on the cover plates which impairs collector performance. Normally, the insulation nearest the absorber plate is exposed to temperatures higher than insulation near other parts of the collector. It may be possible to use one type of insulation adjacent to the absorber plate and another type in areas of the collector which will not be exposed to extreme temperatures. Fiberglass insulation with binders can be preheated to expel volatiles prior to use in collectors. If such pretreatment is used, the upper temperature limit becomes somewhat higher.

S-515-11.2.2 Pipe or Duct Insulation

Pipe or duct insulation shall be stable at the maximum temperature to which it will be exposed in service.

Commentary: General practice for the use and protection of pipe insulation is described in the ASHRAE Handbook of Fundamentals.

S-515-11.2.3 Storage Subsystem Insulation

If insulation whose thermal properties are affected by water is used, the insulation shall be protected in accordance with S-515-11.1.

S-515-12

$S-515-12.1$

$S-515-12.2$

$S-515-12 \cdot 2.1$

$S-515-12 \cdot 2.2$

\section{CATCH BASINS}

\section{Genera1}

Catch basins shall be of adequate size and construction to fulfill their intended functions and be constructed of materials in accordance with Section $515-5$ of MPS.

\section{Materials Performance}

Materials Compatibility

Catch basin materials which are jointed to or in contact with other materials shall have sufficient chemical and physical compatibility with those materials to prevent deterioration.

\section{Coating}

The catch basin coating, when used, shall not be significantly deteriorated during its design life by weathering or by the transfer medium with which it comes in contact. 


\section{$S-515-13$}

$S-515-13.1$

$S-515-13 \cdot 1.1$

$S-515-13.1 .2$

$S-515-13 \cdot 1.3$

S-515-13.1.4

$S-515-13 \cdot 1.5$

\section{ORGANIC COUPLING HOSES}

\section{Materials Performance}

\section{Thermal Stability}

Organic coupling hoses included in the test described in s-515-2.1.2 shall not exhibit cracking, loss of elasticity, or embrittlement at the completion of the test that will significantly impair their function.

Commentary: The selection of coupling hoses and clamps is quite critical. Many failures have been noted due to the clamping of hoses with screw or spring-type clomps, exposing the hose to high temperatures which tend to vulcanize the area beneath the clamp, causing it to lose resiliency and begin to leak. Further tightening of the clamps will temporarily stop leakage but further vulcanizing will occur with the end result being a hard non-resilient ring under the clamp which can no longer be tightened to prevent leakage. Silicone muber hose is one of the few materials which have been tested and tend to maintain their resiliency with no tendency to take a thermal set. The silicone mbber hoses, however, tend to be so pliable that screw-type clamps with perforated bands should not be used as it is possible to extmude the material through the perforations in the band. If this material is used, smooth band clamps should be utilized.

\section{U1traviolet Stability}

Organic coupling hoses which are exposed in service to UV radiation shall not be adversely affected by the radiation. In lieu of other documentation, organic coupling hoses shall not exhibit significant cracking, loss of elasticity or embrittlement after 500 hours exposure as described in ASTM D750-68 (1974).

\section{Compatibility with Heat Transfer Fluid}

Documentation shall be provided to demonstrate that organic coupling hoses which are in direct contact with heat transfer fluids are not significantly degraded by the fluids. In lieu of other documentation, the hoses shall not exhibit cracking, loss of elasticity or embrittlement that will significantly impair their function when tested for 100 hours at the maximum service temperature according to ASTM D471-75 or F146-72.

Commentary: SAE Standard J20e (1974) covers coolant system hoses for automobiles. For solar systems using glycol liquids, this SAE Standard may be applicable for demonstrating compliance with S-515-13.1.3. It is expected, however, that hoses in solar systems will be exposed to more strenuous conditions than automobile hoses.

Compatibility with Piping Materials

Organic coupling hoses which are used to join piping shall be compatible with the piping.

\section{Ozone Degradation}

Documentation shall be provided to demonstrate that organic coupling hoses which are exposed in service to the environment are not significantly degraded by ozone in the air. In lieu of other documentation, the hoses shall exhibit no cracking or loss of elasticity that will significantly impair their function when tested for 100 hours to an ozone atmosphere of $50 \pm 5 \mathrm{Pphm} /$ volume at $23^{\circ} \mathrm{C}$ according to ASTM D1149-64 (1970). 



\section{CONSTRUCTION}

TABLE OF CONTENTS

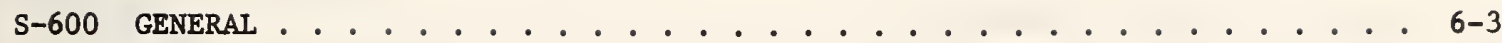

S-600-1 Labeling . . . . . . . . . . . . . . . . . 6-3

S-600-2 Alternate Construction ................. 6-3

S-600-3 Installation, Operation and Maintenance Manual . . . . . . . . 6-3

S-600-4 Replacement Parts . . . . . . . . . . . . . . . . 6 6-4

S-600-5 Maintainability of Systems and Subsystems . . . . . . . . . . 6-4

s-600-6 Safety and Health Requirements . . . . . . . . . . . . . 6-5

S-601 GENERAL STRUCTURAL REQUIREMENTS . . . . . . . . . . . . . . . . 6-7

S-601-1 General . . . . . . . . . . . . . . . . . . 6-7

S-601-2 Design Dead Loads . . . . . . . . . . . . . . . . 6-7

S-601-3 Design Live Loads . . . . . . . . . . . . . . . . . 6-7

S-601-4 wind Loads . . . . . . . . . . . . . . . . . 6-8

S-601-5 Snow Loads . . . . . . . . . . . . . . . . . . 6-9

S-601-6 Selsmic Loads . . . . . . . . . . . . . . . . . . 6-9

S-601-7 Hall Loads . . . . . . . . . . . . . . . . . 6-11

S-601-8 Dynamic Loads . . . . . . . . . . . . . . . . . . . 6-14

S-601-9 Thermal Distortion . . . . . . . . . . . . . . . . 6-14

S-601-10 Co1lector Cover Plates . . . . . . . . . . . . . . 6-14

S-601-11 Connections of Collector Frames and/or Other Support Structures . • 6-14

S-601-12 Storage Tanks . . . . . . . . . . . . . . . . . 6-14

S-607 THERMAL AND MOISTURE PROTECTION . . . . . . . . . . . . . . 6-16

S-607-2 Waterproofing, Damproofing and Vapor Barriers. . . . . . . . . 6-16

S-607-3 Insulation . . . . . . . . . . . . . . . . . . . 6-16

S-615 MEchantCal . . . . . . . . . . . . . . . . . 6-17

S-615-1 Thermal Design . . . . . . . . . . . . . . . . . 6-17

S-615-2 collectors .......................... 6-20 
S-615-3 Mechanical Supporting Devices . . . . . . . . . . . . . 6-24

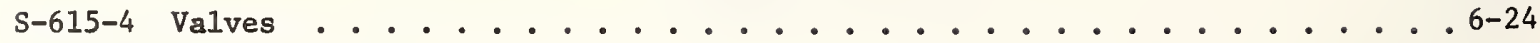

S-615-5 Pumps and Fans .................... 6-... 6 . . . . . .

S-615-6 Mechanical Vibration Isolation ............... 6-24

S-615-7 Thermal storage . . . . . . . . . . . . . . . 6-25

S-615-8 Heat Transfer Fluids . . . . . . . . . . . . . . . 6-28

S-615-9 Waste Disposal .................... 6-28

s-615-10 Plumbing . . . . . . . . . . . . . . . . . . 6 . 29

S-615-11 Auxiliary Energy System . . . . . . . . . . . . . 6-33

S-615-12 Heat Exchangers ................... . 6-33

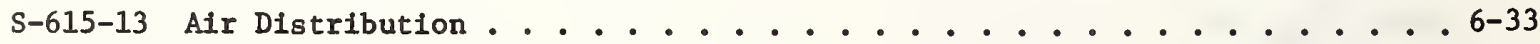

S-615-14 Controls and Instrumentation . . . . . . . . . . . . . 6-34

S-615-15 Chimneys and Vents ................... 6- . . . . . . .

S-615-16 Mechanical Ventilation ................... 6-35 
CONSTRUCTION

$S-600$

$S-600-1$

$S-600-2$

$S-600-3$

$S-600-3.1$
GENERAL

The provisions of this chapter are applicable to solar domestic hot water (DHW) systems. This chapter is intended to be used in conjunction with the Minimum Property Standards (MPS). Bullding construction provisions (Chapter 6) of the MPS are applicable in addition to the items explicitly discussed in this document.

\section{LABELING}

Solar domestic hot water (DHW) systems, subsystems, and components sha11 be labeled or given clear indication ot their operating temperatures, pressures, flow direction and filled weight as appropriate in accordance with $515-1.2$ of the MPS.

Commentary: Labeling requirements for specific material and products are given in Chapter 5 of this document.

\section{ALTERNATE CONSTRUCTION}

Alternate or special methods of construction other than those contained herein, may be used when found acceptable by established HUD procedures and Division 613 of MPS and Section S-101 of this ducument.

INSTALLATION, OPERATION AND MAINTENANCE MANUAL

Manuals shall be provided to describe the installation, operation and maintenance of the DHW systems.

A complete manual as described in S-600-3.1, 3.2, and 3.3 shall be provided to the installer or maintenance contractor. A simplified owners manual shall be provided to the building occupant which shall include as a minimum: system description including a schematic diagram; owner maintenance procedures; and a tabulation of appropriate pressure, temperature and flow information that is indicative of system performance. The owners manual shall also include the names and addresses of manufacturers of all the primary components of the system.

Commentary: It is suggested that each manufacturer of a subsystem should provide installation, operating and maintenonce manuals for each subsystem he provides, and that he show typical systems using his and other subsystems to complete the whole. The installer, who is responsible for the complete installation and therefore for the complete system should assemble all the manuals from the subsystem manufacturers into a complete manual pertinent to the system. He should add any other information needed for an understanding of the complete system and its functioning. Control sequences are determined almost entirely in the field and should be described for the specific installation.

\section{Installation Instructions}

The manual shall include physical, functional and procedural instructions describing how the subassemblies of the DHW systems are to be installed. 
These instructions shall include descriptions of both system interconnections and connections with the dwelling and site.

Mintenance and Operation Instructions

The manual shall completely describe the DHW system, its breakdown into subsystems, its relationship to external systems and elements, its performance characteristics and its required parts and procedures for meeting specified capabilities.

The manual shall list all parts of the systems, by subsystem, describing as necessary for clear understanding of operation, maintenance, repair and replacement, such characteristics as shapes, dimensions, materials, weights, functions, and performance characteristics. The manual shall include a tabulation of those specific performance requirements which are dependent upon specific maintenance procedures. The maintenance procedures including ordinary, preventive and minor repairs, shall be cross-referenced for all subsystems and organized into a maintenance cycle. The manual shall fully describe operating procedures for all parts of the system including those required for implementation of specified planned changes in mode of operation. The instructions shall provide warning against hazards that could arise in the maintenance of the system and shall fullv.descrthe precautions that sha1l be taken to avoid these hazards.

\section{Maintenance Plan}

The manual shall include a comprehensive plan for maintaining the specified performance of the DHW system for its design service lives.

The plan shall include all the necessary ordinary maintenance, preventive maintenance and minor repair work, and projections for equipment replacement, and shall include important pressure, temperature and flow information as checkpoints throughout the system to assist in troubleshooting.

Parts, components, special tools and test equipment required for service, repair or replacement shall be commercially available or available from the system or subsystem manufacturer or supplier.

Commentary: This provision is intended to preclude long periods of system down-time due to the need for the repair or replacement of parts.

\section{Service Complexity}

The DHW systems and subsystems shall be capable of being serviced with a minimum amount of special equipment by a trained service technician using a maintenance manual and common tools.

COMMENTARY: ON LARGER COLLECTOR INSTALLATIONS IT MAY BE DESIRABLE TO MAKE PROVISIONS FOR SUPPLYING ELECTRICAL PONER AND WATER FOR MAINTENANCE PURPOSES,

\section{S-600-5.2 Access for System Maintenance}

All individual items of equipment and components of the DHW systems which may require periodic examination, adjusting, servicing and/or maintenance shall be accessible for inspection, service, repair, removal or replacement without dismantling of any adjoining major plece of equipment or subsystem. 
S-600-6

$S-600-6.1$

$S-600-6.2$

S-600-6.4

$S-600-6.5$

$S-600-6.6$

Commentary: It is recommended that individual collectors in an array be replaceable or repairable without disturbing non-adjacent collectors in the array.

Accessibility as a function of component life is an important consideration. Some manufactured collector systems and many individually designed systems are done in such a way that sequential installation is necessary. This can make it very difficult to replace an individual collector without disturbing the entire array.

\section{SAFETY AND HEALTH REQUIREMENTS}

\section{Genera1}

The incorporation of solar systems into the living unit shall not create an environment which is more hazardous to the occupants than that of a conventional living unit. Materials and the construction used in installation of solar systems shall be in accordance with the fire protection provisions of $\mathrm{S}-405$.

Combustible Liquids

The storage, piping and handling of combustible liquids shall be in accordance with the Flammable and Combustible liquids code NFPA No. 30.

\section{S-600-6.3 Protection From Heated Components}

Components of solar systems which are accessible, located in areas normally subjected to occupant traffic and which are maintained at elevated temperatures shall either be insulated to maintain their surface temperatures at or below $140^{\circ} \mathrm{F}$ at all times during their operation or suitably isolated. Any other exposed accessible components that are maintained at temperatures above $140^{\circ} \mathrm{F}$ shall be identified with appropriate warnings.

\section{System Component Clearances}

Combustible solids adjacent to solar equipment or an integral part of a solar component shall not be exposed to elevated temperatures which may cause ignition.

Commentary: Heating of cellulosic materials as well as other combustible materials over an extended period of time may result in the material reaching and surpassing its autoignition temperature. The most commonly accepted ignition temperature of wood is $392^{\circ} \mathrm{F}$. However, studies have indicated that wood may ignite when exposed to a temperature of $212^{\circ} \mathrm{F}$ for prolonged periods of time. The ignition temperature of plastics may be above or below those of cellulosic materials. Clearances for HVAC equipment, ducting and piping are discussed in NEPA No. 89M. Where applicable, clearances specified by a nationally recognized testing laboratory may be used.

\section{Protection Against Over-Pressure and Over-Temperature}

The total system shall be protected against excessive pressures and temperatures. Pressures shall be limited as specified in S-615-14.

\section{Personal Safety}

Where access for service of cleaning of solar subsystems requires a person to balance on a narrow or (steeply) sloping surface, provisions shall be made for sectirlng a life-line, guard-rail or other personal protective device. 
Components and materials used in the DHW system shall not promote the growth of fung1, mold or mildew in accordance with applicable codes, the test specification of Section 10, UL 181-74 and MPS, Appendix D, Section E.

Commentary: Special consideration should be given to the presence of fungi in air handling systems since such micro-organisms are frequently allergenic.

\section{Protection Against Vermin or Rodents}

Solar energy systems (including piping, fixtures, appliances and other equipment) shall not contribute to the entry or growth of vermin of rodents. Maintenance of physical barriers, minimization of concealed spaces conducive to harboring vermin or rodents, provisions of access for cleaning shall be in accordance with applicable codes such as Section 2.13 of the National Standard Plumbing Code.

\section{S-600-6.9 Protection of Potable Water Supply}

The design and installation of the solar system its subsystems and components shall be accomplished in such a manner as to provide complete protection of the potable water supply. Such installations shall be in accordance with Chapter 10 of the National Standard Plumbing Code and other applicable codes (see Section S-615-10). 
$S-601$

S-601-1

S-601-2

$S-601-3$

S-601-3.1

$S-601-3.2$

GENERAL STRUCTURAL REQUIREMENTS

GENERAL

This section contains those supplemental requirements to Chapter 6 of the MPS needed to cover solar systems which utilize conventional structural materials (materials covered by the current MPS edition). Unless specifically modified herein, the requirements of MPS Chapter 6, apply in addition to the supplemental requirements in this section.

All structural design for solar systems and their mounting structures shall be based on generally accepted engineering practice. All loading shall be in accordance with ANSI A58.1 except as shown otherwise in this document or MPS.

\section{DESIGN DEAD LOADS}

In calculating the dead loads for solar systems, the weights of the transfer liquid in the collector, liquid in storage tank, and liquid in other subsystems and components shall be included, except when using dead load to resist uplift or overturning.

Commentary: Liquids are normally present in systems in which they are the heat transfer medium and thus are a long term sustained load where creep is a consideration. They also effect seismic forces in a fashion similar to any other dead load. However, it is possible to remove liquid, thus they should no be counted on to resist uplift.

\section{DESIGN LIVE LOADS}

\section{$\underline{\text { Roof Mounted Solar Systems }}$}

Resistance to design live roof loads prescribed in Table 6-1.2 of MPS 4900.1 (Table 6-1.3 of MPS 4900.1 and 4920.1) shall not be required for collector panels that are mounted on roofs but do not form an integral part of the roof if adequate access is provided for service and maintenance personnel. For collectors which form an integral part of the roof, resistance to the design live roof loads listed in Table 6-1.2 shall be required.

Commentary: The design live loads contained in Table 6-1.2 of MPS 4900.1 constitute minimum loading requirements needed primarily for human safety. The roof will need to be repaired from time to time; therefore, it must support the workman making the repairs, regardless of the wind and snow loading requirements. This is not the case for accessible roof-mounted collectors; they do not need to support workmen when being repaired. Hence, they need only to sustain the required environmental loading (wind, snow and hail).

\section{Maintenance Loads}

Al1 components of the solar energy systems which must support maintenence personnel shall resist a single concentrated load of 250 lbs. distributed over a $4 \mathrm{sq}$. in. area, acting on the installed component in the most critical locations. Special allowance shall also be made for heavy maintenance equipment, if used. 


$\begin{array}{ll}\text { S-601-4 } & \text { WIND LOADS } \\ \text { S-601-4.1 Flat Plate Collectors Mounted on Roofs and Wa1ls }\end{array}$

Wind loads on flat plate solar collectors shall be those specified for roofs and walls in Section 601-6 of the MPS or as modified in paragraphs S-601-4.1.1,.2, .3, and .4 below.

S-601.4.1.1 Flat plate collectors that are mounted with their cover plates and back surfaces flush with the surface of the roof shall resist the wind loads that would have been imposed on those areas of the roof covered by the collectors.

S-601-4.1.2 Flat plate collectors mounted at an angle or parallel to the surface of the roof on open racks shall resist any uplift load caused by the impingement of wind on the underside of the collector. This wind load is in addition to the equivalent roof area wind pressure and suction loads, and shall be determined by utilizing accepted engineering procedures which may include wind tunnel testing. Equivalent roof area wind loads are those wind loads that would have been applied to the areas of the roof occupled by the collectors. Equivalent roof area wind loads shall be applied to the outer cover plate of the collectors.

S-601-4.1.3 In calculating design wind loads for flat plate collectors mounted on roofs, the internal pressure coefficients, $C_{\text {, }}$, listed in Table 11, ANSI A58.1 shall be taken as zero for the wind priessure within a collector. Collectors that form an integral part of the roof structure shall resist the internal pressures from the inside of the building just as any other roof member.

S-601-4.1.4 Wind loads on flat plate collectors mounted at an angle to a vertical wall shall be the same as those required for equivalent roof eave area as stipulated in section 6.5.3.2.4 of ANSI A58.1. Wind loads on flat plate collectors mounted parallel to, or integral with vertical walls shall be the same as those required for exterior walls.

S-601-4.2 Other Types of Solar Collectors Mounted on Roofs and Walls

Wind loading on other types of solar collectors shall be determined using the results of accepted engineering procedures including the MPS and ANSI A58.1 or physical simulation which may include wind tunnel testing.

\section{S-601-4.3 Roof Wind Loads}

Roof. loading due to wind effects on flat plate collector and concentrating collector support structures and/or enclosures must be included not only in the design of the roof support framing, but also in the design of all structural elements influenced by these loads.

\section{S-601-4.4 Ground Mounted Collectors}

Wind loading on ground-mounted flat plate collectors and their support structures shall be determined in the same manner as that for roof-mounted flat plate collectors. Where flat plate collectors are mounted on open racks, equivalent roof area wind loads shall be those given for nonenclosed structures as given in section 6.6, ANSI A58.1, taking into account local terrain characteristics.

\section{S-601-4.5 Exposed Storage Tanks}

Wind loads on exposed storage tanks shall be determined in accordance with ANSI A58.1. 
S-601-5.1

$S-601-5.1 .1$

$S-601-5.1 .2$

$S-601-5 \cdot 1.3$

$S-601-5.2$

$S-601-5.3$

S-601-6

$S-601-6.1$

$S-601-6.2$

Flat Plate Solar Collectors Mounted on Roofs and Walls

Snow loads acting on flat plate solar collectors or caused by their installation shall be those required for roofs as specified in Section 601-5 of MPS or as modified in paragraphs $5-601-5.1 .1, .2$, and . 3 below.

Flat plate collectors that are mounted with their cover plates and back surfaces parallel to the surface of a roof, and those that are mounted at an angle to the surface of a roof, on open or closed racks in a saw-tooth arrangement shall support the snow loads that would otherwise have been imposed on areas of the roof covered by the collectors. Where collectors are mounted with their cover plates forming steep slopes, shedding of snow from the collector may cause snow to accumulate at the base of the collector or other hazardous conditions which shall be considered in the design of the roof.

Flat plate collectors mounted at an angle to the surface of a wall, and supported by the wall, shall be deslgned to support the same snow loads as an equivalent roof eave area.

Consideration shall be given to the potential local accumulation of snow under flat plate collectors.

$\underline{\text { Roof Loading }}$

A single or multiple saw-tooth array of collectors may cause severe drifting between each mounted collectors (and under open racks) in addition to the snow load on the cover plates. These unusual snow loads must be determined on the basis of local snow conditions.

Other Types of Solar Collectors

Snow loads on other types of solar collectors shall be determined as specified in the applicable portions of ANSI A58.1 and by accepted englneering procedures.

\section{SEISMIC LOADS}

\section{Genera1}

Seismic design requirements for the mechanical and electrical components of solar energy systems are covered in this section. Architectural and structural components shall be designed in accord with MPS Sec. 601-9. The requirements of this section shall apply to the erection, installation, relocation, or replacement of, or addition to, any mechanical or electrical component of, a solar system. If elements of the solar energy system are attached to any existing structural element, or if parts of any existing structural element are modified or replaced with parts different in size and weight, the element, as well as its connections to the building shall be re-designed to comply with the seismic design requirements of Section 601-9 of MPS.

\section{Mechanical and Electrical Components}

For those buildings required to be designed for earthquake by section 601-9 of the MPS, mechanical and electrical components of solar energy systems shall resist seismic forces as specified for parts and portions of buildings in the latest edition of the Unfform Building Code (UBC) [1]. The value of $\mathrm{C}_{\mathrm{p}}$ used in the UBC to establish the seismic force shall be taken from table S $-601-6$.

[1] The Uniform Building Code is published by the International Conference of Building Officials, Whittier, California. 
The design of all connections between the mechanical or electrical components and the structural frame shall allow for anticipated movements of the structure. The detalls of the connections shall be made a part of the contract documents.

Commentary: Mechanical or electrical components of a solar system are subjected to seismic forces generated by their mass and may also be influenced by interaction with elements of the structural system.

TABLE S $-601-6$

\begin{tabular}{|c|c|c|}
\hline Part of System & $\begin{array}{l}\text { Direction of } \\
\text { Force }\end{array}$ & Value of $\mathrm{C}_{\mathrm{p}} \frac{1 /}{2 /}$ \\
\hline $\begin{array}{l}\text { Storage tanks, pressure vessels } \\
\text { boilers, furnaces, absorption } \\
\text { air conditioners, other equipment } \\
\text { using combustible or high temper- } \\
\text { ature energy sources, electrical } \\
\text { motors and motor control devideb, } \\
\text { heat exchangers }\end{array}$ & $\begin{array}{l}\text { any } \\
\text { direction }\end{array}$ & $\begin{array}{l}0.12 \text { when resting on } \\
\text { ground } \\
0.20 \text { when connected to, } \\
\text { or housed, elsewhere } \\
\text { in the building. }\end{array}$ \\
\hline $\begin{array}{l}\text { Flat plate and concentrating } \\
\text { solar collectors }\end{array}$ & $\begin{array}{l}\text { any } \\
\text { direction }\end{array}$ & 0.20 \\
\hline $\begin{array}{l}\text { Tranfer liquid pipes larger } \\
\text { than } 21 / 2 \mathrm{in.} \text { in diameter }\end{array}$ & $\begin{array}{l}\text { any horizontal } \\
\text { direction }\end{array}$ & 0.12 \\
\hline
\end{tabular}

1/ For flexible and flexibly mounted equipment and machinery, appropriate values of $C$ shall be determined by a properly documented dynamic analysis, or by dynamic testihg, using appropriate excitation spectra approeed by HUD. Consideration shall be given to both the dynamic properties of the equipment and machinery and to the building or structure in which it is placed.

2) WHEN LOCATED IN THE UPPER PORTION OF ANY BUILPING WHERE THE HN/D PATIO IS 5:I OR GREATER THE CP VALUE SHALL BE INCREASED BY $50 \%$

WHERE $H_{N}=$ HEIGHT IN FT. OF THE PART OF THE SYSTEM ABOVE THE BASE LEVEL OF $D=$ THE DIMENSION OF THE STRUCTURE IN FEET IN A DIRECTION PARALLEL TO
THE APPLIED FORCE 
The cover plates, lenses, and reflector surfaces of solar collectors shall be protected against or resist the perpendicular impact of a single hallstone of the magnitude stipulated below falling at its terminal velocity.

Hall size: $D=0.3 d$

In which $D=$ hail stone diameter, inches

$d=$ mean annual number of days with hall taken from Figure S-601-7 [1].

Terminal velocities for various hall sizes are given in Table S-601-7. [2]. Compliance with this provision shall be based on documented past hall loading performance or testing using the procedures described in NBS Buflding Sclence Serfes BSS 23 [3] or analytical procedures acceptable to HUD.

Commentary: The correlation of hail size with mean annual number of days with hail was determined using data relating the probability of occurrence of hail particle size to the number of days with hail (tabulated in Ref. [4], and limited statistical information relating the local area covered by a hailstorm, and the regional area for which statistical data is compiled. The hail size indicated has a $5 \%$ probability of being exceeded in any one year (estimated 20 year recurrence interval). The hail requirements in this section are based on available information which does not contain physical test data. Therefore, local hailstone loading performance should be considered in implementing the requirements of this section.

The impact from the vertical terminal velocity is used as a measure of the effect of hail falling with or without horizontal wind. It is possible that a larger impact could occur on surfaces sloped from $30^{\circ}$ to $80^{\circ}$ if the maximum particle diameter occurred similtaneously with a high horizontal wind velocity perpendicular to the surface. It may be overly conservative for particles over I.5" impacting on near vertical surfaces. However, due to the lack of information on this phenomenon and the low probability of its occurrence, it is assumed that the terminal velocity gives the best measure of impact force consistent with the present state of the art.

The loadings specified in this section to determine collector performance closely parallel those that conventional asphalt shingles and built up roofing are expected to withstand for all but the mid-continent hail belt.

[1] Baldwin, J. L., Climates of the United States, U.S. Dept. of Commerce, Washington, D.C. (1973).

[2] Mathey, R. C., Hail Resistance Tests of Aluminum Skin Honeycomb Panels for the Relocatable Lewis Building, Phase II, NBS Report 10193, National Bureau of Standards, Washington, D.C. (1970).

[3] Greenfleld, H., Hall Resistance of Roofing Products, Building Science Series 23, National Bureau of Standards, Washington, D.C. (August 1969).

[4] Storm Data, U.S. Dept. of Commerce, National Oceanic and Atmosphere Administration, Environmental Data Service (monthly periodical). 


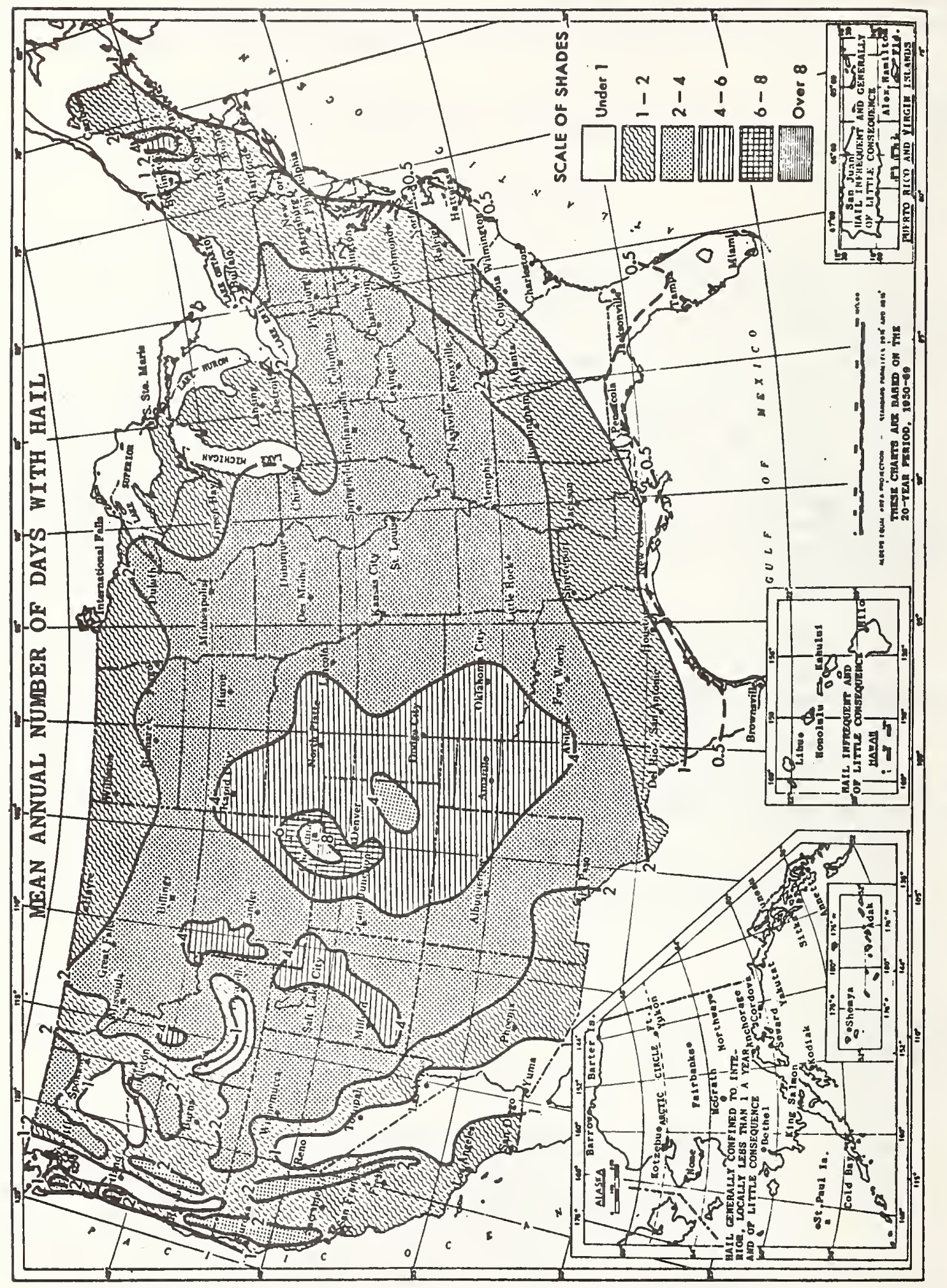


Values of weight and terminal velocity in free fall computed for smooth ice spheres.

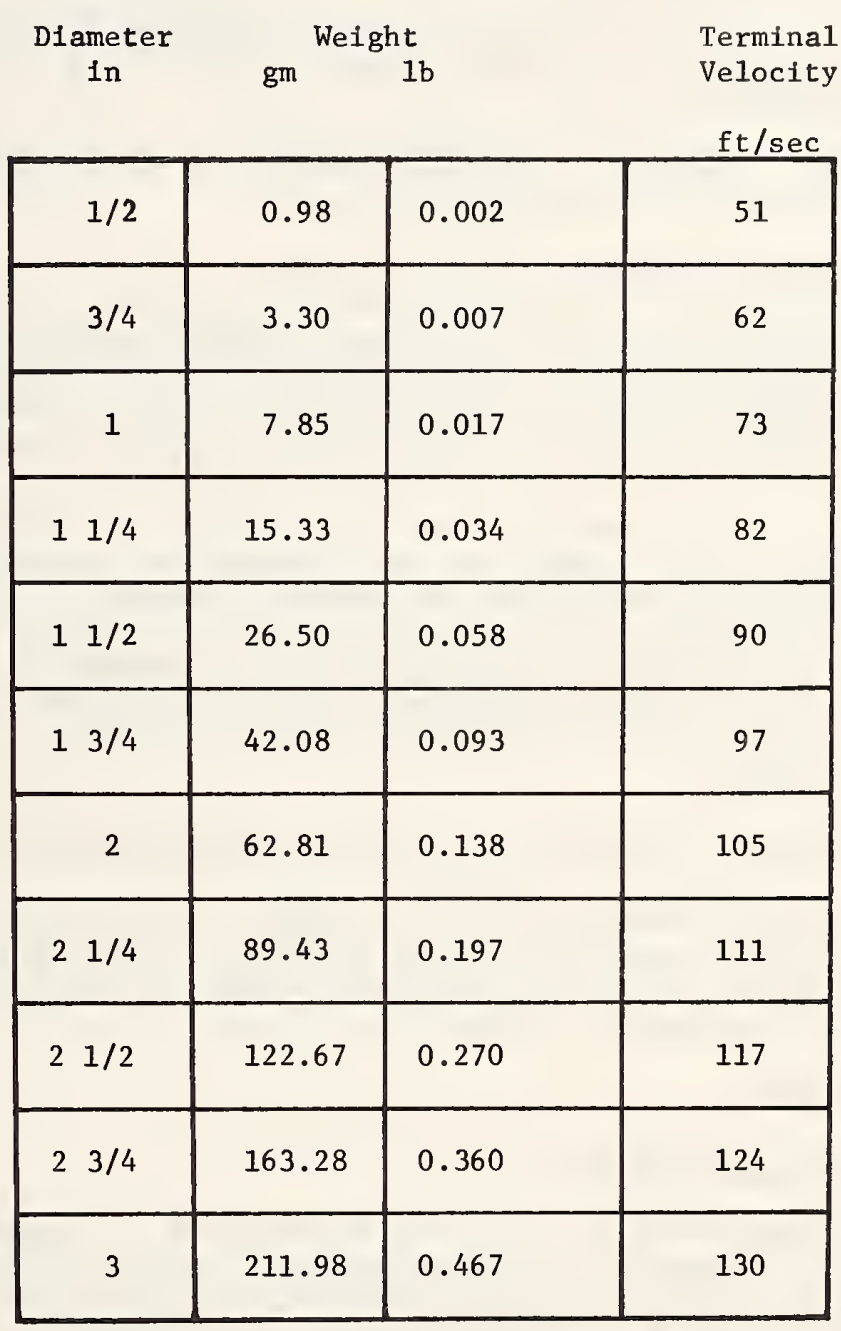

from: Mathey, R. C., Hail Resistance Tests of Aluminum Skin Honeycomb Panels for the Relocatable Lewis Building, Phase II, NBS Report 10193, National Bureau of Standards, Washington, D.C., 1970. 
Dynamic Loads resulting from sun tracking solar collectors or other moving equipment shall be taken into account in the design of the dwelling frame.

Thermal distortion of the mechanical or structural components of the solar system shall not cause premature failure or degradation in system performance greater than the design limits.

Thermal distortion of the solar system, including that occurring during periods of stagnation, shall not cause damage to the system or the supporting dwelling structure.

Commentary: Expansion coefficient data for cover and absorber plate materials is listed in Appendix Tables $B-1$ and $B-3$.

S-601-10 COLLECTOR COVER PLATES

Deflection or local distress of cover plates resulting from the maximum design loading shall not allow the cover plate to become separated from the unit nor result in degradation in collector performance greater than the design limits. This shall be demonstrated by analysis or physical simulation.

Commentary: Since wind can come from any direction, there will be maximum pressure (inward) loading for units mounted on the windward side of an installation and maximum suction (outward) loading for those mounted on the leeward side (unless shielding is provided). Depending on the installation, suction loading can, and often does, exceed pressure loading; hence, cover plate retainers must be adequately designed to prevent them from being separated from the collector frome or induce failure of the cover plate by suction loading.

S-601-11 CONNECTIONS OF COLLECTOR FRAMES AND/OR OTHER SUPPORT STRUCTURES

When collector frames and/or other support structures are mounted on walls, roofs, or other weather resistant surfaces, distortion of the frame from imposed loading shall not cause penetrations or separations of these surfaces such that moisture leaks occur through the weather resistant surfaces.

S-601-12 STORAGE TANKS

S-601-12.1 Design and Fabrication

Storage tanks shall be designed and fabricated to standards embodying principles recognized as good engineering design and fabrication practice for the materials used. These standards shall include those listed in appendices $\mathrm{C}$ and $\mathrm{E}$ of the MPS and others as approved by HUD.

Tanks containing soil or rock like materials shall be designed for lateral pressures in accordance with accepted principles of soll mechanics.

S-601-12.2 Testing

Each liquid storage tank shall be tested in accordance with section S-615-10.10 to prove that leakage does not occur. Storage tanks designed to contain only dry heat storage material need not be leak tested unless a safety hazard can result from a storage tank failure.

S-601-12.3 Environmental and Vehicular Loading

In addition to meeting the design, fabrication and test requirements, stipulated in the preceeding paragraphs of this section, storage tanks shall meet the following loading requirements. 
Unsheltered storage tanks shall resist loads resulting from snow, wind, hall, thermal, and selsmic loading. Sheltered (completely enclosed) tanks need only resist selsmic loading.

S-601-12.3.2 Underground

Underground tanks shall resist soll and hydrostatic loads and foundation loads transmitted to them; and they shall be anchored to prevent flotation resulting from flooding or high ground water level when the tanks are empty. For sites subject to commercial traffic or heavy truck traffic, storage tanks shall resist the wheel loads transmitted to them as specified in AASHTO H2O-44, with no impact. For areas subject to other vehicular or human traffic, the pertinent loads stipulated in section $601-4.3$ of MPS 4910.1 or 4920.1 shall be resisted.

Commentary: The criterion specifies the level of vehicular traffic for which buried components should be designed in cases where heavy vehicular traffic is anticipated to occur in service for purposes of access. The H20-44 truck is considered to be representative of load levels associated with heavy vehicles such as trucks for repair, maintenance, moving, and delivery of fuel. 
S-607

S-607-2

$S-607-2.1$

$S-607-3$

$5-607-3.1$

THERMAL AND MOISTURE PROTECTION

WATERPROOFING, DAMPPROOFING AND VAPOR BARRIERS

Waterproofing of Exterior Storage Tanks, Pipes and Ducts

Underground thermal storage tanks, pipes and ducts, and unsheltered above ground thermal storage tanks, pipes and ducts shall be waterproofed to stop water seepage into the componențs and insulation. See Section 607-2 of MPS and 1972 ASHRAE Handbook of Fundamentals Chapter 17.

\section{INSULATION}

\section{Areas of Application}

Materials used for thermal insulation shall be in accordance with S-515-11 and may be applied to the following areas: walls, roofs, cellings, floors, pipes, ducts, vessels and equipment exposed to the external environment.

Exposed plastic foam (untreated or fire-retardant treated), Kraftasphaltic vapor barrier on mineral and organic fiber insulations, and non-fire-retardant treated loose fill insulation shall not be permitted in habitable areas unless fully protected from the interior of the building by a thermal barrier of $1 / 2$ inch gypsum wallboard having a finish rating of not less than 15 minutes or other approved material having an equivalent finisin rating as determined by ASTM E-119. Thermal barriers shall be installed in a manner wuch that they will remain in place for a minimum of 15 minutes under the same test conditions.

Installed insulation and vapor barriers shall not make contact with recessed light fixtures, motors, fans, blowers, heaters, flues, and chimneys. Thermal insulation shall not be installed within 24 inches of the top or within 3 inches of the side of a recessed electrical fixture enclosure, wiring compartment or ballast unless labeled for the purpose. To retain loose fill insulation from making contact with other energy-dissipating objects, a minimum of 2 inches of air space should be provided and assured by the use of blocking.

Commentary: Although a degree of material combustibility is allowed, the intent is to allow insulating materials which are not more combustible (or flamable) than existing construction and insulation materials, and to preclude any increased fire hazard due to the retention of heat from energy dissipating objects. In areas where occupants are likely to be engaged in normal activities, the insulation should perform its intended function without the increased risk of ignition, rapid flome spread, and heat and smoke generation. Insulation in concealed spaces may be a particular fire problem due to its susceptibility to smoldering and its inaccessibility for fire fighting.

Al2 solar system piping, ducts, heat exchangers, and storage tanks containing heated fluids should be insulated to the following minimum insulation values:

$\begin{array}{ll}\text { Thermal Storage Tanks } & R-11 \\ \text { Pipes I" and less in diameter } & R-4 \\ \text { Ducts, Pipes over I" and less than 4" } & R-6 \\ \text { in diameter, and Heat Exchangers } & \end{array}$

For maximum efficiency, the complete domestic hot water system should be insulated to the above values. 
S-615 MECHANICAL

S-615-1 THERMAL DESIGN

S-615-1.1 Genera1

The solar energy system shall be capable of collecting and converting solar energy into thermal energy. Solar thermal energy shall be used, in combination with a conventional auxiliary energy source and other components such as thermal storage to meet the standards and requirements for domestic hot water set forth in Section 615 of the MPS. The system shall be capable of dissipating thermal energy where this function is included in the design.

Commentary: The prediction of system performance should reflect the cumilative degradation in components resulting from environmental or system wear and deterioration. The residential domestic hot water load is generally considered constant throughout the year for purposes of system design.

S-615-1.2 Back-up

The thermal energy contribution provided by solar energy shall be backed up 100 percent with an auxiliary thermal energy subsystem which will provide the same degree of reliability and performance as a conventional system.

Commentary: The uncertainty in the availabizity of solar energy during inclement weather requires complete back-up of the solar energy contribution to meet hot water requirements.

S-615-1.4 System Capacity - Domestic Hot Water Heating

S-615-1.4.1 Auxillary Energy Subsystem

The auxiliary energy domestic hot water heating subsystem shall meet the minimum requirements for storage, draw and recovery shown in Tables S-615-7.1 or S-615-7.2.

Commentary: There are benefits if the back-up method is designed to minimize the use of a utility supplied, on-line, auxiliary energy service during peak load conditions. The minimum acceptable hot water storage is listed in the MPS but generally solar energy DHW systems have a larger storage capacity than the MPS requirements.

Attention to energy conservation measures for auxiliary energy subsystems utilizing fossil fuels is particularly beneficial with solar DHW systems as combustion inefficiencies and stack losses can extract large penalties in overall energy consumption. Recent studies [1] of gas-fired storage heaters have identified potential $35 \%$ reduction in fuel consumption by the addition of insulation, changed thermostat set point, baffing, forced draft, flue dompers, and electric ignition.

S-615-1.4.2 Solar Energy System

a. Determination of the average annual energy requirements for solar hot water heating applications shall be based on average monthly conditions as the maximum analytical simulation time interval to compare solar energy system performance with the load.

[1] A. D. Little, Inc., "Study of Energy Saving Options for Refrigerators and Water Heaters, Volume 2: Water Heaters," FEA Contract C0-04-50228-00, May 1977 
b. Minimum daily usage of hot water shall be as indicated in Table S-615.1.

Commentary: The design shall allow for the higher requirement where the potential increase in use exists.

c. Minimum hot water supply temperature shall be $140^{\circ} \mathrm{F}$ except for Housing for the Elderly and Care Type Housing. For Housing for the Elderly and Care Type Housing, temperatures are specified in Section 615-6.1 of MPS 4910.1 and 4920.1 respectively. An average source water temperature of $55^{\circ} \mathrm{F}$ shall be used for design purposes if local temperatures are unknown.

Commentary: A residential DHW design temperature of $140^{\circ} \mathrm{F}$ is required by the MPS and is necessary to meet some appliance operating temperatures. Energy cut-off devices which deflect the solar heated liquid from entering storage prevent the storage tank and hence the delivery piping from exceeding the required temperature. Storage may be allowed to go to higher temperatures if means are provided to blend cold water with the delivery stream to achieve the required temperature.

Local source water temperature can vary from 45 to $75^{\circ} \mathrm{F}$ with climate, region, and season. For guidance, a table of source water temperatures is presented in Appendix $A$, Table $A-1$.

d. The solar energy contribution shall be determined as a percentage of the dwelling average annual DHW energy requirements. Analytical simulations or correlations based upon simulations which include the effect of load, solar system performance and climatic conditions shall be utilized to predict the average monthly and annual energy contribution to be provided by solar energy and auxiliary energy.

Commentary: One acceptable method of predicting performance is presented in Appendix A. Parametric studies have shown that a solar energy contribution of between 50 and $80 \%$ of the DHW load is generally optimum when cost benefits have been considered.

S-615-1.7 Protection Against Blockage of Fluid Flow

The entire heat transport system shall be protected to prevent contamination by foreign substances that could impair the flow and quality of the heat transfer fluid beyond acceptable limits.

Commentary: The heat transfer fluid passages in solar collectors and some heat exchangers may have small cross sections in which blockage by dirt, scale, pieces of gasket material, pieces of packing or other foreign matter in the heat transfer fluid could occur.

S-615-1.8 SYSTEM SHUTDOWN

THE SHUTDOWN OF THE SOLAR HEATING OR DOMESTIC HOT WATER SYSTEM IN ONE UNIT OF A MULTI-FAMILY DWEUING SHAL NOT INTERFERE WITH THE FUNCTION OF THESE SYSTEMS IN ANY OTHER UNIT,

COMMENTARY: THIS IS TO PERMIT THE SHUTDOWN OF EQUIPMENT IN AN INDIVIDUAL DWELLING UNIT FOR REPAIRS WITHOUT IMPAIRING THE OPERATION OF THE EQUIPMENT IN OTHER DWELING UNITS THAT ARE CONNECTED TO THE SAME CENTRAL SYSTEM.

\section{S-615-1.9 Excess Collected Energy}

Provisions for dumping excess thermal energy shall be provided when required for safe operation of the system.

Commentary: For systems in which it is not practical to shut the collection system down, the excess energy can be transfered to the external environment using a heat exchanger or alternate methods. 
Table S-615-1 Daily Hot Water Usage $\left(140^{\circ} \mathrm{F}\right)$ for Solar System Design

\begin{tabular}{|c|c|c|c|c|c|c|c|}
\hline Category & $\begin{array}{l}\text { One } \\
\text { and }\end{array}$ & $\begin{array}{l}\text { and Two } \\
\text { Apartmen }\end{array}$ & $\begin{array}{l}\text { Family } \\
\text { nts up }\end{array}$ & $\begin{array}{l}\text { ynits } \\
\text { to } ? 0\end{array}$ & $\frac{1 /}{\text { Units }}$ & $\begin{array}{l}\text { Apts, of } 2 / \\
20-200 \text { Units }\end{array}$ & $\begin{array}{l}\text { Apts. of } \underline{2 /} \\
\text { over } 200 \text { Units }\end{array}$ \\
\hline No. of People & 2 & 3 & 4 & 5 & 6 & --- & --- \\
\hline No. of Bedrooms & 1 & 2 & 3 & 4 & 5 & -- & -- \\
\hline $\begin{array}{l}\text { Hot Water/Unit } \\
\text { (gal/day) }\end{array}$ & 40 & 55 & 70 & 85 & 100 & 40 & 35 \\
\hline
\end{tabular}

1/ Assumes $20 \mathrm{gal}$. per person for farst 2 people and $15 \mathrm{gal}$. per person for additional famlly members.

2/ From: R. G. Werden and L. G. Spielvogel: "Part II Sizing of Servic Water Heating Equipment in Commercial and Institutional Buildings," ASHRAE Transactions, Vol. 75, PII, 1969 p. iv.1.1. 
$S-615-2$

$S-615-2.1$

$S-615-2.1 .1$

$S-615-2.1 .2$

$S-615-2 \cdot 1 \cdot 3$

\section{COLLECTORS}

\section{General Provisions}

\section{Design Flow Rates}

When an array of solar collectors is connected by manifolds, the design shall assure, or provision shall be incorporated in the manifolds and/or collectors to balance the flow rate through each collector. The variation shall not exceed $\pm 20 \%$ of the design flow range.

Commentary: An available method of balancing air and liquid HVAC equipment is described in the National Standards for Field Measurement and Instrumentation: Total System Balance, Vol: 2, No.12173 (Associated Air Balance Council 2146 Sunset Blvd., Los Angeles, California 90026). The method describes procedures and measurements, but does not establish standard balance values.

\section{Tilt and Orientation}

The collector shall be installed in a mount capable of maintaining tilt and azimuth to within $\pm 10^{\circ}$ of design conditions.

Commentary: A fixed collector tilt angle equal to the latitude for domestic hot water applications is typically used. This angle will tend to maximize the year-round performance of domestic hot water heaters. However, deviations of $\pm 10^{\circ}$ from this value, when using conventional flat plate collectors facing south, will have little effect. Size or performance corrections should be made for deviations greater than $\pm 10^{\circ}$, see Appendix A.

Conventional flat plate collector azimuth should be such that the effective aperature generally faces south. However, deviations to the east or west by up to $20^{\circ}$ may not result in a significant decrease in incident radiation. Weather conditions such as morning or evening fog may influence the deviation from south. Size or performance corrections should be made for deviations greater than $\pm 20^{\circ}$, see Appendix A.

If the optimum orientation will seriously interfere with building design requirements, or will impose extensive additional structural provisions, tradeoffs for less optimum orientation or relocation of the collector where the optimum orientation can be utilized should be considered.

The orientation of concentrating type collectors is a function of the collector acceptance angle design and may require tracking within specific limits.

\section{Shading}

Shading of collectors shall be considered during the design so that shading by trees, adjacent collectors or other obstructions is accounted for.

Commentary: in east and west exposures during the entire year, and on south exposures during the winter, the solar altitude may be low enough to cause direct shading and a resultant loss in collection capability. A practical design goal is to limit the reduction in collected useful thermal energy during the month of peak load to less than $5 \%$. 
The cover plate(s) shall not collect or retain dirt to an extent that would significantly reduce its ability to transmit sunlight.

Commentary: The possible collection and retention of dirt by the cover plate and the effect of retained dirt on collector performance may be significant. The retention of dirt may depend on the surface characteristics and tilt angle of the collector. Rainfalz and snow melt are generally sufficient to keep the collector cover plates clean. If periodic scrubbing is necessary for cleaning, the cover plates should be resistant to damage by abrasion resulting from the scrubbing. If the collector is ventilated, provisions should be made for exclusion of dust by appropriate filters.

\section{S-615-2.1.5 Cleaning}

In designs where the Interior surfaces of collector glazing and cover plates or absorber surfaces are not protected against accumulation of dust or dirt, provisions shall be made to allow cleaning of these surfaces as frequently as necessary to prevent a significant deterioration of collector performance.

Commentary: On active collectors that are not hermetically sealed or provided with air filters and in passive installations which may have large air plenums behind glazed surfaces or combine solar collection with view provisions, accessability for periodic cleaning is essential to continued high solar transmittance. Selective absorber surfaces must be kept clean as dust accromulations can change their emittance characteristics.

$S-615-2.1 .6$

Ice Dams and Snow Bulld Up

The design of solar buildings and systems shall prevent the formation of ice dams and snow build up.

Commentary: In very cold climates, water flowing off a warm collector may freeze on cold surfaces inmediately below it (such as exposed eaves), thereby forming an ice dam which can cause water to back up under roofing or into the collector itself. This may be moderated by methods such as elimination of the cold surface or provision of an impervious surface such as continuous flashing. Snow sliding off a collector may pile up at the bottom and cover part of the collector. This would have a tendency to reduce the efficiency of the collector and increase the possibility of thermal breakage of glass in the collector. This may be moderated by methods such as the provision of space below the collector for snow pile up or by the installation of heating cables.

\section{S-615-2.1.7 Mud Splash}

The design of solar buildings and systems shall minimize the possibility of mud splash on collector surfaces.

Commentary: Water muning off collectors located close to the ground can cause mud splashing to coat portions of the collector and reduce its efficiency. Remedies to this include: easy access for cleaning, position of collectors elevated sufficiently to avoid splashing, or provisions of gutters or splash free material at the base of the collector.

S-615-2.1.8 Protection Against Thermal Shock and Pressure

Collectors shall not be damaged or adversely affected by extreme temperature and pressure that could occur by thermal shock resulting from sudden environmental or fluld flow changes during operation. 
Commentary: Thermal shock could result from the passage of hot fluid through a cold collector or cold fluid through a hot collector during start-up.' The designer should either assure that the materials used in the collector can withstand the extreme temperatures and pressures or provide temperature and pressure relief from thermal cycling or shock. See Section S-615-14.1.3.

S-615-2.1.9 Moisture Build-up Control

Means shall be provided to prevent moisture build-up in collectors to an extent that would reduce collector performance below allowable design limits.

Commentary: Moisture build-up in the collector can soak insulation and reduce its effectiveness, leach alkalies out of fiberglass insulation and hasten its degradation, lead to chemical attack on absorber plates and cause condensation on cover plates.

Depending on the design, the likelihood of condensate forming on the interior surface (s) of the cover plate(s) may be high. Desiccants in breather tubes or breather plugs can be used to maintain a dry environment. The desiccants should be located in such a way that they are not in contact with the collector plate and it is desirable that they be capable of regeneration by solar energy as the collector builds temperature.

One additional potential problem with collectors is that, in industrial atmospheres, the introduction of pollutants in condensate solution may cause permanent etching of the underside of the cover plate(s)or chemical attack of the absorber over a period of time. Such etching can permanently reduce the transmittance. When this possible condition exists, design considerations must be given to avoid the problem.

\section{S-615-2.1.10 Access to Components}

If routine maintenance or repair of collector components is anticipated, the collector shall be designed to permit easy access to those components.

Commentary: Some materials such as muber hoses, joint sealants, exterior coatings, etc. may have to be replaced periodically. Also, in some geogrophic locations, the cover plates may have to be cleaned occasionally. If materials in the collector are likely to be replaced, repaired or maintained within the design life of the collector, it is important to provide easy access to those materials.

\section{S-615-2.1.11 Openings}

All openings in the collector enclosure shall be protected to prevent the entry of insects and vermin.

\section{S-615-2.2 Collector Thermal Performance}

\section{S-615-2.2,1 General}

This section is intended to cover component and integral collectors which can be flat plate, concentrating, reflector aided, fixed or tracking types.

\section{S-615-2.2.2 Collector: Component}

This type collector can be characterized as a component for an active solar system requiring the use of powered mechanical equipment to move the heat transfer fluid (liquid or gas) through the collector. The collector thermal performance shall be based upon the slope-intercept method of expressing efficiency for the range of operating conditions including solar power density, heat transfer fluid temperature, ambient temperature, wind, solar radiation incident angle, and flow rates to be used in the design. 
Commentary: The collector performance characteristics can be measured using the ASHRAE test method 93-77 [1] for rating solar collectors or any other method demonstrated to have an overall limit-of-error of less than $\pm 5 \%$. This method provides sufficient efficiency versus operating condition data to construct a curve normalized for insolation and temperature difference between ambient and heat transfer fluid temperature. Curves for typical flat black and selective coated absorber panels with one and two covers are shown in Appendix A for air and water collectors. Collectors with other geometric, optical or thermal characteristics may require additional tests to fully describe their thermal performance for ali environmental and operating conditions. The operating electrical power is recorded and reported during all tests.

$S-615-2 \cdot 2.3$

$S-615-2.2 .5$

\section{Collector: Combined With Storage}

This type of combined component system can be characterized as an active system with integral construction and operation of the components such that the solar radiation collection and storage phenomena cannot be measured separately in terms of flow rate and temperature changes. The system thermal performance 1 s determined by the short term ( 1 to 3 days) collection and storage of thermal energy obtained from solar radiation and the amount of useful energy delivered to the load from storage for part and full load conditions. Experimental performance data, in terms of heat collected and stored or delivered to load, shall be provided for the design conditions including insolation, heat transfer fluid temperature, ambient temperature, wind, solar radiation incident angle; and flow, rates. The daily and average test period electrical operating requirements are reported with system performance.

Commentary: Although a consensus test method to rate and evaluate these systems does not exist, the efficiency in terms of converting incident solar energy into useful thermal energy can be measured and reported as a function of the specified operating conditions.

\section{Passive: Component (Thermosyphon) Systems}

This type collector can be characterized as one in which the collector is a separate component to collect, convert and transfer the thermal energy. The thermal performance of individual collector panels can be obtained from procedures described in Section S-615-2.2.2 active collectors. System performance is obtained from measurements of incident solar energy and hot water delivered to the load for extended periods to determine monthly averages.

Commentary: A thermosyphon water heating system is an example of the application of a passive component type collector where the hot water circulation results from the change in density of the fluid with temperature.

The movement of a heat transfer fluid by natural convection is achieved by relatively low pressure differentials. Pipe sizing for minimum pressure drop is essential. It is necessary that pipe or duct size, shape, distance, and elevations be considered in predicting the performance based upon individual collector panel test data. Design considerations and equipment performance data is available [2].

[1] ASHRAE Standard 93-77, "Methods of Testing Solar Collectors Based on Thermal Performance," Aunerican Society of Heating, Refrigerating and Air-Conditioning Engineers, 345 East 47th Street, New York, N.Y. 10017.

[2] Baughn, J. W. and Dougherty, D. A., "Experimental Investigation and Computer Modeling of Solar Natural Circulation System," Proceedings of the 1977 American Section of ISES Annual Meeting, Orlando, Florida. 
S-615-3.1 Pipe Hangers and Supports

Pipe hangers and supports shall be installed in accordance with the prevalling model plumbing code having jurisdiction in the area.

VALVES

Gate valves or similar valves that open to nearly full pipe bore shall be used for shut off valves. Globe ball or similar valves shall be used for flow control.

S $-615-5 \quad$ PUMPS \& FANS

S-615-5.1 Applicable Standards

a. Pumps shall be installed in accordance with the requirements of the Hydraulic Institute. [1]

b. Fans shall be installed in accordance with the recommendations of the ASHRAE Guide or applicable manuals of NESCA and SMACNA.

c. All moving machinery shall be protected and guarded to comply with the current safety standards of ANSI B15.1 if such machinery is exposed to other than maintenance personnel.

S-615-6 MECHANICAL VIBRATION ISOIATION

S-615-6.1 Genera1 Requirements

All operating mechanical equipment shall be isolated by suitable piping or duct connections and where necessary by isolation pads or foundations to prevent tranșmission of noise or vibration. The dwelling shall be free of objectionable sound as required in HUD circular 1390.2, Noise Abatement and Control.

Equipment conforming to other sound level criteria referenced in these standards shall also be acceptable.

II] Hydraulic Institute Standards for Centrifugal, Rotary and Reciprocating Pumps, Thirteenth Edition, 1975. The Hydraulic Institute, 1230 Keith Building, Cleveland, Ohio 44115. 
This section applies to sensible heat type thermal energy storage devices using gas or liquid as the heat transfer fluid and liquid as the heat storage medium. The storage medium can be contained in a separate enclosure, stored at more than one temperature, or can be a part of the building structure.

Commentary: Some typical storage subsystem arrangements are shown in Appendix A. The interaction between storage temperature and collector operating efficiency must be considered in the design and operation of the thermal storage unit. Designs which enhance storage temperature stratification, control the storage fluid mixing, and which use utility supplied, on-line energy during non-peak load conditions are desirable.

\section{S-615-7.2 Applicable Standards}

Thermal storage shall comply with the design standards of MPS 8ection 615 and the applicable recognized standards given in MPS Appendix E.

\section{S-615-7.3 Thermal Storage Requirements}

\section{S-615-7.3.2 Domestic Hot Water Heating}

The solar thermal energy storage for preheating domestic hot water shall have a volume capacity not less than the number of gallons/storage capacity. shown in Tables $\mathrm{S}-615-7.1$ or $\mathrm{S}-615-7.2$.

Commentary: It is possible to operate a hot water storage container with large temperature gradients permitting the auxiliary energy source to be incorporated in the same container, or the auxiliary energy can be supplied after the water has been removed from the solar heated container. It should be noted that developing effective stratification in a tank reduces its total heat storage copacity as compared to an unstratified condition. Actual system drow rates should be checked against this reduced capacity. Several 1 and 2 tank system configurations are described in Appendix A.

\section{S-615-7.3.4 Therma1 Energy Loss}

The thermal energy loss from storage containers located outside the heated dwelling sha11 not exceed $10 \%$ of the maximum operating thermal energy capacity over an average 24 hour winter design day.

Commentary: Calculations of the thermal loss from tanks, piping, and valves can be performed using average fluid and ambient temperatures and thermal insulation conductivity valves with procedures described in the ASHRAE Handbook of Fundamentals. Section S-607-3.1 contains guidance on insulation valves.

\section{s-615-7.4 Tank Drainage}

Each tank shall be provided with means of emptying the liquid. Each tank located above grade or floor level shall be provided with a valved pipe at Its lowest point to permit emptying the tank. Each buried tank shall have provisions for utilizing a pump or siphon or other means to allow emptying. 
Tanks of large capacity should have an indicator or other means for determining that the tank is full. Tanks should have overflows with outlets located so that spillage will not run into the building structure or damage the premises. Tanks that do not contain potable water but require make up water from the potable water system shall be filled by way of an air gap or other means acceptable to the administrative authority having jurisdiction.

\section{S-615-7.6 Inlet and Outlet Location}

The inlet and outlet piping or ducts for thermal storage sha 1 be located in the container to prevent thermal "short circuiting" of the fluid flow.

Commentary: The collector performance is a function of the fluid temperature, therefore, the storage-to-collector fluid outlet should be located in the coldest portion of the container such as the lower $5 \%$ of a vertical liquid tank. The inlet should be located in the warmest portion of the storage volume but in the case of electric auxiliary below the heating element. Inlets and outlets of liquid containers should be installed to provide flow parallel to the top and bottom of the tank, respectively, to minimize mixing.

\section{S-615-7.7 Auxiliary Energy Input}

Auxiliary energy heating elements or the inlet of heat transferred from auxilfary energy sources to the inside of storage devices shall be located in the warmest practical area of the container.

Commentary: In designs where it is possible to add auxiliary energy to storage, the configuration should be designed to maintain the collector inlet temperature as low as possible. In single tank systems very inefficient collector operation will result if auxiliary heat is introduced at the bottom of the tank. Any possible stratification in the tank will be destroyed and hot water will be circulated to the collector resulting in inefficient operation. On retrofit instalzations, it may be necessary to disconnect the lower electric heating element.

S-615-7.9 Protection Against Maximum Temperature, Pressure and Vacuum

Thermal storage shall be protected against maximum temperature, pressure and vacuum in accordance with the provisions of S-615-74.1.

Commentary: During extended periods with no drow, solar DHW systems can supply thermal energy to such an extent that dangerously high temperatures may be reached in storage tanks. To avoid this, thermostatically controlled valves or other methods may be used to prevent undesired collector heat from entering storage. Such provisions may require collectors to be stagnation tolerant or provide heat dumping capability in the collector circulation loop. In any case, maximum tank temperature should be limited to $180^{\circ} \mathrm{F}$. 
Table S-615-7.1 Direct Fired Water Heater Capacities. I/

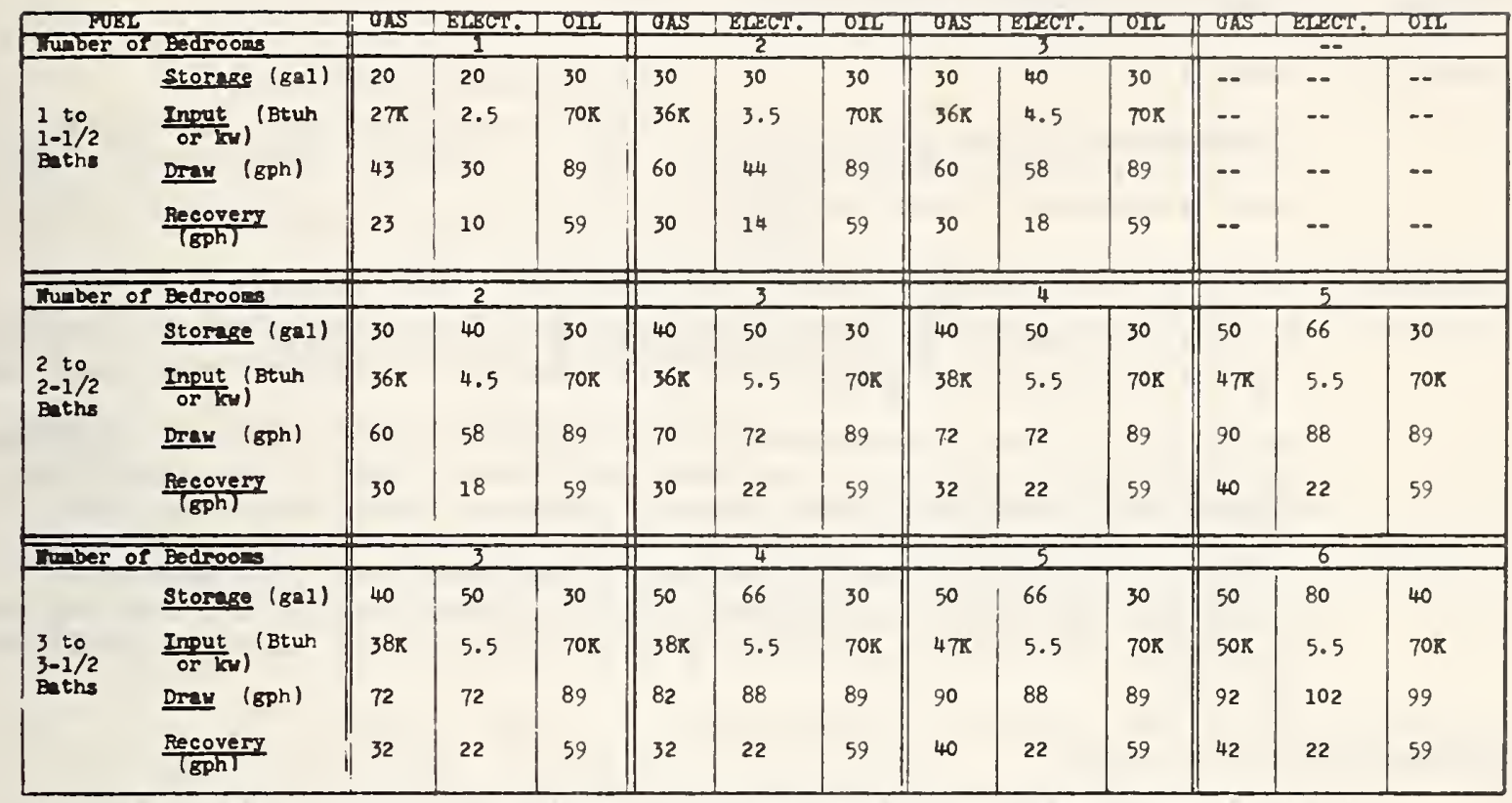

Hote: Storage capac1ty. Input and the recovery requirements indicated in the Table are typlcal and may vary with each individual manufacturer. Any combination of these requirements to produce the

1 hour draw stated w111 be sat1sfactory. Recovery 18 based on 100 p water temperature rise.

Bumple: For a 3-bedroom, 2 bath residence there are three cholces as follows: A 40 gal storage/30 gph recovery gas heator; a $50 \mathrm{gal}$ storage/22 gph recovery electric heater; or a $30 \mathrm{gal} 3 \mathrm{storage} / 59 \mathrm{gph}$ reoovery o11 heater; or an equivalent combination wh1ch w111 produce at least a 70 gph total draw.

Table S-615-7.2 Indirect Fired Water Heater Capacities. 2 /

\begin{tabular}{|c|c|c|c|c|c|c|c|c|c|c|c|}
\hline & \multirow{2}{*}{$\begin{array}{l}\text { NUMBER OF } \\
\text { NUATHROOMS OF } \\
\end{array}$} & \multicolumn{3}{|c|}{1 to $1-1 / 2$} & \multicolumn{3}{|c|}{2 to $2-1 / 2$} & \multicolumn{4}{|c|}{3 to $3-1 / 2$} \\
\hline & & 2 & 3 & 4 & 3 & 4 & 5 & 3 & 4 & 5 & 6 \\
\hline \multirow{3}{*}{$\begin{array}{l}\text { TANK TYPE INDIRECT } \\
\text { BOILER-CONNECTED } \\
\text { WATER HEATER CAPACITIES } \\
\text { (180 F BOILER WATER - } \\
\text { INTERNAL OR EXTERNAL } \\
\text { CONNECTION) }\end{array}$} & $\begin{array}{l}\mathrm{I}-\mathrm{W}-\mathrm{H} \text { rated gal in } 3 \mathrm{hr} \\
100 \mathrm{~F} \text { degree rise }\end{array}$ & 40 & 40 & 66 & 66 & 66 & 66 & 66 & 66 & 66 & 66 \\
\hline & $\begin{array}{l}\text { Manufacturer rated gal. } \\
\text { in } 3 \mathrm{hr} 100 \mathrm{~F} \text { deg rise }\end{array}$ & 49 & 49 & 75 & 75 & 75 & 75 & 75 & 75 & 75 & 75 \\
\hline & Tank capacity in gals. & 66 & 66 & 66 & 66 & 66 & 82 & 66 & 82 & 82 & 82 \\
\hline \multirow{2}{*}{$\begin{array}{l}\text { TANKLESS TYPE INDIRECT } \\
\text { BOILER- CONNECTED WATER } \\
\text { HEATER CAPACITIES } \\
\text { (20O F BOILER WATER - } \\
\text { INTERNAL OR EXTERNAL } \\
\text { CONNECTION) }\end{array}$} & $\begin{array}{l}\text { I-W-H rated gpm. } \\
100 \text { F deg rise }\end{array}$ & 2.75 & 2.75 & 3.25 & 3.25 & 3.25 & 3.75 & 3.25 & 3.75 & 3.75 & 3.75 \\
\hline & $\begin{array}{l}\text { Manufacturer rated, draw } \\
\text { in } 5 \text { min. } 100 \text { F deg rise }\end{array}$ & 15 & 15 & 25 & 25 & 25 & 35 & 25 & 35 & 35 & 35 \\
\hline
\end{tabular}

Note: Heater capacities and inputs are minimum allowable. Varlations in tank size are permitted when recovery $1 \mathrm{~s}$ based on $4 \mathrm{gph} / \mathrm{kw}$ e $100 \mathrm{~F}$ rise for electrical, AGA recovery ratings for gas heaters, and IBR ratings for steam and hot water heaters.

1/ From HUD MPS (4900.1 and 4910.1) Table 6-15.2.

2/ From HUD MPS (4900.1 and 4910.1) Table 6-15.3. 
S-615-8.1 Toxic and/or Combustible Fluids

S-615-8.1.1 General

Requirements for handling non-potable heat transfer flulds are discussed in Sections S-615-9, Waste Disposal; S-615-10, Plumbing; and S-615-12, Heat Exchangers, of this document.

\section{S-615-8.1.2 Detection of Toxic and/or Combustible Fluids}

If toxic or combustible heat transfer flulds are used, means shall be provided for the recognition of leaks and thus the warning of occupants when leaks occur.

Commentary: These substances may be treated in a manner similar to antifreeze and gases when providing for teli-tale indicators. For instance, antifreeze agents, such as ethylene glycol, may be treated with non-toxic dyes which distinguish them clearly. Furthermore, if any such materials are to be stored on the premises, they should be stored in containers which are Zabeled in accordance with the Federal Hazardous Substances Act and be protected from easy opening by children e.g., childproof lids. Safe storage locations should be provided.

\section{S-615-8.1.3 Identification}

Drains and other designated fluid discharge or f1ll points in solar systems at which toxic, combustible, high temperature or high pressure flulds may be discharged shall be labeled with a warning describing the Identification and hazardous properties of the fluid, instructions concerning the safe handling of the fluld, and emergency first ald procedures.

Commentary: The original fluid containers will frequently be discarded after the system is charged which could result in no record of the fluid's properties being retained. The system drain is the point at which the owner or service personnel are most likely to contact the heat transfer fluid and permanent labeling should be retained at that point. Identification may be provided by attaching a tag containing the required information such as may be supplied by the heat transfer fluid manufacturer.

S-615-9 WASTE DISPOSAL

S-615-9.1 Catchment

Systems ut1lizing other than air or potable water as a heat transfer fluld shall provide for the catchment and/or harmless removal of these flulds. from vents, drains or re-charge points as approved by local administrative code authorlty. Potable water shall be discharged to sultable drainage systems connected to the building or site drains. See MPS Section 615-9.

S-615-9.2 Provision of Containment for Discharge Treatment of Toxic and/or Combustible Flulds

Adequately sized and protected receptacles shall be provided when toxic and/or combustible flulds are used in order to collect and store the overflow from: pressure rellef valves, liquids drained from the system when it is being serviced, and Identiflable leakage. Provisions of MPS Section 615-4.4 (Section $615-4.5$ In MPS 4920.1 ) shal1 be applied.

Commentary: When a toxic heat transfer fluid is used (see Section S-515-8.2), a catch basin must be provided. It must be sufficiently large to accept diZution as required by MPS Section 615-9 before disposal. 
If the diluted medirm is biodegradable through conventional sewage treatment, the diluted medium is to be flushed into the sanitary sewer system (not the storm sewer system). Consideration should be given to the effect of flushing solar systems on the "Basic Design Ioading" for sewage treatment, Section CS 603, HUD Handbook 4940.3, Minimum Design Standards for Community Sewage Systems.

S-615-10

$S-615-10.1$

$s-615-10.1 .1$

PLUMBING

Handling of Nonpotable Substances

Potable water supply shall be protected against contamination in accordance with the prevailing model plumbing code having jurisdiction in the area, in addition to the requirements which follow.

\section{Separation of Circulation Loops}

Circulation loops of subsystems utilizing non-potable heat transfer fluids shall either be separated from the potable water system in such a manner that a minimum of two walls or interfaces is maintained between the non-potable liquid and the potable water supply or otherwise protected in such a manner that equivalent safety is provided.

Commentary: Double wall heat exchanger designs are one way of meeting the intent of this criterion. When double wall heat exchanger designs consisting of two single wall heat exchangers in combination with an intermediary potable heat transfer liquid are used, leakage through one of the walls would result in a single wall configuration. Although this design is considered to meet the intent of this criterion, there are several other designs which avoid this probiem.

The use of single wall configurations which solely rely upon potable water pressure to prevent contamination is not considered to be an acceptable solution. Similarly, extra thick single walls are not considered to meet the intent of this criterion

For approval of other than double wall designs, the procedures described in S-101 should be utilized.

S-615-10.1.2 Identification of Nonpotable and Potable Water

In buildings where dual fluid systems, one potable water and the other non-potable fluid, are installed each system may be identified either by color marking or metal tags as required in ANSI A13.1-1956 [1] or other appropriate method as may be approved by the local administrative code authority. Such identification may not be required in all cases.

\section{S-615-10.1.3 Backflow Prevention}

Backflow of nonpotable heat transfer fluids into the potable water system shall be prevented in a manner approved by the local administrative code authority.

Commentary: The use of air gaps and/or mechanical backflow preventers are two possible solutions to this problem. The following are some recognized standards that may be acceptable to the local administrative code cathority: Complete tities are given in Appendix $E$.

[1] Scheme for the Identification of Piping Systems, ANSI A13.1 - 1956. 


$\begin{array}{ll}\text { Air gaps } & \text { ANSI-A112.1.2 } \\ \text { Backflow preventers - } & \text { FCCCHR Chapter } 10 \\ & \text { IAPMO PS } 31-74 \\ & \text { AWWA C506-69 } \\ & \text { A.S.S.E. } 1011 \\ & \text { A.S.S.E. } 1012 \\ & \text { A.S.S.E. } 1013 \\ & \text { A.S.S.E. } 1015 \\ & \text { A.S.S.E. } 1020 \\ & \text { ANSI-AI12.1.1 }\end{array}$

S-615-10.2 Pipe Sizing

Pipe sizing shall be in accordance with recognized methods.

S-615-10.3

Expansion and Contraction

Provisions for expansion and contraction without undue strain or distortion shall be made as required by means of offset branches, expansion compensators, or flexible pipes. Piping shall be adequately supported to prevent undue strain on the flexible pipes and branches.

S-615-10.4 Protection Against Maximum Temperature, Pressure and Vacuum

Systems shall be protected against maximum temperature, pressure and vacuum in accordance with the provisions of S-615-14.1.

S-615-10.5 System Drainage

Liquid systems shall be designed so that complete isolation and drainage of all system components, piping, or storage tanks can take place in a reasonable length of time for maintenance purposes. See S-615-7.4, Tank Drainage.

S-615-10.6 Protection from Scalding

All domestic hot water systems shall be equipped with means for limiting temperature of the hot water for personal use at fixtures to $140^{\circ} \mathrm{F}$.

Commentary: For further discussion, see Section S-615-1.4.2c.

\begin{tabular}{l|l} 
S-615-10.7 & Provision of Valves and Fittings \\
S-615-10.7.1 & Shutoff's
\end{tabular}

All domestic water heaters and water heating systems shall be valved to provide shutoff from the cold water supply systems.

S-615-10.7.2 Water Hamer Arresters

When a liquid is used as the transfer fluid in a solar energy system and quick-closing valves are employed in the design, the piping system shall be able to control or withstand potential "water hammer". Water hammer arresters shall be in compliance with local codes.

S-615-10.7.3 A1r Bleeds

When liquid heat transfer fluids are used in solar heating systems, the systems shall be provided with suitable means for air removal. 
After completion of piping tests and after all equipment has been installed, the entire liquid systems shall be thoroughly flushed to remove sediment, dirt and loose scale, etc. Strainers shall be cleaned or replaced. During the flushing of the system, the collectors must be disconnected or bypassed to preclude passage of debris through the collectors.

S-615-10.9 Expansion Tank8

Adequate provisions for the thermal expansion of solar heat transfer and storage 1lquids that would occur over the service temperature range shall be incorporated into the solar heating system design.

Expansion tanks shall be sized in accordance with the recommendations of 1976 ASHRAE Systems Handbook.

S-615-10.10 Leak Testing

S-615-10.10.1 Pressurized Tanks and Systems

Those portions of heating systems which contain liquid heat transfer fluids and are not directly connected to the potable water supply shall not leak when pressures of not less than 1-1/2 times their design pressure are imposed for a minimum of 15 minutes [1]. The pressure shall be gradually applied and sustained for a sufficient length of time to permit examination of all pipe joints for leakage. Those portions of the system using domestic hot water shall not leak when tested in accordance with the code having jurisdiction in the area where the system is used. In areas having no bullding code, a nationally recognized model code shall be used [1].

\section{S-615-10.10.2 Non-Pressurized Tanks}

Non-pressurized tanks shall be tested visually for leaks by filling tanks with water.

Commentary: A hydrostatic test pressure of 1-1/2 times design pressure is considered a standard test pressure, for pressurized system [2]. For most applications, clear water is used. The temperature of the water should be no lower than that of the ambient atmosphere. Otherwise, sweating will result and proper excomination will be difficult. In environments where freezing may occur, antifreeze or hydrocarbons may be added to keep the water from freezing. Bleeder valves or petcocks should be provided at the highest point or points in the system to permit venting of all air in the piping during the filling operation [2]. Automatic vents must be protected from freezing.

$S-615-10.11$

\section{Discharge of Liquids}

Relief valves shall be piped to discharge to locations acceptable to the local administrative code authority having jurisdiction.

S-615-10.12 Location of Exposed Piping

Piping and equipment shall be located so as not to interfere with normal operation of windows, doors, or other exit openings and so as to prevent damage to piping, equipment, or infury to persons.

[1] The BOCA Basic Plumbing Code, Southern Standard Plumbing Code, The Uniform Plumbing Code, and The National Plumbing Code.

[2] P1ping Handbook, Remo C. King and Sabin Crocker, McGraw-Hill Book Company, 5th Edition. 
Underground water service piping shall be installed in accordance with the provisions of Section 615-5.3 of MPS. Underground heat distribution piping shall be installed in accordance with Section 615-5.3 (k) of MPS.

S-615-10.14 Treatment of Water

When make-up water is of such a quality that excessive corrosion or scaling is known to exist, a sultable water treatment system as recommended by the Water Quality Foundation shall be provided.

Commentary: The use of small water passages in collectors and heat exchangers makes them susceptible to plugging and any size water passage may be subject to reduction ik heat transfer from the precipitation of salts or corrosion products.

\section{S-615-10.15 Freeze Protection}

For systems subject to freezing of the heat transfer fluld, freeze protection by draining, circulation of an anti-freeze agent or other means shall be provided.

Commentary: Some methods of freeze protection (i.e., the circulation of heat transfer fluid from storage) are generally considered to be effective only when used in locations with moderate climatic conditions where freezing is an infrequent occurrence. Consideration should be given to the probability of power failure occurrence when selecting a freeze protection method that is dependent on electrical power for its operation. The use of heat topes for freeze protection is not recormended because of their fire hazard potential.

\section{S-615-10.15.1 Draindown Freeze Protection}

In draindown systems, if drainage of heat transfer fluid to the thermal storage tank is intended, the storage tank shall be sized adequately to accommodate 1t. See S-615-7.3.1 and S-615-10.2. System designs incorporating automatic drainage of heat transfer fluid to storage to prevent freezing of the fluld in solar collectors shall not be constructed of materials which corrode in the presence of air or shall be suitably protected.

Commentary: One means of preventing corrosion during system drainage would be by introducing an inert gas such as nitrogen.

S-615-10.15.2 Draindown Venting

In draindown systems, provisions for venting of collector panels and manifold lines shall be provided as required to allow refill of the collector system without air entrapment.

Commentary: Operation and maintenance of draindown venting must be compatible with venting for normal operations. Draindown venting may employ either venting to the atmosphere or pressurized methods with valves and holding tanks which automatically accomplish the refilling and venting. 
Applicable Standards

S-615-11.1.1 Domestic hot water systems shall comply with the design standards of MPS Section 615 and the applicable recognized standards given in MPS Appendix E.

S-615-11.2 System Interconnection

The interconnections of the auxiliary energy system to the solar energy system shall be made in a manner which will not result in excessive temperature or pressure in the auxiliary system or in bypassing of safety devices of the auxiliary system.

S-615-12

S-615-12.1

\section{HEAT EXCHANGERS}

\section{Sizing}

a. A heat exchanger when used in conjunction with the solar collector and storage shall be evaluated for its effectiveness in transferring heat from the collector to storage. The heat exchanger effectiveness is expressed by:

$$
\varepsilon_{c}=\left(\dot{m}_{p}\right)_{c}\left(t_{0}-t_{i}\right) /\left(\dot{m}_{p}\right)_{m i n}\left(t_{o}-t\right)
$$

where

$\mathrm{C}_{\mathrm{min}}=\left(\dot{\mathrm{m}} \mathrm{p}_{\mathrm{p}}\right)_{\text {min }}=$ the minimum fluid capacitance rate of collector $\left(\mathrm{C}_{\mathrm{c}}\right)$ or $\mathrm{C}_{\mathrm{s}}=\left(\dot{\mathrm{m}}_{\mathrm{p}}\right)_{\mathrm{s}}=$ fluid capacitance rate in the flow circuit between storage $\mathrm{C}_{\mathrm{c}}=\left(\dot{\mathrm{m}}_{\mathrm{p}}\right)_{\mathrm{c}}=$ fluid capacitance rate in the flow circuit between collector and the collector heat exchanger

$\mathrm{t}=$ storage temperature $\left({ }^{\circ} \mathrm{F}\right)$

$\mathrm{t}_{\mathrm{o}}=$ collector outlet temperature $\left({ }^{\circ} \mathrm{F}\right)$

$t_{1}^{\circ}=$ collector inlet temperature $\left({ }^{\circ} \mathrm{F}\right)$

$\varepsilon$ = effectiveness of the collector - storage heat exchanger

$\dot{\mathrm{m}}^{\mathrm{c}}=\mathrm{flow}$ rate of the working fluid $(\mathrm{lb} / \mathrm{h})$

$\mathrm{c}_{\mathrm{p}}=$ fluid specific heat $\left(\mathrm{Btu} / 1 \mathrm{~b} \cdot{ }^{\circ} \mathrm{F}\right)$

Commentary: Diagrams of typical locations and a discussion of heat exchangers are presented in Appendix $A$. Calculation methods for heat exchangers performance are described in the 1972 ASHRAE Handbook of Fundamentals. A minimu effectiveness value of 0.7 is a typical value that is used.

S-615-12.2 Protection Against Maximum Temperature, Pressure and Vacuum

Heat exchanger shall be protected against maximum temperature, pressure and vacuum in accordance with the provisions of S-615-14.1.

S-615-13

AIR DISTRIBUTION

S-615-13.1

Applicable Standards

Design of all solar domestic hot water systems using air collectors shall be in accordance with applicable recommendations of the 1976 ASHRAE Systems Handbook and manuals of NESCA and ARI. Installation shall comply with NFPA Standards 90B, 31, and 54 .

Commentary: Duct work should be designed for the shortest practical mun and elbows should be kept to a minimum. Constrictions should be avoided.

\section{S-615-13.2 Dust and Dirt Prevention}

Duct and fan systems shall be protected against accumulation of deposits of dust or dirt that could reduce flow and efficiency. Air filters are required on the outlet side of rockbed storage in active systems. 
The control subsystem shall be designed so that in the event of a power fallure, or a failure of any of the components in the subsystem, the temperatures and/or pressures developed in the DHW system will not be damaging to any of the components of the systems and the building or present a danger to the occurants. The safety devices shall meet the requirements of Section 515-6.4 of MPS and be demonstrated to be adequately safe and protected for the intended application.

S-615-14.1.1 Automatic Pressure Relief Devices

Adequately sized and responsive pressure relief devices shall be provided in those parts of the energy transport subsystem containing pressurized fluids. A pressure release device shall be provided in each portion of the system where excessive pressures can develop. Each section of the system shail have a pressure relief device so that no section can be valved off or otherwise isolated from a relief device. Automatic pressure rellef devices shall be set to open at not more than the maximum pressure for which the subsystem is designed.

Relief devices shall drain to locations in accordance with Section S-6Z5

Commentary: Care should be taken in the design and layout of the fluid transport system to prevent conditions in which locally excessive pressures are developed as a result of flow restrictions. Precoutions must be taken to assure that heat transfer liquids do not discharge on asphatt base roofing materials or other types of roofing or locations which may be hazardous, cause structural domage, building finish discoloration, or domage to plant materials.

S-615-14.1.2 Vacuum Relief

The solar energy system, including collectors, pipes, tanks, and heat exchangers shall be protected against possible collapse by design or by provision of vacuum relief valves.

Commentary: System components may be subjected to collapse if heating system leakage were to occur or if the system were drained without venting.

S-615-14.1.3 Collector Therma1 Shock

Automatic flow control valves shall be provided for collectors unable to withstand temperature shock.

S-615-14.2 Identification and Location of Controls

Main shutoff valves and switches shall be conspicuously marked and placed in a readily accessible location, in the same manner as electrical service panels, in accordance with Section 240.24 of NFPA 70, and MPS, Section 616.

S-615-14.3 Indirect Water Heaters

Indirect domestic water heater installations shall include operating controls for the heat source, of the type recommended by the boller manufacturer. The installation shall be made in accordance with the boiler manufacturer's instructions. 
Automatic control of the heat transfer fluid circulation between the collector and storage or load shall be used to limit operations to conditions when useful energy can be collected. Designs utilizing collector flow as a fall-safe method shall employ override controls as required.

Commentary: The collector circulation in liquid systems is normally limited to conditions when the absorber plate temperature is greater than the storage or Zoad temperature by a $\Delta t$ of $20^{\circ} \mathrm{F}$ for start-up and a $\Delta t$ of $3^{\circ} \mathrm{F}$ for shut-down. A larger $\Delta t$ may be used for air systems depending upon the circulating fan electrical power requirements.

Sensors should be located to accurately and reliably measure the heat transfer fluid properties used in the control process. The collector temperature sensor used to initiate operation of the circulator is normally zocated in the upper portion of the collector to insure that it senses heated fluid. The storage sensor is normally located below the heating element in resistance heated auxiliary single tank systems and in the lower portion of the preheat tank for two tank systems. Sensors should either be intrusion type or mechanically mounted to the surface for intimate thermal contact and resistance to corrosion, vibration or environmental effects. Lead wire insulation should provide abrasion and environmental protection.

$S-615-15$

$S-615-15.1$

$S-615-16$

$S-615-16.1$

\section{CHIMIEYS AND VENTS}

Termination Helght of Chimneys and Vents

Termination height of chimneys and vents shall be in accordance with NFPA 211.

Commentary: The presence of solar equipment may introduce buizding components that are elevated above the roof ourface, thus producing wind disturbance at a higher level. The standards of NFPA 211 will provide for proper clearance and separation.

\section{MECHANICAL VENTILATION}

\section{Alr Discharge Openings}

Alr discharge openings through roofs or exterior walls shall not be located such that their exhaust will cause the deposition of grease, 1int, condensation or other deleterlous materials on solar optical components. 


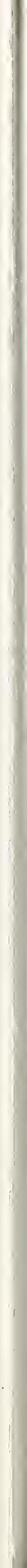


APPENDIX A

METHOD FOR PREDICTING THE THERMAL PERFORMANCE

OF DOMESTIC HOT WATER HEATERS

Applicable to the HUD/States Solar

Domestic Hot Water Initiative Program 
1. Summary of Operation and Design of Solar Water Heaters . . . . . . . . A-2

1. Introduction . . . . . . . . . . . . . . . . . . . . . A-2

2. System Descriptions. . . . . . . . . . . . . . . . . . A-3

3. System Design Factors Affecting Thermal Performance. . . . . . . . . A-12

2. Prediction Method. . . . . . . . . . . . . . . . . . . . A-16

1. Summary of the Prediction Method . . . . . . . . . . . . . . . . A-16

2. Basis of the Prediction Method . . . . . . . . . . . . . . . . A-17

3. Procedure. . . . . . . . . . . . . . . . . . . . A-18

1. Selection of Reference Collector Area, A ref . . . . . . . . . . A-18

2. Adjustments for Collector Characteristics and/or Heat Exchanger Modifiers . . . . . . . . . . . . . . . A-19

3. Adfustments for orientation. . . . . . . . . . . . . . . . A-21

4. Adfustments for Storage Heat Capacity. . . . . . . . . . . . . A-21

5. Adfustments for Cold Water Makeup Temperature. . . . . . . . . . . A-21

6. Example Problem. . . . . . . . . . . . . . . . . . . A-22

3. Supplementary Information. . . . . . . . . . . . . . . . . . . . A-34

1. Modified Collector Performance Characteristics, $F_{R}^{\prime}(\tau \alpha), F_{R}^{\prime} U L$. . . A-34

2. Heat Exchanger Effectiveness, $\varepsilon_{\mathrm{HX}}$. . . . . . . . . . . . . . . A-39

4. References . . . . . . . . . . . . . . . . . . . . . A-48

5. Nomenclature . . . . . . . . . . . . . . . . . . . . . A-49 


\subsection{INTRODUCTION}

The comparison of solar water heating with other applications of solar energy, such as space heating, illustratès major design differences. The influence of changes in ambient temperature on the demand for hot water is considerably less than in the case of space heating and cooling. As ambient temperatures change, the requirements for heating and cooling in a dwelling undergo large variations, thereby requiring installation of large collector and storage facilities with a sizable auxiliary energy supply. Hot water demand, however, is not greatly affected by weather changes. Moreover, the comparatively low operating temperature of a solar collector for domestic hot water heating results in a significantly smaller heat loss than from a collector used for air-conditioning, where overall temperature difference as high as $140^{\circ} \mathrm{F}\left(78^{\circ} \mathrm{C}\right)$ between collector and ambient may be involved. The output of a solar water heater is, therefore, primarily dependent on solar radiation intensity and duration. The requirements for hot water storage are, accordingly, dependent mainly on the hot water use pattern.

The quantity of energy required for domestic hot water is a function of at least the following five factors:
a. local makeup water temperature
b. desired hot water temperature
c. quantity of water used daily
d. daily use schedule
e. storage and line losses

Average monthly makeup water temperature for $14 \mathrm{U} . \mathrm{S}$. cities varies from $32^{\circ} \mathrm{F}\left(0^{\circ} \mathrm{C}\right)$ to $81^{\circ} \mathrm{F}\left(27.2^{\circ} \mathrm{C}\right)$ during a year, as indicated in Table A-1. Therefore, assumption of a nominal value of $55^{\circ} \mathrm{F}\left(13^{\circ} \mathrm{C}\right)$ may not be optimal for sizing of solar energy subsystems. Calculated average daily domestic hot water heating loads for single family detached residence in these 14 cities ranged from 50,000 to 108,000 Btu's for January and from 50,000 to $82,000 \mathrm{Btu}$ 's for July, as shown in Table A-2.

A complete understanding of the solar hot water system requires detailed know1edge of each of the system components. The basic parts of the solar water heater are the solar collector, storage tank, circulating system, and auxiliary energy supply. Other components such as a heat exchanger, expansion tank, and differential temperature controller are commonly used in active systems.

Considerations for freeze protection, corrosion resistance, and overheating have resulted in the use of various heat transfer fluids, drain-down methods, and failsafe devices to meet long term durability and reliability requirements. A solar energy system is usually designed for average weather conditions and seldom provides $100 \%$ of the energy requirements. For extended conditions of low incident solar radiation, auxiliary energy sources back up the solar energy system to meet the total requirement.

The system designs used to meet the thermal performance, durability/reliability, back up and particular building integration needs have resulted in a variety of system configurations and components. Some of the basic approaches used to date to provide hot water heating for residential applications are illustrated in Figures A-1 through A-8. Section 1.2 provides a brief description of these systems. A summary of the features, limitations, and general comments for the eight types of systems is presented in Table A-3. 


\begin{tabular}{|c|c|c|c|c|c|c|c|c|c|c|c|c|c|}
\hline C1ty & Source ${ }^{1}$ & Jan & Feb & Mar & Apr & May & Jun & Ju1 & Aug & Sep & Oct & Nov & Dec \\
\hline 1. Phoenix & $R 1, R \theta, W$ & 48 & 48 & 50 & 52 & 57 & 59 & 63 & 75 & 79 & 69 & 59 & 54 \\
\hline 2. MIamI & พ & 70 & 70 & 70 & 70 & 70 & 70 & 70 & 70 & 70 & 70 & 70 & 70 \\
\hline 3. Los Angeles & $R 1, W$ & 50 & 50 & 54 & 63 & 68 & 73 & 74 & 76 & 75 & 69 & 61 & 55 \\
\hline 4. Albuquerque & W & 72 & 72 & 72 & 72 & 72 & 72 & 72 & 72 & 72 & 72 & 72 & 72 \\
\hline 5. Las Vegas & พ & 73 & 73 & 73 & 73 & 73 & 73 & 73 & 73 & 73 & 73 & 73 & 73 \\
\hline 6. Denver & RI & 39 & 40 & 43 & 49 & 55 & 60 & 63 & 64 & 63 & 56 & 45 & 37 \\
\hline 7. Ft. Worth & L & 56 & 49 & 57 & 70 & 75 & 81 & 79 & 83 & 81 & 72 & 56 & 46 \\
\hline 8. Nashville & R1 & 46 & 46 & 53 & 66 & 63 & 69 & 71 & 75 & 75 & 71 & 58 & 53 \\
\hline 9. Washington, DC & R1 & 42 & 42 & 52 & 56 & 63 & 67 & 67 & 78 & 79 & 68 & 55 & 46 \\
\hline 10. Salt Lake City & w, C & 35 & 37 & 38 & 41 & 43 & 47 & 53 & 52 & 48 & 43 & 38 & 37 \\
\hline 11. Seattle & R1 & 39 & 37 & 43 & 45 & 48 & 57 & 60 & 68 & 66 & 57 & 48 & 43 \\
\hline 12. Boston & $\operatorname{Re}$ & 32 & 36 & 39 & 52 & 58 & 71 & 74 & 67 & 60 & 56 & 48 & 45 \\
\hline 13. Chicago & L & 32 & 32 & 34 & 42 & 51 & 57 & 65 & 67 & 62 & 57 & 45 & 35 \\
\hline 14. New York City & Re & 36 & 35 & 36 & 39 & 47 & 54 & 58 & 60 & 61 & 57 & 48 & 45 \\
\hline
\end{tabular}

1. Data from Handbook of Alr Conditioning System Design, p. 5-41 through 5-46 McGraw H111 Book Company, New York (1965). Abbreviatlons: C-creek, L-lake, Re-reservolr, Ri-river, W-well.

Table A-1 Monthly Temperature $\left(t_{m}\right)$ in ${ }^{\circ} \mathrm{F}$ at Source for C1ty Water in 14 Selected Cities

\begin{tabular}{|l|c|c|}
\hline LOCATION & JANUARY & JULY \\
\hline 1. Phoenix & 92 & 77 \\
2. Miam- & 50 & 50 \\
3. Los Angeles $:$ & 90 & 66 \\
4. Albuquerque & 68 & 68 \\
5. Las Vegas, Nevada & 67 & 67 \\
6. Denver & 101 & 77 \\
7. Ft. Worth & 84 & 61 \\
8. Nashville . & 94 & 69 \\
9. Washington, D.C. & 98 & 73 \\
10. Salt Lake City & 105 & 87 \\
11. Seattle & 101 & 80 \\
12. Boston & 108 & 80 \\
13. Chicago & 108 & 75 \\
14. New York City & 104 & 82 \\
\hline
\end{tabular}

Table A-2 Average Dally Service Hot Water Heating Loads for a Single Family Detached Residence for 14 Selected Cities in January and July (Btu $x 10^{3}$ ) 
System 1 - Direct Heating with Single Tank

This system circulates potable water through the collector and utilizes one storage tank. Efficient operation is dependent upon developing thermal stratification in the storage tank and, consequently, the auxiliary heating source (normally an electric coil) is located in the upper portion of the tank. Solar heated water enters near the center and is removed near the bottom as illustrated in figure A-1. A threeway mixing valve is used to limit the outlet water temperature to the desired maximum. Valves for relief, balancing, venting and direction control are used. The control starts the circulator when the upper portion of the collector is warmer than the lower portion of the storage tank. This type of system can operate effectively in a freeze resistant mode in a moderate climate by pumping heated water through the collector or by the use of heating tapes on the collector and piping during freezing conditions. By depending on these provisions, however, serious damage can result if power is lost.

System 2 - Direct Heating with Preheat Tank and Separate Auxiliary Tank

This system circulates potable water through the collector similar to system 1 but utilizes a preheat tank in addition to an auxiliary tank. Operation of the system is not dependent upon thermal stratification in the auxiliary tank and thus, the use of electric, gas, or oil auxiliary energy does not significantly influence the solar energy contribution to the load. Thermal stratification in the preheat tank are beneficial, however. The circulator is initiated when the upper portion of the collector is warmer than the lower portion of the preheat tank. Flow and safety requirements are similar to system 1 . The system is shown in Figure A-2.

System 3 - Direct Heating with Preheat Tank and Automatic Draindown

This system employs similar features and operating characteristics to system 2 but incorporates draindown provisions for freeze protection. The system must be properly plumbed and vented to completely drain all portions of the collector and exterior lines. The control system uses an exterior mounted thermostatic switch to activate normally closed valves which will open when the temperature decreases to $36^{\circ} \mathrm{F}$ or if the power is lost. The collector and piping must be corrosion resistant or the system must self-pressurize with an inert gas to minimize oxidation effects. The system is shown in Figure A-3.

System 4 - Vented or Low Pressure Draindown

Another type of draindown system, shown in Figure A-4, operates with the preheater tank open or at very low pressure. The collector is mounted above the preheater tank and is drained when the circulation stops. A vent must be located at the top of the collector to admit air or inert gas when draining and to expel air or inert gas when the collector is filling. The pre-heat tank may contain a heat exchanger so water can move to the auxiliary tank using line pressure. Alternatively, the heat exchanger may be replaced by a pressure pump to move water to the auxiliary tank while maintaining service pressure. The circulator operation is controlled in the same manner as other systems.

System 5 - Indirect Heating with Antifreeze Loop and Heat Exchanger

The systems shown in Figures $A-5 a$ and $A-5 b$ are closed loop with an antifreeze as the heat transfer fluid and the storage tank operated at normal domestic water pressures. If a toxic fluid is used, present standards require a double-walled heat exchanger because of contamination considerations. The heat exchanger may be in-line counter flow, tank wrap around or an internal tank type. The importance of stratification for efficient operation is the same as described for system 1. In addition to the vent, relief and check valves, an expansion tank is required to accommodate fluid volume changes with temperature. 
System 6 - Indirect Heating with Air Collector and Air/Water Heat Exchanger

Replacement of the liquid collector with an air collector offers a particular advantage in freezing climates by simplifying the control system and reducing the danger of destructive damage. Other problems which are minimized such as corrosion, leaks, and boiling must be traded off against increased duct size and use of electrical power for the blowers. A small pump is used to transfer the potable water through the heat exchanger which is located within the building envelope for freeze protection. A preheat tank system can be used as shown in Figure A-6 with gas, oil or electric auxiliary heat or a one tank system with electric auxiliary may be used as shown in system 1 .

\section{System 7 - Thermosyphon}

The thermosyphon hot water heating system utilized the change in density of water with temperature to cause the circulation of hot water from the collector to storage. As shown in Figure A-7, the storage tank must be located above the collector so the circulation occurs only when solar energy is absorbed. No control system is necessary when gravity flow is used and the control system for a pressurized or draindown system usually becomes too complicated to justify. Properly designed thermosyphon systems produce a temperature rise of about $15^{\circ} \mathrm{F}$ and peak flow rates of about $15 \mathrm{lb} / \mathrm{hr} \cdot \mathrm{ft}^{2}$. The estblishment and maintenance of a significant temperature gradient in the preheat tank is necessary for efficient operation. Properly sized pipes with minimal flow resistance are essential to satisfactory operation. Thermosyphon systems are usually located in climatic regions in which there is little or no danger of freezing. If there is any possibility of a freeze, the preheat tank, the collectors, and all exposed piping should be drained manually.

\section{System 8 - Combined Collector and Storage}

The use of plastic bags or tubes filled with water and with a transparent cover, shown in Figure A-8, can be used as a source of hot water on a daily basis. The unit is normally manually filled in the morning and the hot water is drawn off in the early evening because the night time heat loss is large. The system is not pressurized and should be capable of being completely drained if used in a freezing climate. 
Table A-3 Summary of the Features, Limitations and General Comments for Various Types of Residential Solar Water Heater Types

System Types

1. Direct heating, single tank (F18. A-1)

2. Direct heating, pump circulation, preheat tank and mixing valve $(F \perp g . A-2)$

3. Direct heating, pump circulation, drainable (F1g. A-3)

4. Direct heating, pump circulation, vented (F1g. A-4)

5. Indirect heating, circulating type (P1g. A-5)

6. Indirect Heating AIr Collector ( 1 Ig. A-6

7. Thermosyphon (F1g. A-7)

8. Collector-Storage Combined (F1g. A-8)
Features

Circulate potable water Storage located below collec tor

S1mple temperature control

to operate pump

Has full main pressure

Mixing valve controls outlet water temperature Same as No. 1

Non-freezing by draining freeze protection effective with power fallure

Non-freezing by draining and venting to storage No $108 s$ of water in collector

Provides freeze protection and corrosion inhibitor

Freeze protection not required if fluld loop in protected area Potable water used in fluid loop

Fluld leakage minimized

No electrical energy for c1rculator required Control hardware not required or minimal Direct heating of potable water

No automatic circulating

or control hardware

Direct heating of potable water
Limitations

Not amenable to use of antifreeze or corrosion inhibitors

Collector and plping must wthstand high pressure or high temperature Not amenable to use of antifreeze or corrosion inhibitors

Loss of water in collector for each drain-down Susceptible to corrosion or must be flushed with Inert gas

Susceptible to corrosion or must be flushed with inert gas

\section{Exposure to no-flow conditions can damage heat transfer fluid \\ Electric power for blower operation may be greater than pump \\ Heat exchanger penalty greater than 11quid \\ Usually used in non-freeze climate \\ Storage tank located above collector}

Manual operation to fill and drain Ovemfght storage not practical
General Comments

Simple reliable low operating cost

Efficlency related to use prof 11 e and storage tank stratification

Provides maximum use of solar energy

Requires draindown valve

Requires pressure pump and control

Requires double wall heat exchangers for toxic heat transfer fluld Requires two pumps

Syatem rellab1l1ty, durab1lity and maintenance more readily predictable. Collector can be used elther with preheat tank or single tank with temperature gradient

Collector and piping sised and configured for low pressure drop to not impede natural fluid flow

The system is usually easily removed for maintenance Readily adaptable to retrof $1 t$ sites 


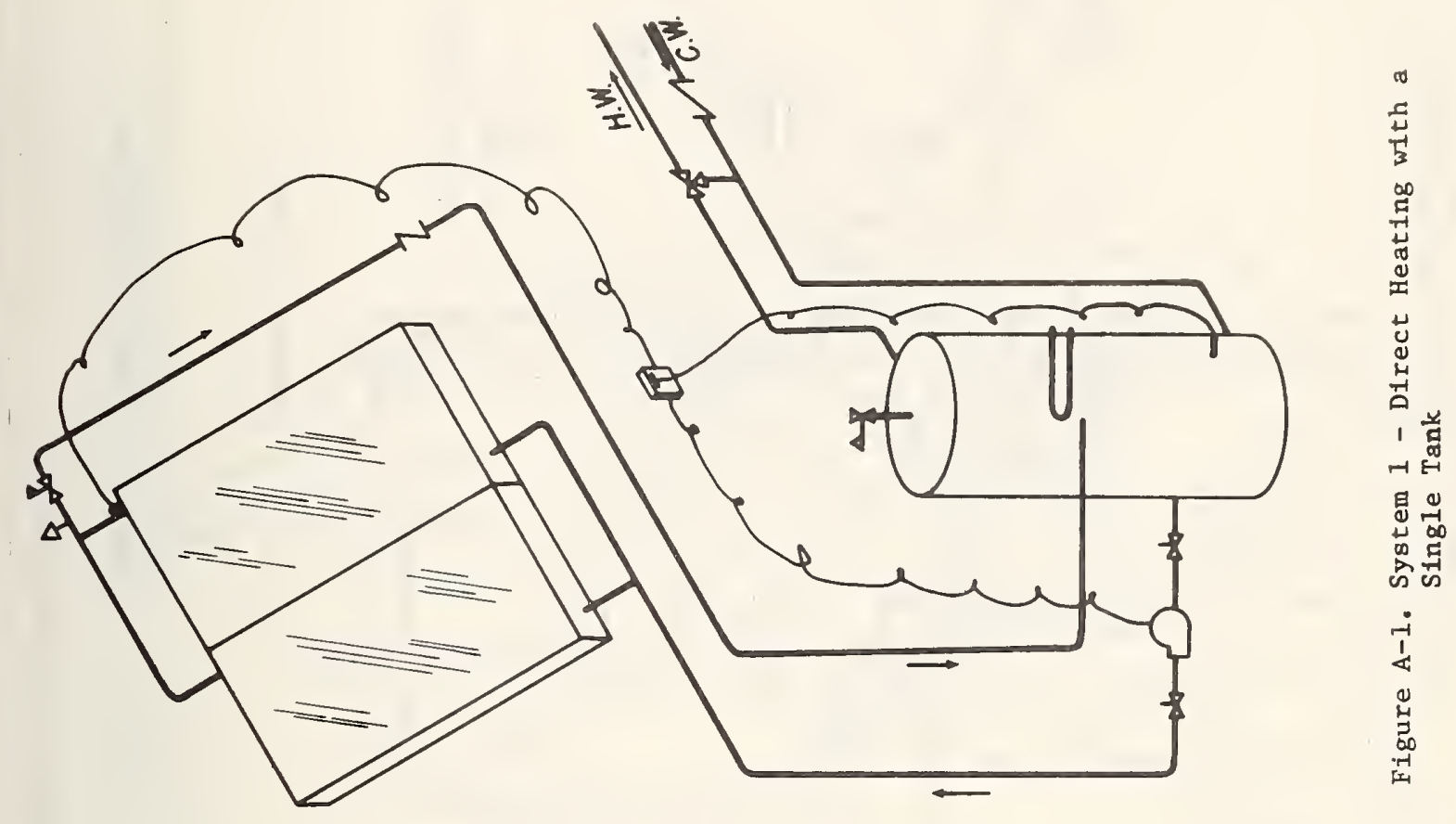

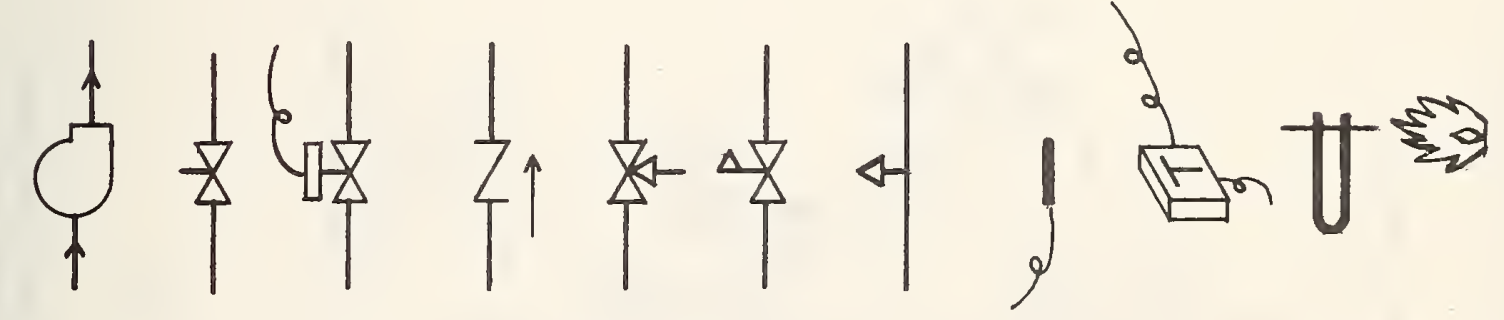

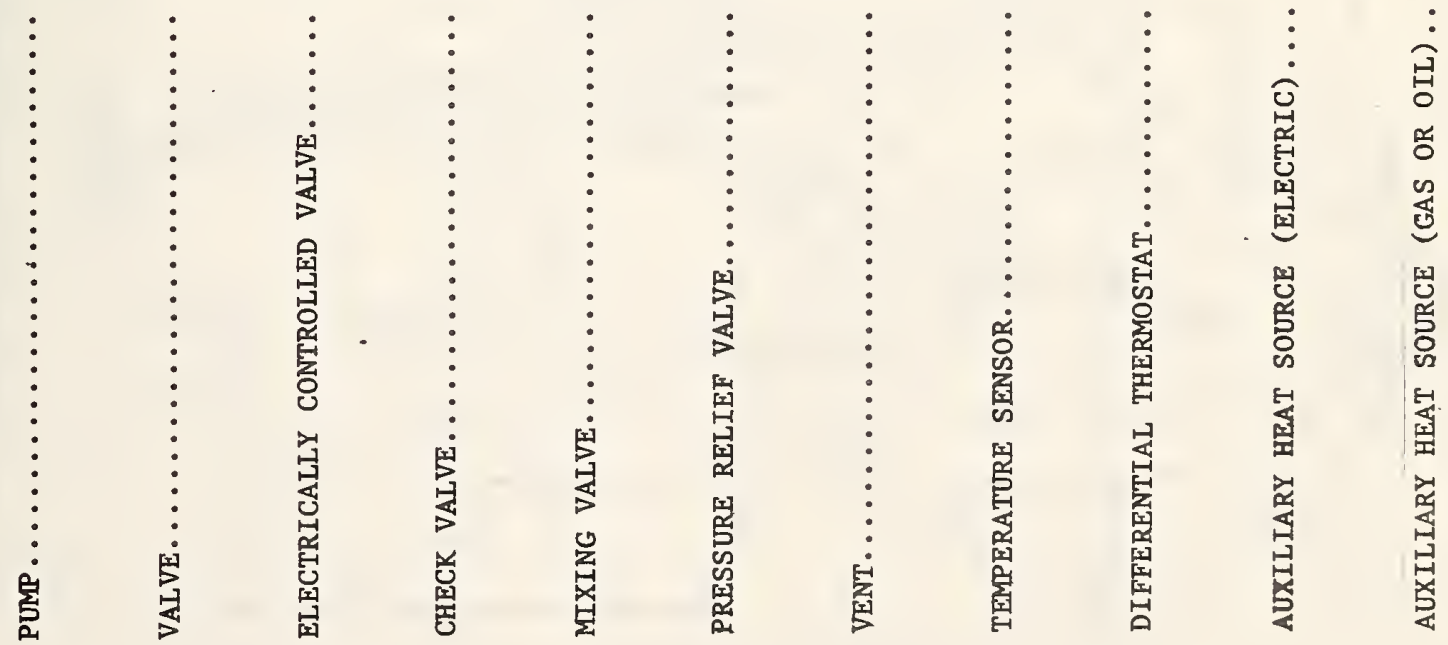




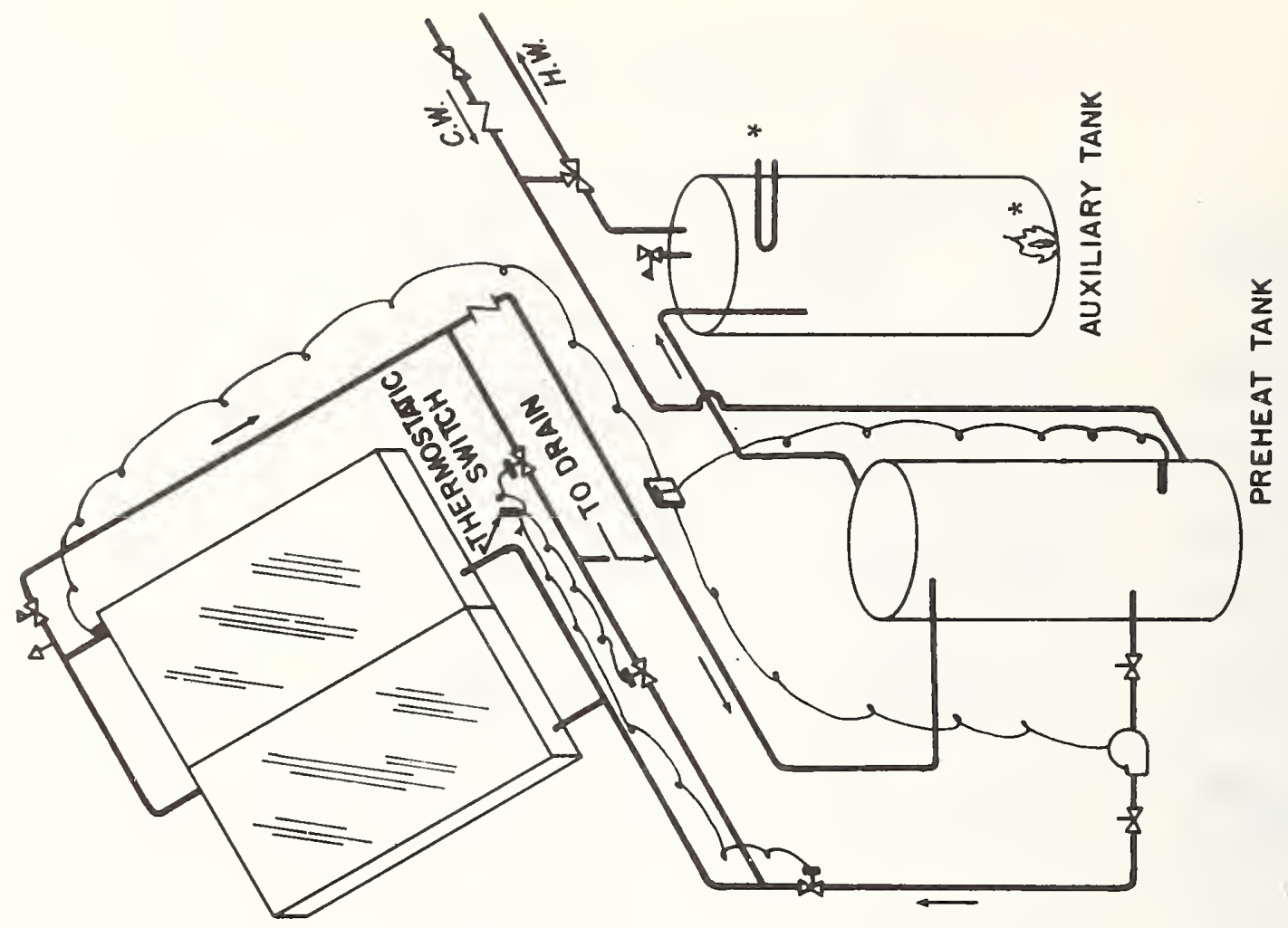



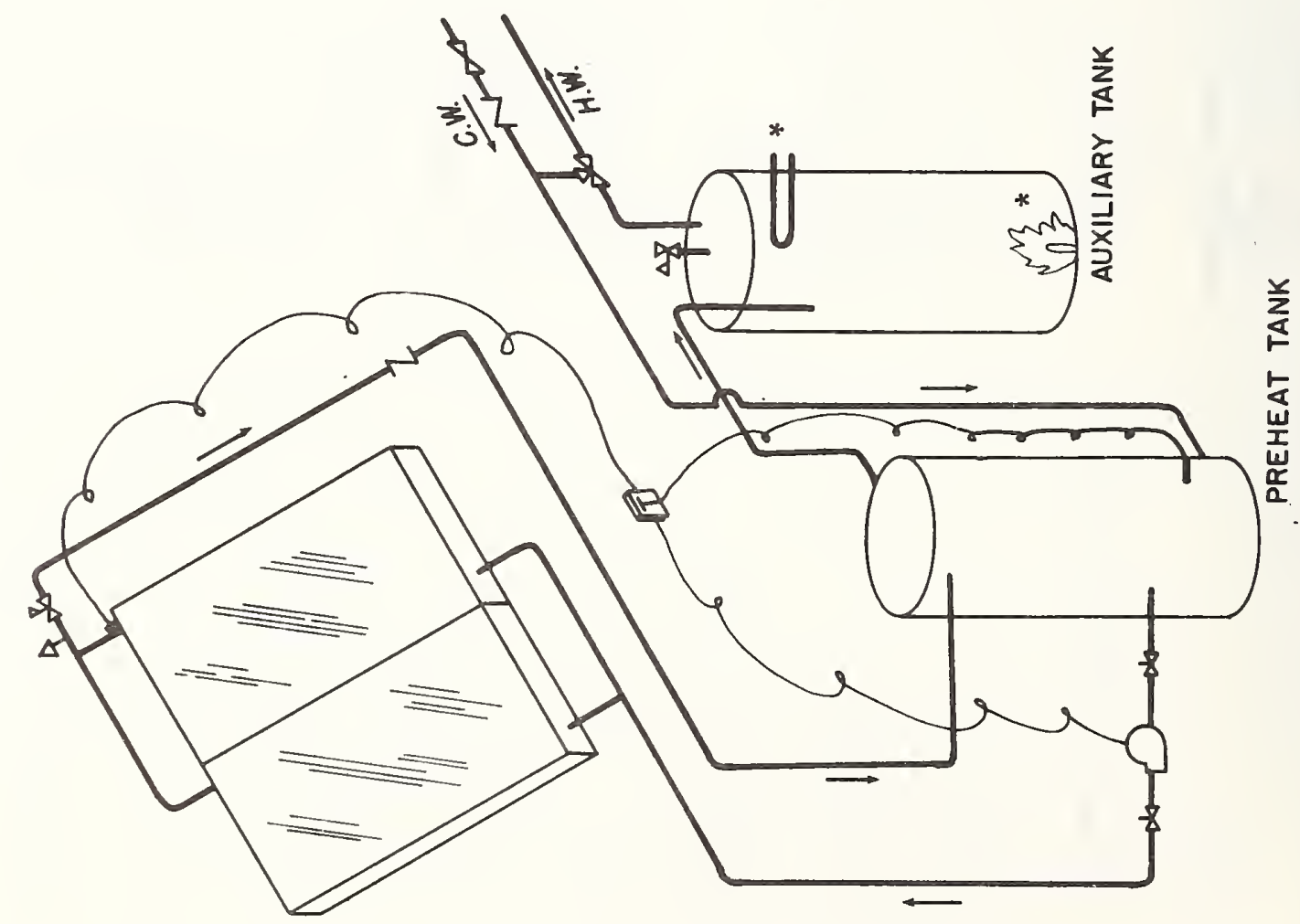

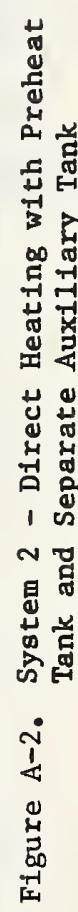




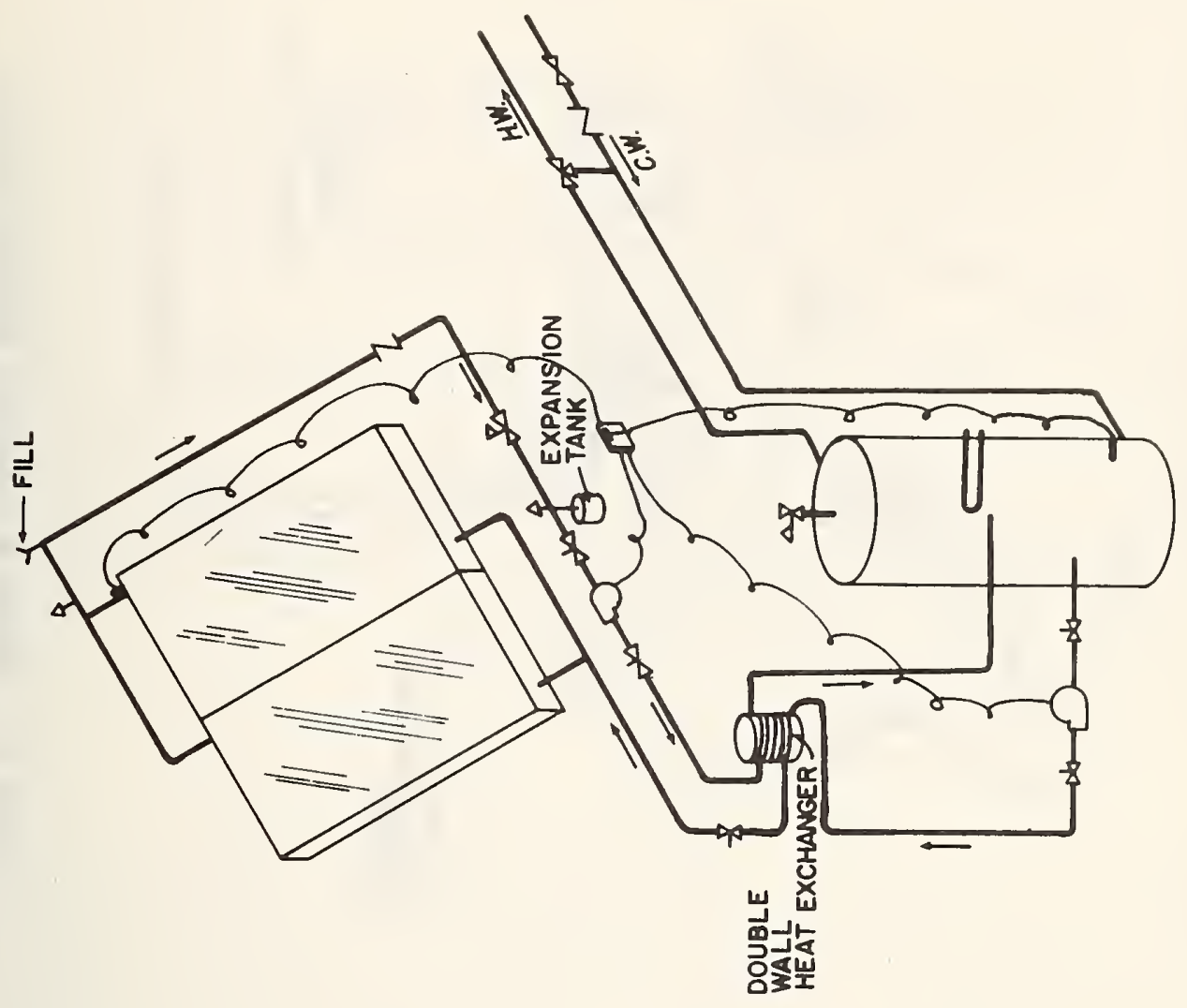

告

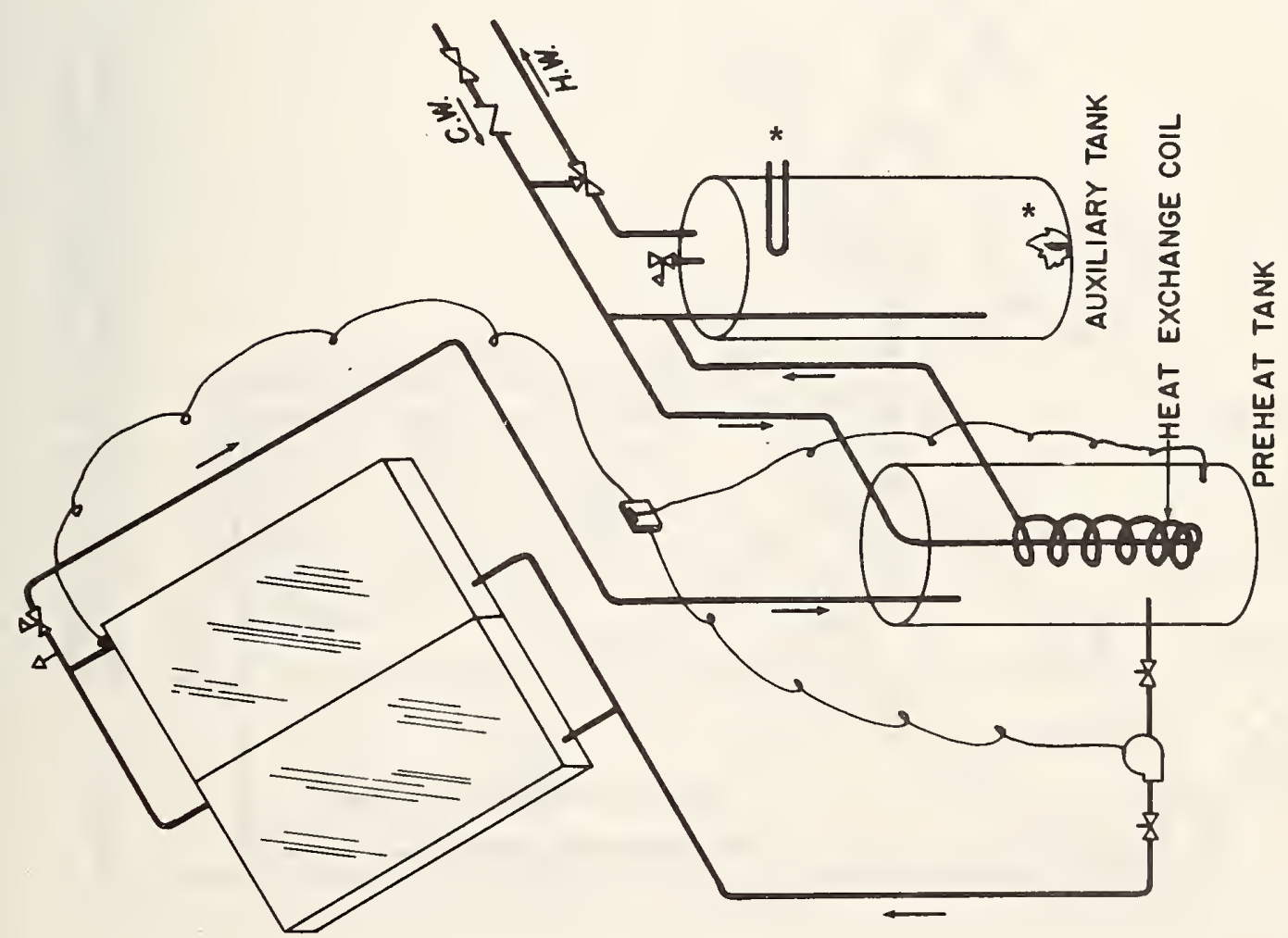

$\begin{array}{ll} & 0 \\ & \end{array}$ 

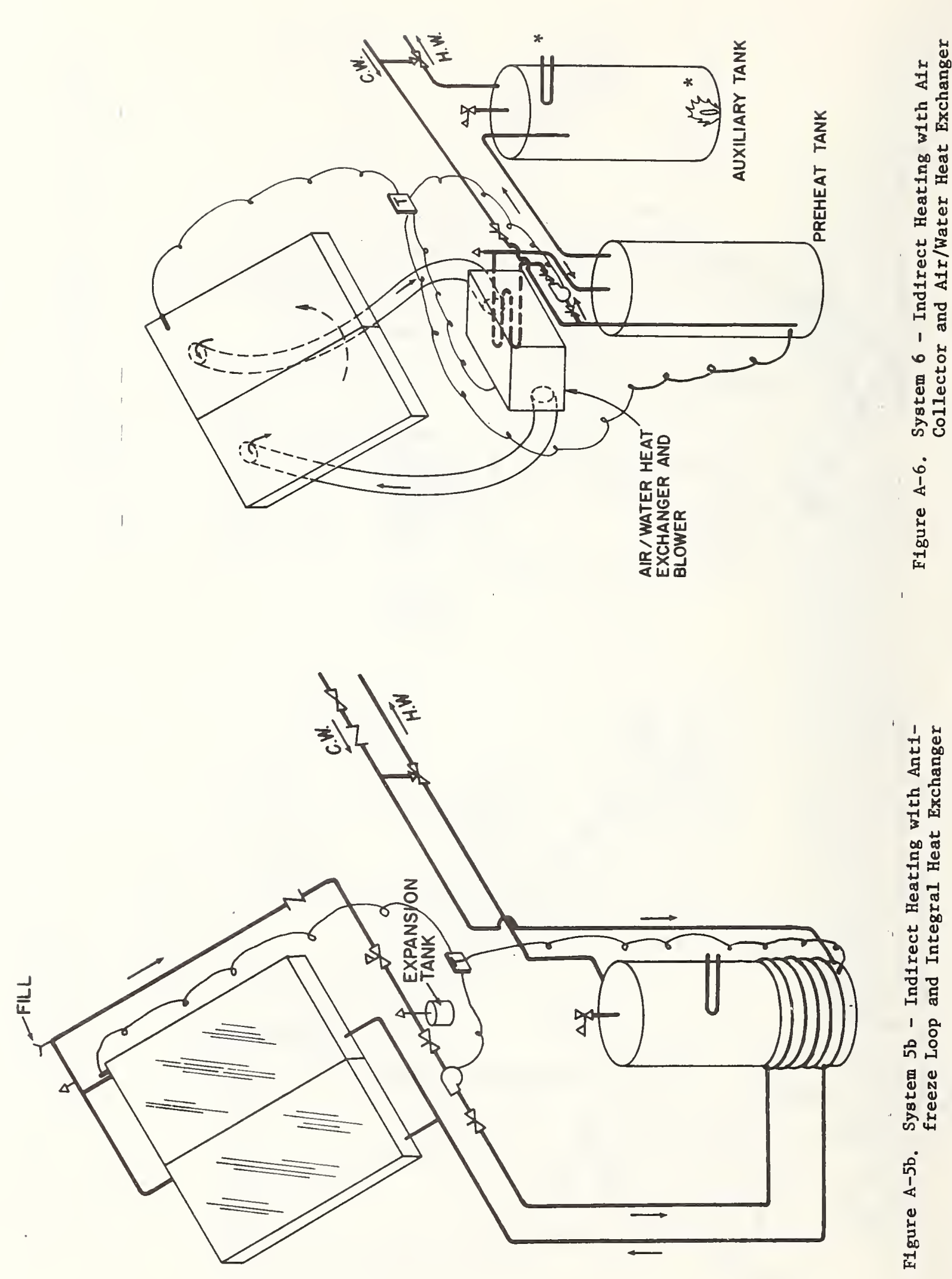

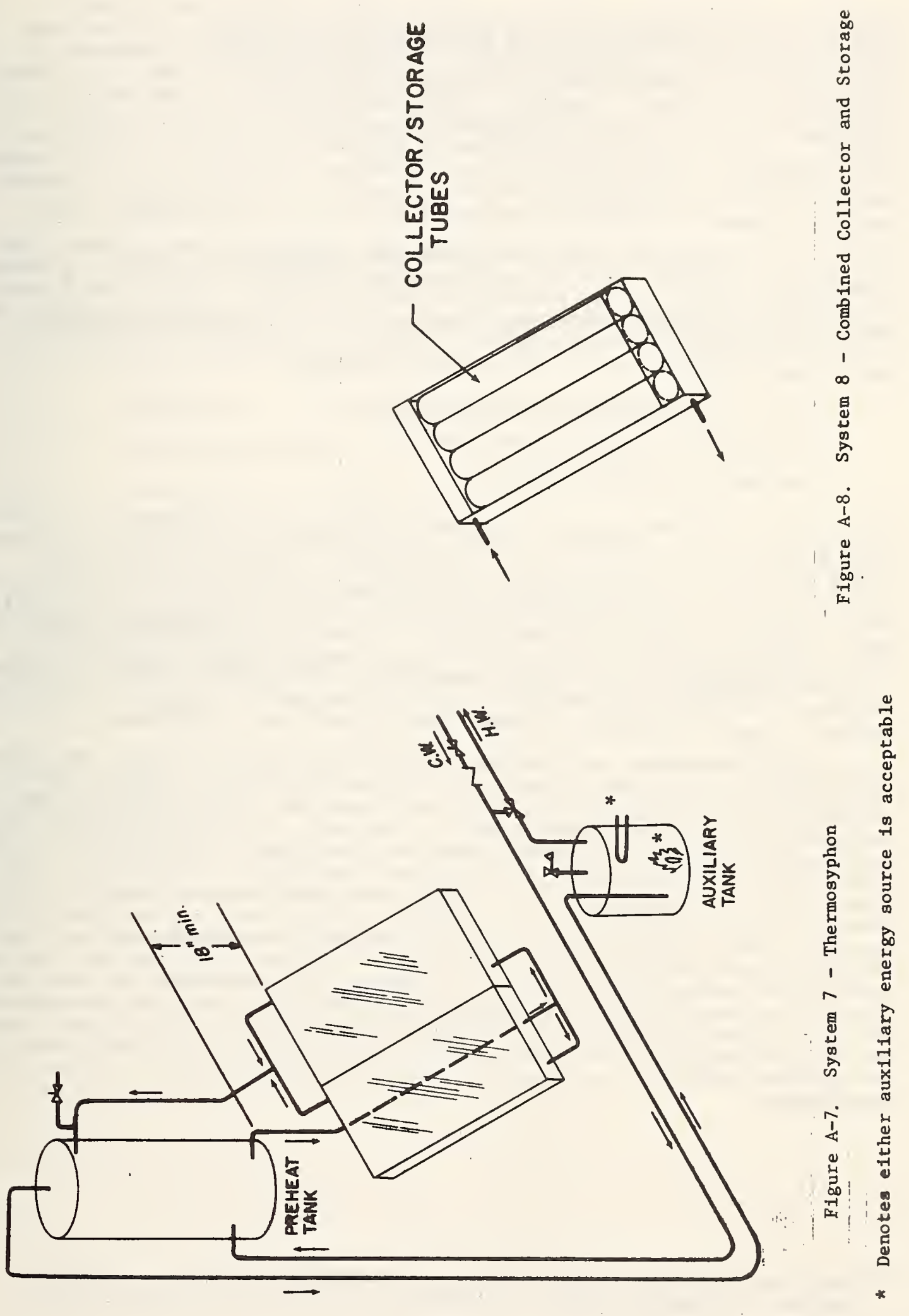
Figures A-1 to A-8 show a number of different system configurations available using solar energy to heat hot water for residential applications. of the eight system types described, simplified methods for predicting thermal performance are available only for those systems containing two storage tanks. These are defined as systems $2,3,4$, and 6 . Section 2.0 will describe the method for sizing solar collectors for these systems, based on the f-chart correlations of references [4] and [5]. However, since single tank active systems such as systems 1 and 5 are also available, some means of performance evaluation is required. Detailed computer simulations using the TRNSYS [7] code are available for these systems. At present, there are no general evaluation procedures available for systems 7 and 8 .

This section includes the results of the detailed computer studies of thermal performance of a reference solar DHW system located in Madison, Wisconsin using TRNSYS. The numerical results are applicable to the similar climatic region of New England, however, the qualitative results should be applicable for all climatic regions. The purpose of this study was to evaluate the effects on system thermal performance of the following design options for the storage subsystem:

- single tank vs. double tank configuration

- stratified vs. mixed tank performance

- nominal vs: improved insulation

The reference solar DHW system is described in Table A-4 and consisted of a direct heating system with a $41.4 \mathrm{sq}$. ft. flat plate, single glazed, non-selective collector facing south at a tilt angle equal to the latitude. The storage tank options considered include a single 80 gallon storage/auxiliary tank as shown in Figure A-1 and a double tank system comprised of an 80 gallon preheat and an 80 gallon auxiliary tank, as shown in Figures A-2 , A-3, and A-4.. The tank heat loss coefficients of 0.13 and $0.071 \mathrm{Btu} / \mathrm{hr}^{\circ} \mathrm{F} \mathrm{ft}{ }^{2}$ correspond to glass fiber insulation thicknesses of $11 / 2$ and 3 inches ( $R-7$ and $R-13) 1 /$ respectively. The hot water load of 70 gallons per day was assumed heated from $55^{\circ} \mathrm{F}$ to $140^{\circ} \mathrm{F}$. Tank ambient conditions of $60^{\circ} \mathrm{F}$ were assumed. Figure A-9 defines the hourly draw profile used for the study.

The results of the study for solar energy systems supplying about $50 \%$ of the energy requirements are summarized in Table A-5. The data represents a complete year's simulation. The results of runs $1 \mathrm{~A}, 1 \mathrm{~B}$, and $1 \mathrm{C}$ show the effect of reducing tank heat loss coefficient on system performance for a two tank, non-stratified system. Run IC represents a limiting case with no storage heat loss, runs $1 \mathrm{~B}$ and $1 \mathrm{~A}$ are for systems with 3 and $11 / 2^{\prime \prime}(R-13$ and $R-7)$ of insulation, respectively. Examination of the results for the storage tank with R-7 insulation (representative of current insulation levels in electric storage heaters) reveal that twice as much heat was lost from the auxiliary tank as from the preheat tank and that the tank heat loss was equivalent to $38 \%$ of the solar energy collected. Since many of the fossil fuel hot water systems installed in residences have even less insulation, the performance of a solar EHW system using existing poorly insulated storage tanks will be even more unsatisfactory. Two ways of improving the system performance are to increase the insulation thickness on each tank and, since the capacity of the auxiliary tank normally has little affect on collector efficiency, to reduce the size of the auxiliary tank, consistent with requirements.

$\underline{1}$ /Heat loss coefficient in $\mathrm{Btu} / \mathrm{h} \cdot{ }^{\circ} \mathrm{F} \cdot \mathrm{ft}^{2}=$ reciprocal of " $\mathrm{R}$ " value. Glass fiber insulation thickness is based on thermal conductivity of $0.25 \mathrm{Btu}-\mathrm{in} / \mathrm{h} \cdot{ }^{\circ} \mathrm{F} \cdot \mathrm{ft}$ for density of $1.51 \mathrm{~b} / \mathrm{ft}^{3}$. 
TABLE A-4

\section{DESCRIPTION OF REFERENCE SOLAR DHW SYSTEM}

\section{USED FOR DETAILED COMPUTER SIMULATIONS}

\section{IN MADISON WISCONSIN}

\section{SYSTEM DESCRIPTION}

- Direct Heating Type Circulating Potable Water in the Collector (Systems 1, 2, 3, and 4)

COLLECTOR DESCRIPTION (Flat Plate, Single Glazed, Non-selective)

- Area: $41.4 \mathrm{ft}^{2}$

- Orientation: $43^{\circ}$ Tilt (equal to latitude), $0^{\circ}$ Azimuth

- Cover Transmittance $=.90$

- Collector Plate Absorptance $=.95$

- Collector Loss Coefficlent $=1.207 \mathrm{Btu} / \mathrm{h} \cdot{ }^{\circ} \mathrm{F} \cdot \mathrm{ft}^{2}$

- Capacitance Rate $\left(C_{c} / A_{c}\right)=10.28 \mathrm{Btu} / \mathrm{h} \cdot{ }^{\circ} \mathrm{F} \cdot \mathrm{ft}^{2}{ }_{\mathrm{c}}$

STORAGE DESCRIPTION (E1ther One or Two Storage Tanks)

- Capacity: 80 Gallons each (20 in. diameter x 63 in. height)

- Stratification: Fully mixed or thermally stratified

- Heat Loss Coefficient: $U=0.13$ or 0.07 or 0 . Btu/h$\cdot{ }^{\circ} \mathrm{F} \cdot \mathrm{ft}^{2}$

\section{$\underline{\text { LOAD DESCRIPTION }}$}

- Dally Draw: 70 Gallons

- Draw Profile: Figure A-9

- Cold Water Temp: $55^{\circ} \mathrm{F}$

- Hot Water Temp: $140^{\circ} \mathrm{F}$ 


\begin{tabular}{|c|c|c|c|c|c|c|c|c|c|}
\hline & 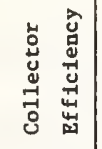 & $\begin{array}{l}5 \\
f\end{array}$ & \begin{tabular}{l}
$n$ \\
\hdashline \\
\hdashline
\end{tabular} & ?ู. & ஸे & స్ చి & m. & ?ี & 号 \\
\hline & 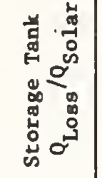 & ) & 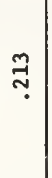 & $\begin{array}{l}1 \\
0\end{array}$ & $\stackrel{\vec{N}}{\mathrm{~N}}$ & $\stackrel{\infty}{\beth}$ & 草 & $\stackrel{\sim}{\dddot{m}}$ & $\tilde{o}$ \\
\hline 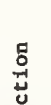 & 丞 & $\stackrel{\circ}{\rightarrow}$ & 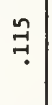 & $!$ & $\stackrel{\infty}{\because}$ & $\stackrel{\square}{\square}$ & $\stackrel{\circ}{?}$ & : & Oे. \\
\hline : & 离总 & 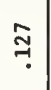 & $\stackrel{0}{0}$ & $!$ & 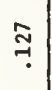 & $\tilde{o}$ & $\stackrel{\circ}{\dddot{7}}$ & ळ. & 守 \\
\hline $\begin{array}{l}\text { 总 } \\
\text { 㟧 }\end{array}$ & 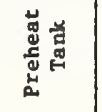 & ?. & $\ddot{\tilde{o ̂}}$ & $\begin{array}{l}1 \\
0\end{array}$ & $\tilde{a}$ & ัั & 1 & 1 & 1 \\
\hline \multicolumn{2}{|c|}{ 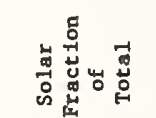 } & 8 & స్ & $\stackrel{\circ}{\circ}$ & ñ & $\mid \begin{array}{l}\infty \\
\overrightarrow{0} \\
0\end{array}$ & $\stackrel{\widetilde{్}}{\mathrm{f}}$ & : & 节 \\
\hline \multicolumn{2}{|c|}{ 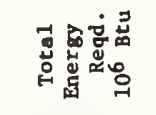 } & $\stackrel{\infty}{\stackrel{\sim}{\sim}}$ & $\begin{array}{l}\circ \\
\dot{-}\end{array}$ & $\begin{array}{l}\dot{a} \\
\dot{a} \\
\overrightarrow{7}\end{array}$ & $\underset{i}{\sim}$ & $\begin{array}{l}8 \\
\dot{2}\end{array}$ & $\begin{array}{l}\infty \\
\dot{i}\end{array}$ & $\begin{array}{l}3 \\
\vdots \\
-7\end{array}$ & $\begin{array}{l}0 \\
\infty \\
\infty \\
-1 \\
-1\end{array}$ \\
\hline \multirow{4}{*}{ 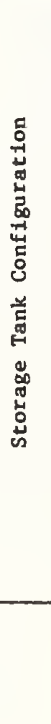 } & 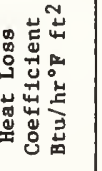 & ๆి & $\overrightarrow{0}$ & $\begin{array}{l}1 \\
0\end{array}$ & $\stackrel{\circ}{\because}$ & $\overrightarrow{0}$ & $\stackrel{\circ}{?}$ & $\stackrel{\circ}{?}$ & $\overrightarrow{\hat{o}}$ \\
\hline & 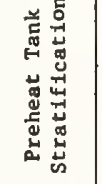 & 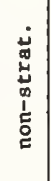 & 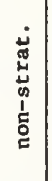 & 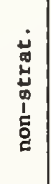 & 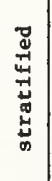 & 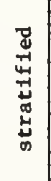 & 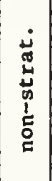 & 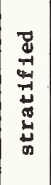 & 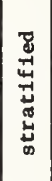 \\
\hline & 䔍 & $\sim$ & $\sim$ & $N$ & $\sim$ & $\sim$ & -1 & -7 & $r$ \\
\hline & $\begin{array}{l}\dot{8} \\
\stackrel{8}{8}\end{array}$ & $\mathbb{I}$ & 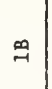 & $\underset{-1}{0}$ & 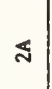 & $\mathscr{N}$ & ल & $m$ & u \\
\hline
\end{tabular}

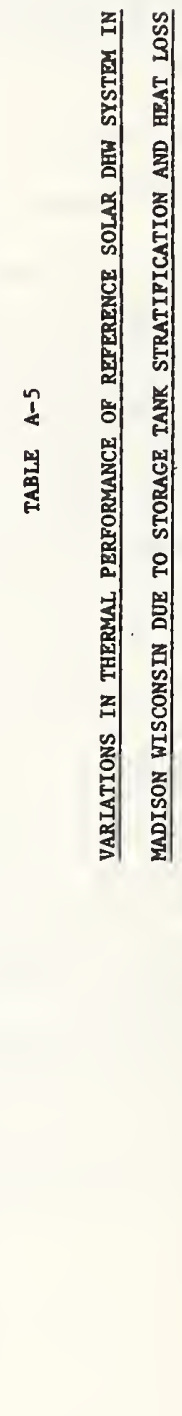


Runs $2 \mathrm{~A}$ and $2 \mathrm{~B}$ were simulations for a two tank system in which the preheat storage tank stratified, for $\mathrm{R}-7$ and $\mathrm{R}-13$ insulation, respectively. Similar to the results for the unstratified two tank system, increasing the tank insulation thickness increased the solar fraction of the load by reducing the heat loss. Note that in each case there was a slight reduction in collector efficiency with increased preheat tank insulation due to the increased water temperature in the better insulated tank. A comparison of runs $1 \mathrm{~A}$ with $2 \mathrm{~A}$ and $1 \mathrm{~B}$ with $2 \mathrm{~B}$ show the increase in performance due to stratification in the two tank system. The primary effect of stratification is to reduce the collector inlet temperature and thus increase collector efficiency; however, a slight reduction in preheat tank heat loss also occurs.

The major effects of stratification on system performance occur in the single tank systems. Examination of run $3 \mathrm{~A}$ reveals the extreme performance penalty resulting from non-stratified operation with a single tank system. In this system, the entire tank would be at the delivery temperature of $140^{\circ} \mathrm{F}$ which would make the collector operate very inefficiently. It is very probable that single tank systems using gas or oil for the auxiliary heat source would operate in this manner since these tanks are constructed with the energy input at the bottom of the tank and free convection circulation of the heated water would prevent stratification. The major improvement in single tank system performance occurs in run $3 B$ due to stratification and results in increased efficiency of the collector and reduced storage tank losses. It is anticipated that stratification will occur in single tank systems only when the auxiliary energy source is located in the upper portion of the tank, for example, with an electric hot water tank having, the lower heater element disconnected. Run $3 \mathrm{C}$ shows that a well insulated, single tank, stratified storage system will have the best overall performance in terms of the fraction of the total load provided by solar and minimum heat loss.

In summary, the storage tank design options can have a major impact on the thermal performance of a solar DHW system. In general, the best performance will occur in single tank, stratified systems that are well insulated, although two tank stratified systems with equivalent insulation thickness perform nearly as well. Since stratification is a phenomena that.may not occur even in single element electric storage tanks unless the piping connections are specifically located to promote stratification, it may be safer to use a two tank system where the lack of stratification does not result in as severe a performance penalty. If a one tank system is selected, the manufacturer should specify that stratification will occur in the tank for the range of operating conditions anticipated and present test data for verification. In two tank systems, the auxiliary tank should be kept as small as practical to reduce losses and in all systems adding insulation to all storage tanks to $R-13$ (the equivalent of 3 inches of fiberglass) provides considerable benefits.

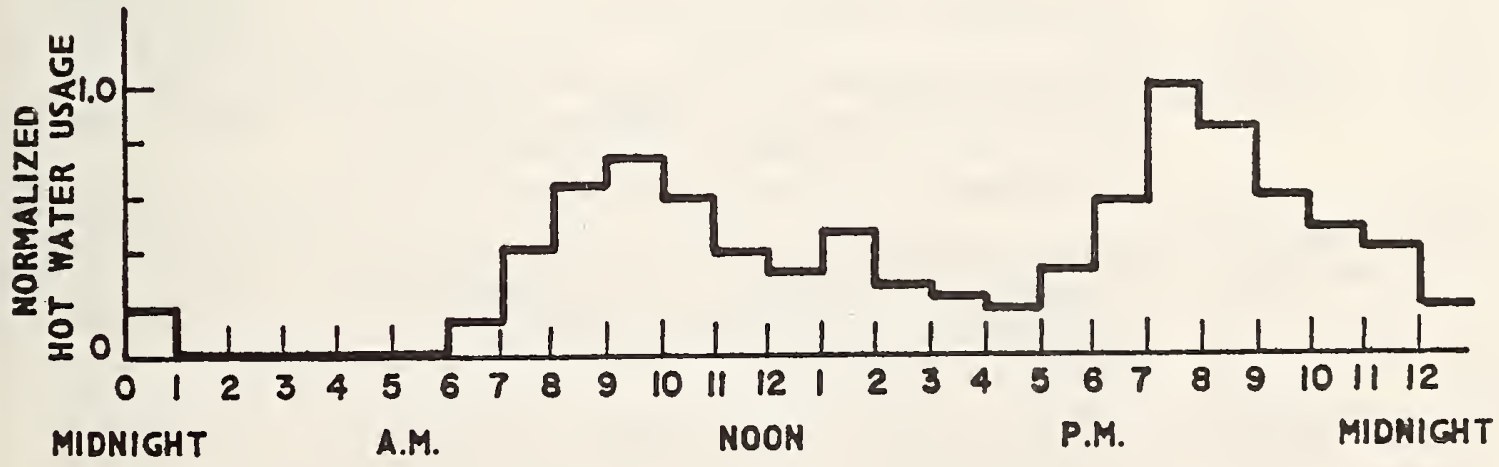

Figure A-9 Assumed Hourly Hot Water Consumption 


\subsection{SUMMARY OF THE PREDICTION METHOD}

In this prediction method, a determination is first made of the collector area required, Aref , to provide $50 \%$ of the domestic hot water load for a reference DHW system and load located in a selected city. If necessary, adjustments are then made to this collector area to account for the differences between the reference system and the actual system under consideration. The collector area modified by the adjustment multipliers gives the final minimum collector area required for the actual system, Areq.

\subsubsection{Description of the Reference System}

Reference system characteristics are described in Table A-6 and system configuration is shown in Figure $\mathrm{A}-2$ and $\mathrm{A}-3$.

\subsubsection{Systems Which Cannot be Analyzed}

The following systems described in section 1.2 cannot be evaluated by this method:

a. Single tank systems (Fig. A-1 and A-5), see section 1.3 for guidance

b. Thermosyphon systems (Fig. A-7), see reference [8] for guidance

c. Combined collector and storage (Fig. A-8)

\subsubsection{Steps in the Analysis Procedure}

a. Determine reference collector area (Aref) from Table A-7 for the city that most closely represents the project location. Further explanation is given in section 2.3.1.

b. Determine the appropriate representative city (MIAMI, TALLAHASSEE, ANIAPOLIS, or BOSTON) to be used in the adjustment analysis if adjustment is necessary. The climatic zones map, Figure A-11, may be useful in making this determination.

c. Adjustment to the reference system area (Aref) is done by multiplying the reference system collector area by the necessary adjustment factors as follows:

$$
\begin{aligned}
& A_{\text {req }} \approx A_{\text {ref }} \times\left(\frac{A}{A_{\text {ref }}}\right)_{c x} \times\left(\frac{A}{A_{\text {ref }}}\right)_{\mathrm{o}} \times\left(\frac{A}{A_{\text {ref }}}\right)_{S} \times\left(\frac{A}{A_{\text {ref }}}\right)_{t} \\
& \text { where: Areq = the required collector area } \\
& \text { Aref = the reference collector area } \\
& \left(\frac{A}{A_{\text {ref }}}\right)_{c x}=\begin{array}{l}
\text { the area adjustment factor due to collector } \\
\text { characteristics and heat exchanger modifier. }
\end{array} \\
& \text { This factor is determined from Figures A-12a } \\
& \text { to } A-15 a \text { and is described in section 2.3.2. } \\
& \left(\frac{A}{A_{\text {ref }}}\right)_{0}=\text { the area adjustment factor due to collector } \\
& \text { orientation. This factor is determined from } \\
& \text { Figures } A-12 b \text { to } A-15 b \text { and is described in } \\
& \text { section 2.3.3. } \\
& \left(\frac{A}{A_{\text {ref }}}\right)_{S}=\text { the area adjustment factor due to storage } \\
& \text { tank heat capacity. This factor is determined } \\
& \text { from Figure A-16 and is described in section } \\
& \text { 2.3.4. }
\end{aligned}
$$




$$
\begin{aligned}
& \left(\frac{A}{A_{\text {ref }}}\right)_{t}=\text { the area adjustment factor due to makeup water } \\
& \text { temperature. This factor is determined from } \\
& \text { Figure } \mathrm{A}-17 \text { and is described in section 2.3.5. }
\end{aligned}
$$

Adjustments for a single parameter variation factor give results that are in agreement with the "f-chart" simulation. Adjustments for multiple parameter variations give results that are within $10 \%$ of the results obtained by an "f-chart" simulation if small in magnitude (that is well within the range of the graphs). If large variations to the reference systems require evaluation, it is recommended that the "f-chart" simulation be employed using the actual system characteristics.

An example of the effect of multiple variations is given in section 2.3.6.

d. For systems employing single tanks or different levels of tank insulation, the factors presented in section 1.3 may assist in evaluation.

e. The actual collector area selected for installation should be the size offered by the manufacturer that meets or exceeds the size determined in the preceding steps a-d.

\section{BASIS OF THE PREDICTION METHOD}

The purpose of this prediction method is to provide an easy-to-use means of determining the approximate collector area required for an active solar domestic hot water (DHW) system that is capable of providing $50 \%$ of the annual energy used for hot water heating for a family of four. An analysis is presented for each of four cities that have been found to have climatic conditions representative of the eleven eastern states participating in the HUD/States Solar Hot Water Initiative Program.

This method for collector sizing is based on computer simulations of a reference solar domestic hot water system. These simulations are believed to provide reasonable system performance prediction but are as yet unvalidated. Until validation using actual systems operating in different climatic regions can be accomplished, this sizing method must be considered useful for guidance purposes only.

The performance of a solar assisted DHW system is usually characterized by the fraction of energy provided by solar of the total energy required both to heat a specified quantity of water from the cold water main temperature to the hot water delivery temperature and to replace the storage tank heat losses. This definition of performance does not include the additional energy requirements due to combustion inefficiency and stack loss for systems using fossil fuel auxiliaries nor does it include the additional energy required to operate the solar system pumps, blowers, controls, or freeze protection system. However, in any analysis of DHW system energy requirements, these energy components must be included.

The collector array area required for a desired performance level of most solar DHW systems is affected by the local climatic conditions, by the characteristics of the solar system, and the hot water load. Climatic factors affecting performance include the available solar radiation, the daytime ambient temperature, the water supply temperature, and to a limited extent, the wind. System characteristics affecting performance include the collector design, orientation, and shading, the method of providing freeze protection and the storage tank configuration (one or two tank system). System performance is particularly sensitive to such component characteristics as collector efficiency, heat exchanger effectiveness (for those systems employing antifreeze for freeze protection) and location and type of the auxiliary energy source and somewhat less sensitive to component characteristics such as storage tank capacity and heat loss. The hot water load characteristics affecting system performance include the dally usage profile, total draw of the system, and the water delivery temperature. 
In this analysis, an active solar DHW system is sized to provide $50 \%$ of the annual energy requirements to heat 70 gallons per day of hot water to a delivery temperature of $140^{\circ} \mathrm{F}$. The cold water main temperature, $t_{\mathrm{m}}$, is assumed constant at $70^{\circ} \mathrm{F}$ for the locations in Florida and $55^{\circ} \mathrm{F}$ for all other locations. The normalized draw profile shown in Figure A-9. is repeated every day. The collector array consists of a flat plate collector with no losses due to shading and with no augmentation due to added reflectors. The collector working fluid may be either air or liquid; however, the storage medium is assumed to be water.

A reference solar DHW system has been defined and its annual performance evaluated using the f-chart computer program for 26 locations in or near the eleven eastern states participating in the HUD/States Solar Hot Water Initiative. The results are shown plotted in Figure A-10 and summarized for $50 \%$ solar contribution in Table A-7. The collector area required for the reference solar DHW system for a $50 \%$ solar contribution is called the reference area ( $\mathrm{A}_{\mathrm{ref}}$ ) for that location. Based on these results, four cities are selected as being representative of the 26 locations. The effects of variations from the reference system have been examined using the f-chart computer program for each of the four cities. In another location, a detailed simulation has been performed using the TRNSYS computer program to evaluate system changes (tank stratification and tank insulation) that cannot be investigated using the f-chart program. These results are described in section 1.3.

The reference hot water system is shown in Figure A-3 and described in Table A-6. In the reference system, a flat plate collector with single glazing and flat black absorber coating is mounted at a tilt angle equal to the latitude and at an azimuth angle of zero (due south). Storage capacity is 1.9 gal. per sq. ft. of collector. In this system, water is circulated directly between the preheat storage tank and collector without any intermediate heat exchanger. This arrangement is called a single loop system and is typical of the draindown type of solar water heaters. In the f-chart code, the preheat tank is assumed fully mixed (unstratified) and assumed to have an equivalent R-13 insulation level. The auxiliary tank is assumed to be an in-line heater with no storage capacity or heat loss. Water is circulated between the collector and preheat storage tank whenever useful thermal energy can be extracted from the solar collector. Whenever there is a draw of hot water from the system, hot water is withdrawn from the auxiliary storage tank and is replaced by solar heated water from the top of the preheat storage tank. This water is in turn replaced by cold makeup water supplied to the bottom of the preheat storage tank. Conventional energy is added to the auxiliary storage tank by combustion of gas or oil or by electric immersion heaters to maintain the temperature of the water in this tank at the prescribed setting of $140^{\circ} \mathrm{F}$.

\subsection{PROCEDURE}

\subsubsection{Selection of the Reference Collector Area, Aref}

The collector area for the reference system ( $A_{\text {ref }}$ ) located at the project site is first selected. Table A-7 lists the collector area required for the reference solar DHW system to provide $50 \%$ of the hot water energy in 26 locations in or near the program area. Emphasized are the four representative locations used in the modification analysis. Figure A-10 may be used if contributions other than $50 \%$ are to be evaluated. The climatic region map, Figure A-11, is included to assist in selecting the most appropriate representative location for a particular system evaluation at a profect site. Information is provided in the following section to adjust the reference system collector area for the following variations.

- modification of the system to a double loop system with energy transfer from the collector loop to the storage loop via a heat exchanger

- selection of a solar collector having different efficlency characteristics $\left(F_{R}(\tau \alpha)_{\eta}\right.$ and $\left.F_{R} U_{L}\right)$ than the reference collector

- orlentation of the collector at a tilt angle and azimuth angle other than the reference system (tilt angle $=$ latitude, azim angle $=0^{\circ}$ ) 
- cold water inlet temperature different than $70^{\circ} \mathrm{F}$ in Florida and $55^{\circ} \mathrm{F}$ elsewhere.

.3.2 Adjustments to Reference System Collector Area Due to Collector Characteristics and/or Heat Exchanger Modifiers

The reference solar DHW system utilizes a single glazed flat plate collector array with a non-selective black paint absorber coating. The reference system is a draindown type consisting of a single loop for energy transport between the collector and preheat storage tank, therefore, no heat exchanger is required.

The collector area requirements for any combination of collector characteristics and heat exchanger modifiers can be determined by multiplying the reference area for that location by the corresponding (A/Aref) $\mathrm{cx}$ for that location and system.

The performance characteristics of a particular flat plate collector are usually determined experimentally using the ASHRAE 93-77 test procedure (Ref 1). These characteristics consist of the intercept factor $F_{R}(\tau \alpha)$ and the slope factor $F_{R} U_{L}$. The reference collector for this study has values ${ }^{\text {for }}$ the intercept and slope Tactors, respectively, of 0.85 and $1.20 \mathrm{Btu} / \mathrm{hr} \cdot{ }^{\circ} \mathrm{F} \cdot \mathrm{ft}^{2}$. These values were reported by the NASA-Lewis Research Center (Ref 2), for a test collector similar to a commercially available single glazed non-selective collector developed under a government contract. The effect of applying a double glazing or selective coating to a collector is usually to reduce both the intercept and slope factors in some predictable manner; however, other factors such as the construction of the collector absorber plate (i.e., tube spacing, absorber plate thickness and thermal conductivity, tube-to-plate joint conductance), the forced convection transfer coefficient between the transport fluid and tube wall and the rear surface conductance all combine to yield significant variations in performance between different collectors of the same generic type. Therefore, it is important to have measured efficiency data for the particular collector selected in the range of operating conditions anticipated for the solar DHW system.

Many solar DHW systems are designed with a double loop energy transport system with either a non-freezing liquid or air circulated through the collector and with potable water used as the energy storage medium. In these systems, a heat exchanger is required to transfer the energy from the collector loop to the storage tank. The performance penalties associated with this heat exchanger can be determined by the heat exchanger modifier given by the following equation:

$$
\begin{aligned}
& \frac{\mathrm{F}_{\mathrm{R}}^{\prime}}{\mathrm{F}_{\mathrm{R}}}=\left\{1+\frac{\mathrm{F}_{\mathrm{R}} \mathrm{U}_{L^{\mathrm{A}} \mathrm{c}}}{\left(\dot{\mathrm{m}}_{\mathrm{p}}\right)_{\mathrm{c}}}\left[\frac{\left(\dot{\mathrm{m}}_{\mathrm{p}}\right)_{\mathrm{c}}}{\varepsilon_{\mathrm{HX}}\left(\dot{\mathrm{m}}_{\mathrm{p}}\right)_{\mathrm{min}}}-1\right]\right\}^{-1} \\
& \left(\dot{\mathrm{m}}_{\mathrm{p}}\right)_{\min }=\text { minimum }\left(\left(\dot{\mathrm{m}}_{\mathrm{p}}\right)_{\mathrm{c}} \text { or }\left(\dot{\mathrm{m}}_{\mathrm{p}}\right)_{\mathrm{s}}\right)
\end{aligned}
$$

where: (mic $\left.{ }_{p}\right)_{c}$ is the product of the collector loop mass flow rate and fluid specific heat $\left(\mathrm{Btu} / \mathrm{h} \cdot{ }^{\circ} \mathrm{F}\right)$;

(íc $)_{p}$ is the product of the storage loop mass flow rate and fluid specific heat $\left(\mathrm{Btu} / \mathrm{h} \cdot{ }^{\circ} \mathrm{F}\right)$;

$\mathrm{F}_{\mathrm{R}} \mathrm{U}_{\mathrm{L}}$ is the experimentally measured collector slope factor $\left(\mathrm{Btu} / \mathrm{h} \cdot{ }^{\circ} \mathrm{F} \cdot \mathrm{ft}^{2}\right.$ ) $A_{C}$ Is the collector array effective area $\left(\mathrm{ft}^{2}\right)$;

$\varepsilon_{\mathrm{HX}}$ is the heat exchanger effectiveness.

Single loop systems without a heat exchanger have a heat exchanger modifier $\mathrm{F}_{\mathrm{R}}^{\prime} / \mathrm{F}_{\mathrm{R}}=1.0$. The above expression is also valid for a single loop system having ${ }_{a} R_{h}$ heat exchanger located within the preheat storage. In this case, $\left(\dot{\mathrm{m}} \mathrm{c}_{\mathrm{p}}\right)_{\min }=\left(\dot{\mathrm{m}} \mathrm{c}_{\mathrm{p}}\right)_{\mathrm{c}}$ and the numerical value for the heat exchanger effectiveness $\varepsilon_{\mathrm{HX}}$ must be based on free convection heat transfer between the heat exchanger surface and the fluid in the tank. 
It is desirable to be able to relate the performance of a solar DHW system having any collector performance characteristic and heat exchanger modifier to the performance of the reference system. In the f-chart methodology, the collector efficiency characteristics and the collector heat exchanger modifier are combined into two modified parameters.

The modified intercept factor is given by:

$$
\mathrm{F}_{\mathrm{R}}^{\prime}(\tau \alpha)_{\mathrm{n}}=\frac{\mathrm{F}_{\mathrm{R}}^{\prime}}{\mathrm{F}_{\mathrm{R}}} \times \mathrm{F}_{\mathrm{R}}(\tau \alpha)_{\mathrm{n}}
$$

The modified slope factor is given by:

$$
\mathrm{F}_{\mathrm{R}}^{\prime} \mathrm{U}_{\mathrm{L}}=\frac{\mathrm{F}_{\mathrm{R}}^{\prime}}{\mathrm{F}_{\mathrm{R}}} \times \mathrm{F}_{\mathrm{R}} \mathrm{U}_{\mathrm{L}}
$$

The use of the collector sizing information presented in this section requires specific values for the collector parameters $F_{R}(\tau \alpha)_{n}$ and $F_{R} U_{L}$ and for the heat exchanger effectiveness $\varepsilon_{\mathrm{HX}}$ so that $\mathrm{F}_{\mathrm{R}} / \mathrm{F}_{\mathrm{R}}$ can be computed using the equation on the previous page. Collector manufacturers using the ASHRAE 93-77 collector test standard report efficiency as a function of the parameter inlet fluid temperature minus ambient temperature divided by insolation; however, some manufacturers report efficiency data using either outlet fluid temperature or average fluid temperature. Since the f-chart procedure utilizes collector parameters based on a plot using collector inlet fluid temperature, it is necessary to convert those manufacturers' test data to equivalent data using inlet temperature conditions, otherwise errors in collector sizing can occur. For purposes of illustrating this procedure, section 3.1 is provided. That section first describes the required data and calculation procedure to convert collector efficiency data to an inlet fluid temperature basis, and then illustrates the calculation of the modified collector characteristics $F_{R}^{\prime}(\tau \alpha)_{n}$ and $F_{R}^{\prime} U_{L}$ for the double loop system containing a heat exchanger.

The required heat exchanger performance parameter "effectiveness" is frequently not stated in heat exchanger manufacturers' catalogs. To facilitate calculation of this parameter, section 3.2 describes several methods of calculating effectiveness depending on the method used by the heat exchanger manufacturer to present performance data. In addition, that section provides a method for estimating heat exchanger effectiveness if no performance data are available.

In this analysis, the f-chart computer program was run for the reference solar DHW system and the required collector area was determined for a system providing $50 \%$ solar for various combinations of the modified collector characteristics $F_{R}^{\prime}(\tau \alpha)_{n}$ and $\mathrm{F}_{\mathrm{R}}^{\prime} \mathrm{U}_{\mathrm{L}}$. The results are shown plotted for the locations characterized by the cities of MIAMI, TALLAHASSEE, ANNAPOLIS, and BOSTON in Figures A-12a to A-15a respectively, in terms of the ratio of collector area required to reference area $\left(A / A_{r e f}\right)_{c x}$. These curves may also be used for comparative performance and economic analysis of different combinations of collector design and heat exchanger performance.1/

1/ These curves lend themselves to use in economic studies in which collector area can be traded against heat exchanger area, since as the heat exchanger effectiveness decreases (due to decreasing heat exchanger area) the required collector area increases. This study is done by first plotting a point corresponding to the unmodified collector characteristics $F_{R}(\tau \alpha)_{n}$ and $F_{R} U_{L}$ on the curve for the appropriate city and noting the corresponding $A / A_{r e f}$. Since the same heat exchanger modifier $\mathrm{F}_{\mathrm{R}}^{\prime} / \mathrm{F}_{\mathrm{R}}$ multiplies the $\mathrm{F}_{\mathrm{R}}(\tau \alpha)$ and $\mathrm{F}_{\mathrm{R}} \mathrm{U}_{\mathrm{L}}$ factors, the collector/heat exchanger combination would plot as a straight line passing through the previously plotted point and having a slope of unity. The intersection of this line with the various contours of $\mathrm{A} / \mathrm{A}_{\text {ref }}$ would give the required relationship between collector area and heat exchanger modifier $\mathrm{F}_{\mathrm{R}}^{\prime} / \mathrm{F}_{\mathrm{R}}$. Since most heat exchanger manufacturers offer a family of heat exchangers of the same basic design but differing in size, a range of effectiveness vs. size can be determined and the $F_{R}^{\prime} / F_{R}$ evaluated for each increment in size thereby establishing the collector area required for each size heat exchanger. Finally, knowing the collector cost per unit area and heat exchanger costs for each size, the minimum cost combination of collector area and heat exchanger can readily be determined. 
The optimum orientation of a collector for a solar DHW system is facing due south (azimuth $=0^{\circ}$ ) with tilt angle equal to the latitude at that particular location. Frequently, optimum orientation of the collector is not possible, particularly when retrofitting a solar system to an existing building where it may be desired to take advantage of an existing roof slope or to avoid shading by an adjacent structure or tree. Therefore, the f-chart program has been run for the reference solar DHW system and the required collector area determined for a system providing $50 \%$ solar for various combinations of tilt angle and azimuth angle. The f-chart methodology does not consider the difference between east facing and west facing collectors; therefore, at locations having strongly anti-symmetric solar radiation patterns with respect to solar noon, the results are not valid and the system designer should orient the collector to take maximum advantage of the local climatic conditions.

The area requirements for various collector tilt and azimuth angles are shown plotted for the locations characterized by the cities of MIAMI, TALIAHASSEE, ANNAPOLIS, and BOSTON in Figure $\mathrm{A}-12 \mathrm{~b}$ to $\mathrm{A}-15 \mathrm{~b}$ respectively, in terms of the ratio of required collecto area to reference system collector area (area at optimum tilt and azimuth angles). Examination of these figures shows a substantial variation in collector area penalty due to non-optimum orientation in the different climatic regions investigated. For example, in the Southern Florida region for collectors tilted at $35^{\circ}$ or less, the area penalties will not exceed $20 \%$ for any collector azimuth up to $90^{\circ}$. In contrast to the South Florida region, in New England for collectors tilted within $20^{\circ}$ of optimum, the maximum azimuth angle is $40^{\circ}$ to limit area penalty to $20 \%$.

2.3.4 Adjustments to Reference System Collector Area Due to Preheat Storage Tank Heat Capacity

The reference system performance is based on an assumed preheat storage tank thermal capacitance of $15 \mathrm{Btu} /{ }^{\circ} \mathrm{F} \cdot \mathrm{ft}^{2}{ }_{\mathrm{c}}$ (approximately $1.9 \mathrm{Gal} / \mathrm{ft}^{2}{ }_{\mathrm{c}}$ ). The variation in required collector area for a $50 \%$ solar contribution with preheat storage tank capacity is shown in Figure A-16 for the four representative climatic regions. Note that although Figure A-16 shows that increasing the storage tank size increases system performance (the effect being more noticeable in colder climatic regions), in reality at some value of storage tank capacity, the increase in tank heat loss will offset the gain due to increased storage capacity and the net performance will diminish. Unfortunately, the f-chart computer program is based on a hot water storage tank having an unusually low heat loss rate in comparison with commercially available storage tanks and, therefore, the optimum storage tank capacity cannot be evaluated.

2.3.5 Adjustment to Reference System Collector Area Due to Variations in Cold Water Makeup Temperature

The reference system performance is based on a constant value of $70^{\circ} \mathrm{F}$ water supply temperature in Florida and $55^{\circ} \mathrm{F}$ elsewhere. Figures $\mathrm{A}-17 \mathrm{a}$ and $\mathrm{A}-17 \mathrm{~b}$ show the variation in required collector area due to variations in water supply temperature for the reference solar DHW system that provides $50 \%$ of the energy requirement. Examination of these results suggest that in Florida, a colder water main temperature increases the collector area requirements while the opposite is true in the New England region and there is virtually no effect in the Mid-Atlantic region. Since the analysis assumed a constant daily draw of 70 gallons and a fixed delivery temperature of $140^{\circ} \mathrm{F}$, the effect of reducing the water supply inlet temperature is to increase the total energy required and this would imply that more collector area is required for a specified annual performance. Since the analysis results show this trend only for the Florida region, there appears to be an offsetting influence related to climatic region. A possible explanation is that with colder water supply temperature in a colder climatic region, the increase in collected energy (due to higher collector efficiency as a result of lower water main supply temperature) is greater than the increased load and a given system will perform better (i.e. a system with a fixed collector area will provide an increased solar fraction of the load). 


\subsubsection{Example Problem}

Determine the collector area required for a solar DHW system providing $50 \%$ of the annual hot water energy requirement for a family of four located in LYNN, Massachusetts (latitude $=42^{\circ}$ ) based on the following system schematic and design parameters:

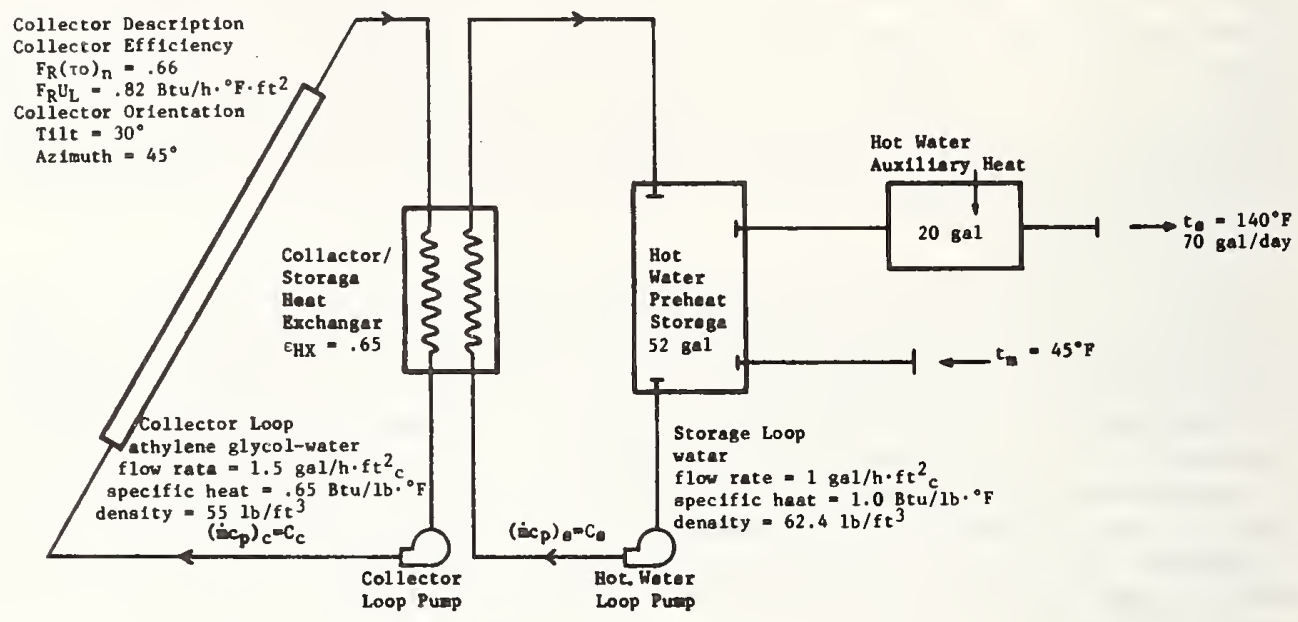

Comparison of the specifled design parameters with the reference system design parameters tabulated in Table A-6 indicate area correction factors are required for the modified collector efficiency characteristics, collector orientation, cold water makeup temperature, and possibly, for preheat storage capacity. As stated previously, the area correction factors were developed specifically for single parameter variations from the reference system. However, since it is desired to evaluate systems with more than one parameter differing from the reference system, the following method gives reasonable results based on the limited number of cases that have been checked.

From Table A-7, the reference system collector area requirement in LYNN is $51.0 \mathrm{sq}$. $\mathrm{ft}$. and from Figure A-11 the regional city representative of LYNN is BOSTON. The collector area correction factors are calculated using the data from BOSTON as follows:

a. Modified Collector Efficiency (A/A ref $)_{C X}$

The collector loop capacitance rate per unit collector area is determined for the specified volumetric flow rate and properties of the glycol-water mixture as follows:

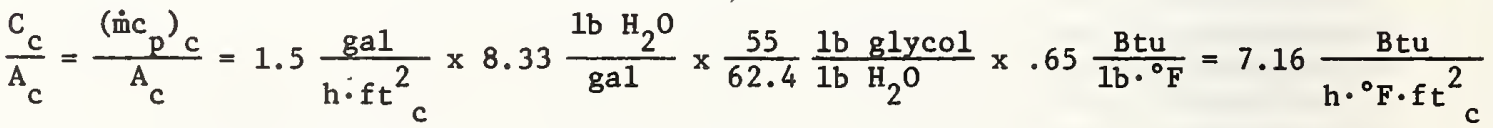

The storage loop capacitance is determined as:

$\frac{\mathrm{C}_{s}}{\mathrm{~A}_{\mathrm{c}}}=\frac{\left({ }_{\mathrm{m}} \mathrm{p}_{\mathrm{p}}{ }^{\prime} s\right.}{\mathrm{A}_{\mathrm{c}}}=1.0 \frac{\mathrm{gal}}{\mathrm{h} \cdot \mathrm{ft}^{2}{ }_{\mathrm{c}}} \times 8.33 \frac{1 \mathrm{~b}}{\mathrm{gal}} \times 1.0 \frac{\mathrm{Btu}}{1 \mathrm{~b} \cdot{ }^{\circ} \mathrm{F}}=8.33 \frac{\mathrm{Btu}}{\mathrm{h} \cdot{ }^{9} \mathrm{~F} \cdot \mathrm{ft}^{2} \mathrm{c}}$

The heat exchanger modifier factor $F_{R}^{\prime} / F_{R}$ is calculated using the following:

$\frac{\mathrm{F}_{\mathrm{R}}^{\prime}}{\mathrm{F}_{\mathrm{R}}}=\frac{1}{1+\frac{{ }_{{ }_{C} \mathrm{~F}_{\mathrm{R}} \mathrm{U}_{L}}}{\mathrm{C}_{\mathrm{C}}}\left(\frac{\mathrm{C}_{\mathrm{c}}}{\varepsilon_{\mathrm{HX}} \mathrm{C}_{\min }}-1\right)}$ 
substituting the specified values of $F_{R} U_{L}, \varepsilon_{H X}$ and $C_{c} / A_{c}$ and recognizing that $\mathrm{C}_{\mathrm{min}}=\mathrm{C}_{\mathrm{c}}$,yields

$\frac{F_{R}^{\prime}}{F_{R}}=\frac{1}{1+\frac{.82}{7.16}\left(\frac{1}{.65}-1\right)}=.94$

$F_{R}^{\prime}(\tau \alpha)_{n}=(.94)(.66)=.62$

$\mathrm{F}_{\mathrm{R}}^{\prime} \mathrm{U}_{\mathrm{L}}=(.94)(.82)=.77$

From Figure A-15a for BOSTON, the modified collector efficiency factor is:

$\left(\mathrm{A} / \mathrm{A}_{\text {ref }}\right)_{\mathrm{CX}}=1.25$

b. Collector Orientation Factor (A/Aref) O

The collector orientation factor is obtained from Figure A-15b for BOSTON by entering the figure at the specified tilt angle of $30^{\circ}$ and azimuth angle of $45^{\circ}$ :

$\left(\mathrm{A} \mathrm{A}_{\text {ref }}\right)_{0}=1.10$

c. Gold Water Makeup Temperature Factor $\left(A / A_{r e f}\right)_{t}$

Figure A-17 gives the area correction factor for BOSTON for a cold water inlet of temperature of $45^{\circ} \mathrm{F}$ as:

$\left(\mathrm{A} / \mathrm{A}_{\text {ref }}\right)_{t}=.97$

d. Storage Tank Capacity Factor $\left(\mathrm{A} / \mathrm{A}_{\text {ref }}\right)_{\mathrm{S}}$

Since the design parameters stated fix the preheat storage tank at 52 gallons and the storage capacitance factors are given relative to a collector area which is yet unknown, an iterative solution is required.

As a trial solution, calculate the collector area based on the previously calculated adjustment factors for collector modified efficiency, orientation and cold water temperature as follows:

$\underline{\text { Trial } 1}$

$A_{\text {req }}=A_{\text {ref }} \times\left(\frac{A}{A_{\text {ref }}}\right)_{C X} \times\left(\frac{A}{A_{\text {ref }}}\right)_{0}\left(\frac{A}{A_{\text {ref }}}\right)_{t}$

$A_{\text {req }}=(51.0)(1.25)(1.10)(.97)=68.0 \mathrm{ft}^{2}$

The storage capacitance parameter is:

$\frac{\mathrm{Mc}}{\mathrm{A}_{\mathrm{C}} \mathrm{P}}=\frac{52 \mathrm{gal} \times 8.33 \frac{\mathrm{lb}}{\mathrm{gal}} \times 1.0 \frac{\mathrm{Btu}}{\mathrm{1b} \cdot{ }^{\circ} \mathrm{F}}}{68.0 \mathrm{ft}^{2} \mathrm{c}}=6.4 \frac{\mathrm{Btu}}{{ }^{\circ} \mathrm{F} \cdot \mathrm{ft}^{2}{ }_{\mathrm{C}}}$

Figure A-16 gives the appropriate adjustment factor for BOSTON as:

$\left(\mathrm{A}_{\text {ref }}\right)_{\mathrm{S}}=1.19$ 
$\underline{\operatorname{Tr} i a 1} 2$

$$
\begin{aligned}
& A_{r e q}=(68.0)(1.19)=80.9 \\
& \frac{{ }_{C}{ }_{p}}{A_{C}}=\frac{(52)(8.33)}{80.9}=5.4 \frac{B t u}{{ }^{\circ} \mathrm{F} \cdot \mathrm{ft}^{2}{ }_{\mathrm{C}}} \\
& \left(\mathrm{A} / \mathrm{A}_{\text {ref }}\right)_{S}=1.22
\end{aligned}
$$

$\underline{\operatorname{Tr} 1 a 13}$

$A_{\text {reqd }}=(68.0)(1.22)=83.0$

$\frac{{ }_{\mathrm{C}} \mathrm{p}}{\mathrm{A}_{\mathrm{c}}}=\frac{(52.0)(0.33)}{83.0}=5.2 \frac{\mathrm{Btu}}{{ }^{\circ} \mathrm{F} \cdot \mathrm{ft}^{2}{ }_{\mathrm{c}}}$

Then $\left(\frac{A}{A_{\text {ref }}}\right)_{S}=1.23$ which is sufficiently close to the calculated value for the second trial solution so that no further trials are necessary. The required collector area is:

$A_{\text {req }}=83.0 \mathrm{ft}^{2}$

\section{e. Computer Program Results}

The foregoing problem was calculated directly using the f-chart computer program for the described solar DHW system and the required collector area, Areq, was $78.5 \mathrm{ft}^{2}$. Therefore, the approximate area is $6 \%$ greater than the exact area, which is deemed acceptable in light of the proposed application. Other sample calculation runs with the approximate method resulted in $\pm 10 \%$ error in collector area when compared with the computer predicted area. The parameters particularly sensitive to these errors are the water inlet temperature and the storage capacity. It is therefore suggested, when using multiple parameters and the modified collector efficiency factor (A/A $\left.A_{\text {ref }}\right)_{c x}$ exceeds a value of 1.5 , that water temperature variation be limited to $\pm 10^{\circ} \mathrm{F}$ to $15^{\circ} \mathrm{F}$ from the reference value of $55^{\circ} \mathrm{F}$ and storage capacity varlation be limited to $\pm 5 \mathrm{Btu} /{ }^{\circ} \mathrm{F} \cdot \mathrm{ft}^{2}{ }_{\mathrm{c}}$ from the reference value of $15 \mathrm{Btu} /{ }^{\circ} \mathrm{F} \cdot \mathrm{ft}^{2} \mathrm{c}$. 
TABLE A-6 SOLAR DHW REFERENCE SYSTEM DESCRIPTION

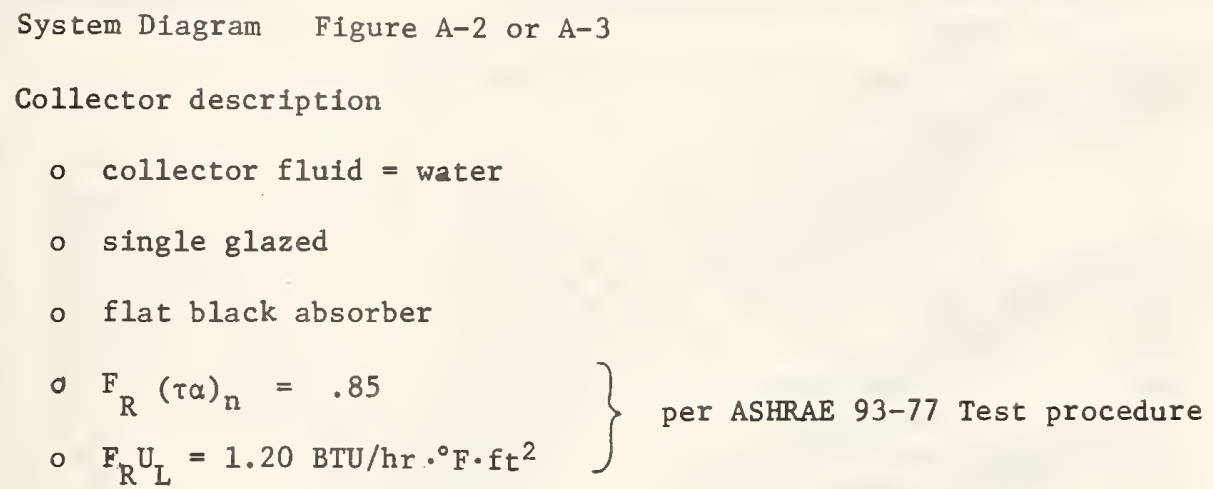

\section{System description}

- two tank (solar preheat and fired auxiliary tanks)

- collector orientation

tilt angle = latitude

azimuth angle $=0^{\circ}$ (due south)

- storage heat capacity $=15 \mathrm{BTU} /{ }^{\circ} \mathrm{F} \cdot \mathrm{ft}_{\mathrm{C}}^{2}$, or $1.9 \mathrm{gal} / \mathrm{ft}_{\mathrm{C}}^{2}$

- storage tank insulation $=\mathrm{R}-13$

- heat transfer fluid = water

Load Description
- draw $=70 \mathrm{gal} / \mathrm{day}$
- delivery temperature $=140^{\circ} \mathrm{F}$
o water main temperature $=70^{\circ} \mathrm{F}$ in Florida, $55^{\circ} \mathrm{F}$ elsewhere
- draw profile (as shown in Fig. A-9) 
Latitude $\left(^{\circ}\right)$

$\begin{array}{ll}1 & \text { Albany, NY } \\ 4 & \text { Amherst, MA } \\ 5 & \text { 1/Annapolis, MD } \\ 7 & \text { Apalachicola, FL } \\ 4 & \text { Blue Hill, MA } \\ 6 & \text { 2/Boston, MA } \\ 0 & \text { Caribou, ME } \\ 7 & \text { Gainesville, FL } \\ 8 & \text { Ithaca, NY } \\ 9 & \text { Jacksonville, FL } \\ 0 & \text { Key West, FL } \\ 1 & \text { Lynn, MA } ., \\ 6 & \text { 3/Miami, FL } \\ 0 & \text { Natick, MA } \\ 2 & \text { Newport, RI } \\ 3 & \text { New York, NY } \\ 0 & \text { Pensacola, FL } \\ 2 & \text { Philadelphia, PA } \\ 5 & \text { Portland, ME } \\ 0 & \text { Schenectady, NY } \\ 3 & \text { Silver Hill, MD } \\ 5 & \text { State Co1lege, PA } \\ 8 & \text { 4/Tallahassee, FL } \\ 9 & \text { Tampa, FL } \\ 0 & \text { Trenton, NJ } \\ 3 & \text { Washington, DC } \\ & \\ & \text { Tand }\end{array}$

$$
\begin{aligned}
& 42.4 \\
& 42.1 \\
& 38.6 \\
& 29.5 \\
& 42.1 \\
& 42.2 \\
& 46.5 \\
& 29.4 \\
& 42.3 \\
& 30.3 \\
& 24.3 \\
& 42.3 \\
& 25.5 \\
& 42.2 \\
& 41.3 \\
& 40.5 \\
& 30.3 \\
& 39.5 \\
& 43.4 \\
& 42.5 \\
& 38.5 \\
& 40.5 \\
& 30.3 \\
& 27.6 \\
& 40.1 \\
& 38.5
\end{aligned}
$$$$
44.0
$$$$
53.0
$$$$
39.0
$$$$
25.0
$$$$
47.0
$$$$
49.6
$$$$
47.5
$$$$
26.4
$$$$
54.0
$$$$
29.2
$$$$
24.1
$$$$
51.0
$$$$
24.1
$$$$
44.0
$$$$
41.5
$$$$
54.0
$$$$
28.3
$$$$
37.5
$$$$
38.5
$$$$
60.0
$$$$
37.0
$$$$
48.5
$$$$
27.0
$$$$
24.1
$$$$
37.5
$$$$
40.5
$$

Participating States: Vermont, New Hampshire, Massachusetts, Connecticut, Rhode Island, Pennsylyania, New Jersey, Delaware, Maryland, Florida

New York Counties: Bronx, Duchess, Greene, Kings, Nassau, New York, Orange, Queens, Richmond, Rockland, Suffolk, Ulster, Westchester

1/ Representative location for Middle Atlantic Region

2/ Representative location for New England Region

3/ Representative location for southern Florida

4/ Representative location for northern Florida

Table A-7: Required Collector Area for 50\% Solar Domestic Hot Water Contribution HUD/State Solar Hot Water Initiative 


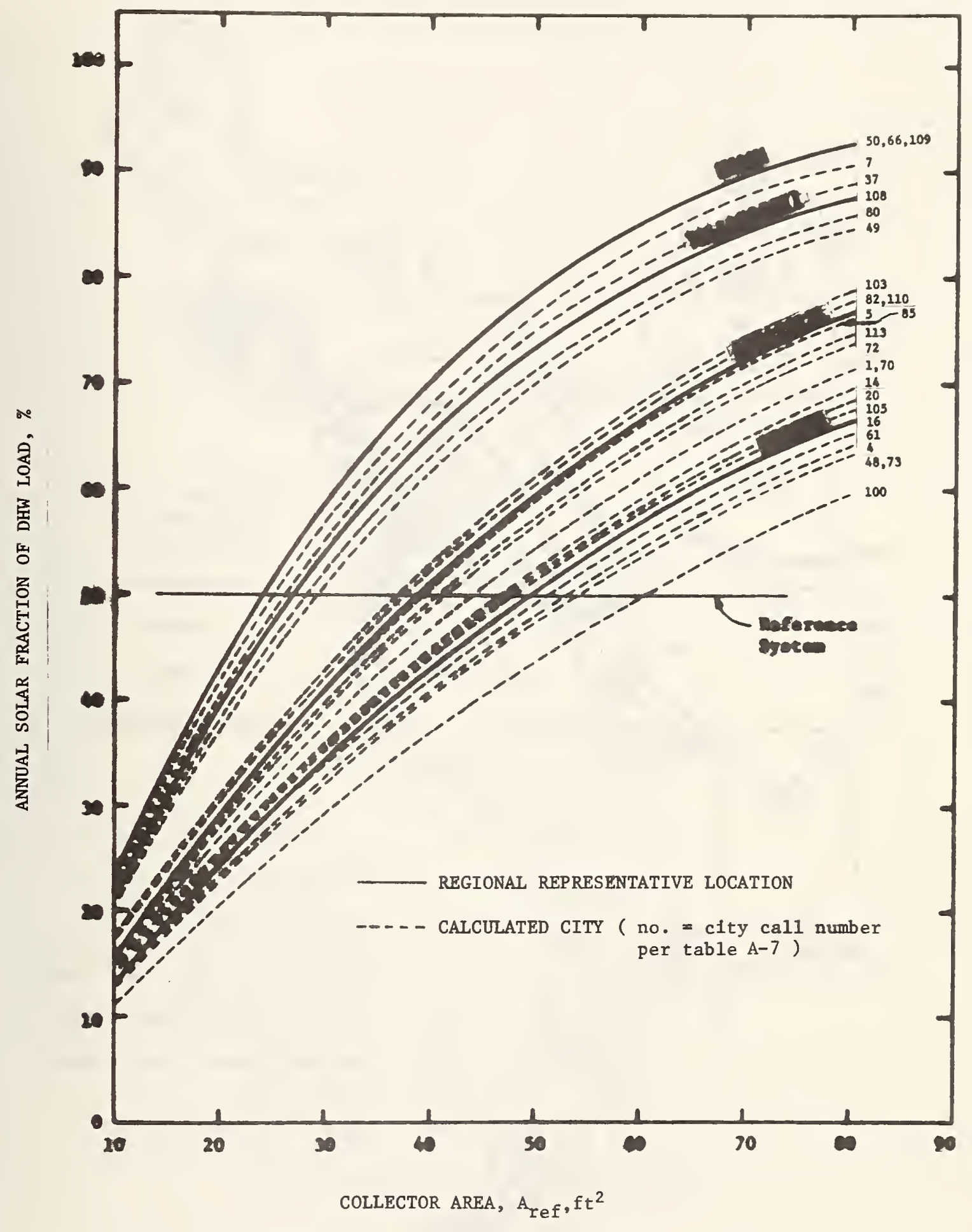

Figure A-10 Collector Area to Provide a Given Annual \% of Domestic Hot Water Load (Reference System) 


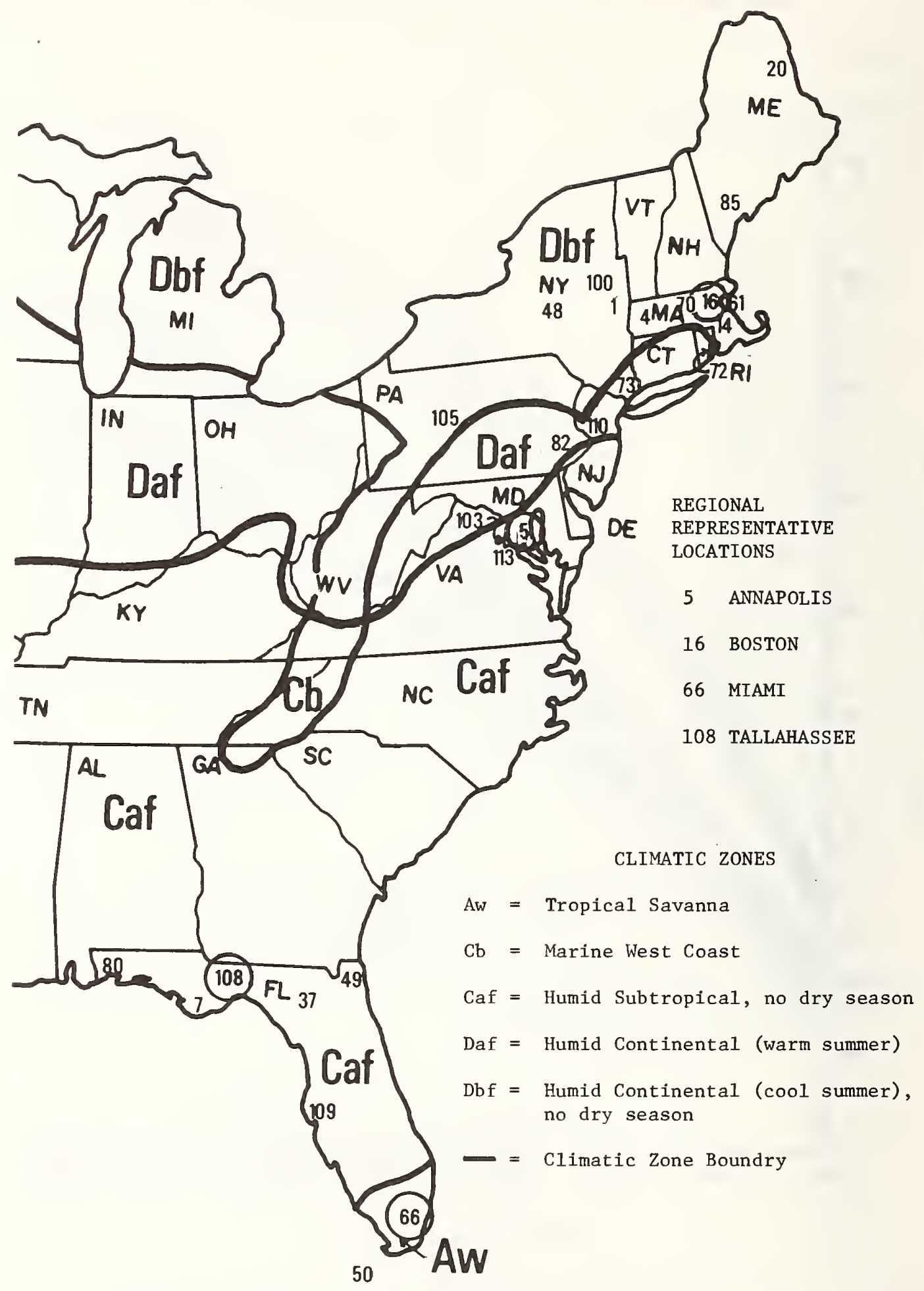

Figure A-11 Climatic Zones

from: G.T. Trewartha, "An Introduction to Climate" 


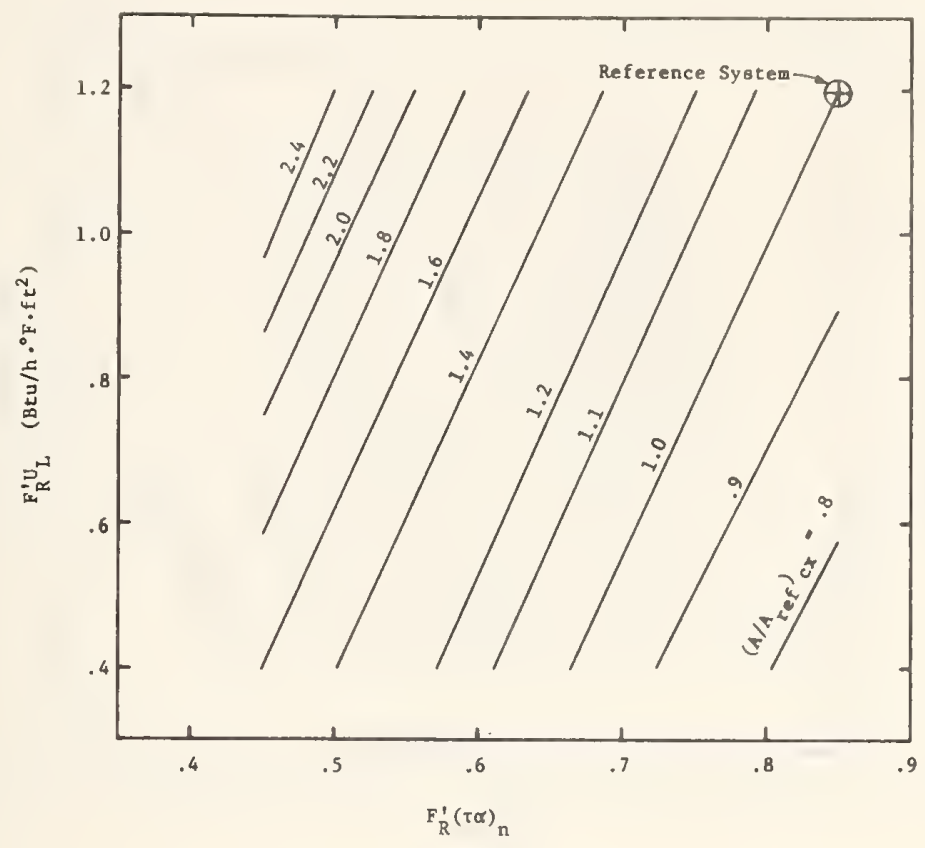

F1gure A-12a Collector Area Multipliers for $\mathrm{F}_{\mathrm{R}}^{\mathrm{p}}(\tau \alpha)_{\mathrm{n}}$ and $\mathrm{F}_{\mathrm{R}}^{\prime} \mathrm{U}_{\mathrm{L}}$ for MIAMI, FL

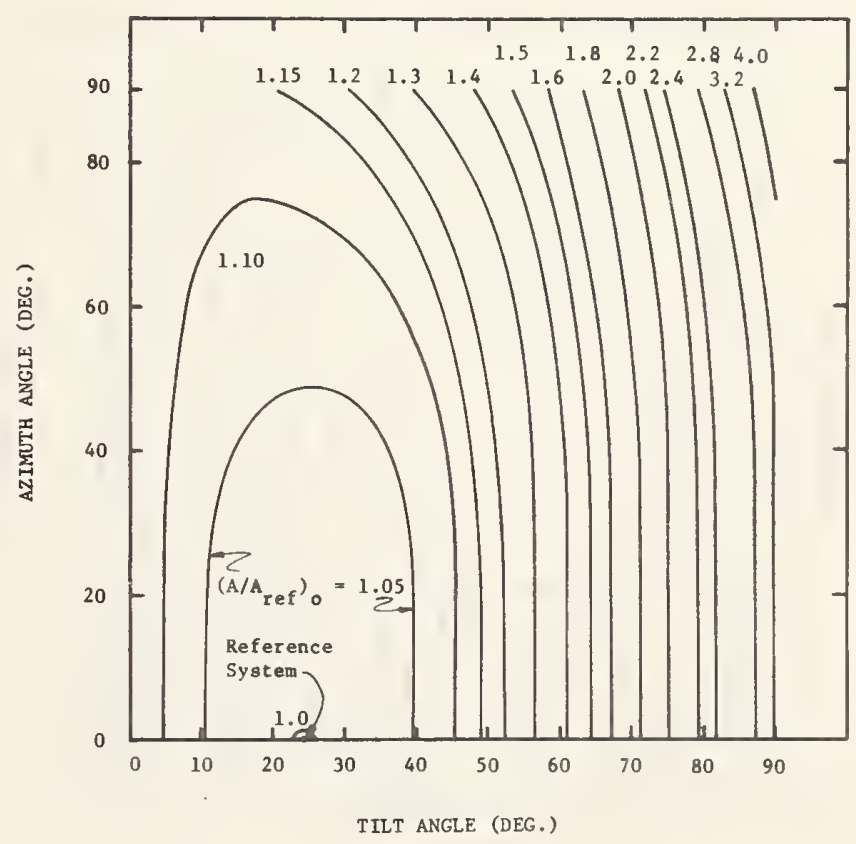

Figure A-12b Collector Area Multipliers for T1lt and Azimuth for MIAMI, FL (Lat. $=25^{\circ}$ ) 


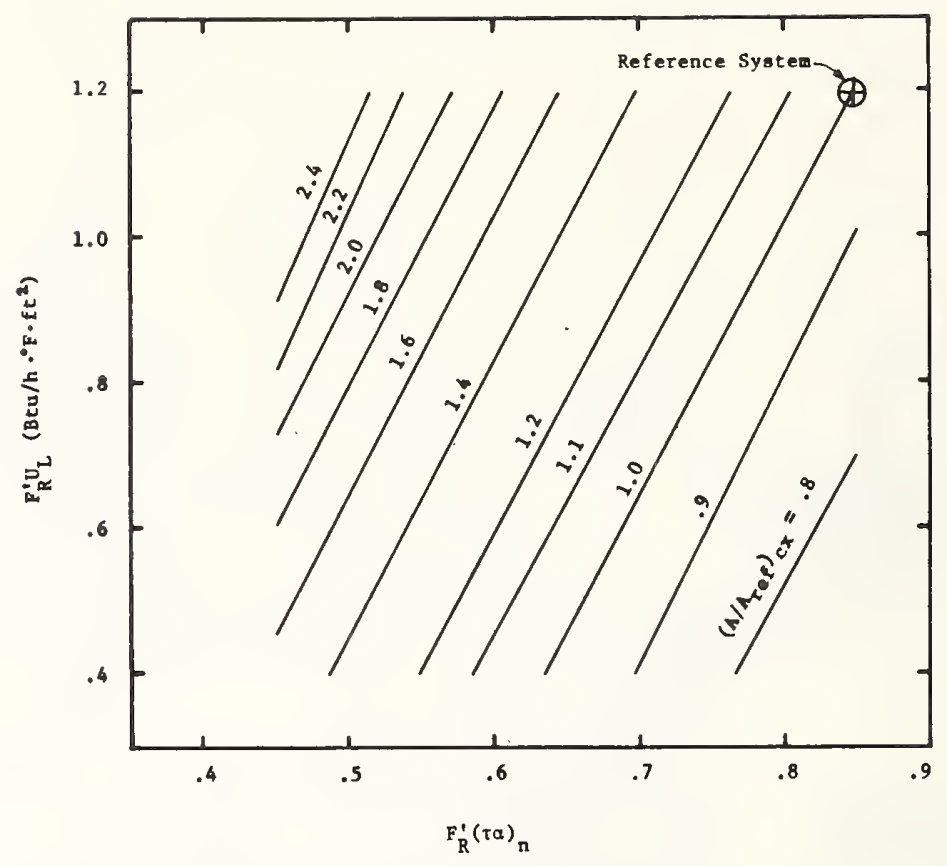

Figure A-13a Collector Area Multipliers for $F_{R}^{\prime}(\tau \alpha)_{n}$ and $F_{R}^{\prime} U_{L}$ for TALLAHASSEE, FL

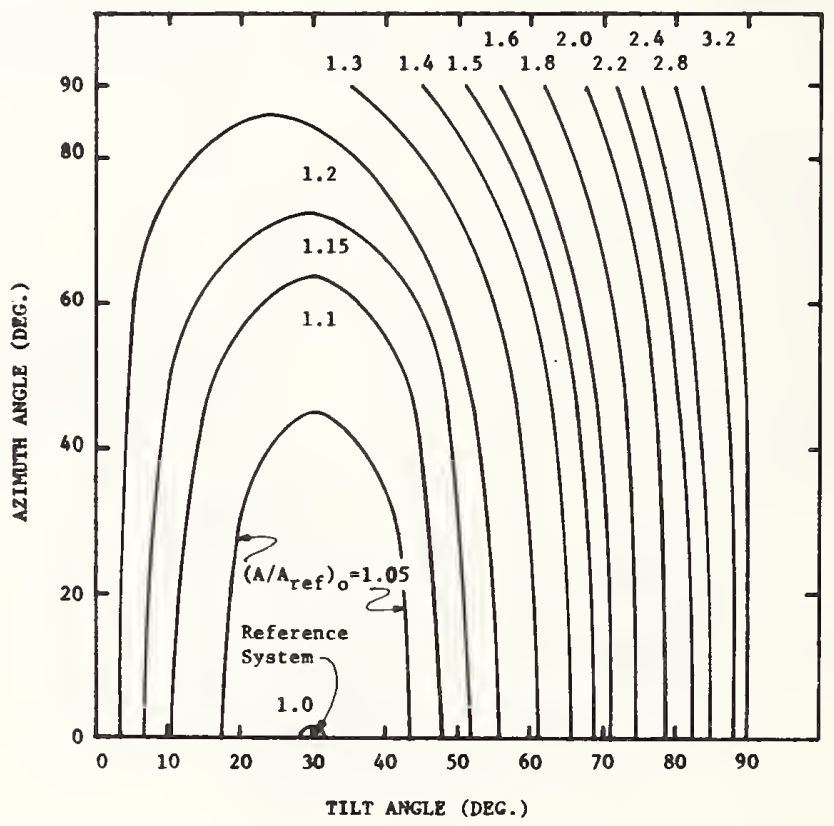

Figure A-13b Collector Area Multipliers for Tilt and Azimuth for TALLAHASSEE, FL ( Lat. $=30^{\circ}$ ) 


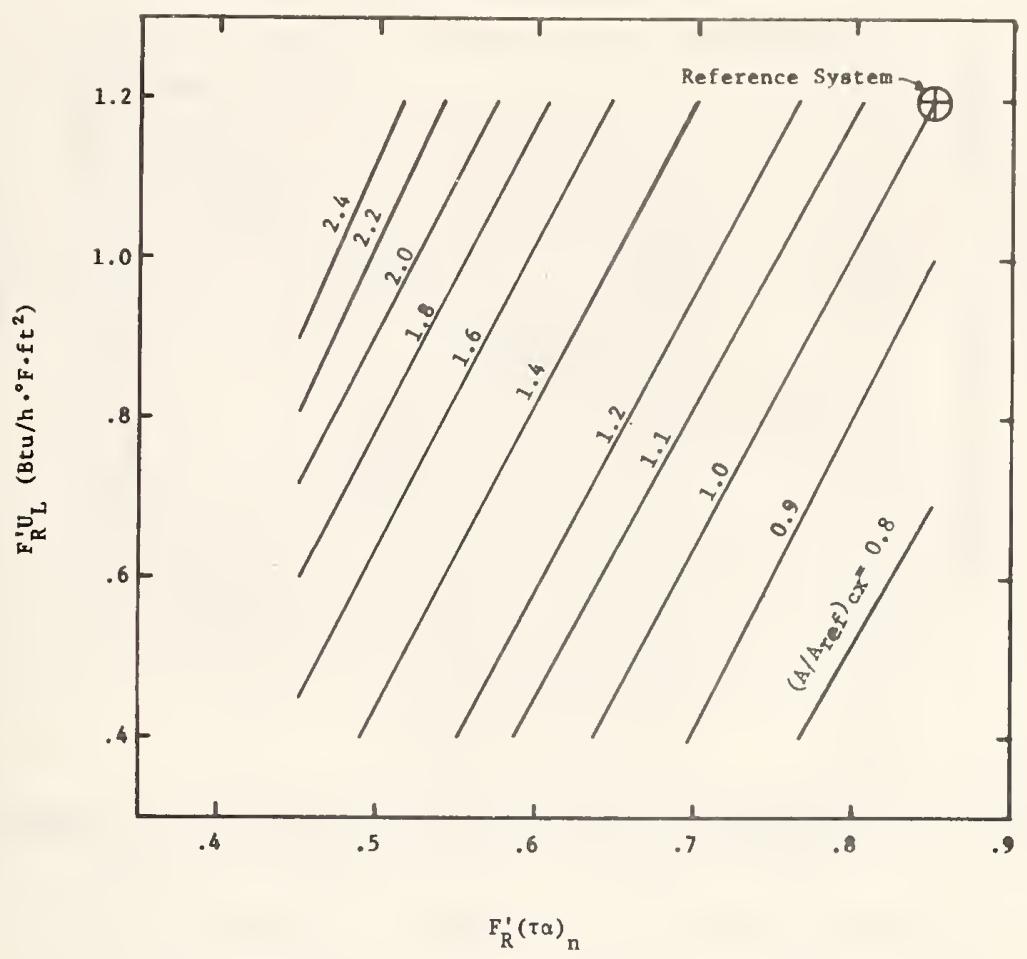

Figure A-14a Collector Area Multipliers for $F_{R}^{\prime}(\tau \alpha)_{n}$ and $F_{R}^{\prime} U_{L}$ for ANNAPOLIS, MD

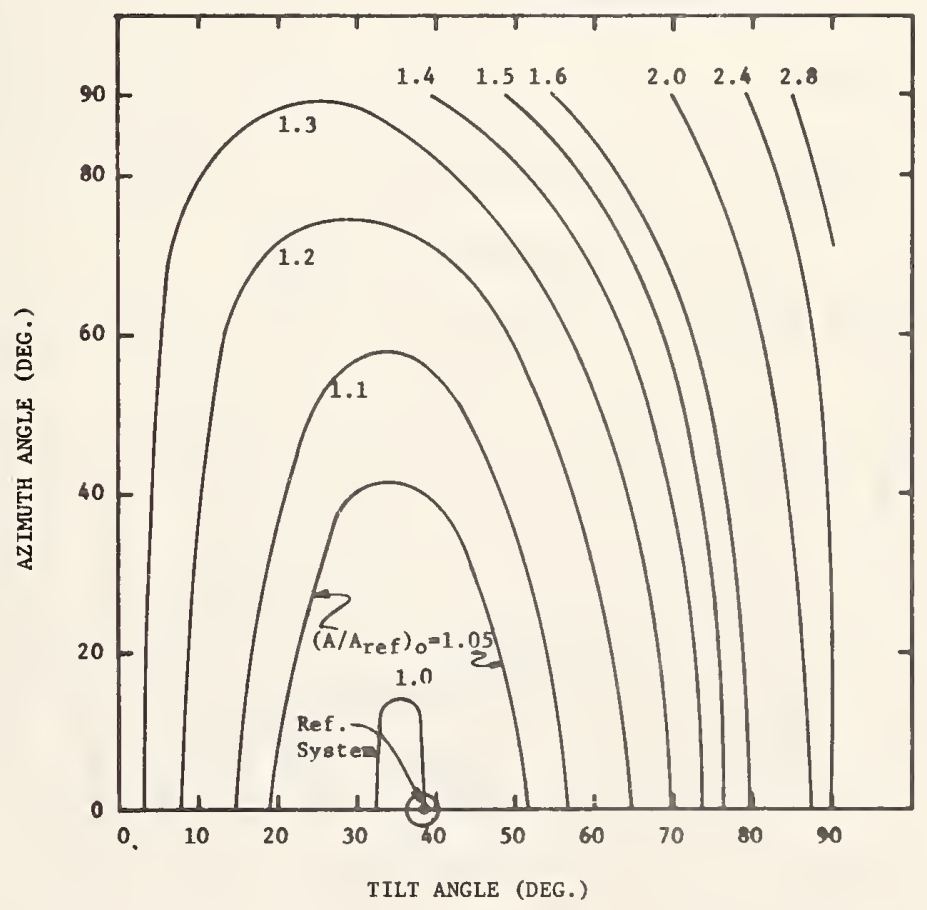

Figure A-14b Collector Area Mu1tipliers for Tilt and Azimuth for ANNAPOLIS, MD (Lat. $=38^{\circ}$ ) 


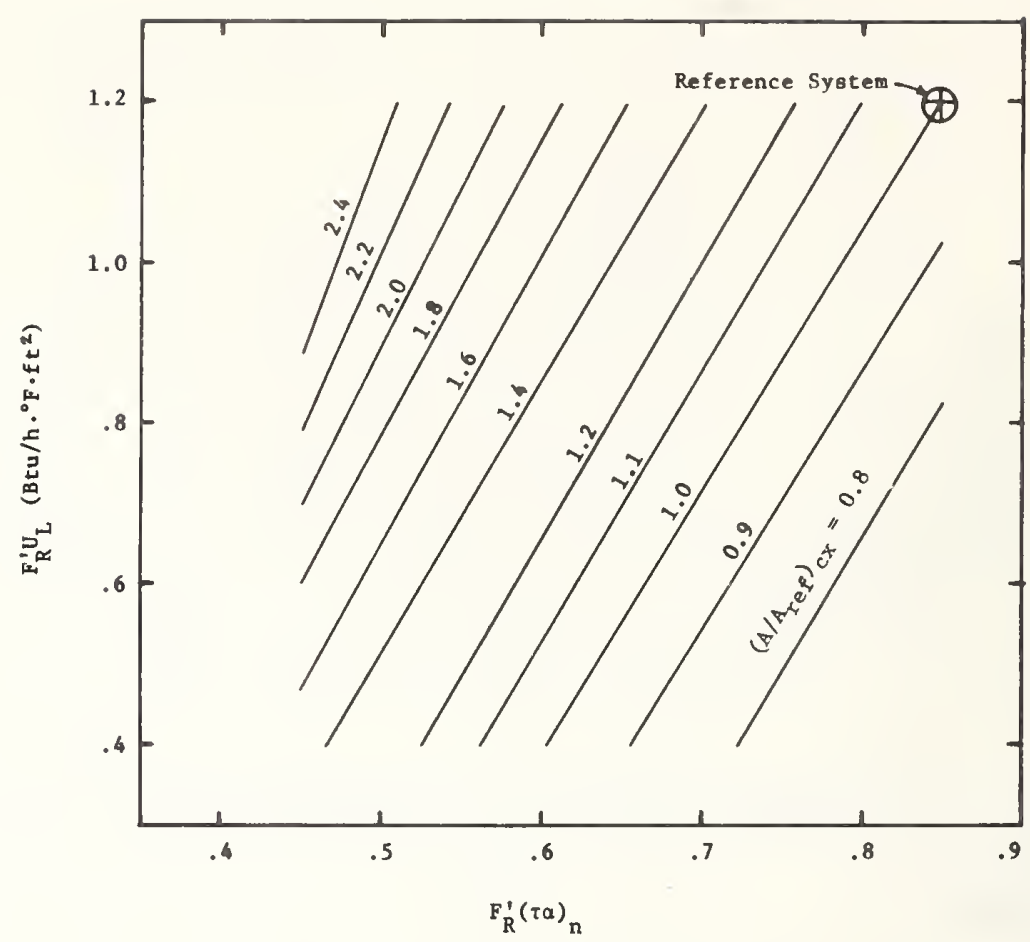

Figure A-15a Collector Area Multipliers for $\mathrm{F}_{\mathrm{R}}^{\prime}(\tau \alpha)_{\mathbf{n}}$ and $F_{R}^{\prime} U_{L}$ for BOSTON, MA

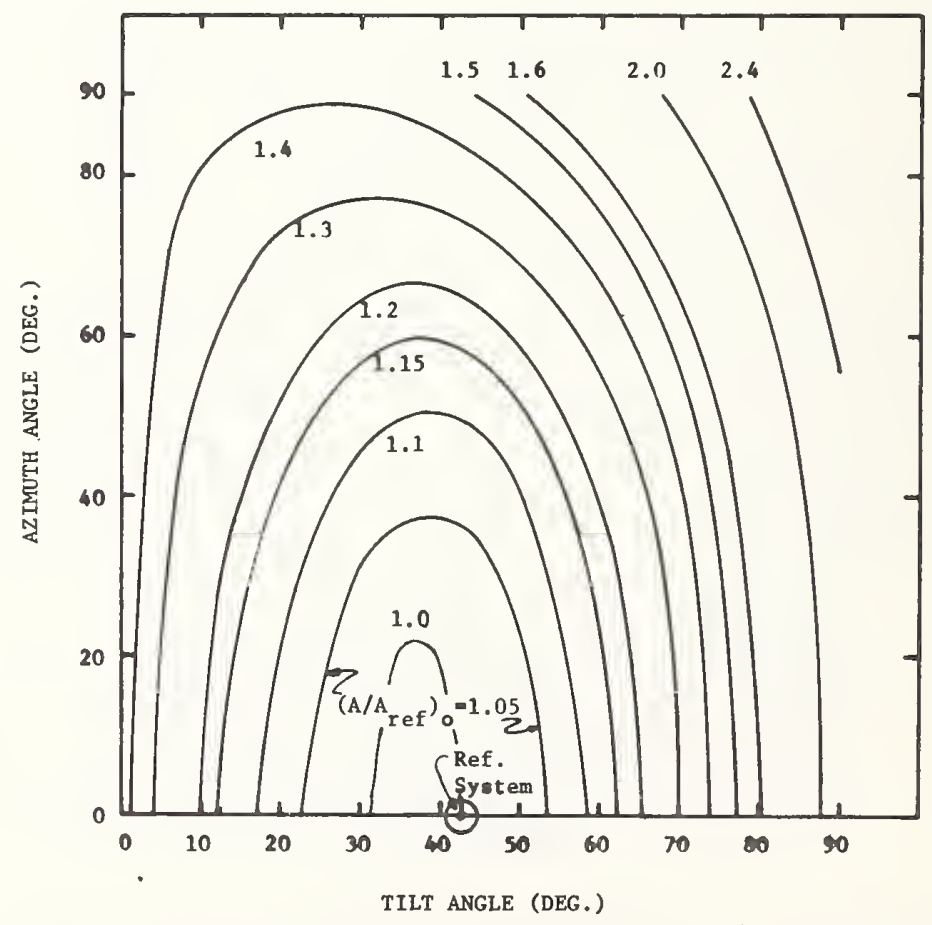

Figure A-15b Collector Area Multipliers for Tilt and Azimuth for BOSTON, MA (Lat. $=42^{\circ}$ ) 


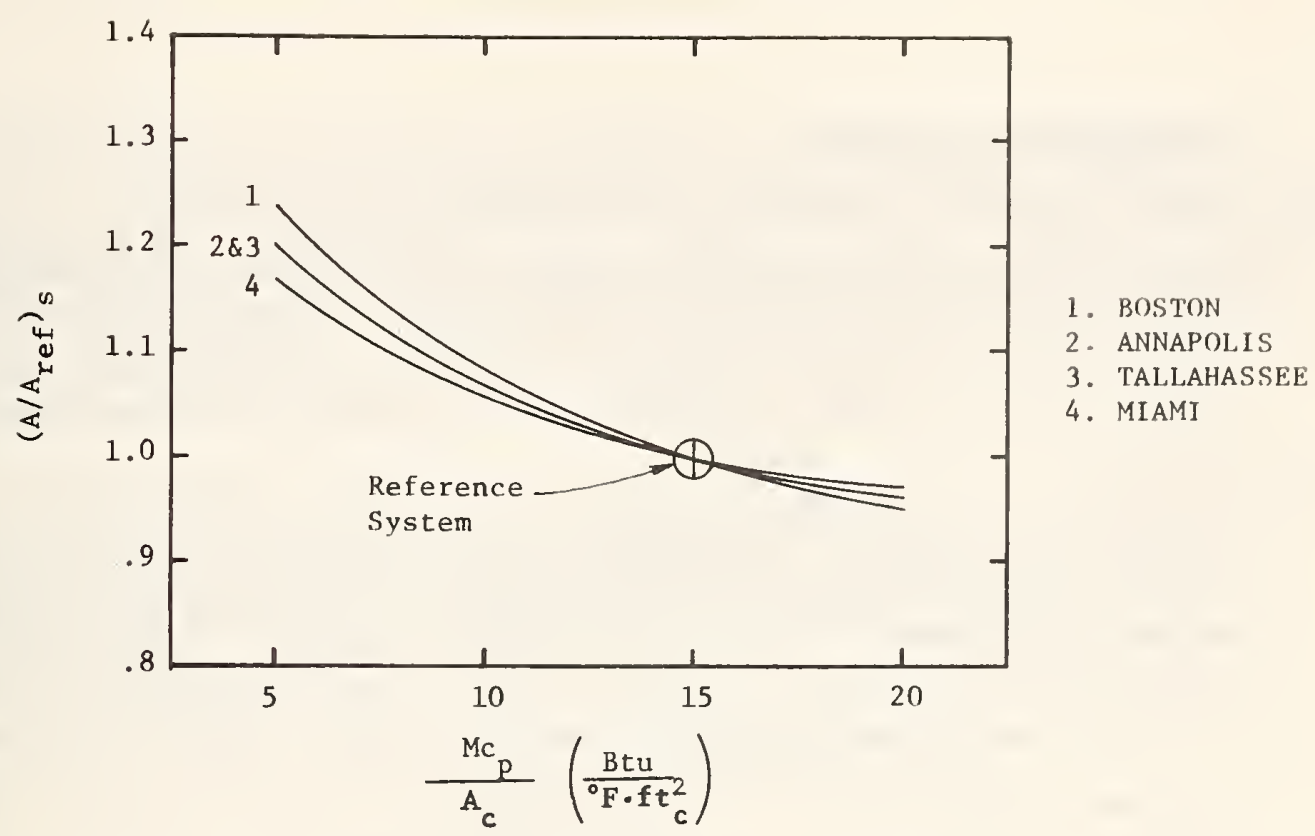

Figure A-16 Collector Area Multiplier for Storage Heat Capacity

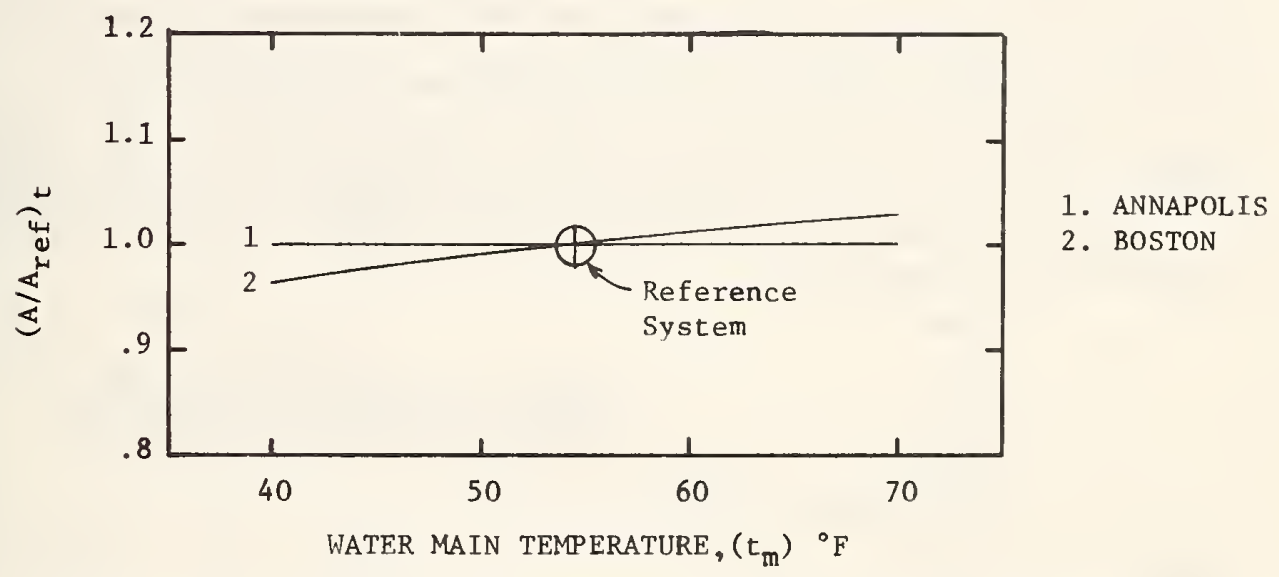

Figure A-17a Collector Area Multiplier for Water Main Temperature, $t_{m}$

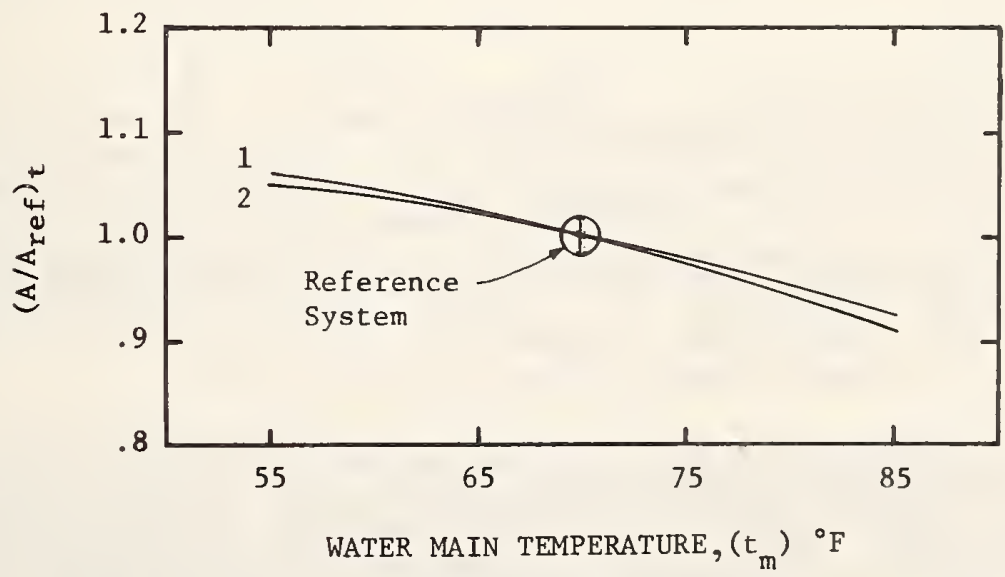

1. MIAMI

2. TALLAHASSEE

Figure A-17b Collector Area Multiplier for Water Main Temperature, $t_{m}$ 
3.1 MODIFIED COLLECTOR PERFORMANCE CHARACTERISTICS, $\mathrm{F}_{\mathrm{R}}^{\prime}(\tau \alpha)_{\mathrm{n}}$ and $\mathrm{F}_{\mathrm{F}}^{\prime} \mathrm{U}_{\mathrm{L}}$

In this section, the procedure for calculating the modified collector performance characteristics $\mathrm{F}_{\mathrm{R}}^{\prime}(\tau \alpha)_{\mathrm{n}}$ and $\mathrm{F}_{\mathrm{R}}^{\prime} \mathrm{U}_{\mathrm{L}}$ used in Figures $\mathrm{A}-12 \mathrm{a}$ to $\mathrm{A}-15 \mathrm{a}$ is explained. The procedure is for a liquid system containing a collector/storage heat exchanger which is the most complex case, however, it is also applicable for air collectors and for liquid systems which do not contain a collector/storage heat exchanger.

To calculate the combined performance characteristics, it is necessary to first establish the performance characteristics for the collector alone, $F_{R}(\tau \alpha)_{n}$ and $F_{R} U_{L}$. Both of the characteristics are then corrected for the effects of the collector/ storage heat exchanger by the heat exchanger modifier factor, $F_{R}^{\prime}$ which includes corrections for both the heat exchanger effectiveness and capacitance rates. This step gives $\mathrm{F}_{\mathrm{R}}^{\prime}(\tau \alpha)_{\mathrm{n}}$ and $\mathrm{F}_{\mathrm{R}}^{\prime} \mathrm{U}_{\mathrm{L}}$.

A worksheet is provided for these calculations.

3.1.1 Collector Performance Characteristics, $\mathrm{F}_{\mathrm{R}}(\tau \alpha){ }_{\mathrm{n}}, \mathrm{F}_{\mathrm{R}} \mathrm{U}_{\mathrm{L}}$

The performance characteristics for the collector alone are determined from manufacturers data which may be presented in any of several forms, and which covers the appropriate range of operational temperatures, insolation, tilt angle, and fluid flow rates. For information purposes, a set of performance curves for a number of typical collectors are presented in Figure A-21a and A-21b.1/ The collector performance efficiency curve must be plotted such that the y axis is the thermal efficiency $(n)$ and the $x$ axis is the temperature difference between a reference fluid temperature $\left(t^{*}\right)$ and the ambient temperature divided by the incident solar radiation $\left[\left(t^{*}-t_{a}\right) / I_{t}\right]$ as shown below.

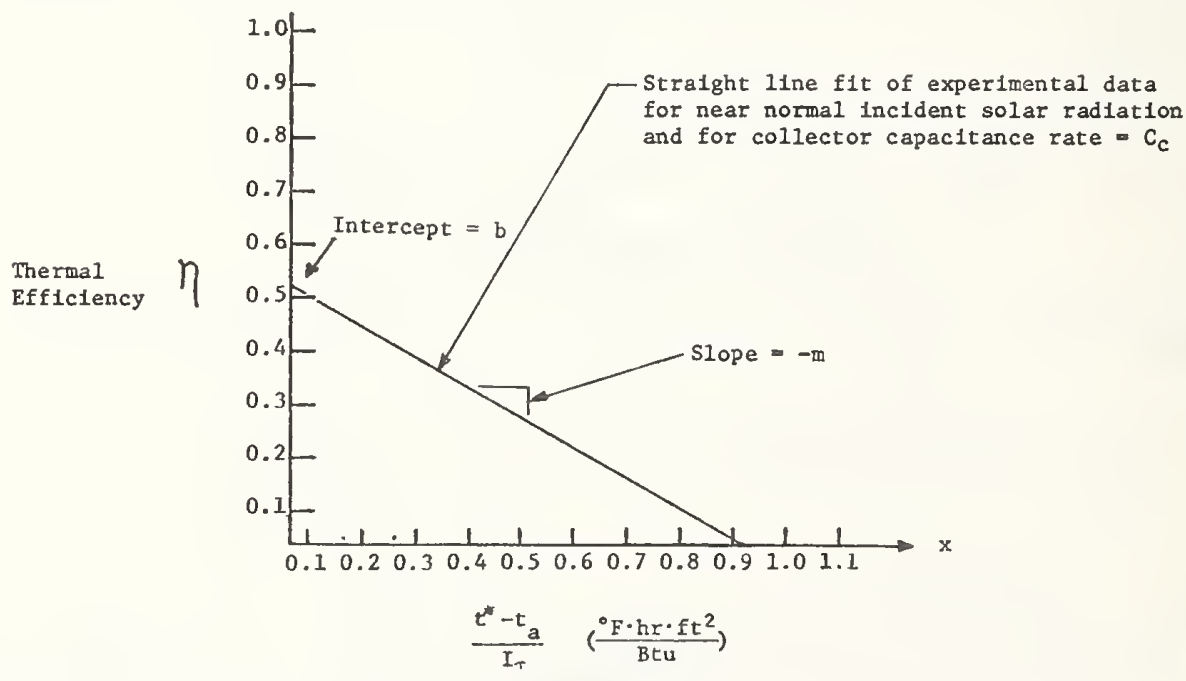

The equation of the straight line fit of the experimental data, in the operating range, is given by: $\mathrm{y}=-\mathrm{mx}+\mathrm{b}$

where: $-\mathrm{m}=$ the slope of the straight line

$\mathrm{b}=$ the $\mathrm{y}$ axis intercept (value of $\mathrm{y}$ when $\mathrm{x}=0$ )

I/ ASHRAE 93-77 defines the collector efficiency using the gross collector area whereas previous data was generally reported using aperture area. Figures A-2la and A-21b present data for several liquid collector types with the efficiency based upon gross area and aperture area, respectively. Calculations in this procedure can be performedwith either area; however, the efficiency and area must be consistent in all portions of the calculation. 
Using ASHRAE 93-77 as the basis for reporting performance data, the reference temperature t* in the plot of experimental data is the fluid inlet temperature. In this case the collector characteristics $F_{R}(\tau \alpha)_{n}$ and $F_{R} U_{i}$ are obtained directly from the efficiency graph as the value of the intercept and slope, respectively. However, in some cases the data are based on other reference temperatures. The following procedure describes the determination of $F_{R}(\tau \alpha)_{n}$ and $F_{R} U_{L}$ for three different values of reference temperature.

The following data are required:

- values of slope in and intercept b for a straight line plot of efficiency data

- temperature basis (either inlet, average, or exit fluid temperature)

- the ratio of the collector capacitance rate to effective area $\mathrm{C}_{\mathrm{c}} / \mathrm{A}_{\mathrm{e}}$ for the collector test. $1 /$

where $\mathrm{C}_{\mathrm{c}}=$ collector fluid capacitance rate $\left(\dot{\mathrm{m}}_{\mathrm{p}}\right.$ ) $\mathrm{Btu} / \mathrm{h} \cdot{ }^{\circ} \mathrm{F}$

$A_{e}=$ effective collector area used in efflciency tests

Case $1 \quad t *=t_{\text {in }}$ (fluid inlet temperature)

then $\quad F_{R}(\tau \alpha)_{n}=b$ (the $y$ axis intercept of the data line)

$\mathrm{F}_{\mathrm{R}} \mathrm{U}_{\mathrm{L}}=\mathrm{m}$ (the magnitude of the data line slope)
Case 2 $t *=\frac{{ }_{\text {in }}+{ }^{t} \text { out }}{2}$ (average of inlet and exit temperature)

then

$F_{R}(\tau \alpha)_{n}=b \times\left[\frac{1}{1+\frac{m_{e}}{2 C_{c}}}\right]$

and

$$
\mathrm{F}_{\mathrm{R}} \mathrm{U}_{\mathrm{L}}=\mathrm{m} \times\left[\frac{1}{1+\frac{\mathrm{mAe}}{2 \mathrm{C}_{\mathrm{c}}}}\right]
$$

Case $3 \quad t *=t_{\text {out }}$ (fluld exit temperature)

then

$$
\begin{aligned}
& F_{R}(\tau \alpha)_{n}=b \times\left[\frac{1}{1+\frac{m A_{e}}{C_{c}}}\right] \\
& F_{R} U_{L}=m \times\left[\frac{1}{1+\frac{m A_{e}}{C_{c}}}\right]
\end{aligned}
$$

Figure A-19 has been provided to facilltate calculation of the adjusted test data. In this figure, the required $\mathrm{F}_{\mathrm{R}} \mathrm{U}_{\mathrm{L}}$ is obtained directly by entering the curve with the measured value of slope $m$ and rising vertically to the intersection with the appropriate value of the parameter $C_{c} / A_{e}$ (noting that solid lines are for the case 3 situation and dashed lines for case 2). Since the term $F_{R}(\tau \alpha)_{n} \times \mathrm{m} / \mathrm{b}$ is numerically equal to the value of $F_{R} U_{L}$, the required value of $F_{R}(\tau \alpha)_{n}$ is obtained by multiplying the previously determined $F_{R} U_{L}$ by the ratio b/m in consistant units.

$1 /$ Note that with liquid collectors, the $\mathrm{C}_{\mathrm{c}} / \mathrm{A}_{\mathrm{e}}$ ratio can differ substantially between the collector efficiency test and the proposed application without seriously affecting the f-chart performance predictions. However, with alr collectors, the $\mathrm{C}_{\mathrm{c}} / \mathrm{A}_{\mathrm{e}}$ ratio and the series arrangement of collectors, i.e. the number of collectors in series must be similar between the test and proposed application for the f-chart procedure to be valid. 
3.1.2 Collector Heat Exchanger Modifier, $\frac{\mathrm{F}_{\mathrm{R}}^{\prime}}{\mathrm{F}_{\mathrm{R}}}$

Calculate the collector loop and storage loop capacitance rates and determine the minimum capacitance rate. The loop capacitance rate is the product of the mass flow rate, $\dot{\mathrm{m}}(\mathrm{lb} / \mathrm{h})$ and fluid specific heat, $\mathrm{c}_{\mathrm{p}}\left(\mathrm{Btu} / \mathrm{lb} \cdot{ }^{\circ} \mathrm{F}\right)$.

$$
\begin{array}{ll}
c_{c}=\left(\dot{m}_{p}\right)_{c} & \text { collector loop } \\
c_{s}=\left(\dot{m} c_{p}\right)_{s} & \text { storage loop }
\end{array}
$$

The minimum capacitance rate $\mathrm{C}_{\text {min }}$ is the lesser of $\mathrm{C}_{\mathrm{c}}$ or $\mathrm{C}_{\mathrm{s}}$.

The effectiveness of the collector/storage heat exchanger, $\epsilon_{\mathrm{HX}}$ is a function of the particular heat exchanger design and size and capacitance rate of each loop. If a numerical value of $\varepsilon_{\mathrm{HX}}$ is not known, section 3.2 describes procedures whereby values can be calculated or estimated depending on information available from the heat exchanger manufacturer.

The heat exchanger modifier is determined by first calculating the following dimensionless parameters:

$$
\begin{aligned}
& x=\frac{C_{C}}{\varepsilon_{H X} C_{\text {min }}} \\
& y=\frac{A_{C}\left(F_{R} U_{L}\right)}{C_{c}}
\end{aligned}
$$

where $A_{c}=$ the effective area of the collector array

The heat exchanger modifier is then determined either from the following equation or from figure $\mathrm{A}-20$.

$$
\frac{F_{R}^{\prime}}{F_{R}}=\frac{1}{1+y(x-1)}
$$

Note that for any solar DHW systems without a collector/storage heat exchanger,

$$
\frac{\mathrm{F}_{\mathrm{R}}^{\prime}}{\mathrm{F}_{\mathrm{R}}}=1
$$

The values for the modified collector performance characteristics are calculated as follows:

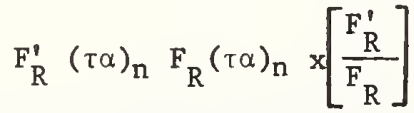

$$
\begin{aligned}
& \mathrm{F}_{\mathrm{R}}^{\prime} \mathrm{U}_{\mathrm{L}}=\mathrm{F}_{\mathrm{R}} \mathrm{U}_{\mathrm{L}} \times\left[\frac{\mathrm{F}_{\mathrm{R}}^{\prime}}{\mathrm{F}_{\mathrm{R}}}\right]
\end{aligned}
$$


PROJECT:

Collector Efficiency Data From Test

intercept, $b=$

slope, $\quad m=\quad\left(\mathrm{Btu} / \mathrm{h} \cdot{ }^{\circ} \mathrm{F} \cdot \mathrm{ft}^{2}\right)$

reference temperature basis: 1. $t_{\text {in }}, 2 . \frac{t_{\text {in }}+t_{\text {out }}}{2}, 3 . t_{\text {out }}$

collector test area, $A_{e}=\quad\left(\mathrm{ft}^{2}\right)$

collector volumetric flow rate $=$

Correction to $t_{\text {in }}$ basis (use Figure A-19 or the following steps):

Case 1: (no correction) $\mathrm{F}_{\mathrm{R}}(\tau \alpha)_{\mathrm{n}}=$ $F_{R} U_{L} \quad=$

Case 2: $F_{R}(\tau \alpha)_{n}=b \times\left[\frac{1}{1+\frac{m A_{e}}{2 C_{c}}}\right]=$

$$
\mathrm{F}_{R} U_{L}=\mathrm{m} \times\left[\frac{1}{1+\frac{\mathrm{mA}_{\mathrm{e}}}{2 \mathrm{C}_{\mathrm{c}}}}\right]=
$$

$\frac{c_{c}}{A_{e}}=\frac{\dot{m} c}{A_{e}}=\left(\begin{array}{l}\text { volumetric } \\ \text { flow rate }\end{array}\right)($ density $)\left(\begin{array}{l}\text { time } \\ \text { conversion }\end{array}\right)\left(\begin{array}{l}\text { specific } \\ \text { heat }\end{array}\right) /$ test area

where: for liquids, density $=\left(\begin{array}{ll}8.33 \mathrm{lb} / \mathrm{gal}\end{array}\right) \times\left(\begin{array}{l}\text { specific } \\ \text { gravity }\end{array}\right)$

for air, density $=0.75 \mathrm{lb} / \mathrm{ft}^{3}$, at $70^{\circ}$ and $1 \mathrm{~atm}$.

specific heat $=0.24 \mathrm{Btu} / 1 \mathrm{~b} \cdot{ }^{\circ} \mathrm{F}$

Case 3: $\quad F_{R}(\tau \alpha)_{n}=b \times\left[\frac{1}{1+\frac{\mathrm{mA}_{e}}{\mathrm{C}_{\mathrm{c}}}}\right]=$

$F_{R} U_{L}=m \times\left[\frac{1}{1+\frac{\mathrm{mA}_{e}}{\mathrm{C}_{c}}}\right]=$ 
Collector Heat Exchanger Modifier, $\frac{F_{R}^{\prime}}{F_{R}}$

for single loop systems without a collector/storage heat exchanger,

$\frac{\mathrm{F}_{\mathrm{R}}^{\prime}}{\mathrm{F}_{\mathrm{R}}}=1$

Capacitance Rate

$$
\begin{aligned}
& \mathrm{C}_{\mathrm{c}}=\text { (from above) } \quad \mathrm{Btu} / \mathrm{h} \cdot{ }^{\circ} \mathrm{F} \\
& \mathrm{C}_{s}=\text { (calc. as for } \mathrm{C}_{c} \text { above) = } \\
& \mathrm{C}_{\min }=\text { (lesser of } \mathrm{C}_{c} \text { of } \mathrm{C}_{s} \text { ) = } \\
& \text { Collector Array Area } \mathrm{A}_{\mathrm{C}}=\mathrm{ft}^{2}
\end{aligned}
$$

Collector Storage Heat Exchanger Effectiveness, $\varepsilon_{\mathrm{cs}}=$

$$
\begin{aligned}
& x=\frac{C_{c}}{\varepsilon_{c s} C_{m i n}}= \\
& y=\frac{A_{c}\left(F_{R} U_{L}\right)}{C_{c}}=
\end{aligned}
$$

$$
\frac{F_{R}^{\prime}}{F_{R}}=\text { from figure } \quad \text { or }=\frac{1}{1+y(x-1)}=
$$

Modifled Collector Performance Characteristics

$$
\begin{aligned}
& F_{R}^{\prime}(\tau \alpha)_{n}=F_{R}(\tau \alpha)_{n} \times\left[\frac{F_{R}^{\prime}}{F_{R}}\right]= \\
& F_{R}^{\prime} U_{L}=F_{R} U_{L} \times\left[\frac{F_{R}^{\prime}}{F_{R}}\right]
\end{aligned}
$$




\subsection{HEAT EXCHANGER EFFECTIVENESS, $\varepsilon_{\mathrm{HX}}$}

In the evaluation of a double loop solar DHW system performance using the "f-chart" method, the calculation procedure requires an explicit value for heat exchanger effectiveness $\varepsilon_{H X}$. This section describes two approaches to calculation of effectiveness, based on different ways design data may be provided by a heat exchanger manufacturer. In situations when no manufacturer design data is available, a method is described to estimate heat exchanger effectiveness.

\section{Definitions}

- Overall conductance (AU) ${ }_{\mathrm{Hx}}$ for a heat exchanger is the product of the overall heat transfer coefficient $U$ (which depends on the thermal properties of each fluid, the fluid mass flow rate and the heat exchanger geometry) and the assoclated heat transfer surface area.

- Effectiveness $\varepsilon_{\mathrm{HX}}$ is the ratio of the actual rate of heat transfer in the exchanger to the theoretical maximum rate of heat transfer that would occur only in a counterflow exchanger with infinite surface area.

- Log-mean temperature difference $\Delta t_{L M}$ is the effective temperature difference between the inlet and outlet fluids such that the product of $\Delta t_{L M}$ and (AU) $H X$ equals the actual heat transfer rate.

The basic relationships are developed in the following paragraphs.

In the following schematic heat exchanger drawing, the hot stream with capacitance rate $C_{H}$ and inlet temperature $t_{h}$, in and the cold stream with capacitance rate $C_{C}$ and inlet temperature $t_{c}$, in both enter a heat exchanger that has an overall conductance ${ }^{(\mathrm{AU})} \mathrm{HX} \cdot$

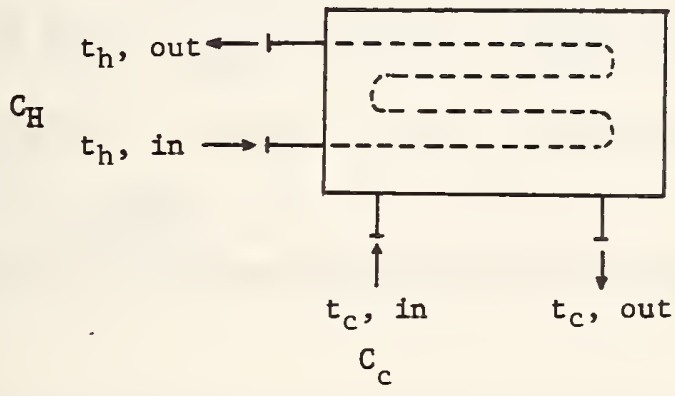

Heat Exchanger with overall Conductance (AU) $\mathrm{HX}$

The actual heat transfer rate is given by

$$
\begin{aligned}
Q & =C_{c}\left(t_{c} \text {, out }-t_{c} \text {, in }\right) \\
& =C_{H}\left(t_{h}, \text { In }-t_{h} \text {, out }\right) \\
& =(\text { Avt })_{\operatorname{HX}} \Delta t_{L M}
\end{aligned}
$$


The maximum theoretical heat transfer rate would occur if the fluid having the minimum capacitance rate were heated (or cooled) to the inlet temperature of the maximum capacitance rate fluid, i.e.

$$
\begin{aligned}
& \text { if } \mathrm{C}_{\mathrm{min}}=\mathrm{C}_{\mathrm{H}} \\
& \text { Then } Q_{\max }=C_{H}\left(t_{h, \text { In }}-t_{c} \text {, fn }\right) \\
& \text { Or if } \mathrm{C}_{\mathrm{min}}=\mathrm{C}_{\mathrm{C}} \\
& \text { Then } Q_{\max }=C_{c}\left(t_{h, 1 n}-t_{c}, i n\right) \\
& \text { The effectiveness is given by } \\
& \varepsilon_{\mathrm{HX}}=\frac{Q}{Q_{\max }}-\frac{C_{c}\left(t_{c_{2} \text { out }}-t_{c, \text { In }}\right)}{C_{\min }\left(t_{h, \text { In }}-t_{c, \text { In }}\right)}=\frac{C_{H}\left(t_{h, \text { In }}-t_{H, \text { out }}\right)}{C_{\min }\left(t_{\text {, }, \text { in }}-t_{c, \text { In }}\right)}
\end{aligned}
$$

The log mean temperature difference is a complex function of the hot and cold fluid inlet and outlet temperatures and depends on the heat exchanger flow arrangement. The term $\Delta t_{\text {LM }}$ is defined in terms of a reference $\log$ mean temperature difference for a counterflow heat exchanger $\left(\Delta t_{L M}\right) c f$ and a correction factor $K$ as follows:

$$
\begin{aligned}
& \Delta_{L M}=\left(\Delta t_{L M}\right)_{c f} \times K \\
& \text { where }\left(\Delta t_{L M}\right)_{c f}=\frac{\left(t_{h, \text { in }}-t_{c, \text { out }}\right)-\left(t_{h, \text { out }}-t_{c, \text { in }}\right)}{\log _{e}\left(\frac{t_{h, \text { in }}-t_{c, \text { out }}}{t_{h, \text { out }}-t_{c, \text { in }}}\right)}
\end{aligned}
$$

and $R$ depends on the particular heat exchanger flow geometry and the following dimensionless temperature ratios $R_{1}$ and $R_{2}$ :

$$
\begin{aligned}
& R_{1}=\frac{t_{c} \text {, out }-t_{c, \text { in }}}{t_{h, \text { in }}-t_{c, \text { in }}} \\
& R_{2}=\frac{t_{h, \text { in }}-t_{h, \text { out }}}{t_{c, \text { out }}-t_{c, \text { in }}}
\end{aligned}
$$

Tabular or graphical values of $\left(\Delta t_{L M}\right)_{C f}$ and $\mathrm{K}$ are usually provided by heat exchanger

\section{Example 1}

Calculate the effectiveness of a counterflow heat exchanger located in the collector/ storage circulation loop. Assume the collector circulation loop flow rate is $2 \mathrm{gpm}$ and the storage loop flow rate is $6 \mathrm{gpm}$ and that fluid leaves the collector at $120^{\circ} \mathrm{F}$ and fluid leaves the storage tank at $100 \mathrm{PF}$. The heat exchanger manufacturers performance data for the specific heat exchanger and fluid properties is given in the following curves: 


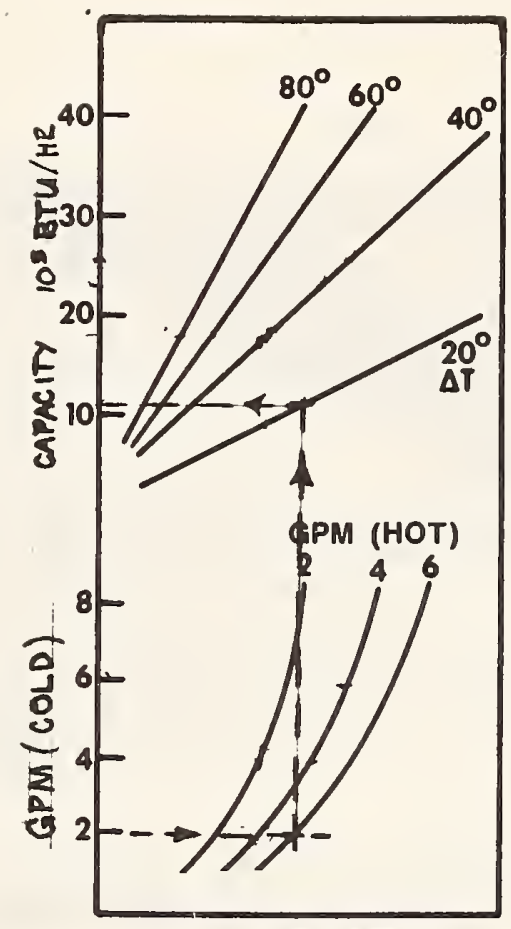

Enterlng the above curve with $2.0 \mathrm{gpm}$ (cold) and $6.0 \mathrm{gpm}$ (hot), with a $120^{\circ} \mathrm{F}-100^{\circ}=$ $20^{\circ} \mathrm{F} \Delta \mathrm{t}$, the actual heat transfer rate $1 \mathrm{~s}$ determined to be $11,000 \mathrm{Btu} / \mathrm{h}$. The maximum rate of heat transfer 1s:

$$
\begin{aligned}
Q_{\max } & =C_{\min } \Delta t=C_{\min }\left(t_{h}, \text { In }-t_{c}, \text { In }\right)= \\
& +2.0 \frac{\mathrm{gal}}{\min }=8.33 \frac{1 \mathrm{~b}}{\mathrm{gal}} \times 60 \frac{\mathrm{min}}{\mathrm{h}} \times 1.0 \frac{\mathrm{Btu}}{1 \mathrm{~b}^{\circ} \mathrm{F}} \times 20^{\circ} \mathrm{F}=20,000 \mathrm{Btu} / \mathrm{h} .
\end{aligned}
$$

From the definition, the heat exchanger effectiveness is calculated as:

$$
\varepsilon_{\mathrm{HX}}=\frac{Q_{\text {act }}}{Q_{\max }}=\frac{11,000}{20,000}=.55
$$

\section{Example 2}

Calculate the effectiveness of a two pass shell and tube heat exchanger transferring heat between water and a heat transfer fluld. Water enters the heat exchanger at $110^{\circ} \mathrm{F}$ and $10 \mathrm{gpm}$ and the heat transfer fluid enters the heat exchanger at $160^{\circ} \mathrm{F}$ and $15 \mathrm{gpm}$. The properties of the heat transfer fluld are $c_{\mathrm{p}}=.65 \mathrm{Btu} / 1 \mathrm{~b} \cdot{ }^{\circ} \mathrm{F}$ and density $=55 \mathrm{lb} / \mathrm{ft}^{3}$.

The manufacturers data consist of the following:

- overall heat transfer coefficlent $U=150 .\left(B t u / h \cdot{ }^{\circ} \mathrm{F} \cdot \mathrm{ft}^{2}\right.$ )

- heat transfer surface area $A=30.0 \mathrm{ft}^{2}$

- a table of factors to convert the performance of a counterflow heat exchanger to the performance of the actual heat exchanger by the $\log$ mean temperature difference correction factor $\mathrm{K}$ is shown as follows: 
$\mathrm{R}_{1}$

\begin{tabular}{|c|c|c|c|c|c|c|c|c|c|c|c|c|c|c|c|}
\hline & .05 & .1 & .15 & .2 & .25 & .3 & .35 & .4 & .45 & .5 & .6 & .7 & .8 & .9 & 1.0 \\
\hline .2 & & & & & & & & .999 & .993 . & .984 & .972 & .942 . & .908 . & .845 & .71 \\
\hline .4 & \multirow{2}{*}{\multicolumn{4}{|c|}{ 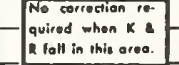 }} & & & .994 & .983 & .971. & .959 & .922 & .855 & .70 & & \\
\hline .6 & & & & & & .992 & .980 & .965 & .948 . & .923 & .840 & & & & \\
\hline .8 & & & & & 995 & .981 & 265 & .845 & .916 & .872 & & & & & \\
\hline 7.0 & & & & & .988 & .970 & .949 & .918 & .867 & .770 & & & & & \\
\hline .2 .0 & & & \begin{tabular}{|l|}
.997 \\
\end{tabular} & .973 & .940 & .845 & .740 & & & & & & & & \\
\hline 3.0 & & & .977 & .933 & .835 & & & & & & & & & & \\
\hline 4.0 & & .993 & .950 . & .850 & & & & & & & & & & & \\
\hline 5.0 & & .982 & .917 & & & & & & & & & & & & \\
\hline 6.0 & & .968 & .855 & & & & & & & & & & & & \\
\hline 8.0 & & .930 & & & & & & & & & & & & & \\
\hline 10.0 & .996 & .880 & & & & & & & & & & & & & \\
\hline 12.0 & .985 & .720 & & & & & & & & & & & & & \\
\hline 14.0 & .972 & & & & & & & & & & & & & & \\
\hline 16.0 & .958 & & & & & & & & & & & & & & \\
\hline 18.0 & .940 & & & & & & & & & & & & & & \\
\hline 20.0 & .915 & & & & & & & & & & & & & & \\
\hline
\end{tabular}

Example of Heat Exchanger Log-Mean

Temperature Difference Correction Factor, K

Since neither of the fluid exit temperatures are known, it is necessary to use a trial and error procedure.

The capacitance rate for the heat transfer fluid (hot) is given by:

$$
c_{\mathrm{h}}=\left(15 \frac{\mathrm{gal}}{\mathrm{mIn}}\right) \times\left(8.33 \frac{16 \mathrm{H}_{2} \mathrm{O}}{\mathrm{gaI}}\right)=\left(\frac{55}{62.4} \frac{16 \mathrm{fluid}}{16 \mathrm{H}_{2}{ }^{0}}\right) \times\left(60 \frac{\mathrm{min}}{\mathrm{h}}\right) \times\left(.65 \frac{\mathrm{Btu}}{1 \mathrm{~b} \cdot{ }^{\circ} \mathrm{F}}\right)=4295 \frac{\mathrm{Btu}}{\mathrm{h} \cdot{ }^{\circ} \mathrm{F}}
$$

The capacitance rate for the water (cold) is given by:

$$
\mathrm{C}_{\mathrm{c}}=10 \frac{\mathrm{gal}}{\mathrm{min}} \times 8.33 \frac{1 \mathrm{~b} \mathrm{H} \mathrm{H}^{\circ}}{\mathrm{ggl}} \times 60 \frac{\mathrm{mln}}{\mathrm{h}} \times 1.0 \frac{\mathrm{Btu}}{1 \mathrm{~b} \cdot{ }^{\circ} \mathrm{F}}=4998 \frac{\mathrm{Btu}}{\mathrm{h} \cdot{ }^{\circ} \mathrm{F}}
$$

Assume the exit temperature of the water $t_{c}$, out is $130^{\circ} \mathrm{F}$.

The actual heat transfer rate is calculated from equation (3.2.1) as:

$$
\begin{aligned}
& Q=C_{c}\left(t_{c, \text { out }}-t_{c, \text { in }}\right)=4998(130-110)=99960 \frac{B t u}{h} \\
& t_{h, \text { out }}=t_{h, \text { in }}-\frac{Q}{C_{h}}=160-\frac{99960}{4295}=136.7^{\circ} \mathrm{F}
\end{aligned}
$$

The reference log mean temperature difference for a counter flow heat exchanger is calculated from equation $(3.2 .6)$ as:

$$
\left(\Delta t_{L M}\right)_{\text {cf }}=\frac{(160-130)-(136.7-110)}{\log _{e}\left(\frac{160-130}{136.7-110}\right)}=28.3^{\circ} \mathrm{F}
$$

Since the heat exchanger is not of the counter flow arrangement, a correction factor $\mathrm{K}$ must be determined from the manufacturers supplied data, in this example based on the computed values of $R_{1}$ and $R_{2}$ as follows from equations (3.2.7) and (3.2.8): 


$$
\begin{aligned}
& R_{1}=\frac{130-110}{160-110}=.4 \\
& R_{2}=\frac{160-136.7}{130-110}=1.16
\end{aligned}
$$

$K$ is then determined from the supplied table (by extrapolation) as: $K=.90$

Then from equations $(3.2 .3)$ and $(3.2 .5)$

$$
Q=(\Delta U)_{\mathrm{HX}} \times\left(\Delta t_{\mathrm{LM}_{\mathrm{Cf}}}\right)_{\mathrm{C}} \times \mathrm{K}=(150)(30)(28.3)(.90)=114615 \frac{\mathrm{Btu}}{\mathrm{h}^{\bullet}}
$$

and $t_{c \text {, out }}=110+\frac{114615}{4998}=132.9^{\circ} \mathrm{F}$.

Since the original exit temperature of the water was estimated to be $130^{\circ} \mathrm{F}$, the procedure is repeated unt 11 the estimated water temperature and the calculated water temperature are the same.

For this problem, the exit water temperature is then calculated to be

$$
t_{c, \text { out }}=131.2^{\circ} \mathrm{F}
$$

The actual heat transfer rate is then

$$
Q=4988(131.2-110)=105,960 \mathrm{Btu} / \mathrm{h} \text {. }
$$

The maximum possible heat transfer rate would occur if the minimum capacitance rate fluid (the hot fluid in this example) were cooled'to the cold fluld inlet temperature.

$$
Q_{\max }=C_{\min }\left(t_{h} \text {, in }-t_{c, \text { in }}\right)=4295(160-110)=214,750 \frac{\text { Btu }}{h}
$$

The heat exchanger effectiveness is given by equation (3.2.4) as:

$$
\varepsilon_{\mathrm{HX}}=\frac{105,960}{214,750}=.49
$$

The heat exchanger effectiveness can be assumed to be a constant for a given heat exchanger and fluid mass flow provided the thermal properties of the fluids do not vary substantially and provided no change of phase occurs. Thus, the calculated value of effectiveness based on an assimed set of inlet temperatures would still be valid over a range of hot fluid and cold fluid inlet conditions usually found in most solar heating applications.

For the case where there are no performance data available for the particular heat exchanger, an estimate of effectiveness can be made from the data of reference [3] for a range of different heat exchanger designs, provided the overall conductance (AU) $\mathrm{HX}$ is known. Figure A-18 shows the effectiveness of counter flow, parallel flow, and cross flow heat exchangers as a function of the ratio (AU) $\mathrm{HX} / \mathrm{C}_{\min }$ with the ratio $\mathrm{C}_{\min } / \mathrm{C}_{\max }$ as the parameter. For the cross flow arrangement usually found in the liquid to air heat exchangers, $C_{\min }$ is usually the air side capacitance rate and the parameter $\mathrm{C}_{\text {mixed }} / \mathrm{C}_{\text {unmixed }}$ shown in Figure $\mathrm{A}-18$ for this arrangement is equivalent to $\mathrm{C}_{\min } / \mathrm{C}_{\max }$. 
If the particular flow arrangement of a heat exchanger is unknown, the effectiveness can be estimated by taking an average of the calculated effectiveness for the counter flow and parallel flow arrangements for the given $(\mathrm{AU})_{\mathrm{HX}} / \mathrm{C}_{\min }$ and $\mathrm{C}_{\min } / \mathrm{C}_{\max }$ design parameters.

For situations in which a heat exchanger consists of a coil of tubing submerged in a tank of water, $C_{\min }$ is the capacitance rate of the fluid circulating through the coil and $C_{\max }$ is essentially infinite. Thus, the ratio $C_{\min } / C_{\max }=0$ is used to determine effectiveness from any of the three arrangements shown since for $C_{\min } / C_{\max }=0$, the expressions for effectiveness as a function of $(\mathrm{AU})_{\mathrm{HX}} / \mathrm{C}_{\mathrm{min}}$ for all flow arrangements reduce to the same expression.
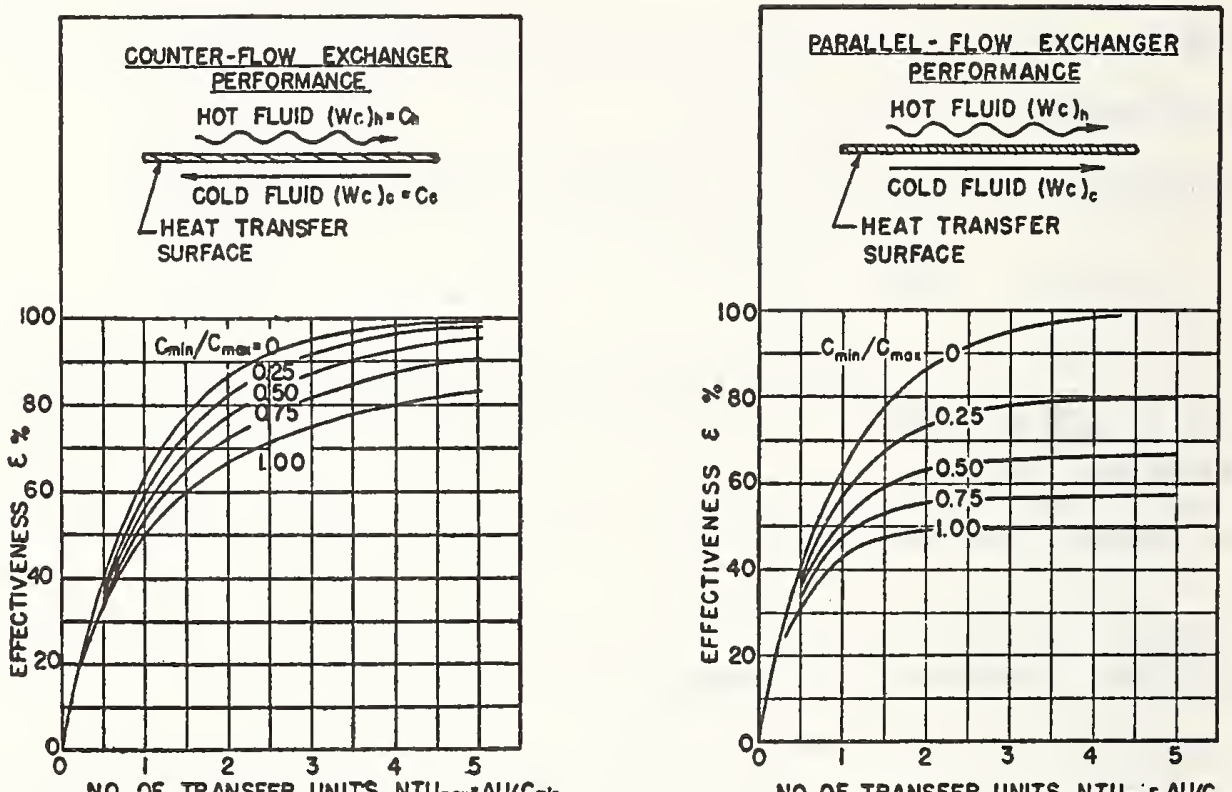

NO. OF TRANSFER UNITS, NTU men"AWC $C_{\text {mh }}$

NO. OF TRANSFER UNITS, NTU max $A U C_{\min }$

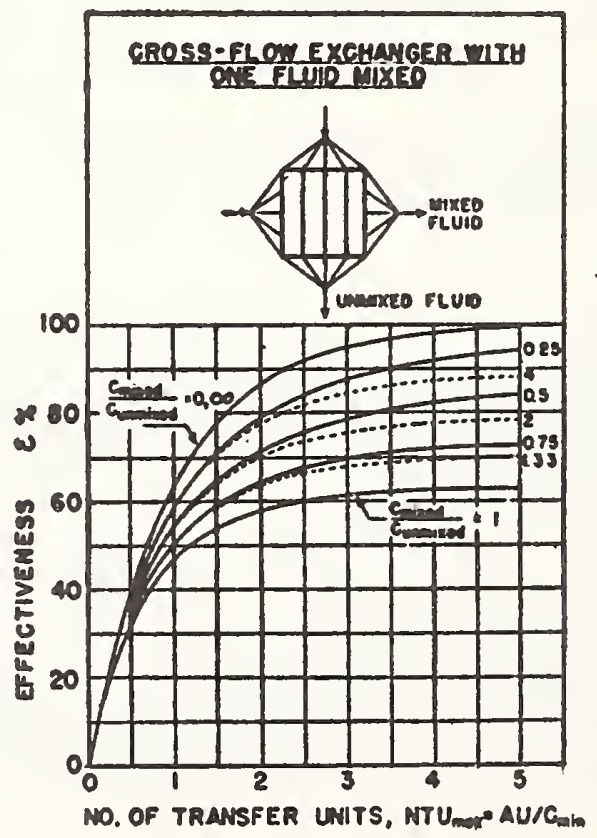

Figure A-18 General Heat Exchanger Performance [3] 


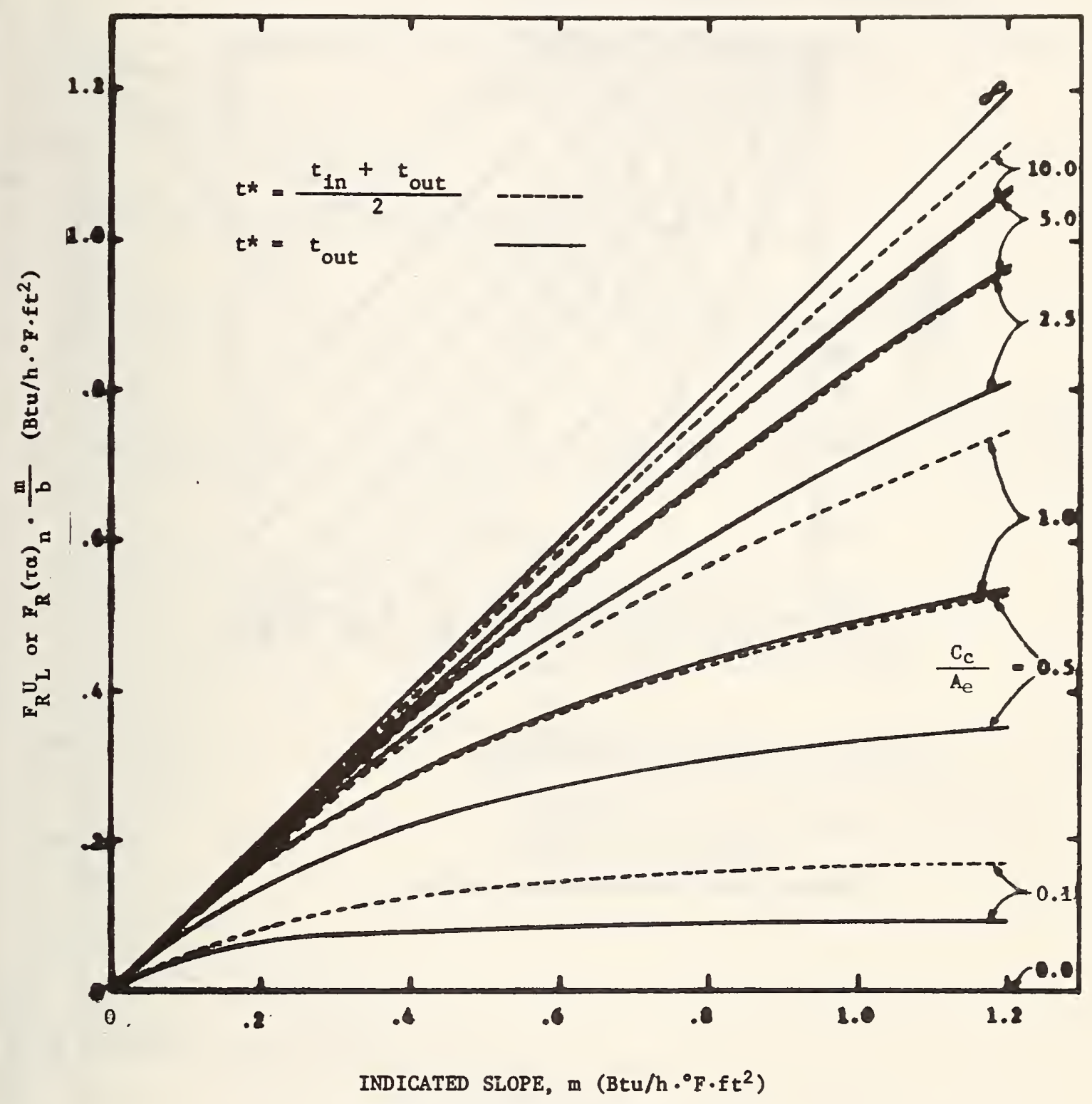

Figure A-19 Correction of $F_{R}(\tau \alpha)_{n}$ and $F_{R} U_{L}$ to $t_{1 n}$ Basis 


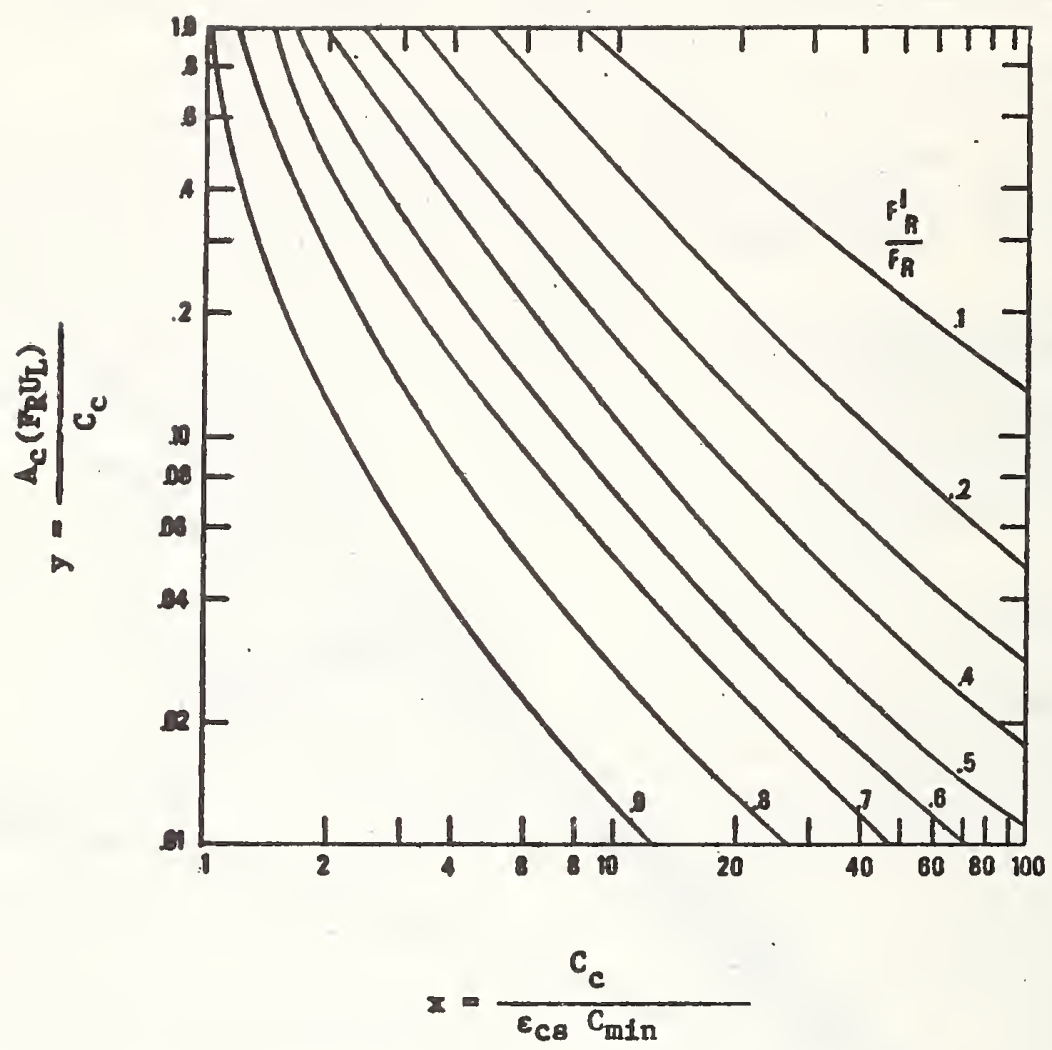

Figure A-20 Heat Exchanger Modifier 


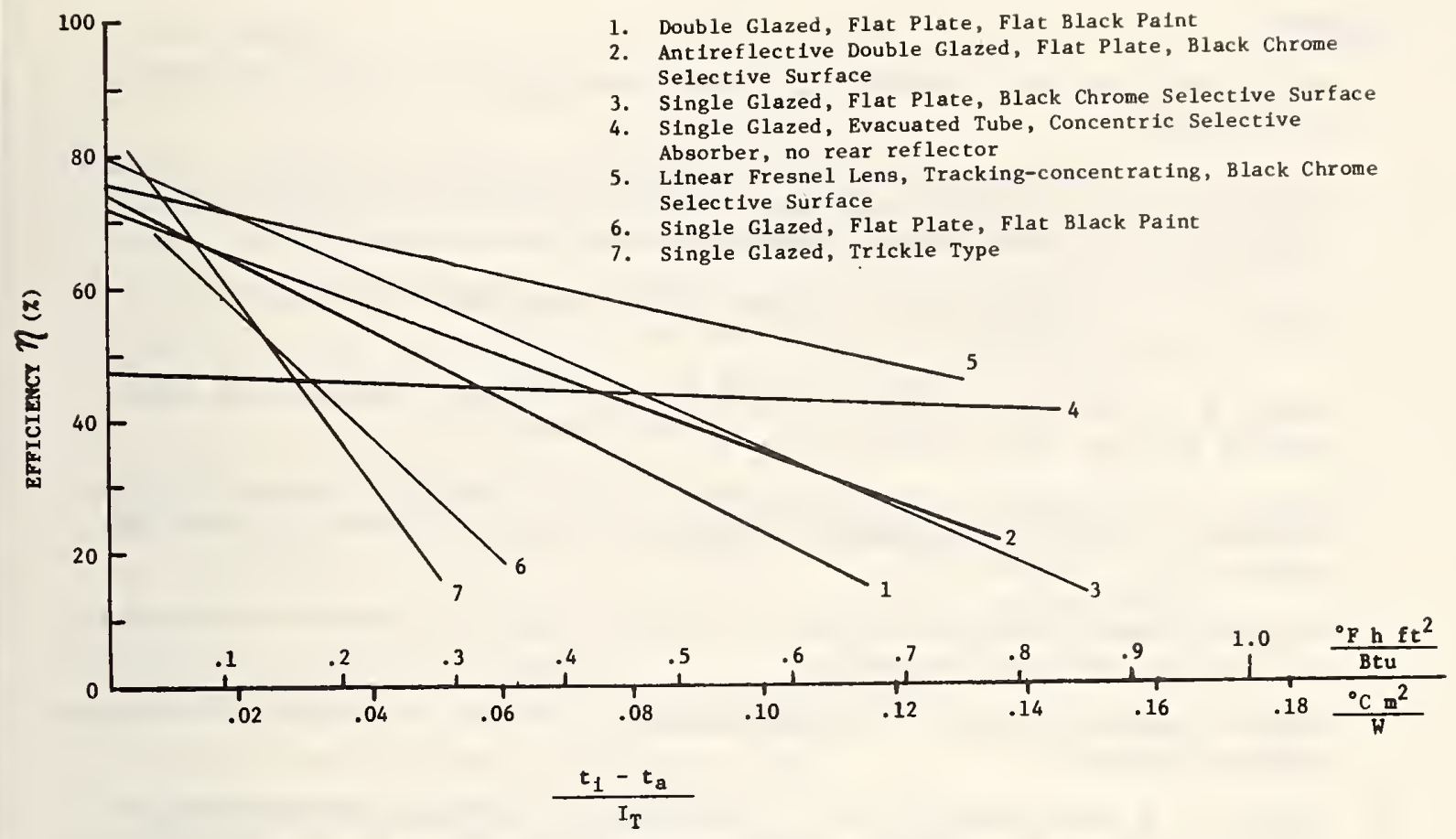

Figure A-21a Typical Thermal Efficiency Curves for Liquid Collectors Based on Collector Aperture Area

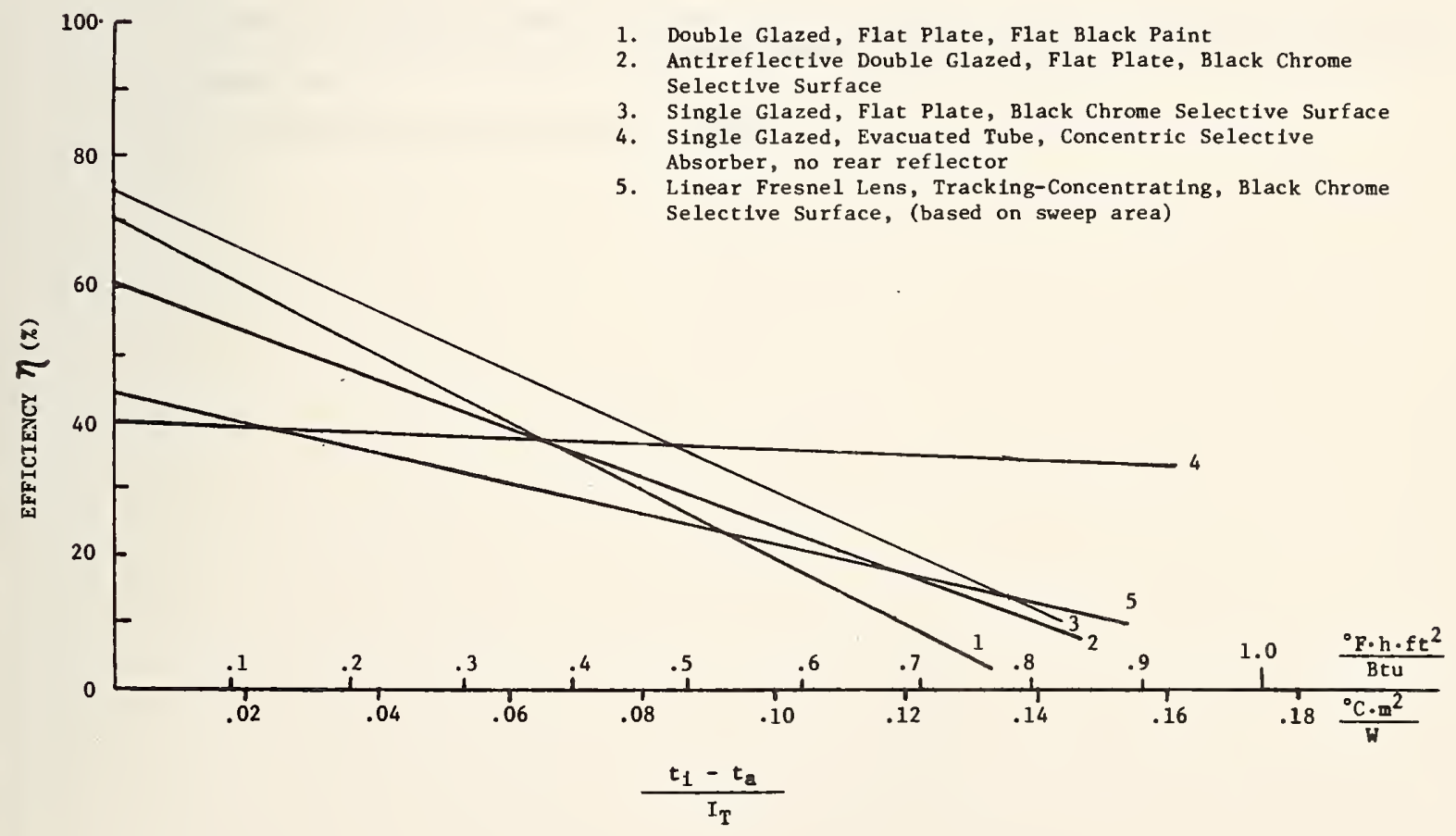

Figure A-21b Typical Thermal Efficiency Curves for Liguid Collectors Based on Collector Gross Frontal Area 


\section{REFERENCES}

1. ASHRAE Standard 93-77, "Methods of Testing Solar Collectors Based on Thermal Performance."

2. Johnson, S. M. and Simon, F. F., "Evaluation of Flat-Plate Collector Performance Obtained Under Controlled Conditions in a Solar Simulator," Proceedings of American Section ISES Meeting, Winnipeg, Canada, Vol. 2, August 1976.

3. Kays, W. M. and London, A. L., "Compact Heat Exchangers," National Press, Palo Alto, California, 1955.

4. Klein, S. A., Beckman, W. A., and Duffie, J. A., "Design Procedure for Solar Heating Systems," Solar Energy, Vol. 18, pp. 113-127, 1976.

5. Klein, S. A., Beckman, W. A., and Duffie, J. A., "A Design Procedure for Solar Air Heating Systems," Proceedings of American Section ISES Meeting, Winnipeg, Canada, Vo1. 4, August 1976.

6. "f-Chart Computer Program Version 1.2," Solar Engineering Laboratory, University of Wisconsin, Madison, Wisconsin.

7. "TRNSYS Computer Program," Solar Engineering Laboratory, University of Wisconsin, Madison, Wisconsin.

8. Baughn, J. W. and Dougherty, D. A., "Experimental Investigation and Computer Modeling of Solar Natural Circulation System," Proceedings of the 1977 American Section of ISES Annual Meeting, Orlando, Florida. 


\section{NOMENCLATURE}

$A_{C}$ - Collector area (aperture or gross basis) $\left[\mathrm{ft}^{2}\right]$

$A_{\text {ref }}$ - Collector area for reference system [ $\mathrm{ft}^{2}$ ]

Areq - Collector area required to meet \% of DHW load [ $\mathrm{ft}^{2}$ ]

(AU) $\mathrm{HX}$ - Heat exchanger heat transfer factor $\left[\mathrm{Btu} /\left(\mathrm{h} \cdot{ }^{\circ} \mathrm{F}\right)\right]$

$\mathrm{C}_{\mathrm{c}}=\left(\dot{\mathrm{m}}_{\mathrm{p}}\right)_{\mathrm{c}}-$ Fluid capacitance rate of the collector working fluid $\left[\mathrm{Btu} /\left(\mathrm{h} \cdot{ }^{\circ} \mathrm{F}\right)\right]$

$\mathrm{C}_{\min }=(\stackrel{\mathrm{m} c}{\mathrm{p}})_{\min }-\mathrm{Min}$. fluid capacitance rate $\left[\mathrm{Btu} /\left(\mathrm{h} \cdot{ }^{\circ} \mathrm{F}\right)\right]$

$\mathrm{C}_{\mathrm{s}}=\left(\dot{\mathrm{m}}_{\mathrm{p}}\right)_{\mathrm{s}}-\mathrm{Flu} \dot{\mathrm{f}}$ capacitance rate of the storage loop $\left[\mathrm{Btu} /\left(\mathrm{h} \cdot{ }^{\circ} \mathrm{F}\right)\right]$

$c_{p}-$ Fluid specific heat $\left[\mathrm{Btu} /\left(\mathrm{h} \cdot{ }^{\circ} \mathrm{F}\right)\right]$

$\mathrm{F}_{\mathrm{R}}$ - Collector heat removal factor

$\mathrm{F}_{\mathrm{R}}^{\prime}$ - Combined form of the collector heat exchanger effectiveness $\left(\varepsilon_{\mathrm{c}}\right)$ and the collector heat removal factor $\left(F_{R}\right)$

$\dot{\mathrm{m}}$ - Mass flow rate of the working fluid either air or liquid $(1 \mathrm{~b} / \mathrm{h})$

$M$ - Mass of thermal storage (1b)

NTU - Number of heat transfer units (dimensionless)

$R_{1}, R_{2}$ - Heat exchanger temperature ratios

$\mathrm{t}_{\mathrm{m}}$ - Temperature of water matn supply $\left[{ }^{\circ} \mathrm{F}\right]$

$t_{s}$ - Temperature of domestic hot water supply $\left[{ }^{\circ} \mathrm{F}\right]$

$\mathrm{U}$ - Heat loss coefficient (storage tanks and pipes) [Btu/(h. $\left.{ }^{\circ} \mathrm{F} \cdot \mathrm{ft}{ }^{2}\right)$ ]

$\mathrm{U}_{\mathrm{L}}$ - Collector heat loss factor $\left[\mathrm{Btu} /\left(\mathrm{h} \cdot{ }^{\circ} \mathrm{F} \cdot \mathrm{ft}^{2}\right)\right]$

$\varepsilon_{\mathrm{HX}}$ - Heat exchanger effectiveness

$n$ - Thermal efficiency (ratio of the thermal energy removed from the collector, to the total incident solar radiation on the collector aperture area or collector gross area

$(\tau \alpha)_{n}$ - Transmittance-absorptance product at normal incidence 
APPENDIX B

MATERIALS TABLES 


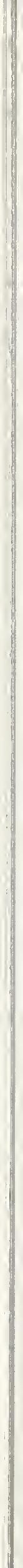




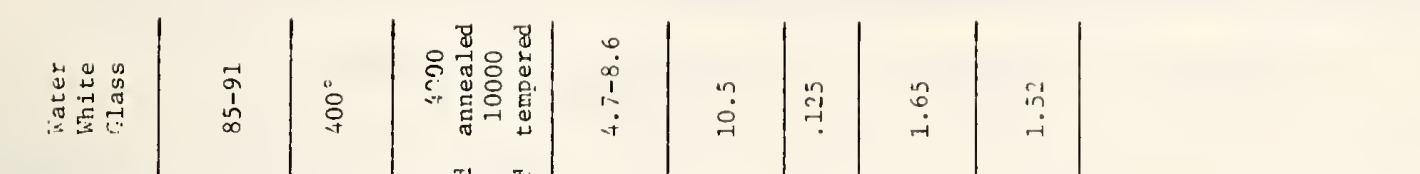

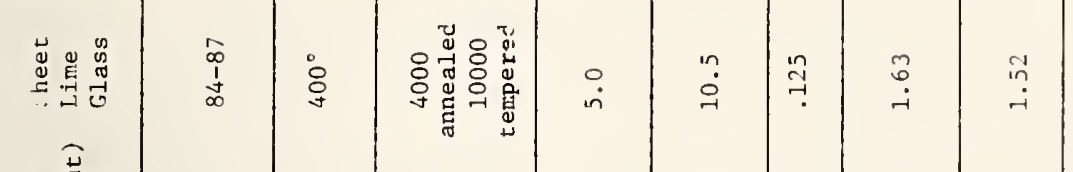

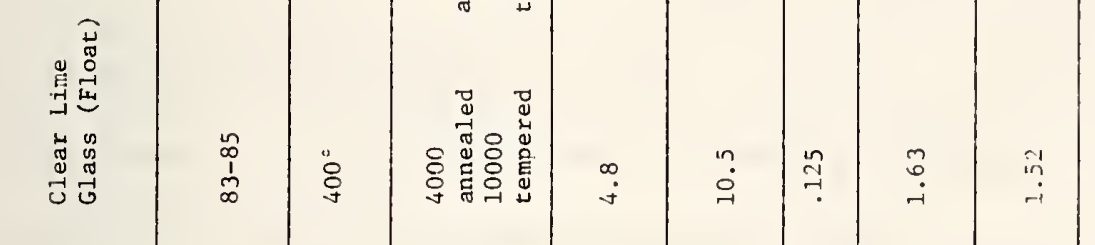

(1)

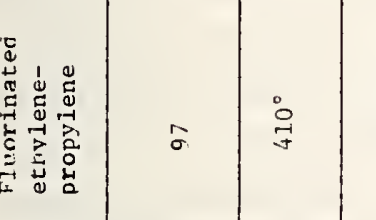

)

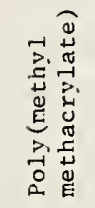

高

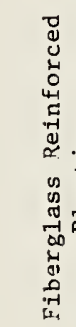

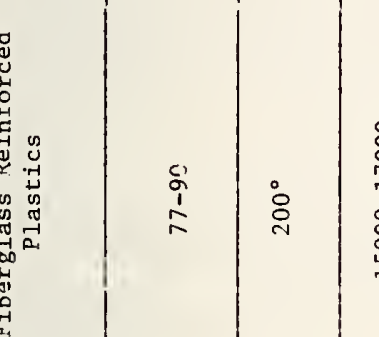

竞

?.

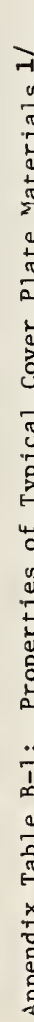

高

ำ

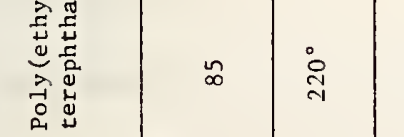

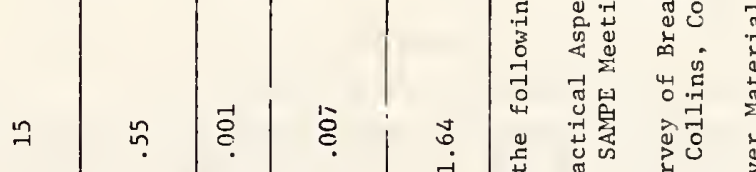

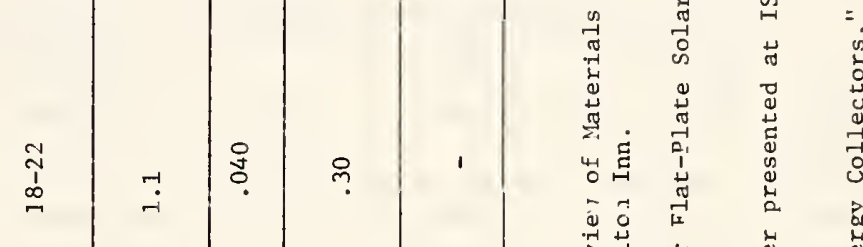

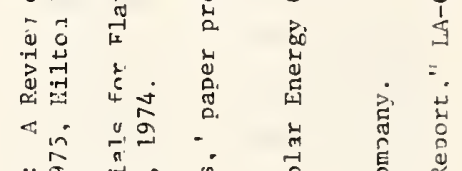

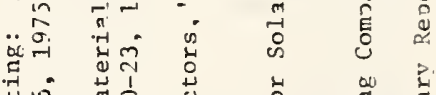

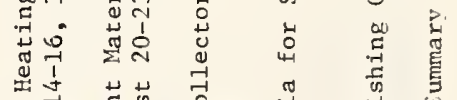

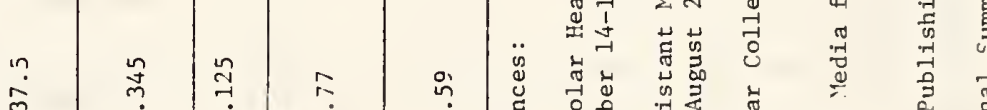

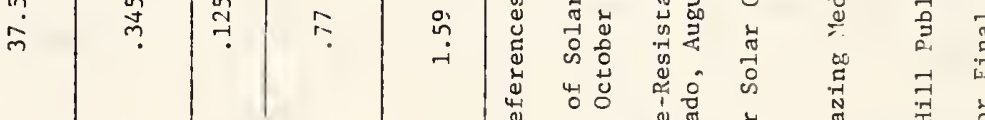

प की

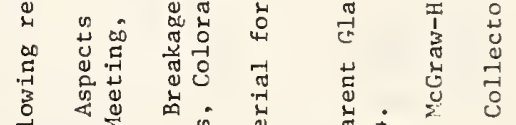

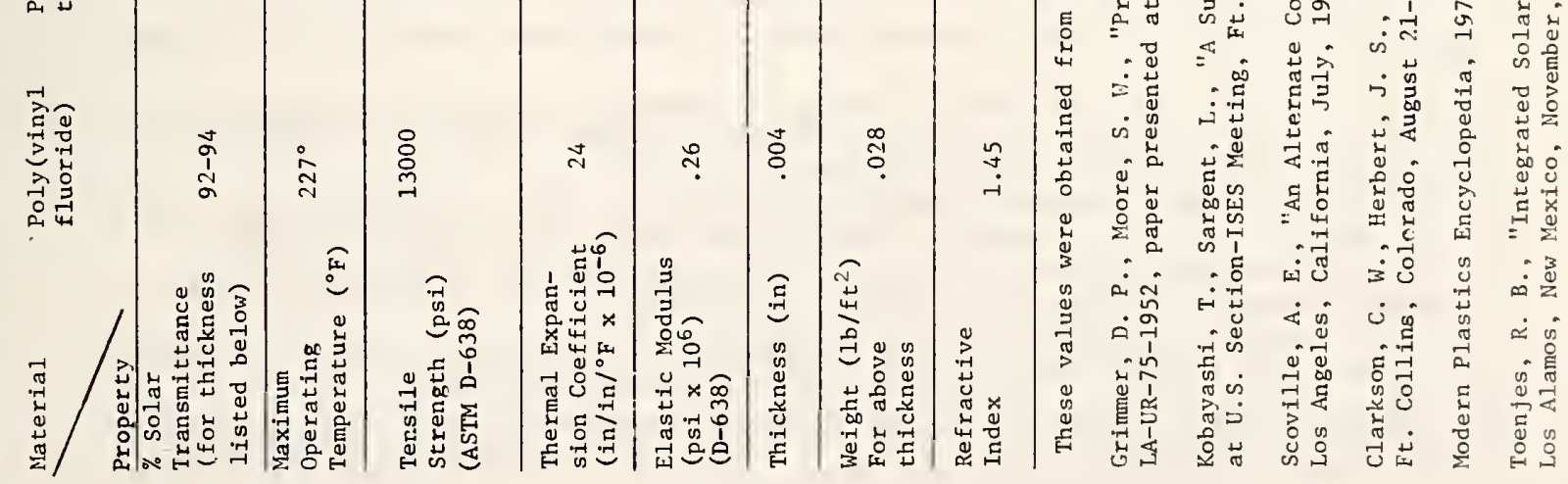

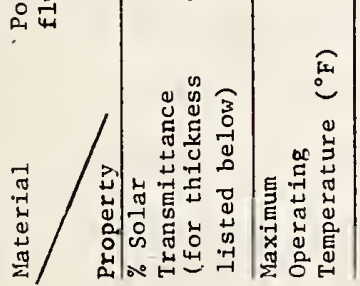

§ิ

$\stackrel{\circ}{-i}$

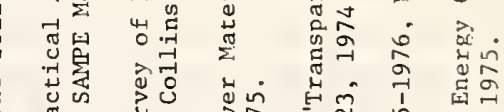

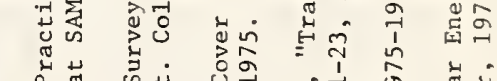




\begin{tabular}{|c|c|c|c|c|c|}
\hline Property & $\underset{a}{\text { Absorptance } 1 /}$ & $\begin{array}{c}\text { Emittance } \\
\varepsilon\end{array}$ & $\frac{\alpha}{\varepsilon}$ & $\begin{array}{l}\text { Breakdown } \\
\text { Temperature } \\
{ }^{\circ} \mathrm{F}\left({ }^{\circ} \mathrm{C}\right)\end{array}$ & Comments \\
\hline
\end{tabular}

\begin{tabular}{|c|c|c|c|c|c|}
\hline Black Chrome & $.87-.93$ & .1 & $\sim 9$ & & \\
\hline Alkyd Enamel & .9 & .9 & 1 & & $\begin{array}{l}\text { Durability Limited at High } \\
\text { Temperatures }\end{array}$ \\
\hline $\begin{array}{l}\text { Black Acrylic } \\
\text { Paint }\end{array}$ & $.92-.97$ & $.84-.90$ & 21 & & \\
\hline $\begin{array}{l}\text { Black Inorgantc } \\
\text { Paint }\end{array}$ & $.89-.96$ & $.86-.93$ & $\sim 1$ & & \\
\hline $\begin{array}{l}\text { Black Silicone } \\
\text { Paint }\end{array}$ & $.86-.94$ & $.83-.89$ & $\sim 1$ & & Silicone Binder \\
\hline $\begin{array}{l}\mathrm{PbS} / \mathrm{S} 11 \text { icone } \\
\text { Paint }\end{array}$ & .94 & .4 & 2.5 & $662(350)$ & $\begin{array}{l}\text { Has a High Emittance for } \\
\text { Thicknesses }>10 \mu \mathrm{m}\end{array}$ \\
\hline $\begin{array}{l}\text { Flat Black } \\
\text { Paint }\end{array}$ & $.95-.98$ & $.89-.97$ & $w 1$ & & \\
\hline Ceramic Ename1 & .9 & .5 & 1.8 & & Stable at High Temperatures \\
\hline Black Zinc & .9 & .1 & 9 & & \\
\hline $\begin{array}{l}\text { Copper Oxide } \\
\text { over Aluminum }\end{array}$ & .93 & .11 & 8.5 & $392(200)$ & \\
\hline $\begin{array}{l}\text { Black Copper } \\
\text { over Copper }\end{array}$ & $.85-.90$ & $.08-.12$ & $7-11$ & $842(450)$ & Patinates with Moisture \\
\hline $\begin{array}{l}\text { Black Chrome } \\
\text { over Nickel }\end{array}$ & $.92-.94$ & $.07-.12$ & $8-13$ & $842(450)$ & Stable at High Temperatures \\
\hline $\begin{array}{l}\text { Black Nickel } \\
\text { over Nickel }\end{array}$ & .93 & .06 & 15 & $842(450)$ & $\begin{array}{l}\text { May be Influenced by Moisture } \\
\text { at Elevated Temperatures }\end{array}$ \\
\hline $\begin{array}{l}\mathrm{N} 1-Z \mathrm{n}-\mathrm{S} \text { over } \\
\text { Nickel }\end{array}$ & .96 & .97 & 14 & $536(280)$ & \\
\hline $\begin{array}{l}\text { Black Iron } \\
\text { over Steel }\end{array}$ & .90 & .10 & 9 & & \\
\hline
\end{tabular}

1/ Dependent on thickness and vehicle to binder ratio.

G. E. McDonald, "Survey of Coatings for Solar Collectors", NASA TMX-71730, paper presented at Workshop on Solar Collectors for Heating and Cooling of Bulldings, November 21-23, 1974, New York City.

G. E. McDonald, "Variation of Solar-Selective Properties of Black Chrome with Plating Time", NASA TMX-71731, May 1975.

S. W. Moore, J. D. Balcomb, J. C. Hedstrom, "Design and Testing of a Structurally Integrated Steel Solar Collector Unit Based on Expanded Flat Metal Plates", LA-UR-74-1093, paper presented at U. S. Section-ISES Meeting, Ft. Collins, Colorado, August 19-23, 1974.

D. P. Grimer, S. W. Moore, "Practical Aspects of Solar Heating: A Review of Materials Use in Solar Heating Applications", paper presented at SAMPE Meeting, October 14-16, 1975, Hilton Inn.

R. B. Toenjes, "Integrated Solar Energy Collector Final Summary Report", LA-6143-MS, Los Alamos Sclentific Laboratory, Los Alamos, New Mexico, November 1975.

G. L. Merr111, "Solar Heating Proof-of-Concept Experiment for a Public School Building", Honeywell Inc., Minneapolis, Minnesota National Science Foundation Contract No. C-870.

D. L. Kirkpatrick, "Solar Collector Design and Performance Experlence", for the Grover Cleveland School, Boston, Massachusetts, paper presented at Workshop on Solar Collectors for Heating and Cooling of Bufldings, November 21-23, 1974, New York City. 
Appendix lable B-3: Properties of Typical Absorber Substral: Materials 1/

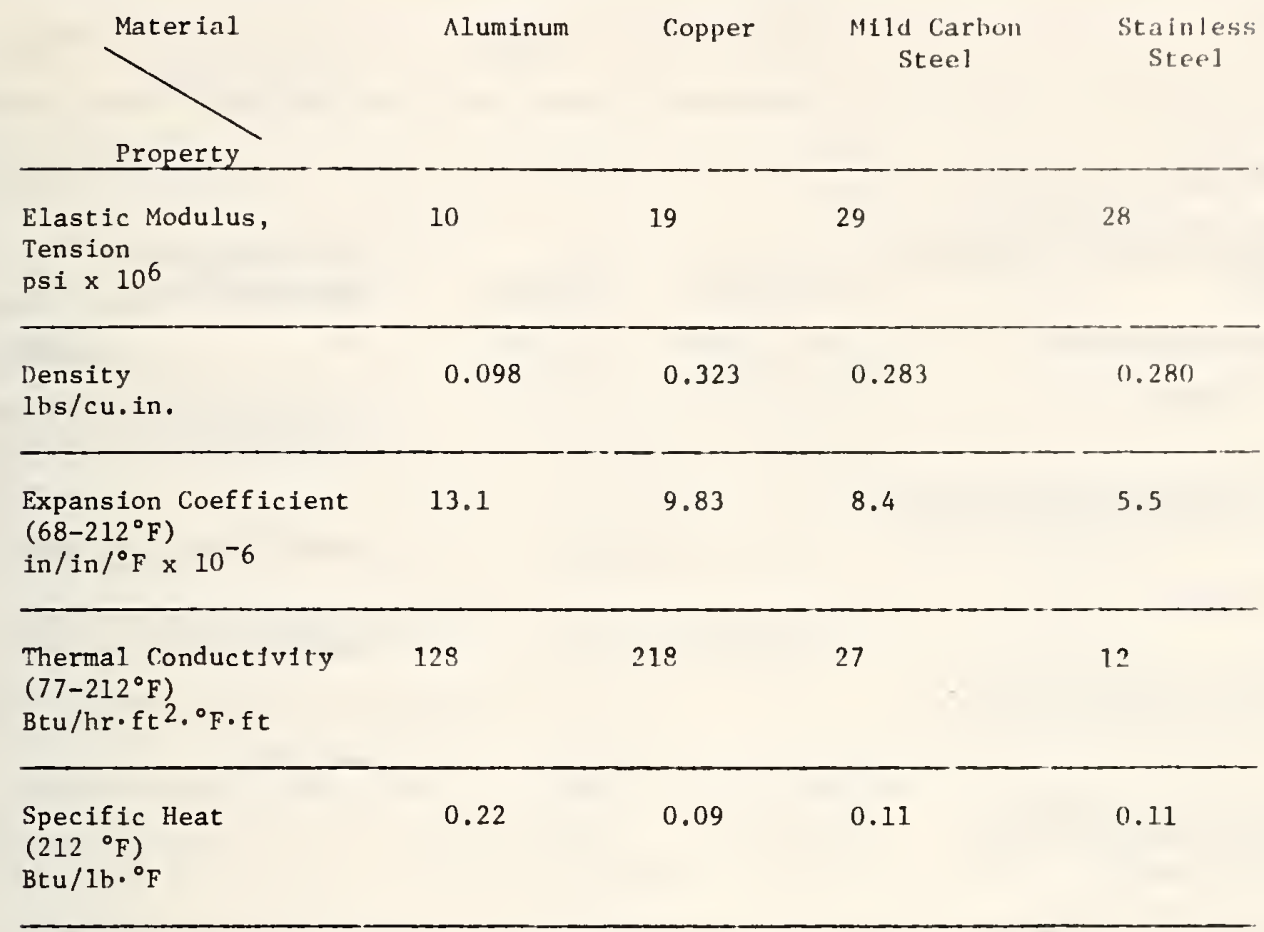

1/ Typical valves: standard specifications or manufacturer's literature should be consulted for specific types or alloys. 


\section{Ferrous pipe \& fittings}

Steel plpe, black and hot dipped zinccoated (galvanized) welded and seamless for ordinary use

Steel pipe welded and seamless

Nipples, Plpe, threaded

Plpe fittings: (bushings, locknuts and plugs) Iron, steel and aluminum (threaded) 125-150 1bs.

Ma1leable-1ron threaded fittings, 150 and 300 1bs.

Unions, pipe, steel or malleable iron; threaded connection, $150 \mathrm{lbs}$. and 250 1 bs.

Standard Specification for Seamless and Welded Ferritic Stainless Steel Tubing for General Service

Standard Specification for Seamless and Welded Austentic Stain1ess Steel Tubing for General Service

\section{Nonferrous metal11c p1pe and fittings}

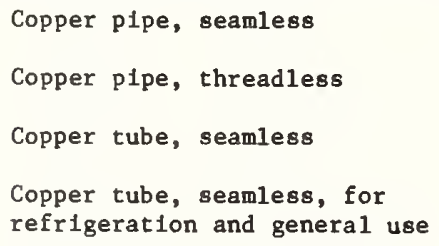

$\begin{array}{ll}\text { B125.2-1972 } & \text { A120-73 } \\ \text { B125.1-1972 } & \text { A53-73 } \\ --- & -- \\ & \\ -- & \\ - & \end{array}$

WW-P-406D-1973 WW-P-406D-1-1974

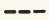

ASME SA53

WW-N-351b-1967 WW-N-351b [1] -1970

CS5-65

WW-P-471B-1970

WW-P-521F-1968

WW-U-531D

A268-73

A269-73

B42-75

WW-P-377d-1962

ASME SB42

B302-74a

B74-74b

ASME SB75

B280-75

B88-75

WW-T-775a-1962

WW-T-799D-1971

B251-75

B136-74

WW-T-791A-1971

B43-75

WW-P-351a-1963

ASME SB43
ASME SB251

ASME SB135
WW-P. 460b-1967 WW-P-460b-1-1972

M-T-725a-1973 
Appendix Table 13-4: continued

Description
ANS 1

ASTM
Welded Copper Tube

kielded Copper Nickel Pipe and Tube

Welded Copper and Copper Alloy Tube

Welded Copper Alloy Water Tube

Welded Brass Tube

Welded Copper Alloy Pipe

Copper-silicon alloy seamless pipe and tube

Wrought copper and bronze solder-joint pressure fitting

Wrought copper and wrought copper alloy solder-joint drainage fittings

Aluminum-alloy seamless pipe and seamless extruded tube

Aluminum-alloy drawn seamless tubes

Aluminum-alloy drawn tubes for general purpose application

--
---
--
--
H26. 3-1973
B16. 22-1973
B16.29-1973

H38.7

H38. 7

H38.17-1974

H38. 18-1974

for general purpose application

ed tubes

Wrought aluminum and aluminum alloy welding fittings

H38.19-1974

Pipe hangers and supports

Pipe hangers and supports, materials, design and manufacture

Pipe hangers and supports, selection and application

Polybutylene (PB) plastic hot-water distribution systems ( $180^{\circ} \mathrm{F}$ Max.)

Plastic hot-water distribution systems: chlorinated poly (vinyl chloride) (CPVC) for water service $\left(180^{\circ} \mathrm{F}\right.$ Max.)

Cold water service, clamps, hose, low pressure

Standard methods of testing rubber hose

Standard method of test for sealability of gasket materials

Standard method of test for fluid resistance of gasket materials

$$
\text { B- } 447
$$

B-543

B-586

B-587

B-608

B315-75
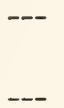

B241

B310-74a

B483-73

B491-73

B361-73

$--$

WW-H-171D-1970

MSS SP-58-1975 2/

MSS SP-69-1966
D3309-74

D2846-73

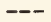

D380-75

$\mathrm{J} 2.5$

2193.1-1970

F37-68

F146-72 


\section{$\underline{\text { Valves }}$}

Standard for solenold valves for use with volatile refrigerants and water

Valves, pressure, reducing and regulating for installation on domestic water supply lines

Water pressure reducling valves for domest1c water supply systems
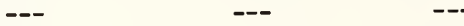

ARI 760,1975

Valves, automatic rellef (For water/ steam).

ANS

Valves, cast 1ron gate, $125 \& 2501$ b;

threaded and flanged

Combination check and relief valves

Valves, bal1

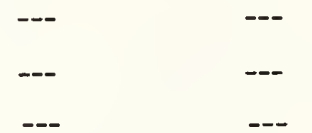

WW-V-58a-1966

IAPMO TSC-8-66

Valves, bronze, angle, check and globe, 125 and $150 \mathrm{lb}$, threaded and flanged or soldered

Valves, water heater drain

Globe type loglighter valves, angle or straight pattern

Valves, electrically operated

Valves ( 125 pound bronze gate)

Valves (150 pound corrosion resiatant, cast, flanged)

Valves (butterfly)

Low velocity duct construction standards

High velocity duct construction standards

Fibrous glass duct construction standards

Pressure sensitive tape standards

for fibrous glass duct

WW-V-35a-1965

IAPMO PS15-71

ASSE 1003,1970

Duct liner application standard

F1re damper guide
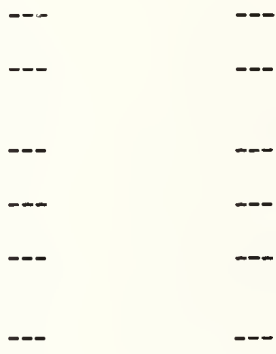

$--$

\section{$\cdots$}

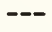

$--$

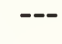

-..

$--$

$--$

WH-V-51d-1967

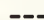

ASSE 1005

IAPMO PS10-66

1)

UL 429,1955

MSS SP 37, 1969

MSS SP 42

MSS SP 67, 1966

SMACNA

SMACNA

SMACNA

SMACNA

SMACNA

SMACNA

1/ International Association of Plumbing and Mechanical Officials, 5032 Alhambra Avenue, Los Angeles, California 90032

2/ Manufacturers Standardization Soclety of the Valve and Fitting Industry, 1815 North Fort Meyer Drive, Arlington, Virginia 22209 
Appendix Table B-5: Temperature and Pressure Ratings for Ball Valves 1/

\begin{tabular}{|c|c|c|c|c|c|}
\hline \multirow{2}{*}{$\begin{array}{c}\text { Size } \\
\text { (inches) }\end{array}$} & \multirow{2}{*}{ Temperature, } & \multicolumn{4}{|c|}{ Materials (Pressure in psi) } \\
\hline & & $\overline{\text { Bronze }}$ & Iron & Carbon Steel & Alloy Steel \\
\hline \multirow[t]{3}{*}{$1 / 2$} & -20 to 100 & 200 and 400 & & 1000 & 1000 \\
\hline & 150 & 400 & & 850 & 850 \\
\hline & 200 & 150 and 400 & & 700 & 700 \\
\hline \multirow[t]{3}{*}{ TO } & 250 & $152 /$ and 400 & & 500 & 500 \\
\hline & 300 & 300 & & 300 & 300 \\
\hline & 325 & 200 & & 200 & 200 \\
\hline \multirow[t]{3}{*}{$3 / 4$} & 353 & 125 & & 125 & 125 \\
\hline & 375 & 90 & & 90 & 90 \\
\hline & 400 & 60 & & 60 & 60 \\
\hline \multirow[t]{3}{*}{1} & -20 to 100 & 400 & & 720 & 720 \\
\hline & 150 & 400 & & 710 & 710 \\
\hline & 200 & 400 & & 700 & 700 \\
\hline \multirow[t]{2}{*}{ TO } & 250 & 400 & & 500 & 500 \\
\hline & 300 & 300 & & 300 & 300 \\
\hline \multirow[t]{4}{*}{2} & 325 & 200 & & 200 & 200 \\
\hline & 353 & 125 & & 125 & 125 \\
\hline & 375 & 90 & & 90 & 90 \\
\hline & 400 & 60 & & 60 & 60 \\
\hline \multirow[t]{2}{*}{$2-1 / 2$} & -20 to 100 & & 220 & 275 & 275 \\
\hline & 150 & & 205 & 255 & 255 \\
\hline T0 & 200 & & 190 & 240 & 240 \\
\hline 12 & 250 & & 180 & 225 & 225 \\
\hline
\end{tabular}

I/ These ratings for ball valves, presented in Federal specification WW-V-35a-1975, are intended for guidance and are not intended to be restrictive. Valves should not be used for pressures and temperatures exceeding the manufacturer's rating.

2/ 15 pounds saturated steam temperature. 
Appendix Table B-6: Thermal Storage Unit Containers $1 /$

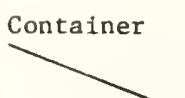

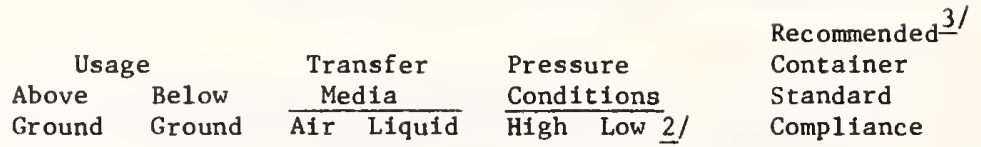

Protective
Coating

Recommended

Material

Ground

Ground

ir Liquid

$\begin{array}{llllllll}\text { Aluminum } & \mathrm{X} & \mathrm{X} & \mathrm{X} & \mathrm{X} & \mathrm{X} & \mathrm{X} & \text { ANSI B96. } 1\end{array}$

1973

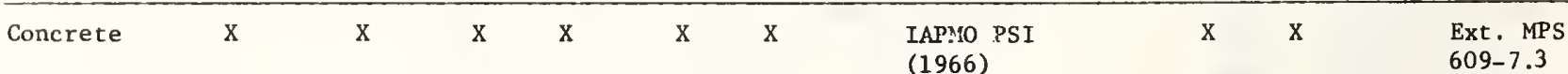

(1966)

609-7.3

Int. TTP-95A(3)

27 May 66

\begin{tabular}{|c|c|c|c|c|c|c|}
\hline Earth & $x$ & $\mathrm{X}$ & $\mathrm{X}$ & $\begin{array}{l}\text { Vapor Barrier } \\
\text { Materials as }\end{array}$ & $\begin{array}{l}\text { Vapor Barrier } \\
\text { Covering of }\end{array}$ & MPS 507.2 . \\
\hline
\end{tabular}

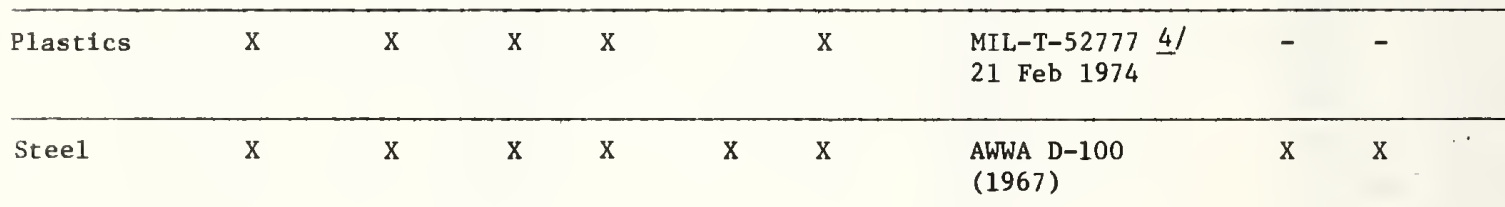

Ext. MPS

$609-7.4$ II

Ext. \& Int.

AWWA D102

(1964)

Wood $X \quad X \quad x \quad x \quad$ NFO 8 (1965)

1/ Thermal Storage Unit - any container, space, or device which has the capacity to store transfer media (1iquid or solid) containing thermal energy for later use.

$2 /$ Low pressure systems are those subjected to atmospheric pressure only, i.e. vented.

3/ When applicable, ASME Boiler and Pressure Vessel Code, Section VIII may be used.

4/ Refers to fiber reinforced polyester containers

5/ In lieu of interior galvanized, glass-lined or stone-lined tanks. 


\begin{tabular}{|c|c|c|c|c|c|c|}
\hline & Water & $\begin{array}{l}50 \% \text { Ethylene } \\
\text { Glycol/Water }\end{array}$ & $\begin{array}{l}\text { 50\% Propylene } \\
\text { G1ycol/Water }\end{array}$ & $\begin{array}{l}\text { Sillcone } \\
\text { Fluld }\end{array}$ & Aromatics & $\begin{array}{c}\text { Paraffinic } \\
\text { Oil }\end{array}$ \\
\hline $\begin{array}{l}\text { Freezing Point, } \\
{ }^{\circ} \mathrm{F}\left({ }^{\circ} \mathrm{C}\right)\end{array}$ & $32(0)$ & $-33(-36)$ & $-28(-33)$ & $-58(-50)$ & $\begin{array}{l}-107 \text { to }-25 \\
(-73 \text { to }-32)\end{array}$ & -- \\
\hline $\begin{array}{l}\text { Bolling Point, } \\
{ }^{\circ} \mathrm{F}\left({ }^{\circ} \mathrm{C}\right) \text { (at atm. } \\
\text { pressure) }\end{array}$ & $212(100)$ & $230(110)$ & -- & None & $\begin{array}{l}300-400 \\
(149-204)\end{array}$ & $700 \quad(371)$ \\
\hline Fluld Stability & $\begin{array}{l}\text { Requires } \mathrm{pH} \\
\text { or } 1 \text { hhibitor } \\
\text { monitoring }\end{array}$ & $\begin{array}{l}\text { Requires } \mathrm{pH} \\
\text { or Inhibitor } \\
\text { monitoring }\end{array}$ & $\begin{array}{l}\text { Requires pH } \\
\text { or inhibitor } \\
\text { monitoring }\end{array}$ & Good & Good & Good \\
\hline $\begin{array}{l}\text { Flash Point, } \\
{ }^{\circ} \mathrm{F}\left({ }^{\circ} \mathrm{C}\right)\end{array}$ & None & None & $600(315)$ & $600(315)$ & $\begin{array}{l}145-300 \\
(63-149)\end{array}$ & $455(235)$ \\
\hline $\begin{array}{c}\text { Spec1fic Heat } \\
\left(73^{\circ} \mathrm{F}\right) \\
{\left[\mathrm{Btu} /\left(1 \mathrm{~b} \cdot{ }^{\circ} \mathrm{F}\right)\right]}\end{array}$ & 1.0 & 0.80 & 0.85 & $0.34-0.48$ & $0.36-0.42$ & 0.46 \\
\hline $\begin{array}{l}\text { Viscosity } \\
\left(\text { cstk at } 77^{\circ} \mathrm{F}\right)\end{array}$ & 0.9 & 21 & 5 & $50-50000$ & $1-100$ & - \\
\hline Toxicity & $\begin{array}{l}\text { Depends on } \\
\text { Inhibitor } \\
\text { used }\end{array}$ & $\begin{array}{l}\text { Depends on } \\
\text { Inhibitor } \\
\text { used }\end{array}$ & $\begin{array}{l}\text { Depends on } \\
\text { Inhibitor } \\
\text { used }\end{array}$ & Low & Moderate & -- \\
\hline
\end{tabular}

1/ These data are extracted from manufacturers 11terature to 1llustrate the properties of a few types of liquid that have been used as transfer fluids.

2/ It is important to Identify the conditions of tests for measuring flash point. Since the manufacturers literature does not always specify the test, these values may not be directly comparable. 
Hên

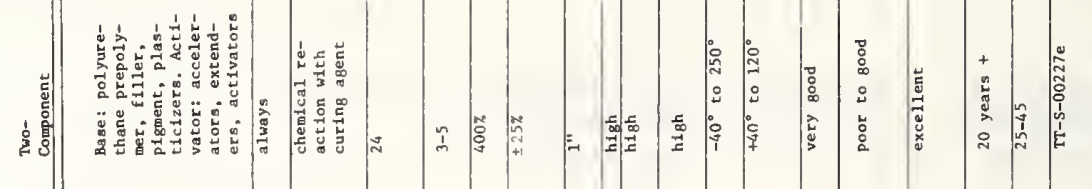

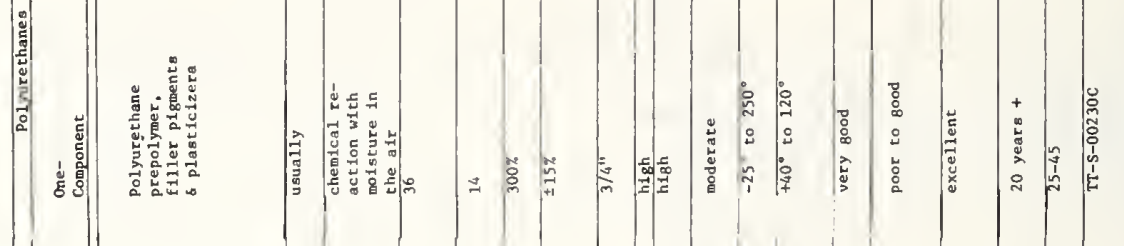

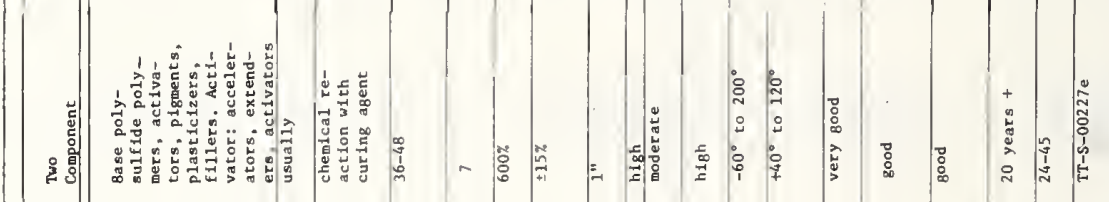

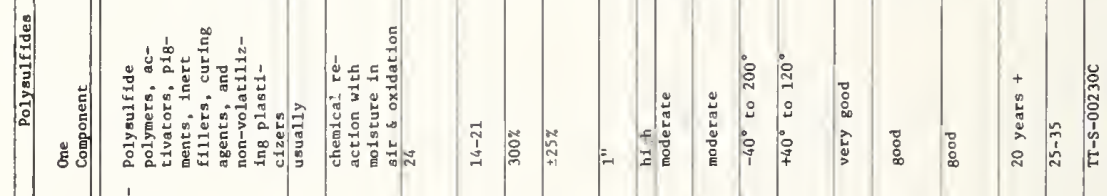

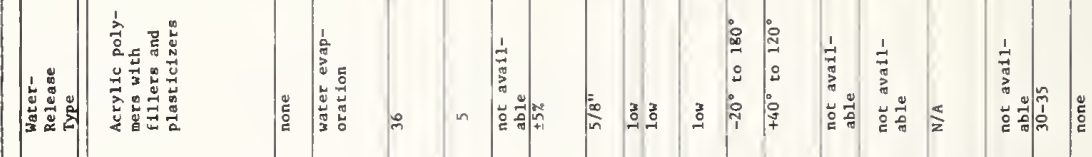

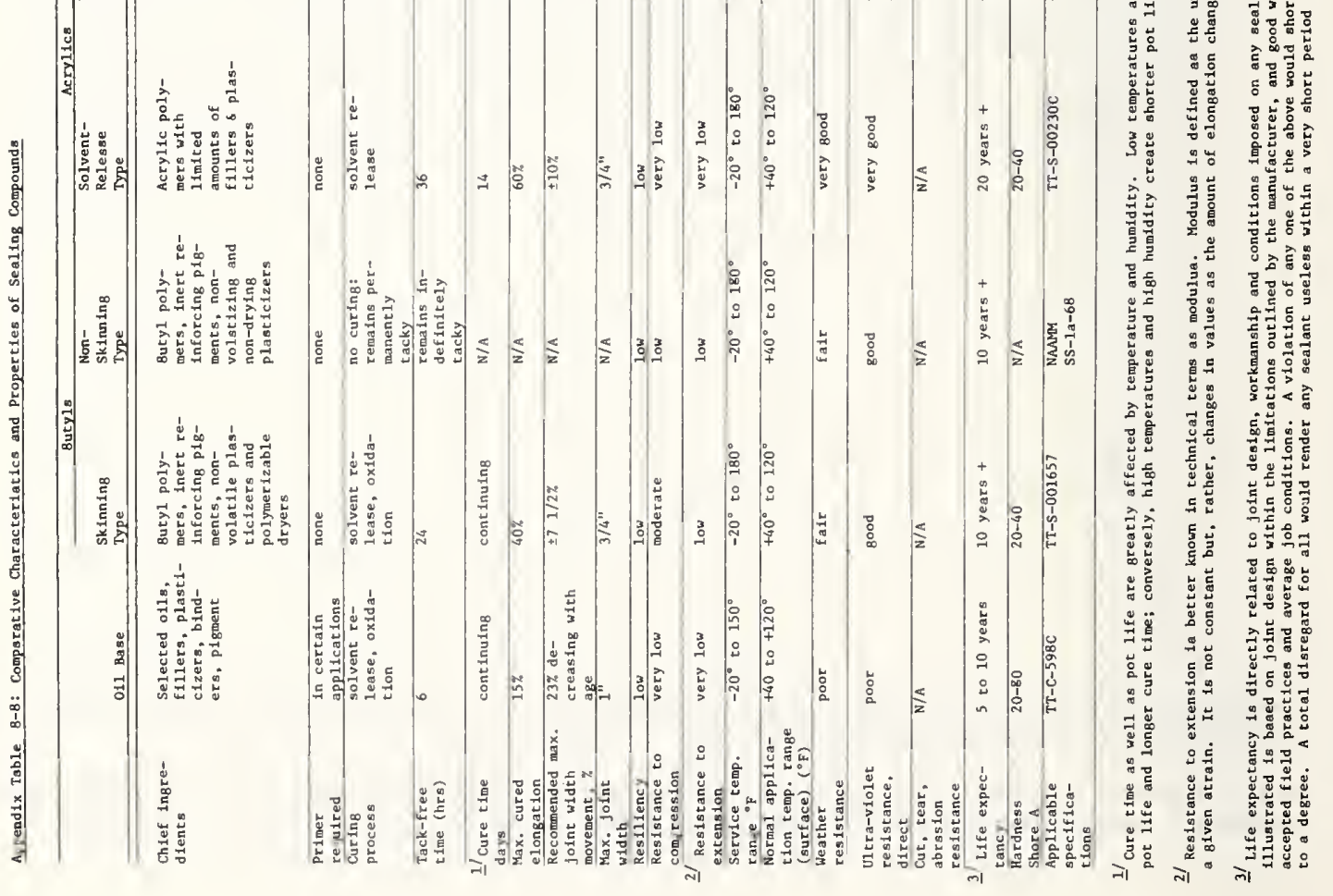

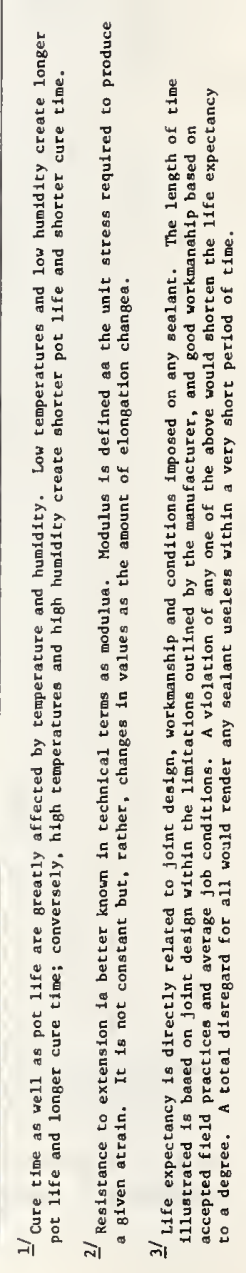




\section{DEFINITIONS}

General: Abbreviations, terms, phrases, and words and their derivatives used in these Intermediate standards for solar application shall have the meanings given in this Appendix. The terms defined herein apply only for The Department of Housing and Urban Development (HUD) purposes and may differ in some respects from definitions prepared for building codes or other purposes. Wherever possible, the meaning in common use in the residential construction fleld is used.

Active Solar System: An assembly of collectors, thermal storage device(s), and transfer liquid which converts solar energy into thermal energy, and in which energy in addition to solar is used to accomplish the transfer of thermal energy.

Air Gap: An air gap in a potable water distribution system is the unobstructed vertical distance through the free atmosphere between the lowest opening from any pipe or faucet supplying water to a tank, plumbing fixture, or other device and the flood level rim of the receptacle. (NSPC)*

Auxiliary Energy Subsystem: Equipment utilizing energy other than solar both to supplement the output provided by the solar energy system as required by the design conditions, and to provide full energy backup requirements during periods when the solar H, or DHW systems are inoperable.

Backflow: The unintentional reversal of flow in a potable water distribution system which may result in the transport of forelgn materials or substances into the other branches of the distribution system. (NBS)

Backflow Preventer: A device or means to prevent backflow.

Back Pressure: Pressure created by any means in the water distribution system on the premises, which by being in excess of the pressure in the water supply main could cause backflow. (NBS)

Back Siphonage: The backflow of possibly contaminated water into the potable water supply system as a result of the pressure in the potable water system becoming unintentionally less than the atmospheric pressure in the plumbing fixtures, pools, tanks, or vats that may be connected to the potable water distribution piping. (NBS)

Chemical Compatibility: The ability of materials and components in contact with each other to resist mutual chemical degradation, such as that caused by electrolytic action or plasticizer migration.

Collector, Combined: The collector and storage are constructed and operated such that they functionally perform as one unit and the thermal performance of the individual components cannot be meaningfully measured.

Collector, Component: Collector that is not structurally integrated with the storage or building. The collector performance can be thermally characterized as an individual component with a moving heat transfer fluid.

Collector Efficiency (instantaneous): The ratio of the amount of energy removed by the heat transfer fluid per unit of aperture over a time period of 5 minutes or less to the total incident solar radiation on the collector for the same time period under steady state conditions (test method details described in ASHRAE 93).

Collector, Integral (Passive): The collector 1s constructed and operated as part of the building structure and heating system. The thermal performance is considered a part of the building heating load and solar energy provides a significant fraction of the building heat requirements.

* Abbreviations in parentheses indicate the sources of the definitions used here. (See Appendices $\mathrm{E}$ and $\mathrm{F}$ ) 
Collector Subsystem: The assembly used for absorbing solar radiation, converting it into useful thermal energy, and transferring the thermal energy to a heat transfer fluid.

Components: An individually distinguishable product that forms part of a more complex product (i.e., subsystem or system).

Contaminants (hazardous): Materials (solids or liquids or gasses) which when added unintentionally (or intentionally) to the potable water supply cause it to be unfit for human or animal consumption. (ASSE 1013)

Control Subsystem: The assembly of devices and their electrical, pneumatic or hydraulic auxiliarles used to regulate the processes of collecting, transporting, storing, and utilizing energy in response to the thermal, safety, and health requirements of the building occupants.

Creep: A time-dependent deformation resulting from sustained loads which can be influenced by local environmental factors such as, thermal atmosphere and/or cycling, and solar radiation.

Cross Connection: Any physical connection or arrangement between two otherwise separate piping systems, one of which contains potable water and the other either water of unknown or questionable safety or steam, gas, chemicals, or other substances whereby there may be a flow from one system to the other, the direction of flow depending on the pressure differential between the two systems.

Design Life: The period of time during which an $\mathrm{H}$, and DHW system is expected to perform its intended function without requiring major maintenance or replacement.

Design Limits: The allowable range in design specifications.

DHW: Domestic hot water system.

DWV: Drain, Waste, Vent.

Emittance: The ratio of the radiant energy emitted by a body to the energy emitted by a black body at the same temperature.

Energy Transport Subsystem: That portion of the $H$, and DHW systems which contains heat transfer fluids and transports energy throughout the system.

Failure: Inability to perform intended function.

Failure (structura1): Failure of a structure or any structural element is defined as one of the following:

(a) Sudden, locally-increased curvature, major spalling, or structural collapse.

(b) The inability of the structure to resist a further increase in load.

(c) Structural deflections under design loads that cause significant performance degradation of the component or subsystem.

Flow Condition: The condition obtained when the heat transfer fluid is flowing through the collector array under normal operating conditions.

브i Heating syatem,

Heat Capacity: The amount of heat necessary to raise the temperature of a given mass one degree.

Heat Transfer Medium: A medium, liquid, or air or solid, which is used to transport thermal energy.

Laminated Glass: Consists of two or more sheets of glass held together by an intervening layer or layers of plastic material. 
MAP: Manual of acceptable Practices. A HUD Document providing information and guidance to assist in the use of the MPS.

Maximum "Flow" Temperature: The maximum temperature that will be obtained in a component when the heat transfer fluid is not flowing through the system.

Maximum Service Temperature: The maximum temperature to which a component will be exposed in actual service, either with or without the flow of heat transfer fluid.

Minimum Service Temperature: The minimum temperature to which a component will be exposed in actual service, either with or without the flow of heat transfer fluid.

MPS 4900.1: FHA "Minimum Property Standards For One and Two Family Dwellings."

MPS 4910.1: FHA 'Minimum Property Standards For Multifamily Housing."

"No-Flow" Condition: That condition obtained when the heat transfer fluid is not flowing through the collector array due to shut-down or malfunction and the collector is exposed to the amount of solar radiation that it would receive under normal operating conditions.

Non-Potable Water: Water containing impurities in amounts sufficient to cause disease or harmful physiological effects and not conforming in its bacteriological and chemical quality to the requirements of the Public Health Service Drinking Water Standards or the regulations of the public health authority having jurisdiction.

Outgassing: The emission of gases by materials and components usually during exposure to elevated temperature or reduced pressure.

Passive Solar System: An assembly of natural and architectural components including collectors, thermal storage device(s) and tranfer fluid which converts solar energy into thermal energy in a controlled manner and in which no fans or pumps are used to accomplish the transfer of thermal energy. The prime elements in a passive solar system are usually some form of thermal capacitance and solar energy control.

Pitting: The process by which localized material loss is caused in materials or components by erosion or chemical decomposition.

Physical Compatibility: The ability of materials and components in contact with each other to resist degradation by physical actions such as differential thermal expansion.

Plasticizer migration: The process by which plasticlzers used in plastics migrate within the specimen and either concentrate in a narrow boundary area or migrate to another material in connection with the specimen.

Potable Water: Water free from impurities present in amounts sufficient to cause disease or harmful physiological effects and conforming in its bacteriological and chemical quality to the requirements of the Public Health Service Drinking Water Standards or the regulations of the public health authority having jurisdiction.

Pphm: Parts per hundred million.

Premature (Failure, etc.): Failure that occurs before the design lifetime.

Safety Glass: Glazing materials predominately inorganic in character which meet the appropriate requirements of the ANSI Standard and includes laminated glass, tempered glass and wired glass.

Safety Glazing Materials: Glazing materials so constructed, treated or combined with other materials as to minimize the likelihood of cutting and piercing injuries resulting from human contact with these glazing materials.

Significant (Deterioration, Loss, etc.): Deterioration that either results in a decrease in performance greater than the design limits or in the creation of a hazard.

Solar Absorptance: The ratio of the amount of solar radiation absorbed by a surface to the amount of radiation incident on it (for terrestrial applications usually calculated for Air Mass 2 characteristics). 
Solar Building: A bullding which utilizes solar energy by means of an active or passive solar system.

Solar Degradation: The process by which exposure to sunlight deteriorates the properties of materials and components.

Solar Energy: The photon energy originating from the sun's radiation in the wavelength region from 0.3 to 2.7 micrometers.

Solar Heating System: The complete assembly of subsystems and components necessary to convert solar energy into thermal energy for heating purposes in combination with auxiliary energy when required.

Solar Time: The hours of the day as reckoned by the apparent position of the sun. Solar noon is that instant on any day at which time the sun reaches its maximum altitude for that day. Solar time is very rarely the same as local standard time in any locality.

Storage Subsystem: The assembly used for storing thermal energy so that it can be used when required.

Subsystem: A major, separable, functional assembly of a system such as complete collector, or storage, assembly, etc.

System: The complete assembly necessary to supply heat and/or domestic hot water to the dwelling.

Thermal Energy: Heat possessed by a material resulting from the motion of molecules which can do work.

TLV, Threshold Limit Values: Threshold limit values refer to afrborne concentrations of substances and represent conditions under which it is belfeved that nearly all workers may be repeatedly exposed day after day without adverse effect. Threshold 11mit values refer to time-welghted concentrations for a 7 or 8-hour workday and 40-hour workweek.

Toxic Fluids: Gases or liquids which are poisonous, irritating and/or suffocating, as classified in the Hazardous Substances Act, Code of Federal Regulations, Title 16, Part 1500 .

Transmittance: The ratio of the radiant flux transmitted through and emerging from a body to the total flux incident on it.

UV: Ultra-violet radiation, that part of the terrestrial solar spectrum between 0.3 and 0.4 micrometers.

Water Hammer: The term used to identify the hammering noises and severe shocks that may occur in pressurized water supply systems when flow is halted abruptly by the rapid closure of a valve or faucet (NBS).

Water Hammer Arrester: A manufactured device, other than an air chamber, containing a permanently sealed cushion of gas or air designed to provide protection against excessive shock pressure without maintenance.

97 1/2\% Winter Design Temperature: The outdoor air temperature will be lower than the stated values for not more than 65 hours per year (2 1/2\% of the 2,160 hours in December, January and February). 


\section{REFERENCED STANDARDS}

AASHTO H20-44 Standard Specification for Highway Bridges

ANSI A13.1 (1956) Scheme for the Identification of Piping Systems

ANSI A58.1 (1972) Building Code Requirements for Minimum Design Loads

in Buildings and Other Structures

ANSI A112.1.1 (1971) Performance Requirements, Methods of Test for

(ASSE 1001-1970) Pipe-Applied Atmospheric-Type Anti-Siphon Vacuum Breakers

ANSI Al12.1.2 Air Gaps in Plumbing Systems (Reaffirmation and redesignation of A40.4-1942)

ANSI B9.1 (1971) Safety Code for Mechanical Refrigeration

ANSI B15.1 (1972) Safety Standard for Mechanical Power Transmission Apparatus

ANSI B16.18 (1972) Cast Bronze Solder Joint Pressure Fittings

ANSI B31.1, Section I (1973) Power Piping

ANSI B96.1 (1973) Specification for Welded Aluminum-Alloy Field-Erected Storage Tanks

ANSI B124.1 (1971) Safety Standard for Air Filter Units (UL 900-April 1971)

ANSI B137.1 (1971) Steel Underground Tanks for Flammable and Combustible Liquids (UL 58-July 1971)

ANSI B191.1 (1976) Standard for Heat Pumps (UL 559)

ANSI S2.8 (1972) Gulde for Describing the Characteristics of Resilient Mountings

ANSI Z95.1 (1974) Oil Burning Equipment (NFPA 31-1972)

ANSI Z97.1 (1975) Performance Specifications and Methods of Test for Safety Glazing Material Used in Bulldings

ARI Standard 240 (1975) Standard for Unitary Heat Pump Equipment

ARI Standard 260 (1967) Standard for Application, Installation, and Servicing of Unitary Systems

ARI Standard 410 Forced Circulation Alr-Cooling and Air-Heating Coils

ARI Standard 760 (1975) Standard for Solenoid Valves for Use with Volatile Refrigerants and Water

ASHRAE 37-69 Method of Testing for Unitary Air Conditioning and Heat Pump Equipment

ASHRAE 55-74 (1974) Thermal Environmental Conditions for Human Occupancy

ASHRAE 90-75 (1975) Energy Conservation in New Building Design

ASHRAE 93-77 (1977) Methods of Testing Solar Collectors Based on Thermal Performance

ASHRAE 94-77 (1977) Method of Testing Thermal Storage Devices Based on Thermal Performance 
ASHRAE Handbook of Fundamentals

ASME SA-53, Section VIII Boiler and Pressure Vesse1 Code

ASSE 1011 Performance Requirements for Hose Connection Vacuum Breakers

ASSE 1012 Performance Requirements for Backflow Preventers with Intermediate Atomospheric Vent

ASSE 1013 Performance Requirements for Reduced Pressure Principle Back Pressure Backflow Preventers

ASSE 1015 Performance Requirements for Double Check Valve Type Back Pressure Backflow Preventers

ASSE 1020 Performance Requirements for Vacuum Breakers, Ant1-S1phon, Pressure Type

ASTM A53-75 Specification for Welded and Seamless Steel Pipe

ASTM C739-73, Section 10.4 (1973) Flame Resistance Permanency

ASTM D471-75 Test for Rubber Property - Effect of Liquids

ASTM D660-44 (1970) Evaluating Degree of Resistance to Checking of Exterfor Paints

ASTM D661-44 (1975) Evaluating Degree of Resistance to Cracking of Exterior Paints

ASTM D714-56 (1974) Evaluating Degree of Blistering of Paints

ASTM D750-68 (1974) Recommended Practice for Operating Light-and-Weather Exposure Apparatus (Carbon-Arc Type) for Artificlal Weather Testing of Rubber Compounds

ASTM D772-47 (1975) Evaluating Degree of Flaking (Scaling) of Exterior Paint

ASTM D822-60 (1973) Recommended Practice for Operating Light-and-Water-Exposure Apparatus (Carbon-Arc Type) for Testing Paint, Varnish, Lacquer, and Related Products

ASTM D1081-60 (1974) Test for Evaluating Pressure Sealing Properties of Rubber and Rubber-Like Materials

ASTM D1149-64 (1970) Test for Accelerated Ozone Cracking of Vulcanized Rubber

ASTM D1308-57 (1973) Test for Effect of Household Chemical on Clear and Pigmented Organic Finishes

ASTM D1384-70 Corrosion Test for Englne Antifreeze in Glassware

ASTM D2247-68 (1973) Testing Coated Metal Specimens at 100 Percent Relative Humidity

ASTM D2570-73 Simulated Service Corrosion Testing of Engine Antifreeze

ASTM D2776-72 Tests for Corrosivity of Water in the Absence of Heat Transfer (Electrical Methods)

ASTM E72-74a Conducting Strength Tests of Panels for Bullding Construction ASTM E84-70 (1970) Surface Burning Characteristics of Building Materials 
ASTM E108-75 (1975) Methods of Fire Tests of Roof Coverings (NFPA 256-1970)

ASTM E154-68 Testing Materials for Use as Vapor Barriers Under Concrete Slabs and as Ground Cover in Crawl Spaces

ASTM E424-71 Test for Solar Energy Transmittance and Reflectance (Terrestrial) of Sheet Materials

ASTM F146-72 Test for Fluid Resistance of Gasket Materials

ASTM G1-72 Recommended Practice for Preparing, Cleaning, and Evaluating Corrosion Test Specimens

ASTM G16-71 Recommended Practice for Applying Statistics to Analysis of Corrosion Data

ASTM G46-76 Recommended Practice for Examination and Evaluation of Pitting Corrosion

AWWA C203-73 Standard for Coal-Tar Protective Coatings and Linings for Steel Water Pipelines

AWWA C506-69 Backflow Prevention Devices-Reduced Pressure Principle and Double Check Valve Types

AWWA D100 (1967) Steel Tanks - Standpipes, Reservoirs and Elevated Tanks for Water Storage

AWWA D102 Painting and Repainting Steel Tanks, Standpipes, Reservoirs, and Elevated Tanks for Water Storage

BMC, Section M302 (1975) Specific Requirements for the Materials, Design, and Fabrication of Ductwork.

CPSC 16 CFR, Part 1201 (1976) Architectural Glazing (Code of Federal Regulation)

Federal Hazardous Substances Act, Code of Federal Regulations, Title 16, Part 1500

FCCCHR, Chapter 10 Manual of Cross-Connection Control (Foundation for Cross Connection Control Research)

FS-DD-G-451C (1972) Glass, Plate, Sheet, Figured (Float, Flat, for Glazing, Corrugated, Mirrors and Other Uses)

FS-TT-C-00598C(1) Caulking Compound, 011 and Resin Base Type (For Buflding Construction) (18 March 1971)

FS-TT-S-001543A Sealing Compound: Silicone Rubber Base (For Caulking, Sealing, and Glazing in Buildings and Other Structures) (9 June 1971)

FS-TT-S-001657 Sealing Compound: Single Component, Butyl Rubber Based, Solvent Release Type (for Buildings and Other Types of Construction) (8 October 1970)

FS-TT-S-00227E(3) Sealing Compound Elastomeric Type, Multi-compound (For Caulking, Sealing and Glazing in Buildings and Other Structures) (9 October 1970)

FS-TT-S-00230C(2) Sealing Compound: Elastomeric Type, Single Component (For Caulking, Sealing and Glazing in Buildings and Other Structures) (9 October 1970) 
FS-TT-P-95A(3) Palnt, Rubber: For Swlmming Pools and Other Concrete and Masonry Surfaces, 27 May 1966

FS-WW-U-516B Unions, Brass or Bronze, Threaded Pipe Connections and SolderJoint Tube Connections

FS-WW-U-531D Unions, Pipe, Steel or Malleable Iron; Threaded Connection, $150 \mathrm{lbs}$. and $250 \mathrm{lbs}$.

FS-WW-V-35B (1973) Valve, Ball

IAPMO PS 31-74 Specification for Backflow Prevention Devices

IAPMO PSI Prefabricated Concrete Septic Tanks (1966)

NACE TM-01-69 (1972) Laboratory Corrosion Testing of Metals for the Process Industries

NACE TM-02-70 Method of Conducting Controlled Velocity Laboratory Corrosion Tests

NACE TM-01-71 Autoclave Corrosion Testing of Metals in High Temperature Water

NACE TM-02-74 Dynamic Corrosion Testing of Metals in High Temperature

National Primary Drinking Water Regulation - Federal Register, 24 December 1975

NFPA 30 (1973) Flamable and Combustible Liquids Code

NFPA 31 (1974) Standard for the Installation of 011 Burning Equipment

NFPA 54 (1974) National Fuel Gas Code

NFPA 70 (1976) Section 240.24, National Electrical Code

NFPA 89M (1971) Clearances for Heat Produclng Appliances

NFPA 90A (1976) Standard for the Installation of Air Conditioning and Ventilating Systems

NFPA 90B (1973) Standard for the Installation of Warm Air Heating and Air Conditioning Systems

NFPA 211 (1972) Standard for Chimneys, Fireplaces, and Vents

NFPA 321 (1973) Basic Classification of Flammable and Combustible Liquids

NFO 8 National Forest Products Association, The Wood Tank

NRCA - A Manual of Roofing Practice 1970 (71)

NSPC, Section 2.13 Ratproofing

MIL-T-52777 21 February 1974 Military Specifications for Tanks:

Storage, Underground, Glass Fiber Relnforced Plastic

MSS SP-73 Silver Brazing Joints for Cast and Wrought Solder Joint Fittings

SAE J447e(1964) Prevention of Corrosion of Metals 
SAE J20e(1974) Coolant System Hoses

Threshold Limit Values for Chemical Substances and Physical Agents in the Workroom Environment with Intended Changes, 1975 - American Conference of Governmental Industrial Hygienists

UL 58 (1973) Standard for Steel Underground Tanks for Flammable and Combustible Liquids (ANSI B137.1-1971)

UL 174 (1972) Standard for Household Electric Storage-Tank Water Heaters (ANSI C33.87-1972)

UL 181-74, Section 10 Factory-Made Air Duct Materials and Air Duct Connectors

UL 296 (1974) Standard for 011 Burners

UL 573 (1972) Standard for Electric Space-Heating Equipment (ANSI C33.12-1972)

UL 726 (1973) Standard for O11-Fired Boiler Assemblies

UL 727 (1973) Standard for O11-Fired Central Furnaces (ANSI 296.1-1973)

UL 730 (1974) Standard for 011-Fired Wall Furnaces

UL 732 (1974) Standard for 011-Fired Water Heaters

UL 900 (1971) Safety Standard for Air Filter Units (ANSI B124.1-1971)

UL 1042 (1973) Standard for Electric Baseboard Heating Equipment (ANSI C33.951973)

Water Quality Criteria 1972, National Academy of Science and National Academy of Engineering 


\section{ABBREVIATIONS}

(Code Groups, Associations, and Gov't Agencies)

AASHTO

AGA

AMCA

ANSI

ARI

ASHRAE

ASME

ASSE

ASTM

AWWA

BMC

BOCA

CISPI

CPSC

CS

FCCCHR

FS

HUD

HVI

IAPMO

IBR

ICBO

IEC

ISES

ISO

MCA

MSS

NACE

NAS / NRC

NBS

NEMA

NESCA

NFO

NFPA

NRCA

NSF

NSPC

PL

SAE

SBI

SMACNA

SPMA

TEMA

UBC

UPC

UMC

UL
American Association of State Highway and Transportation officials American Gas Association

Air Moving and Conditioning Association, Inc.

American National Standards Institute

Air-Conditioning and Refrigeration Institute

American Society of Heating, Refrigerating, and Air Conditioning

Engineers

American Society of Mechanical Engineers

American Society of Sanitary Engineering

American Society for Testing and Materials

American Water Works Association, Inc.

Basic Mechanical Code (Division of BOCA)

Building Officials and Code Administrators International, Inc.

Cast Iron Soil Pipe Institute

Consumer Product Safety Commission

Commercial Standard

Foundation for Cross-Connection Control and Hydraulic Research

Federal Specifications

Department of Housing and Urban Development

Home Ventilating Institute

International Association of Plumbing and Mechanical officials

Institute of Boiler and Radiator Manufacturers (Now Hydronic Inst.)

International Conference of Building Officials

International Electrotechnical Commission

International Solar Energy Society

International Standards Organization

Mechanical Contractor's Association

Manufacturer's Standardization Society of the Valve and

Fitting Industry

National Association of Corrosion Engineers

National Academy of Science/National Research Council

National Bureau of Standards

National Electrical Manufacturer's Association

National Environmental Systems Contractors Association

National Forest Products Association

National Fire Protection Association

National Roofing Contractor's Association

National Sanitation Foundation Testing Laboratory, Inc.

National Standard Plumbing Code

Public Law

Society for Automotive Engineers

Steel Boiler Institute (Now Hydronic Institute)

Sheet Metal and Air Conditioning Contractors National

Association, Inc.

Sump Pump Manufacturer's Association

Tubular Exchanger Manufacturer's Association, Inc.

Uniform Building Code

Uniform Plumbing Code

Uniform Mechanical Code

Underwriter's Laboratories, Inc. 


\begin{tabular}{|c|c|c|c|}
\hline $\begin{array}{l}\text { U.S. DEPT. OF COMM. } \\
\text { BIBLIOGRAPHIC DATA } \\
\text { SHEET }\end{array}$ & $\begin{array}{l}\text { 1. PIBHIKATION (OR RLPORTANO. } \\
\text { NBSIR 77-1272 }\end{array}$ & $\begin{array}{l}\text { 2. Ciov't Arcession } \\
\text { No. }\end{array}$ & 3. Recipient's Accession No. \\
\hline \multicolumn{3}{|l|}{ 4. TITI I: AND SUBTITI.I: } & 5. Publication Date \\
\hline \multirow{2}{*}{\multicolumn{3}{|c|}{$\begin{array}{l}\text { Intermediate Standards for Solar Domestic Hot Water Systems/ } \\
\text { HUD Initiative }\end{array}$}} & July 1977 \\
\hline & & & $\begin{array}{l}\text { 6. Performing Organization Codc } \\
465.00\end{array}$ \\
\hline \multicolumn{3}{|c|}{$\begin{array}{l}\text { 7. AUTHow(S) } \\
\text { Solar Energy Program Team, Center for Building Technology }\end{array}$} & 8. Performing Organ. Report No. \\
\hline \multirow{2}{*}{\multicolumn{3}{|c|}{$\begin{array}{l}\text { 9. PERFORMING ORGANIZATION NAME ANI ADDRESS } \\
\text { NATIONAL BUREAU OF STANDARDS } \\
\text { DEPARTMENT OF COMMERCE } \\
\text { WASHINGTON, D.C. } 20234\end{array}$}} & $\begin{array}{l}\text { 10. Project/Task/Work Unit No. } \\
4656500\end{array}$ \\
\hline & & & $\begin{array}{l}\text { 11. Contract/Grant No. } \\
\text { IAA-H-38-76 }\end{array}$ \\
\hline \multirow{2}{*}{\multicolumn{3}{|c|}{$\begin{array}{l}\text { 12. Sponsoring Organization Name and Complete Address (Street, City, State, ZIP) } \\
\text { Division of Energy, Building Technology \& Standards } \\
\text { Office of Policy Development and Research } \\
\text { Department of Housing and Urban Development } \\
\text { Washington, D.C. } 20410\end{array}$}} & $\begin{array}{l}\text { 13. Type of Report \& Period } \\
\text { Covered } \\
\text { Final }\end{array}$ \\
\hline & & & 14. Sponsoring Agency Code \\
\hline
\end{tabular}

15. SUPPIEMENTARY NOTES

16. ABSTRAC T (A 200-word or less factual summary of most significant information. If document includes a significant bibliography or literature survey, mention it here.)

This report presents standards for the use of solar domestic hot water systems in residential applications. The standards have been developed for application in numerous housing programs of the Department of Housing and Urban Development and are a companion document to be used in conjunction with the HUD "Minimum Property Standards for One and Two Family Dwellings," 4900, and "Minimum Property Standards for Multifamily Housing," 4910. To the greatest extent possible, these standards are based on current state-of-the-art practice and on nationally recognized standards including the MPS and the HUD "Interim Performance Criteria for Solar Heating and Combined Heating/Cooling Systems and Dwellings."

17. KEY WORDS (six to twelve entries; alphabetical order; capitalize only the first letter of the first key word unless a proper name; separated by semicolons)

Solar buildings; solar collectors; solar domestic hot water systems; standards; thermal storage

\begin{tabular}{|c|c|c|}
\hline $\begin{array}{l}\text { 18. AVAILABILITY } \quad X] \text { Unlimited } \\
\text { [ For Official Distribution. Do Not Release to NTIS }\end{array}$ & $\begin{array}{l}\text { 19. SECURITY CLASS } \\
\text { (THIS REPURT) } \\
\text { UNCL ASSIFIED }\end{array}$ & $\begin{array}{l}\text { 21. NO. OF PAGES } \\
151\end{array}$ \\
\hline $\begin{array}{l}\text { [.] Order From Sup. of Doc., U.S. Government Printing Office } \\
\text { Washington, D.C. 20402, SD Cat. No. C. I3 }\end{array}$ & $\begin{array}{l}\text { 20. SECURITY CLASS } \\
\text { (THIS PAGE) }\end{array}$ & 22. Price \\
\hline $\begin{array}{l}\text { Order From Narional Technical Information Service (NTIS) } \\
\text { Springfield, Virginia } 22151\end{array}$ & UNCLASSIFIED & $\$ 6.75$ \\
\hline
\end{tabular}

